UNIVERSIDADE DE SÃO PAULO

ESCOLA DE EDUCAÇÃO FÍSICA E ESPORTE

\title{
ANÁLISE DE PARÂMETROS BIOMECÂNICOS NA LOCOMOÇÃO DE CRIANÇAS PORTADORAS DE PÉ TORTO CONGÊNITO
}

\author{
Renato José Soares
}

SÃo PAULO

2007 


\title{
ANÁLISE DE PARÂMETROS BIOMECÂNICOS NA LOCOMOÇÃO DE CRIANÇAS PORTADORAS DE PÉ TORTO CONGÊNITO
}

\author{
RENATO JOSÉ SOARES
}

\begin{abstract}
Tese apresentada à Escola de Educação Física e Esporte da Universidade de São Paulo, como requisito parcial para obtenção do grau de Doutor em Educação Física.
\end{abstract}




\section{AGRADECIMENTOS}

O agradecimento é um gesto muito importante em todos os momentos de nossas vidas e certamente, não poderia deixar de expressar gratidão às pessoas especiais que foram e ainda são muito importantes em minha vida.

\section{Agradeço, com muita estima:}

Ao meu orientador, Professor Doutor Alberto Carlos Amadio. Tive o privilégio de conviver, nesta etapa importante de minha vida, com um verdadeiro orientador. Sua maneira simples de ser espelha os mais nobres. Homem digno de todas as possíveis homenagens. Serei eternamente grato por todas as oportunidades que me proporcionou.

Ao Professor Doutor João Paulo Vilas-Boas. Sua maneira vivaz de se expressar e seu entusiasmo no pensamento me fizeram conhecer o verdadeiro professor. Obrigado por me acolher em Portugal.

Ao Professor Doutor Luis Mochizuki. Conviver, quase diariamente, com uma pessoa muito especial capaz de unir sabedoria, simplicidade e paciência foi muito importante para minha formação. Obrigado por todos os conselhos e todas as contribuições para meu crescimento como pessoa e profissional.

Ao Professor Doutor Júlio Cerca Serrão. Um dos melhores professores que tive a oportunidade de conhecer. Sua didática em aula, associada ao seu entusiasmo em ensinar, contribuíram para minha formação acadêmica. Obrigado pela confiança depositada em mim.

Ao Professor Doutor Antonio Carlos Guimarães (in memorian). Os momentos que tive a oportunidade de conviver com este Mestre certamente estarão sempre vivos em minha memória.

Ao Professor Doutor António Marques Teixeira. Este nobre professor me fez compreender o quanto se deve valorizar aspectos simples, porém importantes, da vida: amizade, humildade e simplicidade.

Ao Professor Doutor José Maia. Muito obrigado por me acolher em 
Portugal. Ao Professor Doutor Jorge Bento, por me ensinar a essência da formação de um Doutor.

Aos professores idealizadores do programa de intercâmbio tripartite entre a Universidade de São Paulo, Universidade Federal do Rio Grande do Sul e a Universidade do Porto.

Ao Professor Doutor Rubens Correa Araújo, pessoa em que sempre me espelhei como profissional. Agradeço por sempre acreditar em meu potencial.

Aos voluntários do estudo e seus pais, por mostrarem que os obstáculos da vida não são merecedores de tristezas e lamentações.

A todos os amigos do Laboratório de Biomecânica da EEFE-USP: Jacqueline, Roberto, Kátia, Cláudia, Andreja, Luís, Érika, Yuji, Silvia, Ewertton, Ludgero, Germano, Allan, Fábio José, Fábio Micolis, Daniel, Sandro, Anice, João Paulo, Flávia, Fernanda, Rodrigo, Ana Paula, Renata e Tiago, por me agüentarem durante todos estes anos.

A todos componentes do grupo PET. Agradeço por entenderem a importância desta pesquisa e por darem continuidade nesta temática de investigação.

A todos que conviveram comigo no Gabinete de Biomecânica da FD-UP: ao Engenheiro Pedro, pela grande amizade e pelas contribuições intensas durante 0 processo de recolha dos dados; à amiga Raquel, por me acolher durante minha chegada ao laboratório; ao grande homem Lima, por sempre estar disposto a ajudar nas horas mais difíceis; ao professor Leandro, pelas grandes contribuições nas recolhas e tratamentos dos dados; à amiga Filipa, por estar presente nos momentos de dificuldades das recolhas; ao amigo Filipe, pelos momentos importantes de descontração; a amiga Aline, pela amizade e contribuições durante as recolhas. Agraceço também a toda comunidade de estudantes brasileiros da Faculdade de Desporto da Universidade do Porto.

À Coordenadoria de Aperfeiçoamento de Pessoal de Ensino Superior (CAPES), pelos apoios realizados no processo de construção desta Tese. 
À Doutora Laura Fernanda Alves Ferreira, responsável pelo serviço de Ortopedia Infantil do Hospital Universitário da USP, e ao Doutor Eduardo Almeida, responsável pelo setor de Ortopedia e Traumatologia do Hospital Maria Pia na cidade do Porto, pois sem estes dois Mestres nada disto teria ocorrido. Pessoas iluminadas e com pensamento à frente que me apoiaram e contribuíram para todo 0 processo deste estudo.

Ao amigo e colega de profissão Daniel Rogério, pelas constantes trocas de informações durante a formação deste projeto de pesquisa.

À amiga Márcia Regina de Sá e Célia Yamaoka. A convivência com vocês me fez perceber o quanto é importante valorizar o trabalho realizado com amor e profissionalismo.

À Maria Lúcia Vieira Franco, bibliotecária da EEFEUSP, pelas correções da formatação, essenciais para conclusão desta Tese e a amiga Maria do Carmo Souza de Almeida, pelas correções ortográfica e gramatical do texto.

À Ilza Santos, Maria de Lourdes Silva e Márcio Aparecido do Nascimento, pela constante atenção em todos os momentos do doutoramento.

A todos os amigos e profissionais do Departamento de Fisioterapia da Universidade de Taubaté e do Grupo Equality, por entenderem as minhas ausências durante o processo de formulação dessa Tese.

Aos eternos amigos do intercâmbio tripartite Cássio Meira, Flávio Castro, Jerry Ribeiro, João Vinagre, Pedro Fonseca e Silvio Saranga.

Do fundo do meu coração, à minha esposa Alex Sandra. Amiga e grande parceira que dividiu comigo todas as alegrias e que me apoiou, como ninguém, nos momentos mais difíceis. Sua cumplicidade é digna de meu eterno agradecimento.

A toda minha família, por sempre me apoiarem em todas as etapas da minha vida. Ciso, Cecília, Cizinho, Thais, Hilário, Clarice, Ana, Jarrod, Julia, Vó Branca, Vô Plínio (in memorian), Vó Chica (in memorian) e Vô Castanho (in memorian), obrigado pelo constante apoio. Pai e mãe, não tenho palavras para agradecer tudo que fizeram e fazem por mim. Amo muito vocês. 
"De tudo, ficaram três coisas: A certeza de que estamos sempre começando... A certeza de que precisamos continuar... A certeza de que seremos interrompidos antes de terminar...

Portanto devemos: Fazer da interrupção um caminho novo... Da queda um passo de dança... Do medo, uma escada... Do sonho, uma ponte... Da procura, um encontro..." 


\section{SUMÁRIO}

Página

LISTA DE TABELAS ..........................................................

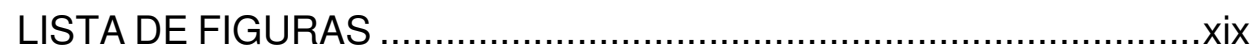

LISTA DE SIGLAS, ABREVIAÇÕES E SÍMBOLOS ......................xxxiv

LISTA DE ANEXOS ....................................................... xxxvii

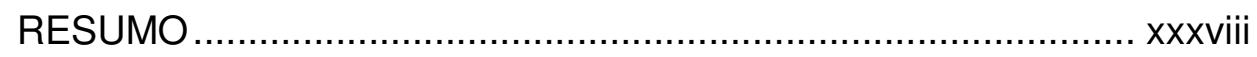

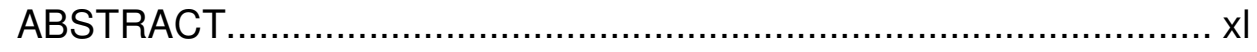

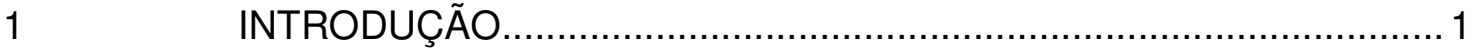

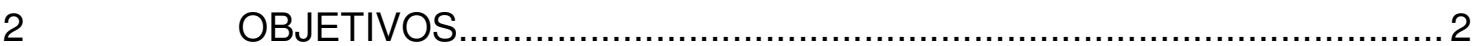

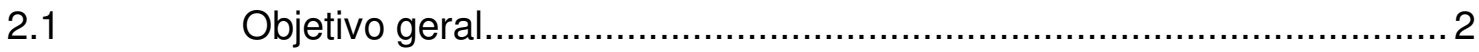

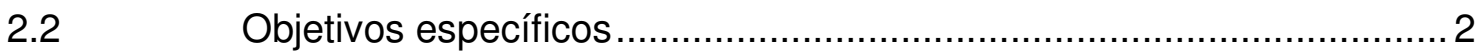

3

REVISÃO DE LITERATURA ................................................ 3

3.1 Métodos de mensuração em biomecânica ...................................... 3

Análise biomecânica da locomoção humana .................................11

3.2.1 Características gerais da locomoção .......................................... 12

3.2.2 A locomoção infantil............................................................. 19

3.2.3 A influência dos receptores plantares na locomoção..........................26

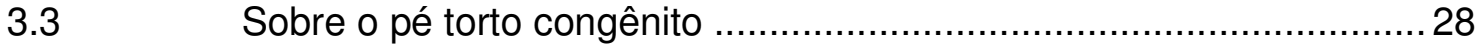

3.3.1 Tipos de classificações para o pé torto congênito ..............................29

3.3.2 Conduta clínica utilizada para o pé torto congênito ............................ 32

3.3.3 A análise biomecânica da locomoção em crianças com pé torto congênito .......................................................................... 35

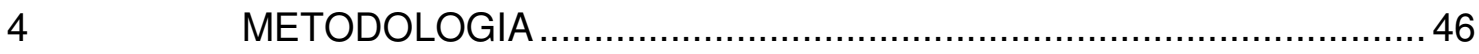

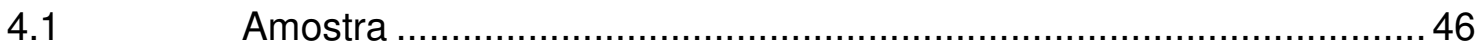


4.2 Instrumentos de medição ............................................................... 46

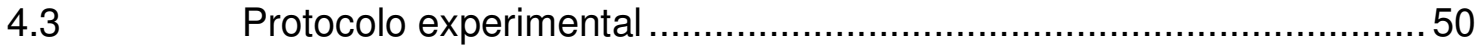

4.3.1 Análise da marcha auto-selecionada .............................................52

4.3.1.1 Procedimento experimental ..................................................... 52

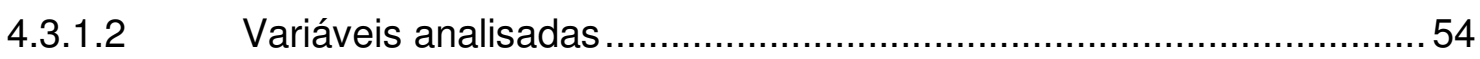

4.3.2 Análise do salto vertical com contra-movimento...............................58

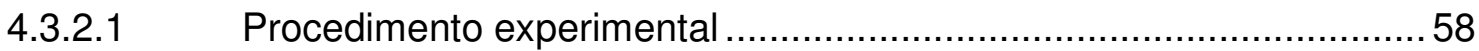

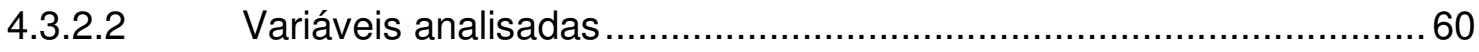

4.4 Tratamento matemático dos dados ................................................62

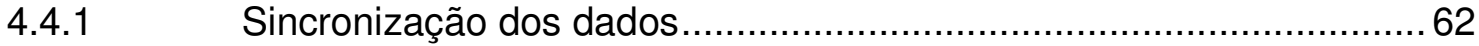

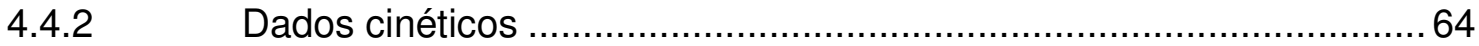

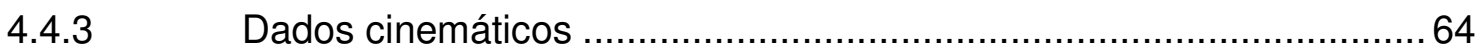

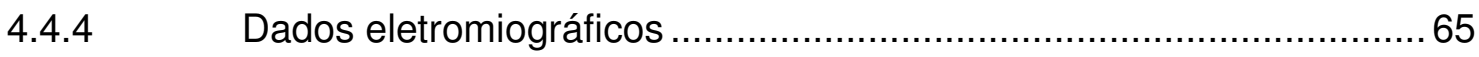

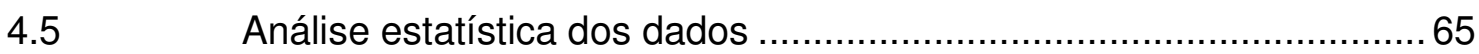

4.6 Controle do erro experimental e limitações metodológicas .................76

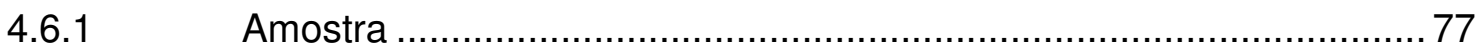

4.6.2 Ambiente experimental ........................................................... 77

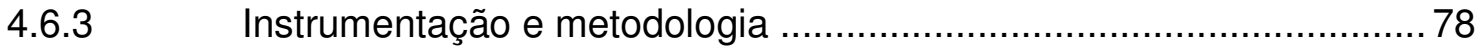

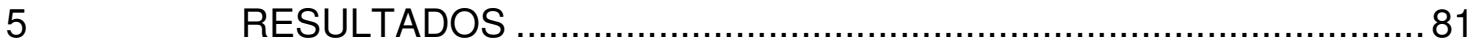

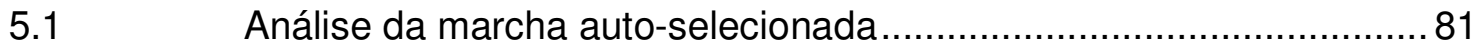

5.2 Análise do salto vertical com contra-movimento..............................100

5.3 Análise da sensibilidade plantar .................................................. 124

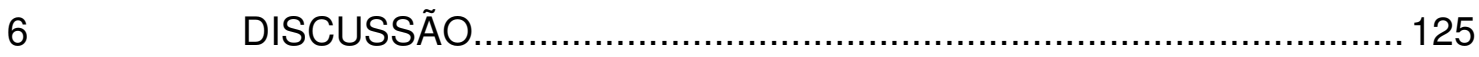

6.1 Marcha auto-selecionada ................................................... 126

6.2 Salto vertical com contra-movimento ............................................131

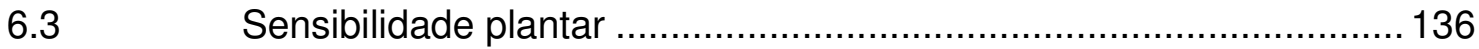


Página

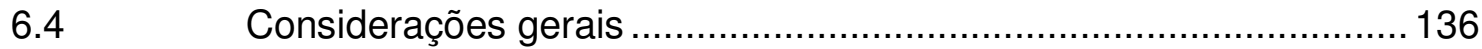

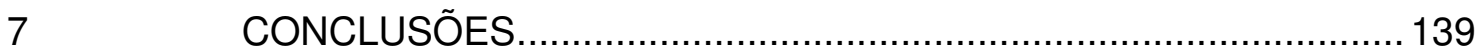

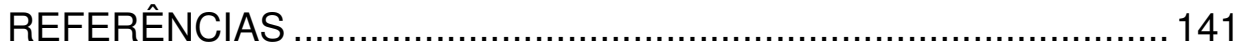

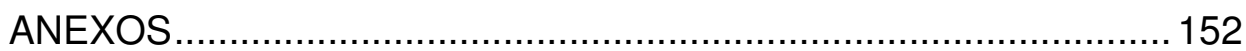

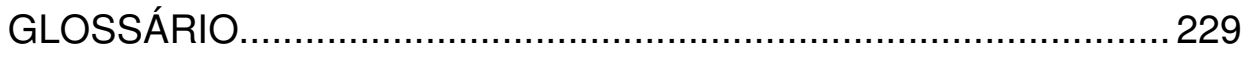




\section{LISTA DE TABELAS}

Página

TABELA 1 - Descrição dos parâmetros encontrados na aterrissagem de sujeitos com diferentes características do posicionamento subtalar: supinadores $(\mathrm{N}=16)$, pronadores $(\mathrm{N}=16)$ e neutros $(\mathrm{N}=16)$. (Adaptado de HARGRAVE, CARCIA e GANSNEDER, 2003).

TABELA 2 - Média e desvio padrão de parâmetros de variação angular do joelho e do quadril, em graus, de crianças $(\mathrm{N}=30)$ e adultos $(\mathrm{N}=28)$ durante dois momentos da aterrissagem do salto vertical: início do contato (IC) e máxima magnitude da FRS vertical (M_FRS). ( $\left.{ }^{\star} \mathrm{P}<0,05\right)$ (adaptado de SWARTZ et al., 2005).

TABELA 3 - Resultados de parâmetros da FRS vertical para diferentes tipos de saltos em crianças. Intensidades dos sinais normalizadas pelo peso corporal (PC). Adaptado de McKAY et al. (2005).

TABELA 4 - Classificação dos pacientes com pé torto congênito segundo características de avaliação clínica. Adaptado de BANSAL, DANIEL e RAI (1988)

TABELA 5 - Características metodológicas da utilização de radiografia em pacientes com pé torto congênito.

TABELA 6 - Classificação de crianças portadoras de pé torto congênito, de acordo com aspectos anatômicos, radiológicos e funcionais, segundo OTIS e BOHNE (1986).

TABELA 7 - Características de variação angular da marcha com pé torto congênito, com respectivas médias e desvios padrão (adaptado de OTIS \& BOHNE, 1986). 
Página

TABELA 8 - Dados referentes a média e desvio padrão da força de reação do solo (FRS), normalizados pelo peso corporal, encontrados na marcha de diferentes grupos avaliados no trabalho de DAVIES et al. (2001)

TABELA 9 - Representação da interpretação da sensibilidade cutânea plantar por meio do uso dos monofilamentos de SemmesWeistein (VON PRINCE \& BUTLER, 1967, apud SOUZA et al., 2005).

TABELA 10 -Variáveis calculadas a partir das componentes vertical (Fz), ântero-posterior (Fy) e médio-lateral (Fx) da FRS selecionadas na marcha. 54

TABELA 11 - Variáveis angulares calculadas a partir da componentes vertical,

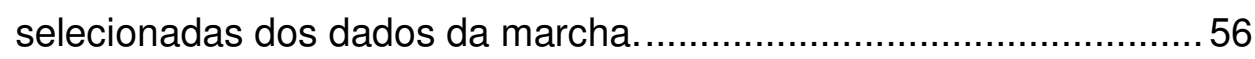

TABELA 12 -Classificação dos monofilamentos em três diferentes situações. 57

TABELA 13 -Características dos valores próprios encontrados nas cinco componentes principais, relacionados com os parâmetros da marcha, para os dados da FRS, com valores maiores do que 01. 68

TABELA 14 - Variâncias explicadas para cada componente principal em cada parâmetro investigado na marcha. ( ${ }^{*}$ variância $\left.>0,5\right)$.

TABELA 15 -Características dos valores próprios encontrados nas três componentes principais, para os dados de variação angular, com valores maiores do que 01 .

TABELA 16 - Variâncias explicadas para cada componente principal em cada parâmetro de variação angular investigado na marcha autoselecionada. ( ${ }^{*}$ variância $\left.>0,5\right)$ 
TABELA 17 -Variáveis calculadas a partir das componentes vertical ( $\mathrm{Fz})$, ântero-posterior (Fy) e médio-lateral ( Fx) da FRS selecionadas dos dados da marcha, após a análise das componentes principais.

TABELA 18 - Variáveis das componentes vertical da FRS, eletromiografia e de variação angular que foram avaliadas no salto vertical e que obtiveram diferenças significativas entre os grupos.

TABELA 19 - Apresentação do coeficiente de variação (CV) das curvas da FRS vertical, médio-lateral e ântero-posterior na fase de apoio da marcha auto-selecionada dos grupos avaliados: Controle (Cont.), PTC bilateral lado direito (Bil. D.), PTC bilateral lado esquerdo (Bil. E.), PTC unilateral lado acometido (Acom.) e PTC unilateral lado não acometido (Ñ Acom.).

TABELA 20 - Apresentação do coeficiente de variação (CV) das curvas de variação angular da articulação do tornozelo na fase de apoio da marcha dos grupos avaliados: Controle (Cont.), PTC bilateral lado direito (Bil. D.), PTC bilateral lado esquerdo (Bil. E.), PTC unilateral lado acometido (Acom.) e PTC unilateral lado não acometido (Ñ Acom.).

TABELA 21 - Apresentação do coeficiente de variação (CV) das curvas de variação angular da articulação do joelho na fase de apoio da marcha dos grupos avaliados: Controle (Cont.), PTC bilateral lado direito (Bil. D.), PTC bilateral lado esquerdo (Bil. E.), PTC unilateral lado acometido (Acom.) e PTC unilateral lado não acometido (Ñ Acom.). 
TABELA 22 -Dados referentes aos parâmetros analisados, após a análise dos componentes principais, da marcha auto-selecionada, nas comparações entre os grupos: Controle (Cont.), PTC com acometimento bilateral lado direito (Bil. D.), PTC com acometimento bilateral lado esquerdo (Bil. E.), PTC com acometimento unilateral lado acometido (Acom.) e PTC com acometimento unilateral lado não acometido (Ñ Acom.).

TABELA 23 - Apresentação do coeficiente de variação (CV) das curvas da FRS vertical nas fases de preparação e aterrissagem do salto vertical com contra-movimento dos grupos avaliados. 100

TABELA 24 -Apresentação dos coeficientes de variação (CV) das atividades dos músculos gastrocnêmio medial e tibial anterior, nas fases de preparação e aterrissagem do salto vertical com contramovimento dos grupos avaliados: Controle (Cont.), PTC bilateral lado direito (Bil. D.), PTC bilateral lado esquerdo (Bil. E.), PTC unilateral lado acometido (Acom.) e PTC unilateral lado não acometido (Ñ Acom.)

TABELA 25 - Apresentação dos coeficientes de variação (CV) para as curvas de variação angular do joelho e tornozelo, nas fases de preparação e aterrissagem do salto vertical com contramovimento dos grupos avaliados: Controle (Cont.), PTC bilateral lado direito (Bil. D.), PTC bilateral lado esquerdo (Bil. E.), PTC unilateral lado acometido (Acom.) e PTC unilateral lado não acometido (Ñ Acom.) 
TABELA 26 -Dados referentes aos parâmetros analisados do salto vertical o, nas comparações entre os grupos: Controle (Cont.), PTC com acometimento bilateral lado direito (Bil. D.), PTC com acometimento bilateral lado esquerdo (Bil. E.), PTC com acometimento unilateral lado acometido (Acom.) e PTC com acometimento unilateral lado não acometido (Ñ Acom.). Dados da força foram classificados como: PTC unilateral (Unil.), PTC bilateral (Bil.) e Grupo Controle (Cont.).

TABELA 27 -Distribuição percentual (\%) entre os grupos PTC unilateral lado acometido (Acom.), PTC unilateral lado não acometido ( $\tilde{\mathrm{N}}$ Acom.), PTC bilateral lado direito (Bil. Dir.), PTC bilateral lado esquerdo (Bil. Esq.) e grupo controle (Cont.), para as categorias criadas $(1=$ sensibilidade normal; 2 = predisposição de alteração sensitiva; 3 = alteração sensitiva).

TABELA 28 - Dados da força vertical de reação do solo do estudo piloto 1, na esteira instrumentada e piso fixo, normalizados pelo peso corporal ( $\left.{ }^{*} p \leq 0,05\right)$.

TABELA 29 -Dados da força vertical (FZ) de reação do solo do estudo piloto 1 , em piso fixo, normalizados pelo peso corporal ( $\left.{ }^{*} p \leq 0,05\right)$.

TABELA 30 - Dados da força ântero-posterior ( $F X$ min e máximo) de reação do solo e dos impulsos de frenagem e propulsão, do estudo piloto 1 , em piso fixo, normalizados pelo peso corporal $\left({ }^{*} p \leq\right.$ $0,05)$. 158

TABELA 31- Dados da força médio-lateral $(F X)$ de reação do solo do estudo piloto 1 , em piso fixo, normalizados pelo peso corporal ( ${ }^{*} p \leq$ $0,05)$. 
TABELA 32 - Dados de pressão plantar (KPa) durante a marcha da criança, no estudo piloto $2\left({ }^{*} p \leq 0,05\right)$.

TABELA 33 - Área de contato $\left(\mathrm{cm}^{2}\right)$ na região do antepé e retropé durante as diferentes velocidades de locomoção analisadas no estudo piloto $3\left({ }^{*} p \leq 0,05\right)$

TABELA 34 -Média do pico de pressão $(\mathrm{KPa})$ e máxima força vertical de reação do solo (porcentagem do peso corporal - \%PC) na região do retropé, durante as diferentes velocidades de locomoção analisadas no estudo piloto $3\left({ }^{*} p \leq 0,05\right)$.

TABELA 35 - Média e desvio padrão da integral do sinal eletromiográfico (iEMG) para os músculos tibial anterior (TA) e gastrocnêmio medial (GM), tanto para o grupo controle (C) quanto para o pé torto congênito direito (PTC_D) e esquerdo (PTC_E) durante a fase da preparação/salto. Dados normalizados pelo pico máximo de ativação muscular $\left({ }^{*} p \leq 0,05\right)$.

TABELA 36 - Média e desvio padrão da integral do sinal eletromiográfico (iEMG) para os músculos tibial anterior (TA) e gastrocnêmio medial (GM), tanto para o grupo controle (GC) quanto para o pé torto congênito direito (PTC_D) e esquerdo (PTC_E) durante a fase de aterrissagem. Dados normalizados pelo pico máximo de ativação muscular ( $\left.{ }^{*} p \leq 0,05\right)$.

TABELA 37 -Dados da avaliação com os monofilamentos de SemmesWeistein. Para melhor visualização estes estesiômetros, foram classificados de 1 a 6 em ordem crescente de acordo com o aumento do diâmetro do filamento 
TABELA 38 -Dados gerais relacionados com os parâmetros avaliados no experimento 1 do grupo controle.

TABELA 39 -Dados gerais relacionados com os parâmetros avaliados no experimento 1 do grupo de crianças com PTC bilateral.

TABELA 40 -Dados gerais relacionados com os parâmetros avaliados no experimento 1 do grupo de crianças com PTC unilateral.

TABELA 41 - Dados referentes aos parâmetros da marcha, nas comparações entre os grupos: Controle (Cont.), PTC bilateral lado direito (Bil. D.), PTC bilateral lado esquerdo (Bil. E.), PTC unilateral lado acometido (Acom.) e PTC unilateral lado não acometido ( $\tilde{\mathrm{N}}$ Acom.). $p \leq 0,05$.

TABELA 42 -Dados referentes aos parâmetros analisados da marcha autoselecionada, nas comparações entre apoio esquerdo (Esq.) e direito (Dir.), para o grupo PTC bilateral.

TABELA 43 -Dados referentes aos parâmetros analisados da marcha autoselecionada, nas comparações entre lado acometido e não acometido, para o grupo PTC unilateral.

TABELA 44 -Dados referentes aos parâmetros analisados da marcha autoselecionada, nas comparações entre os grupos: Controle (Cont.), PTC com acometimento bilateral lado direito (Bil. D.), PTC com acometimento bilateral lado esquerdo (Bil. E.), PTC com acometimento unilateral lado acometido (Acom.) e PTC com acometimento unilateral lado não acometido (N Acom.). p $\leq 0,05$. 
TABELA 45 -Dados gerais relacionados com os parâmetros avaliados no experimento 2, salto vertical com contra-movimento, do grupo de crianças com PTC bilateral.

TABELA 46 -Dados gerais relacionados com os parâmetros avaliados no experimento 2, salto vertical com contra-movimento, do grupo de crianças com PTC unilateral.

TABELA 47 -Dados referentes aos parâmetros do salto vertical nas comparações entre apoio esquerdo (Esq.) e direito (Dir.), para o grupo PTC bilateral.

TABELA 48 - Dados referentes aos parâmetros analisados do salto vertical com contra-movimento, nas comparações entre lado acometido e lado não acometido para o grupo PTC unilateral.

TABELA 49 -Dados referentes aos parâmetros do salto vertical, nas comparações entre os grupos: Controle (Cont.), PTC bilateral lado direito (Bil. D.), PTC bilateral lado esquerdo (Bil. E.), PTC unilateral lado acometido (Acom.) e PTC unilateral lado não acometido ( $\tilde{\mathrm{N}}$ Acom.), Dados da força foram classificados como: PTC unilateral (Unil.), PTC bilateral (Bil.). $p \leq 0,05$.

TABELA 50 -Dados referentes aos parâmetros analisados do salto vertical, para os parâmetros Fmax1 e TC, nas comparações entre os grupos: Controle (Cont,), PTC bilateral (Bil.) e PTC unilateral (Unil.). 
TABELA 51 -Dados referentes aos parâmetros do salto vertical, nas comparações entre os grupos: Controle (Cont.), PTC bilateral lado direito (Bil. D.), PTC bilateral lado esquerdo (Bil. E.), PTC unilateral lado acometido (Acom.) e PTC unilateral lado não

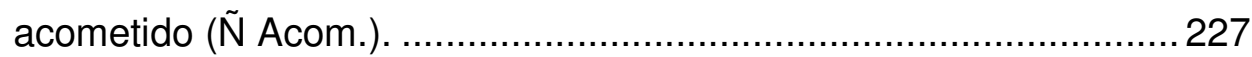

TABELA 52 - P-valor para os grupos PTC unilateral lado acometido (Acom.), PTC unilateral lado não acometido (Ñ Acom.), PTC bilateral lado direito (Bil. Dir.), PTC bilateral lado esquerdo (Bil. Esq.) e grupo controle (Cont.), para as categorias criadas $(1=$ sensibilidade normal; 2 = predisposição de alteração sensitiva)........228 


\section{LISTA DE FIGURAS}

Página

FIGURA 1 - Componentes vertical (Fz), ântero-posterior (Fy) e médio-lateral (Fx) da força de reação do solo, com suas intensidades normalizadas pelo peso corporal (PC)

FIGURA 2 - Ilustração da FRS vertical durante o movimento de salto vertical com contra-movimento, normalizado pelo peso corporal (PC).

FIGURA 3 - Valores do pico de pressão nas regiões do primeiro metatarso, hálux e calcanhar durante a marcha nas comparações entre os trabalhos de KELLIS (2001), MACHADO, HENNIG e RIEHLE (2001) e HENNIG e ROSENBAUM (1991). O primeiro autor considerou o calcanhar (calc) como um todo, os outros dividiram o calcanhar em duas áreas: medial (calc med) e lateral (calc lat).

FIGURA 4 - Ilustração de um pé torto congênito unilateral em um recém nascido sem tratamento corretivo (MORCUENDE, DOLAN, DIETZ e PONSETI, 2004).

FIGURA 5 - Evolução de um tratamento para correção da deformidade do pé torto congênito. A) deformidade instalada. B) correção de tal deformidade (MORCUENDE et al., 2004).

FIGURA 6 - Características do tempo e duração da ativação dos músculos gastrocnêmio medial e tibial anterior na marcha de crianças com pé torto congênito, comparado com um grupo controle (adaptado de OTIS \& BOHNE, 1986). 
FIGURA 7 - Ângulo de progressão do pé em um instante da fase de apoio na marcha: ângulo $(\alpha)$ entre a linha de progressão (LP) e o eixo longitudinal do pé (EL) (Adaptado de BEYAERT et al., 2003).

FIGURA 8 - Relação do ângulo do joelho com o vetor resultante da força de reação ao solo (Adaptado de BEYAERT et al., 2003).

FIGURA 9 - Ilustração das câmeras de vídeo utilizadas para o experimento.

A) câmera digital; B) câmera analógica com o posicionamento do diodo emissor de luz.

FIGURA 10 - Eletrodos utilizados no experimento. Nota-se a existência do pré-amplificador, dos dois eletrodos de captação do sinal elétrico muscular e do eletrodo de referência (Laboratório de Biomecânica da FADE-UP, Porto).

FIGURA 11 -Demonstração de um monofilamento de Semmes-Weistein (SORRI, Inc.).

FIGURA 12 - Diagrama de blocos representando o fluxograma das etapas metodológicas seguindo protocolo experimental. 51

FIGURA 13 -Posicionamento dos marcadores brancos nas regiões predeterminadas do segmento inferior dos voluntários. 52 
FIGURA 14 - llustrações das características da avaliação da sensibilidade plantar: A) Aplicação do teste na superfície plantar, com força necessária para envergar o monofilamento; B) Áreas prédeterminadas para avaliação sensitiva: região central do hálux (1), bases do primeiro (2) e quinto metatarsos (3), além das regiões plantar do tubérculo do quinto metatarso, no arco plantar (4) e central plantar do calcanhar (5), tanto do pé esquerdo quanto do direito (PRÄTORIUS, KIMMESKAMP \& MILANI, 2003).

FIGURA 15 -Variáveis calculadas a partir das componentes da FRS adquiridas na marcha das crianças. A) FRS vertical; B) FRS ântero-posterior; C) FRS médio-lateral. 55

FIGURA 16 -Variáveis angulares, identificadas com um círculo, das articulações do joelho e tornozelo calculadas a partir da componente vertical da FRS adquiridas na marcha de uma criança com acometimento de PTC bilateral.

FIGURA 17 - Posicionamento dos eletrodos para o experimento de salto vertical com contra-movimento.

FIGURA 18 - Demonstração de uma coleta do salto vertical com contramovimento 59

FIGURA 19 - Ilustração do posicionamento das câmeras de vídeo para captarem o plano sagital de movimento das crianças. Entre as câmeras encontra-se a plataforma de força. 
FIGURA 20 - llustração das fases analisadas do movimento de salto vertical com contra-movimento, baseadas nos dados da FRS vertical. Fase A - preparação. Fase B - aterrissagem; círculos, nos dados angulares das articulações do joelho e tornozelo, referem-se aos parâmetros analisados; regiões tracejadas, nos dados eletromiográficos (EMG), referem-se às regiões investigadas.

FIGURA 21 - llustração dos parâmetros adquiridos da FRS vertical para 0 experimento: Força máxima na fase $A(F \max 1)$, força máxima na fase $B(F \max 2)$ e sua respectiva taxa de crescimento (TC). 62

FIGURA 22 - Descrição das características temporais identificadas na marcha e no salto vertical, baseadas nos dados da FRS vertical. Foram analisados os tempos antes do início do apoio e do salto vertical $\left(T_{1}=b-a\right)$ e os tempos de apoio da marcha e de todas as fases do salto $\left(T_{2}=c-b\right)$.

FIGURA 23 - Variáveis calculadas para a marcha auto-selecionada, após a análise das componentes principais.

FIGURA 24 - llustração das variáveis das componentes vertical da FRS, eletromiografia e de variação angular que foram avaliadas no salto vertical que obtiveram diferenças significativas entre os grupos; regiões tracejadas, nos dados eletromiográficos (EMG), referem-se às regiões investigadas. 
FIGURA 25 - llustração das médias e desvios-padrão da FRS Vertical, com sua intensidade normalizada pelo peso corporal (PC), além do coeficiente de variação $(\mathrm{CV})$, para a marcha auto-selecionada em todos os grupos analisados. Dados normalizados na base do tempo, tendo todo o ciclo da fase de apoio $100 \%$.

FIGURA 26 Ilustração das médias e desvios-padrão da FRS Ânteroposterior, com sua intensidade normalizada pelo peso corporal $(\mathrm{PC})$, além do coeficiente de variação (CV), para a marcha autoselecionada em todos os grupos analisados. Dados normalizados na base do tempo, tendo todo o ciclo da fase de apoio $100 \%$

FIGURA 27 - Ilustração das médias e desvios-padrão da FRS Médio-lateral, com sua intensidade normalizada pelo peso corporal (PC), além do coeficiente de variação (CV), para a marcha autoselecionada em todos os grupos analisados. Dados normalizados na base do tempo, tendo todo o ciclo da fase de apoio $100 \%$.

FIGURA 28 - llustração das médias e desvios-padrão da variação angular da articulação do tornozelo, além do coeficiente de variação (CV), para a marcha auto-selecionada em todos os grupos analisados.

FIGURA 29 - llustração das médias e desvios-padrão da variação angular da articulação do joelho, além do coeficiente de variação (CV), para a marcha auto-selecionada em todos os grupos analisados. 
FIGURA 30 - Gráfico referente ao parâmetro taxa de crescimento 1 (TC 1) da FRS vertical para os grupos avaliados: Controle (Cont.), PTC com acometimento bilateral lado direito (Bil. D.), PTC com acometimento bilateral lado esquerdo (Bil. E.), PTC com acometimento unilateral lado acometido (Acom.) e PTC com acometimento unilateral lado não acometido (Ñ Acom.). *Cont. $<$ Acom./ Bil.D. / Bil.E. / Ñ Acom.; ${ }^{+}$Bil. D. < Acom./ Ñ Acom. / Cont. $(p<0,05)$.

FIGURA 31 - Gráfico referente ao parâmetro Fy_min da FRS ântero-posterior para os grupos avaliados: Controle (Cont.), PTC com acometimento bilateral lado direito (Bil. D.), PTC com acometimento bilateral lado esquerdo (Bil. E.), PTC com acometimento unilateral lado acometido (Acom.) e PTC com acometimento unilateral lado não acometido (N Acom.). ${ }^{\#} \tilde{N}$ Acom > Cont. / Acom. / Bil. D.; * Bil. D. < Bil. E. $(p<0,05)$.

FIGURA 32 - Gráfico referente ao ângulo do tornozelo no instante de máxima magnitude de força vertical na fase inicial do apoio da marcha (cine_tornozelo2) para os grupos avaliados: Controle (Cont.), PTC com acometimento bilateral lado direito (Bil. D.), PTC com acometimento bilateral lado esquerdo (Bil. E.), PTC com acometimento unilateral lado acometido (Acom.) e PTC com acometimento unilateral lado não acometido ( $\tilde{N}$ Acom.). * Cont. $<$ Ñ Acom./ Acom./ Bil.D.; ${ }^{+}$Bil. E. < N Acom./ Acom./ Bil.D. $(p<0,05)$. 
FIGURA 33 - Gráfico referente ao ângulo do joelho no instante de máxima magnitude de força vertical na fase inicial do apoio da marcha (cine_joelho2) para os grupos avaliados: Controle (Cont.), PTC com acometimento bilateral lado direito (Bil. D.), PTC com acometimento bilateral lado esquerdo (Bil. E.), PTC com acometimento unilateral lado acometido (Acom.) e PTC com acometimento unilateral lado não acometido (N Acom.). * $\tilde{N}$

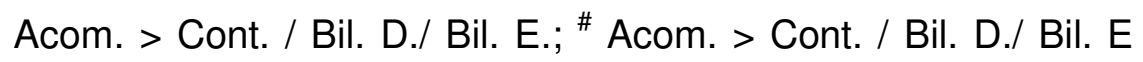
$(p<0,05)$.

FIGURA 34 - Gráfico referente ao ângulo do tornozelo no instante de deflexão da força vertical na fase de médio apoio da marcha (cine_tornozelo3) para os grupos avaliados: Controle (Cont.), PTC com acometimento bilateral lado direito (Bil. D.), PTC com acometimento bilateral lado esquerdo (Bil. E.), PTC com acometimento unilateral lado acometido (Acom.) e PTC com acometimento unilateral lado não acometido (Ñ Acom.). ${ }^{*}$ Cont. $<\tilde{N}$ Acom / Acom; ${ }^{+}$Bil. E. $<\tilde{N}$ Acom / Acom $(p<0,05)$.

FIGURA 35 - Gráfico referente ao ângulo do joelho no instante de deflexão da força vertical na fase de médio apoio da marcha (cine_joelho3) para os grupos avaliados: Controle (Cont.), PTC com acometimento bilateral lado direito (Bil. D.), PTC com acometimento bilateral lado esquerdo (Bil. E.), PTC com acometimento unilateral lado acometido (Acom.) e PTC com acometimento unilateral lado não acometido (N Acom.). ${ }^{\#} \tilde{N}$ Acom > Acom. / Cont / Bil. D / Bil. E.; ${ }^{*}$ Acom > Cont / Bil. D. / Bil. E. $(p<0,05)$. 
FIGURA 36 - Gráfico referente segundo pico da FRS vertical (fz 2) da FRS ântero-posterior para os grupos avaliados: Controle (Cont.), PTC com acometimento bilateral lado direito (Bil. D.), PTC com acometimento bilateral lado esquerdo (Bil. E.), PTC com acometimento unilateral lado acometido (Acom.) e PTC com acometimento unilateral lado não acometido (Ñ Acom.). * Cont. $>$ Acom./ Bil.D. / Bil.E. / Ñ Acom; " Acom. < Bil. D./ Bil. E. $(p<0,05)$.

FIGURA 37 - Gráfico referente impulso de propulsão (I_prop) da FRS ânteroposterior para os grupos avaliados: Controle (Cont.), PTC com acometimento bilateral lado direito (Bil. D.), PTC com acometimento bilateral lado esquerdo (Bil. E.), PTC com acometimento unilateral lado acometido (Acom.) e PTC com

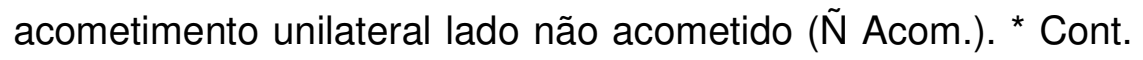
$>\tilde{N}$ Acom/ Acom. / Bil.D. / Bil.E.; + Ñ Acom < Acom. / Bil.D / Cont. $(p<0,05)$.

FIGURA 38 -Gráfico referente ao ângulo do tornozelo no instante do segundo pico da FRS vertical na fase de apoio da marcha (cine_tornozelo4) para os grupos avaliados: Controle (Cont.), PTC com acometimento bilateral lado direito (Bil. D.), PTC com acometimento bilateral lado esquerdo (Bil. E.), PTC com acometimento unilateral lado acometido (Acom.) e PTC com

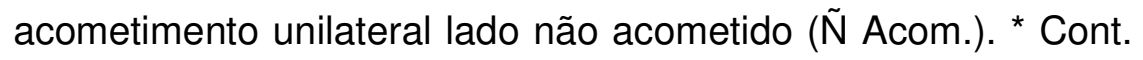
$<\tilde{N}$ Acom / Acom / Bil. D. / Bil. E.; ". Ñ Acom. > Bil. D. / Bil. E. / Cont. $(p<0,05)$. 
FIGURA 39 - Gráfico referente ao ângulo do joelho no instante do segundo pico da FRS vertical na fase de apoio da marcha (cine_joelho4) para os grupos avaliados: Controle (Cont.), PTC com acometimento bilateral lado direito (Bil. D.), PTC com acometimento bilateral lado esquerdo (Bil. E.), PTC com acometimento unilateral lado acometido (Acom.) e PTC com

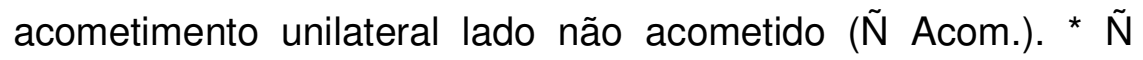
Acom > Cont. / Bil. D / Bil. E / Acom.; ${ }^{+}$Bil. E. < Acom. / Cont. / $\tilde{\mathrm{N}}$ Acom. $(\mathrm{p}<0,05)$.

FIGURA 40 - Ilustração das médias e desvios padrão da FRS vertical, com suas intensidades normalizadas pelo peso corporal (PC), além do coeficiente de variação (CV), na fases de preparação do salto vertical com contra-movimento, em todos os grupos analisados.

FIGURA 41 - Ilustração das médias e desvios padrão da variação angular na articulação do joelho durante a fase de preparação do salto vertical com contra-movimento, além do coeficiente de variação (CV), em todos os grupos analisados.

FIGURA 42 - Ilustração das médias e desvios padrão da variação angular na articulação do tornozelo durante a fase de preparação do salto vertical com contra-movimento, além do coeficiente de variação (CV), em todos os grupos analisados.

FIGURA 43 - Ilustração das médias e desvios padrão da atividade eletromiográfica do músculo gastrocnêmio medial, normalizados pela média do sinal, na fase de preparação do salto vertical com contra-movimento, além do coeficiente de variação (CV), em todos os grupos analisados. 
FIGURA 44 - llustração das médias e desvios padrão da atividade eletromiográfica do músculo tibial anterior, normalizados pela média do sinal, na fase de preparação do salto vertical com contra-movimento, além do coeficiente de variação (CV), em todos os grupos analisados.

FIGURA 45 - Ilustração das médias e desvios padrão da FRS vertical, com suas intensidades normalizadas pelo peso corporal (PC), além do coeficiente de variação (CV), na fase de aterrissagem do salto vertical com contra-movimento, em todos os grupos analisados.

FIGURA 46 - llustração das médias e desvios padrão da variação angular na articulação do joelho durante a fase de aterrissagem do salto vertical com contra-movimento, além do coeficiente de variação (CV), em todos os grupos analisados.

FIGURA 47 - llustração das médias e desvios padrão da variação angular na articulação do tornozelo durante a fase de aterrissagem do salto vertical com contra-movimento, além do coeficiente de variação (CV), em todos os grupos analisados. 109

FIGURA 48 - llustração das médias e desvios padrão da atividade eletromiográfica do músculo gastrocnêmio medial, normalizados pela média do sinal, na fase de aterrissagem do salto vertical com contra-movimento, além do coeficiente de variação (CV), em todos os grupos analisados. 
FIGURA 49 - Ilustração das médias e desvios padrão da atividade eletromiográfica do músculo tibial anterior, normalizados pela média do sinal, na fase de aterrissagem do salto vertical com contra-movimento, além do coeficiente de variação (CV), em todos os grupos analisados.

FIGURA 50 - Gráfico referente máxima dorsiflexão plantar da fase A do salto vertical (Cine1_tornozelo) para os grupos avaliados: Controle (Cont.), PTC com acometimento bilateral lado direito (Bil. D.), PTC com acometimento bilateral lado esquerdo (Bil. E.), PTC com acometimento unilateral lado acometido (Acom.) e PTC com acometimento unilateral lado não acometido (Ñ Acom.). * Cont. > Acom. / Bil. D.; ${ }^{+} \tilde{N}$ Acom > Acom. $(p<0,05)$.

FIGURA 51 - Gráfico referente ao parâmetro $F \operatorname{max1}$ da FRS vertical para os grupos avaliados: Controle (Cont.), PTC bilateral (Bil.), PTC unilateral (Unil.). *Unil. < Bil. $(p<0,05)$.

FIGURA 52 -Gráfico referente às características do sinal RMS eletromiográfico da fase A para o gastrocnêmio medial para os grupos avaliados: Controle (Cont.), PTC com acometimento bilateral lado direito (Bil. D.), PTC com acometimento bilateral lado esquerdo (Bil. E.), PTC com acometimento unilateral lado acometido (Acom.) e PTC com acometimento unilateral lado não acometido (Ñ Acom.). * Acom. < ̃̃ Acom/ Bil. D./ Bil. E./ Cont. $(p<0,05)$. 
FIGURA 53 - Gráfico referente às características de variação angular do tornozelo (cine2_tornozelo) na fase de retirada do contato do pé com o solo para os grupos avaliados: Controle (Cont.), PTC com acometimento bilateral lado direito (Bil. D.), PTC com acometimento bilateral lado esquerdo (Bil. E.), PTC com acometimento unilateral lado acometido (Acom.) e PTC com

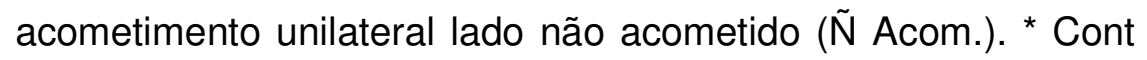
< Acom. / N Acom/ Bil. D./ Bil. E.; ${ }^{+} \tilde{N}$ Acom < Acom. / Bil. D. / Bil. E. $(p<0,05)$.

FIGURA 54 -Gráfico referente às características angulares do joelho (cine2_joelho) na fase de retirada do contato do pé com o solo para os grupos avaliados: Controle (Cont.), PTC com acometimento bilateral lado direito (Bil. D.), PTC com acometimento bilateral lado esquerdo (Bil. E.), PTC com acometimento unilateral lado acometido (Acom.) e PTC com

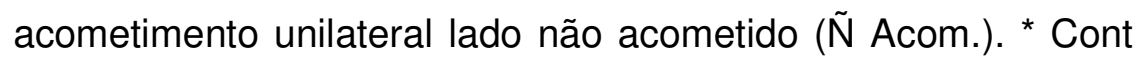
< Acom. / N Acom. $(\mathrm{p}<0,05)$.

FIGURA 55 -Gráfico referente às características angulares do joelho (cine3_joelho) no momento da aterrissagem (fase B) para os grupos avaliados: Controle (Cont.), PTC com acometimento bilateral lado direito (Bil. D.), PTC com acometimento bilateral lado esquerdo (Bil. E.), PTC com acometimento unilateral lado acometido (Acom.) e PTC com acometimento unilateral lado não acometido (Ñ Acom.). * Cont < Acom. / N Acom. $(p<0,05)$. 
FIGURA 56 - Gráfico referente às características angulares do tornozelo (cine3_tornozelo) no momento da aterrissagem (fase B), para os grupos avaliados: Controle (Cont.), PTC com acometimento bilateral lado direito (Bil. D.), PTC com acometimento bilateral lado esquerdo (Bil. E.), PTC com acometimento unilateral lado acometido (Acom.) e PTC com acometimento unilateral lado não acometido (Ñ Acom.). * Cont. < Acom. / Bil. D./ Bil. E. $(p<0,05)$.

FIGURA 57 - Gráfico referente taxa de crescimento da FRS avaliada no salto vertical para os grupos avaliados: Controle (Cont.), PTC bilateral (Bil.), PTC unilateral (Unil.). * Cont < Unil. / Bil. $(p<0,05)$.

FIGURA 58 - Gráfico referente às características do sinal RMS eletromiográfico do gastrocnêmio medial, na fase $\mathrm{B}$, para os grupos avaliados: Controle (Cont.), PTC com acometimento bilateral lado direito (Bil. D.), PTC com acometimento bilateral lado esquerdo (Bil. E.), PTC com acometimento unilateral lado acometido (Acom.) e PTC com acometimento unilateral lado não acometido (Ñ Acom.). ${ }^{*} \tilde{N}$ Acom. > Acom. / Bil. D./ Bil. E./ Cont. ; ${ }^{+}$Bil. D. $>$Cont. $(p<0,05)$. 
FIGURA 59 - Gráfico referente às características de maior dorsiflexão plantar na fase B (Cine4_tornozelo), para os grupos avaliados: Controle (Cont.), PTC com acometimento bilateral lado direito (Bil. D.), PTC com acometimento bilateral lado esquerdo (Bil. E.), PTC com acometimento unilateral lado acometido (Acom.) e PTC com acometimento unilateral lado não acometido (Ñ Acom.). * Cont $<$ Acom./ Bil. D./ Bil. E. $(p<0,05)$.

FIGURA 60 - llustração da esteira rolante instrumentada (KISTLER, 9810S1x),

FIGURA 61 - Variáveis da FRS normalizadas pelo peso corporal (PC). A) FRS vertical - Fz; B) FRS ântero-posterior - Fy; C) FRS médiolateral - Fx.

FIGURA 62 - Ilustração da FRS, magnitude vertical, dos apoios direito e esquerdo, durante as coletas de marcha em esteira (apoio esquerdo $n=13$ e direito $n=16$ ) e em piso fixo (apoio direito e esquerdo $n=12$ ), no estudo piloto 1 , normalizados pelo peso corporal.

FIGURA 63 - Médias e desvios padrão dos dados da FRS, normalizados pelo peso corporal da criança, adquiridos em piso fixo. $\mathrm{N}=12$.

FIGURA 64 - Ilustração da palmilha com sensores resistivos, do sistema $F$ Scan, utilizada no estudo piloto 2 , com objetivo de quantificar as características de distribuição da pressão plantar.

FIGURA 65 - Ilustração da coleta de dados com a utilização do sistema $F$ Scan, no estudo piloto 2, com a mensuração da pressão plantar na locomoção de crianças com PTC 
FIGURA 66 - Divisão das áreas da planta do pé: retropé $(0 \%$ até $30 \%$ do comprimento do pé), mediopé (30\% até $60 \%$ do comprimento do pé) e antepé (60\% até $100 \%$ do comprimento do pé).

FIGURA 67 - llustração das características de pressão plantar durante os apoios direito e esquerdo na marcha da criança no estudo piloto 2.

FIGURA 68 - Colocação da palmilha instrumentada PEDAR no calçado do voluntário.

FIGURA 69 - Gráfico da média do pico de pressão $(\mathrm{KPa})$ na região do retropé, durante as diferentes velocidades de locomoção analisadas no estudo piloto $3\left({ }^{*} \mathrm{p} \leq 0,05\right)$.

FIGURA 70 -Gráfico da máxima força vertical de reação do solo (porcentagem do peso corporal - \%PC) na região do retropé, durante as diferentes velocidades de locomoção analisadas no estudo piloto 3 ( $\left.{ }^{*} p \leq 0,05\right)$.

FIGURA 71 - Demonstração das divisões, baseadas na FRS vertical, para análise das características eletromiográficas dos músculos gastrocnêmio medial direito (GMD) e esquerdo (GME) e tibial anterior direito (TAD) e esquerdo (TAE) durante o salto vertical com contra-movimento. A - preparação; B - aterrissagem. Foram realizadas cinco tentativas para cada sujeito avaliado.

FIGURA 72 - Ilustrações das características da avaliação da sensibilidade plantar. Aplicação do teste na superfície plantar, com força necessária para envergar o monofilamento 
xxxiv

\section{LISTA DE SIGLAS, ABREVIAÇÕES E SÍMBOLOS}

$\alpha$

Acom.

ACP

Bil.

Bil. D.

Bil. E.

cine joelho1

cine_joelho2

cine_joelho3

cine_joelho4

cine_joelho5

cine_tornozelo1

cine_tornozelo2

cine_tornozelo3

cine_tornozelo4

cine_tornozelo5

cine1_tornozelo

cine2_joelho

cine2_tornozelo

cine3 joelho

cine3_tornozelo

cine4_tornozelo ângulo

PTC unilateral lado acometido

Análise dos Componentes Principais

PTC bilateral

PTC bilateral lado direito

PTC bilateral lado esquerdo

Ângulo do joelho no momento do início da fase de apoio da marcha

Ângulo do joelho no momento de Fz1 da marcha

Ângulo do joelho no momento de Fz min da marcha

Ângulo do joelho no momento de Fz2 da marcha

Ângulo do joelho no momento final da fase de apoio da marcha

Ângulo do tornozelo no momento do início da fase de apoio da marcha

Ângulo do tornozelo no momento de Fz1 da marcha

Ângulo do tornozelo no momento de Fz min da marcha

Ângulo do tornozelo no momento de Fz2 da marcha

Ângulo do tornozelo no momento final da fase de apoio da marcha

Máxima amplitude de dorsiflexão-flexão do tornozelo na fase $A$ do salto vertical

Amplitude articular do joelho no final da fase A do salto vertical

Amplitude articular do tornozelo no final da fase A do salto vertical

Amplitude articular do joelho no início da fase $B$ do salto vertical

Amplitude articular do tornozelo no início da fase $B$ do salto vertical

Máxima amplitude de tornozelo do joelho na fase $B$ do salto vertical 


\section{LISTA DE SIGLAS, ABREVIAÇÕES E SÍMBOLOS (cont.)}

Cont.

COP

CV

EMG

$F \max 1$

FADE-UP

FRS

Fx 1

Fx 2

Fx 3

Fx 4

Fy max

Fy min

Fz 1

Fz 2

Fz min

GC

GM

$H_{0}$

$\mathrm{H}_{1}$

I_fren

I_prop
Grupo controle

Centro de pressão

Coeficiente de variação

Eletromiografia

Máxima FRS vertical na fase $A$ do salto vertical

Faculdade de Desporto da Universidade do Porto

Força de reação do solo

Primeiro valor máximo encontrado da FRS médio-lateral na marcha

Segundo valor encontrado máximo da FRS médio-lateral na marcha

Terceiro valor encontrado máximo da FRS médio-lateral na marcha

Quarto valor encontrado máximo da FRS médio-lateral na marcha

Primeiro pico positivo da força ântero-posterior na marcha

Primeiro pico negativo da FRS ântero-posterior na marcha

Primeiro valor máximo da FRS vertical na marcha

Segundo valor máximo da FRS vertical na marcha

Valor mínimo da FRS vertical calculado entre Fz1 e Fz2 na marcha

Grupo controle

Músculo gastrocnêmio medial

Hipótese verdadeira ou nula

Hipótese alternativa

Impulso de frenagem: Integral do sinal da FRS ântero-posterior

relacionada a fase de frenagem na marcha

Impulso de propulsão: Integral do sinal da FRS ântero-posterior na fase de propulsão na marcha 


\section{LISTA DE SIGLAS, ABREVIAÇÕES E SÍMBOLOS (cont.)}

\begin{tabular}{|c|c|}
\hline Ñ. Acom. & PTC unilateral lado não acometido \\
\hline PC & Porcentagem do peso corporal \\
\hline PTC & pé torto congênito \\
\hline RMS_GM_pos & $\begin{array}{l}\text { Análise do sinal eletromiográfico do gastrocnêmio medial por meio do } \\
\text { RMS na fase B do salto vertical }\end{array}$ \\
\hline RMS_GM_pre & $\begin{array}{l}\text { Análise do sinal eletromiográfico do gastrocnêmio medial por meio do } \\
\text { RMS na Fase A do salto vertical }\end{array}$ \\
\hline SNC & Sistema nervoso central \\
\hline TA & Músculo tibial anterior \\
\hline TC & $\begin{array}{l}\text { Relação entre a máxima força da fase B com o tempo para atingir esta } \\
\text { magnitude a partir do momento do início da aterrissagem do salto }\end{array}$ \\
\hline TC 1 & $\begin{array}{l}\text { Taxa de crescimento 1: Razão entre Fz1 e o tempo decorrido do início do } \\
\text { apoio até esta magnitude na marcha }\end{array}$ \\
\hline TC 2 & $\begin{array}{l}\text { Taxa de crescimento 2: Razão entre Fz2 e o tempo decorrido de Fz min } \\
\text { até Fz2 na marcha }\end{array}$ \\
\hline Unil. & PTC unilateral \\
\hline USP & Universidade de São Paulo \\
\hline
\end{tabular}




\section{LISTA DE ANEXOS}

Página

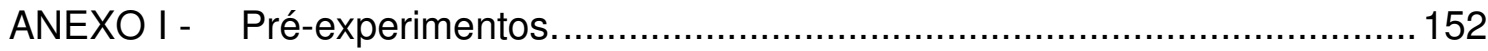

ANEXO II - Termo de consentimento livre e esclarecido:...................................... 177

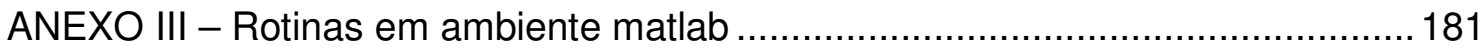

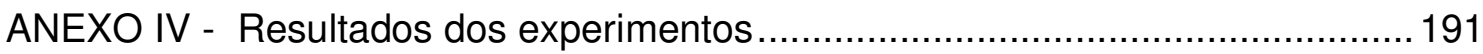


xxxviii

\title{
RESUMO
}

\section{ANÁLISE DE PARÂMETROS BIOMECÂNICOS NA LOCOMOÇÃO DE CRIANÇAS PORTADORAS DE PÉ TORTO CONGÊNITO}

\author{
Autor: RENATO JOSÉ SOARES \\ Orientador: PROF. DR. ALBERTO CARLOS AMADIO
}

O pé torto congênito idiopático é a deformidade congênita de maior prevalência na ortopedia. Estudos da locomoção podem favorecer condutas na reabilitação de crianças com tal disfunção. Neste trabalho foram analisados parâmetros biomecânicos da marcha e do salto vertical com contra-movimento, além do estudo do limiar de percepção plantar de crianças com pé torto congênito, tratadas cirurgicamente. Para análise dos resultados, foram utilizados testes estatísticos não paramétricos. Não foram identificadas alterações na sensibilidade plantar. Apesar da semelhança das curvas médias de força, variação angular e eletromiografia, as variáveis biomecânicas mostraram diferenças. Na marcha, as crianças com pé torto mostraram maior taxa de crescimento para o primeiro pico da força vertical; no apoio médio, maiores flexão do joelho e dorsiflexão do tornozelo, e menor força vertical; na fase de propulsão, menores força ântero-posterior, segundo pico da força vertical e flexão plantar. Enquanto que as mesmas crianças mostraram na fase de preparação do salto vertical, menor dorsiflexão; na impulsão, maior flexão do joelho e menores flexão plantar, força vertical e atividade do músculo gastrocnêmio medial; e na aterrissagem, maior taxa de crescimento da força vertical, menor flexão plantar e maior flexão do joelho. O entendimento de como o sistema locomotor opera durante as atividades analisadas pode contribuir para 
xxxix

direcionamentos relacionados com os estímulos adequados de atividades físicas para essas crianças.

PALAVRAS-CHAVE: pé torto congênito; biomecânica clínica; locomoção humana. 


\title{
ABSTRACT
}

\section{ANALYSIS OF BIOMECHANICAL PARAMETERS IN THE LOCOMOTION OF CHILDREN WITH CLUBFEET}

\author{
Author: RENATO JOSÉ SOARES \\ Adviser: PROF. DR. ALBERTO CARLOS AMADIO \\ Idiopathic clubfoot is the most prevalent congenital deformity in
} orthopedics. Locomotion studies in children with such a deformity can help towards better rehabilitation. The aim of this study was to analyze the gait and countermovement jump biomechanics, and to describe the perception threshold in children with congenital clubfoot who have been surgically treated. For data analysis, non-parametric statistical tests were applied. Changes in plantar sensitivity were not found. Despite similar force, kinematics, and electromyography curves along groups, it was found differences for some biomechanical variables. For gait, children with clubfoot showed higher vertical force increase to the first peak. At midstance, they showed higher knee flexion and ankle dorsiflexion, and lower vertical force. At toe off, they presented lower anterior-posterior force, second vertical force peak, and plantar flexion. For jump, during the preparation phase, they presented smaller dorsiflexion; during propulsion, they showed larger knee flexion and smaller plantar flexion, vertical force and $\mathrm{m}$ medial gastrocnemius activity. In landing, there was a higher vertical force growth rate, less plantar flexion, and larger knee flexion. The understanding of how the locomotion system work contributes to choose the best stimuli to be applied during physical activity for those children.

KEYWORDS: clubfeet; clinical biomechanics; human locomotion. 


\section{INTRODUÇÃO}

O pé torto congênito (PTC) é uma doença que acomete no Brasil cerca de 2:1000 nascidos vivos (SODRÉ, 1998). O acometimento pode ser bilateral ou unilateral e sua etiologia não é totalmente esclarecida (RICHARDS, 2002). Caracteriza-se por apresentar uma deformidade centralizada no tálus, com inversão e flexão plantar do retropé associados à inversão e adução do mediopé e antepé (RICHARDS, 2002). Quando não tratada precocemente, a criança pode apresentar deformidades na região, as quais geram dificuldades na marcha e em outras atividades funcionais.

Para o tratamento, tem-se necessidade da intervenção precoce realizada por meio de tratamentos cirúrgicos ou conservadores, com objetivo de correção das deformidades ocorridas na região. Além disso, há preocupação do acompanhamento periódico, pois recidivas e deformidades residuais podem necessitar de novos tratamentos (OTIS \& BOHNE, 1986; THEOLOGIS, HARRINGTON, THONMPSOM \& BENSON, 2003).

Os métodos de avaliação mais usados no acompanhamento clínico são as análises radiológicas e fotográficas, exame físico e questionários embasados em atividades funcionais e nível de dor (ARONSON \& PUSKARICH, 1990; THEOLOGIS et al., 2003). Entretanto, métodos biomecânicos podem ser empregados para análises quantitativas e, dessa forma, permitem o conhecimento acerca de parâmetros objetivos da locomoção de portadores de PTC. Com o consenso sobre a importância de avaliações quantitativas, atualmente investigações utilizam métodos biomecânicos para análise de parâmetros da marcha dessa população (ARONSON \& PULKARICH, 1990; BEYAERT, HAUMONT, PAYASANT, LASCOMBES \& ANDRE, 2003; HEE, LEE \& LEE, 2001; KAROL, CONCHA \& JOHNSTON, 1997; OTIS \& BOHNE, 1986; THEOLOGIS et al., 2002; WIDHE \& BERGGREN, 1994).

No entanto, apesar da marcha caracterizar-se como uma das atividades funcionais essenciais (ANDRIACCHI \& ALEXANDER, 2000; WINTER, 1983), há também a necessidade de entendermos como essas crianças se adaptam a situações que exijam esforços diferenciados ao dessa atividade de locomoção, 
como é o caso, por exemplo, do salto vertical. Esse por sua vez, é um movimento comum em atividades esportivas e de treinamento durante a reabilitação e pode favorecer uma potencial situação de risco ao aparelho locomotor, decorrente das variadas estratégias utilizadas entre os indivíduos (DUFEK \& BATES, 1990).

Em adição, com o conhecimento de que informações sensoriais do pé influenciam nas atividades motoras (CLIFFORD, JAMES \& MARK, 2000) e que não há, nas referências da literatura, informações se de fato crianças com PTC apresentam tais deficiências sensoriais, nota-se a importância do melhor entendimento dessas características.

Dessa forma, as investigações propostas podem possibilitar a compreensão das adaptações envolvidas com os mecanismos de gerenciamento da função motora, fato importante para estabelecer estratégias adequadas para recuperação de portadores de tais deficiências e entender os desequilíbrios funcionais que os predispõem às lesões (HERD, MACNICOL \& ABDOUD, 2004).

\section{OBJETIVOS}

\section{$2.1 \quad$ Objetivo geral}

Caracterizar parâmetros biomecânicos em crianças com história de PTC.

\section{$2.2 \quad$ Objetivos específicos}

- Interpretar as variáveis biomecânicas selecionadas da marcha e salto vertical com contra movimento em crianças com história de PTC.

- Identificar as características da sensibilidade plantar em crianças com história de PTC. 


\section{REVISÃO DE LITERATURA}

\subsection{Métodos de mensuração em biomecânica}

A Biomecânica pode ser definida como uma interdisciplina que descreve, analisa e avalia o movimento humano, construída a partir dos conhecimentos da física, química, matemática, fisiologia e anatomia (WINTER, 1990). De acordo com AMADIO e DUARTE (1996), essa interdisciplina é a ciência que trata de análises físico-matemáticas de sistemas biológicos e, conseqüentemente, de movimentos humanos; baseia-se na mecânica clássica e é dividida em duas sub-áreas: a cinemática e a cinética.

A cinemática pode ser definida como a área envolvida na descrição do movimento, independente da força que o causa. Suas variáveis estudadas incluem o deslocamento linear e angular, velocidades e acelerações (AMADIO \& DUARTE, 1996; MANN \& HAGY, 1980; WINTER, 1990).

A cinética é um termo empregado para a análise das forças internas e externas, que causam o movimento. As forças internas vêm das atividades musculares, ligamentares ou da fricção dos músculos e articulações. A força externa é decorrente, na locomoção humana, da força de reação do solo (FRS) que atua no corpo humano e age em todo o sistema locomotor (WINTER, 1990).

Para analisar e investigar o movimento humano, a Biomecânica utilizase de métodos de avaliação, dentre as quais se destacam a eletromiografia (EMG), dinamometria, cinemetria e antropometria.

No presente trabalho, foram utilizados métodos biomecânicos vinculados com a EMG, a dinamometria e a cinemetria, as quais serão descritas a seguir. A EMG registra a atividade elétrica associada à contração muscular oriunda dos potenciais de ação deflagrados pelas unidades motoras (P.A.U.M.). Por proporcionar um método de avaliação que possibilita a caracterização da atividade elétrica muscular de forma direta, a EMG cinesiológica surgiu como mais um meio para avaliar e entender o movimento humano (HERMENS, FRERIKS, DISSELHORST-KLUG \& RAU, 2000; SUTHERLAND, 2001). No entanto, inicialmente essa metodologia foi desenvolvida para o estudo do potencial de ação 
anormal, tal como a fasciculação e a fibrilação, além de testar o atraso na velocidade de condução nervosa. Atualmente, a eletromiografia proporciona a investigação dinâmica dos músculos durante a locomoção (SUTHERLAND, 2001).

O registro do sinal elétrico muscular requer eletrodos de captação de sinal, um sistema de amplificação e filtragem, um conversor analógico-digital e um sistema de armazenamento e processamento dos dados (SUTHERLAND, 2001). A função do eletrodo é captar o sinal elétrico do músculo; por isso é confeccionado com materiais metálicos de ótima condução elétrica; como exemplo, o ouro, o cloreto de prata ou a prata pura. Existem diferentes tipos de eletrodos, os quais podem ser utilizados por meios de técnicas invasivas ou não invasivas. Para os métodos invasivos, destacam-se a utilização de eletrodos do tipo agulha e fio, os quais são colocados internamente no ventre muscular (SHUTHERLAND, 2001; SODERBERG \& KNUTSON, 2000). O método para a identificação do sinal elétrico muscular de forma não invasiva, utilizado no presente trabalho, é baseado na utilização de eletrodos de superfície, os quais são fixados na pele da região na qual se encontra o músculo. Por não gerarem desconforto ao sujeito avaliado, esse é o método mais utilizado atualmente no campo da investigação da locomoção humana (SODERBERG \& KNUTSON, 2000).

Os registros da atividade elétrica muscular podem ser contaminados por interferências oriundas de diversas fontes: do suprimento elétrico do próprio sistema de captação da EMG, dos dispositivos elétricos que operam com corrente contínua do local, de artefatos mecânicos provenientes da interface eletrodotecido, de movimentos ligados ao balanço dos cabos que transmitem o sinal dos eletrodos ao amplificador, além da interferência da atividade de outros músculos da região, conhecida como cross-talk (BASMANJIAN \& DE LUCA, 1985; CLANCY, MORIN \& MERLETTI, 2002).

Para restringir as possíveis fontes de ruídos provenientes de campos eletromagnéticos, prioriza-se desligar os demais equipamentos que não fazem parte da coleta. Pode-se também utilizar um pré-amplificador de sinais biológicos na proximidade dos eletrodos, o qual faz com que fiquem conhecidos como ativos. O sistema que não possui tal amplificação é considerado como passivo e encontra-se mais susceptível a presença de ruídos junto ao sinal biológico. 
Adicionalmente, com o objetivo de também minimizar o registro de ruídos externos, há eletrodos que possuem duas (bipolares) ou mais áreas de detecção (multipolares), que têm como função rejeitar sinais com características de amplitudes iguais, encontrados nos ruídos eletromagnéticos externos, como no caso da corrente de $60 \mathrm{~Hz}$ ou $50 \mathrm{~Hz}$ (BASMANJIAN \& DE LUCA, 1985; CLANCY, MORIN \& MERLETTI, 2002).

Portanto, por meio de eletrodos bipolares com amplificadores, como os utilizados no presente estudo, o sinal detectado será o oriundo do potencial de ação das unidades motoras e dos sinais eletromagnéticos externos; porém, apenas o potencial de ação passa pelo processo de amplificação e registro do sinal.

Além dos eletrodos de captação da atividade elétrica muscular, deve ser utilizado um eletrodo adicional, conhecido como referência, o qual irá permitir um mecanismo de cancelamento do efeito de interferência do ruído elétrico externo. Esse eletrodo deve ser colocado sobre um tecido eletricamente inativo, como uma proeminência óssea (HERMENS et al., 2000). Para minimizar o ruído oriundo de outros músculos próximos às áreas de detecção, é necessário seguir alguns procedimentos padronizados. Tais preocupações são mais visíveis durante a realização da EMG de superfície, a qual deve se preocupar com a padronização da geometria e tamanho dos eletrodos, bem como com a preparação da pele e técnica de fixação desse equipamento de captação do sinal (BASMANJIAN \& DE LUCA, 1985). Portanto, a pele deve ser preparada para que haja a diminuição dos artefatos provenientes da interface pele/eletrodo e conseqüentemente diminuição da impedância local. Para isso, preconiza-se a realização da tricotomia e limpeza com álcool no local e, em seguida, os eletrodos de superfície devem ser bem fixados em direção longitudinal às fibras musculares (BASMANJIAN \& DE LUCA, 1985).

O local do posicionamento dos eletrodos no ventre muscular deve seguir metodologia padronizada de acordo com o descrito na literatura, visto que 0 melhor posicionamento ainda é discutido. DE LUCA (1997) preconiza a colocação do eletrodo no sentido longitudinal à fibra muscular, no ponto médio entre o ponto motor e a junção miotendínea. 
ARAÚJO (1998) investigou diversas técnicas de posicionamento de eletrodos e verificou que tanto a colocação do eletrodo no ponto médio entre as inserções musculares, quanto à colocação no ponto motor podem ser bem indicadas, dependendo da situação. Atualmente, destaca-se também o projeto SENIAN (Surface Eletromyographics for Non-Invasive Assessment of Muscles), desenvolvido por um grupo de pesquisadores europeus, o qual estabeleceu recomendações de posicionamento de eletrodos para 22 músculos (HERMENS et al., 2000).

Existem também recomendações quanto à freqüência de aquisição e tratamento matemático dos dados para EMG com objetivo de minimizar erros na análise dos sinais de EMG. Como o sinal EMG varia de 12 a $1000 \mathrm{~Hz}$, para a sua aquisição, preconiza-se uma freqüência de amostragem com pelo menos o dobro da maior freqüência do sinal amostrado (HERMENS et al., 2000).

Para o processamento do sinal, dependendo do objetivo da análise, inicialmente recomenda-se a sua retificação, a qual pode ser feita em onda completa com inversão da polaridade negativa. Em seguida, realiza-se a filtragem do sinal: o filtro passa baixa irá eliminar componentes de alta freqüência, e o filtro passa alta irá eliminar componentes de baixa freqüência (SODERBERG \& COOK, 1984). Sabendo que a freqüência do sinal EMG abaixo de $20 \mathrm{~Hz}$ é instável, preconiza-se a realização de um filtro passa alta entre $10 \mathrm{a} 20 \mathrm{~Hz}$. Como os sinais coletados em EMG de superfície geralmente possuem uma freqüência abaixo de $500 \mathrm{~Hz}$, preconiza-se a realização de um filtro passa baixa entre 400 a $500 \mathrm{~Hz}$ (CLANCY, MORIN \& MERLETTI, 2002). Há também o processo que realiza um filtro, conhecido como Notch, que elimina freqüências específicas, dentre as quais se destacam as de $60 \mathrm{~Hz}$ ou de $50 \mathrm{~Hz}$, comuns da rede elétrica. A seguir, é feita a normalização dos dados, que é um processo o qual minimiza as diferenças que dificultam a comparação intra e inter indivíduos.

Para diminuição da variabilidade do traçado da EMG, têm-se várias metodologias de normalização, dentre as quais se destacam as realizadas pela contração isométrica voluntária máxima, pela média do sinal em uma determinada janela de coleta e pelo pico do sinal eletromiográfico (BRUDEN \& BARTLETT, 1999; SODERBERG \& KNUTSON, 2000). Esse processamento matemático deve 
estar de acordo com o objetivo específico do trabalho, para aumentar a fidedignidade e reprodutibilidade do sinal coletado (AMADIO, COSTA, SACCO, SERRÃO, ARAÚJO, MOCHIZUKI \& DUARTE, 1999; AMADIO \& DUARTE, 1996; WINTER, 1990).

Após esses procedimentos, o próximo passo será descrever a atividade eletromiográfica por meio de valores numéricos que traga relação da forma do pulso com a taxa de disparo das unidades motoras. Isso pode ser realizado por meio de expressões matemáticas que advêm de um modelo estocástico dos trens de potenciais de ação das unidades motoras obtidos de resultados empíricos (BASMANJIAN \& DE LUCA, 1985). Dentre as expressões matemáticas mais usadas, destacam-se a média do valor retificado, a média da integral do valor retificado, o RMS e o espectro da densidade de potência.

Todos esses parâmetros são descritos em função do tempo de contração, considerando o desenvolvimento constante de força durante uma contração (DE LUCA \& VAN DYK, 1975). Em relação ao parâmetro matemático escolhido para análise, quando se tem como objetivo representar de forma numérica um pulso resultado do registro mioelétrico, deve-se considerar uma vantagem da escolha do RMS sobre a média e a integral do valor retificado. Para realização da média ou da integral do sinal, anteriormente realiza-se a sua retificação. Contudo, quando o sinal é retificado, uma porção do sinal é cancelada, fato que pode diminuir a média ou a integral. A realização da média quadrada do sinal pode resolver tal problema, pois, assim, não se tem o cancelamento do sinal positivo, fato que ocorre durante a retificação. Nota-se, portanto, que o desenvolvimento da equação do RMS apresenta uma vantagem sobre o cálculo da média do valor retificado e da integral. O RMS segue então três passos: inicialmente o sinal é elevado ao quadrado, logo após é realizada a média, e finalmente a raiz da média (DE LUCA \& VAN DYK, 1975).

Como definido, a cinemática descreve o movimento humano. Seus parâmetros são descritores de movimentos observados e utilizados, principalmente, para descrever as características de velocidade, aceleração e desaceleração, além dos deslocamentos linear e angular. Historicamente, os estudos cinemáticos estão relacionados ao progresso tecnológico de sistemas de 
aquisição de imagens (AMADIO \& DUARTE, 1996; WINTER, 1990). Desde os tempos da pré-história, observam-se descrições de movimentos desenhados em cavernas. Artistas sempre retrataram, por meio de pinturas e estátuas, formas relacionadas à descrição do movimento humano. Em 1885, Jules Etienne Marey, um fisiologista francês, por meio de um sistema revolucionário na época, conseguiu registrar parâmetros da marcha humana. Na mesma época, Eadweard Muybridge, um inglês que morava nos Estados Unidos, registrou a corrida humana com o disparo sincronizado de 24 câmeras fotográficas. Com essas imagens, Muybridge realizou uma projeção rápida, simulando movimento (WINTER, 1990).

A cinemetria, portanto, utiliza imagens obtidas por meio da fotografia, filme, película, fluoroscopia, dentre outros métodos, para investigar um determinado movimento com a finalidade de medir os parâmetros cinemáticos existentes de forma direta ou indireta (AMADIO \& DUARTE, 1996).

Exemplos de métodos diretos de medição cinemática são os goniômetros, os quais são potenciômetros elétricos que podem ser acoplados ao corpo para mensurar o ângulo articular. Um braço do goniômetro é fixado em um segmento, e o outro braço fixado no segmento adjacente com o centro desse equipamento posicionado no eixo articular. Dessa forma, consegue-se registrar as características angulares em um plano e, dependendo do equipamento, fazer registros multiplanares (WINTER, 1990).

A complexidade do movimento humano traz a necessidade da existência de um sistema de processamento de imagem para possibilitar a captação de todos os dados relativos ao movimento. Este processamento é uma técnica indireta, pois a análise é feita a partir da imagem coletada (AMADIO \& DUARTE, 1996; WINTER, 1990).

A fim de que isso seja possível, há necessidade de padronizar os referenciais que serão identificados nos segmentos que fazem parte da avaliação. Para isso, utiliza-se de discretos pontos marcadores fixados, geralmente, na pele sobre proeminências ósseas (YUAN, RYD \& BLANKEVOORT, 1997).

O processamento de imagem pode ser classificado como procedimento óptico ou óptico-eletrônico. Esses procedimentos podem ser realizados por meio de processos fotoelétricos e fotoquímicos. O processo fotoelétrico utiliza-se da 
videografia e das câmeras óptico-eletrônicas. Este último é composto de emissores luminosos colocados em pontos anatômicos específicos do corpo de um receptor que capte sinais infravermelhos, além de um software que realiza a análise das coordenadas dos pontos demarcados quadro a quadro.

Para a reconstrução tridimensional do movimento, há a necessidade da utilização de pelo menos duas câmeras sincronizadas, não paralelas e não métricas, com o auxílio de um sistema conhecido como DLT (Direct Linear Transformation). Os processos fotoquímicos, realizados com auxílio da fotografia, cronofotografia e a cinematografia, utilizam-se de aparelhos que registram os dados por meio de uma película (AMADIO \& DUARTE, 1996).

Atualmente, destaca-se também a utilização de instrumentos que registram as características dos movimentos articulares de forma muito precisa, com investigação dos movimentos acessórios articulares. Esse estudo baseia-se na capacidade de identificação das características dos movimentos fisiológicos e acessórios articulares, tendo como principais instrumentos de investigação a fluoroscopia e a ressonância nuclear magnética dinâmica. KANEKASU, BANKS, HONJO, NAKATA e KATO, em 2004, realizaram um estudo para analisar as características funcionais de pacientes submetidos à cirurgia para colocação de prótese total de joelho. Para isso, utilizaram um sistema de análise de imagens fluoroscópica tridimensional durante o movimento de ajoelhar. POWERS, WARD, FREDERICSON, GUILLET e SHELLOCK, em 2003, investigaram movimentos da articulação fêmoropatelar, por meio da utilização de uma ressonância nuclear magnética dinâmica.

A dinamometria é utilizada para medir os parâmetros cinéticos do movimento por meio da mensuração da ação deformadora da força sobre os corpos (WINTER, 1990; AMADIO et al., 1999).

A mais comum força que atua em nosso corpo é a força de reação do solo (FRS), a qual age em nossos pés durante a locomoção. A FRS, portanto, é de fato a aplicação direta da terceira lei de Newton, pois é a resposta das ações do sistema locomotor na superfície de contato (WINTER, 1990). A plataforma de força é o método mais utilizado para identificar a FRS durante a locomoção, com a obtenção de parâmetros de força nos sentidos vertical, ântero-posterior e médio- 
lateral. As plataformas, geralmente fixas no solo ou acopladas a esteiras rolantes, são construídas por diversos tipos de sensores os quais são posicionados geralmente nos quatro cantos da plataforma ou centralizados abaixo dela (CHAO, LAUGHMAN, SCHNEIDER \& STAUFFER, 1983; WINTER, 1990). Esses sensores possibilitam a conversão das cargas aplicadas em sinais elétricos e são conhecidos como transdutores de força. Geralmente, os transdutores mais utilizados são os do tipo strain gauge (sensores de deformação), os piezelétricos, os piezoresistidos e os capacitivos. Para os do tipo strain gauge, utilizado no presente estudo, um metal calibrado com o transdutor sofre uma pequena mudança em sua dimensão; essa deflexão mecânica (cerca de 1\%) resulta no desequilíbrio de voltagem proporcional à força aplicada. Os piezoresistidos baseiam-se na mudança da resistência do material com os mesmos princípios dos strain gauge. Os piezelétricos são construídos com materiais cristalinos, dentre eles o Quartzo, e requerem a deformação da estrutura atômica do material. Com isso, geram mudanças nas características elétricas que são transformadas em sinais proporcionais à força aplicada (WINTER, 1990).

Após essas transformações, todos os sinais coletados são amplificados, filtrados e convertidos para sinais digitais, sendo seqüencialmente enviados a um computador, o qual terá instrumentos para calcular tais grandezas cinéticas.

Para mensurar as forças em duas ou mais direções, é necessário usar transdutores de força bi ou tri-direcional. Dessa forma, quantifica-se a FRS em sua magnitude de força direcionada para cima (força vertical), além das direcionadas para frente e para trás (força ântero-posterior), e para a direita e esquerda (força médio-lateral) (WINTER, 1990; ZATSIORSKY, 2002).

Outra força externa de grande importância a ser avaliada na locomoção é a pressão. Atualmente, para a análise da pressão plantar, têm-se disponível diferentes instrumentos com o mesmo princípio, os quais possuem pequenos sensores ou matrizes de sensores que mensuram a força durante o contato com uma superfície. A quantidade de pressão é determinada pela divisão da magnitude da força mensurada pela área conhecida de cada sensor existente. Esses instrumentos de medição geralmente são encontrados em forma de sistemas com plataformas e palmilhas flexíveis (ORLIN \& McPOIL, 2000). 
A análise das forças internas é complexa em razão do grande número de variáveis envolvidas e sua mensuração é realizada com base em um modelo mecânico que depende da aquisição, da descrição do movimento, da acurácia das mensurações antropométricas e das forças externas. Com tais dados, podemos realizar o procedimento da dinâmica inversa, estratégia que permite estimar as forças e momentos internos com base em medidas externas e modelos (LOBO DA COSTA, 2000; WINTER, 1990). Outro método é a análise das forças internas de forma direta com a utilização de transdutores implantados cirurgicamente (BEYNNON, JOHNSON \& FLEMING, 2002).

\subsection{Análise biomecânica da locomoção humana}

Conforme descrito por SHUTHERLAND (2001), a origem da investigação científica da locomoção humana iniciou-se no século 17 , com as contribuições notáveis de Borelli, Galvani, Newton, Descartes, Marey, Carlet, Duchene, Muybridge, dos irmãos Weber e de Braune e Fischer. A partir desta época, os métodos de análise empregados nas áreas de investigação em Biomecânica evoluíram exponencialmente, fato que trouxe novas perspectivas para o entendimento da locomoção.

Estudos buscam um melhor entendimento de tais características durante a marcha, pois essa é considerada o movimento voluntário mais comum e mais repetitivo realizado pelo corpo humano (WINTER, 1983). A corrida tem suas particularidades importantes do ponto de vista funcional e no contexto da reabilitação. Contudo, o salto, dentre eles o vertical, pode favorecer uma potencial situação de risco ao aparelho locomotor, decorrente das variadas técnicas utilizadas entre os indivíduos, que geralmente são influenciadas pelas estratégias de posicionamento das articulações do joelho e tornozelo na fase de aterrissagem (DUFEK \& BATES, 1990).

Naturalmente, para o entendimento de características de anormalidade da locomoção humana, há necessidade de se compreender características comuns deste fenômeno. 


\subsubsection{Características gerais da locomoção}

Embora exista uma alta variabilidade das características funcionais na locomoção (HERZOG, NIGG, READ \& OLSSON, 1989; WINTER, 1983), certas peculiaridades são universais e formam a base para determinar parâmetros importantes ligados ao seu gerenciamento. Esse entendimento tem um grande significado para a compreensão da locomoção e sua influência na estrutura corporal (ANDRIACCHI \& ALEXANDER, 2000; LOBO DA COSTA, 2000). Diante disso, torna-se necessário esclarecer algumas características que envolvem o comportamento da locomoção humana.

Tem-se como consenso a divisão das fases da marcha em fase de apoio (60\% de todo ciclo da marcha) e balanço (40\%). A literatura considera subdivisões para as duas fases, denominadas de contato inicial, resposta à carga (10\% do ciclo), apoio médio (10 a $30 \%$ ), apoio terminal (30 a $50 \%$ ), pré-balanço (50 a $60 \%$ ), balanço inicial (60 a $73 \%$ ), balanço médio (73 a $87 \%$ ) e balanço terminal (87 a 100\%). Vale ressaltar que essa porcentagem é referente ao ciclo total da marcha (passada), sendo $0 \%$ o toque inicial do pé e $100 \%$ o segundo toque do mesmo pé (CHAMBERS \& SUTHERLAND, 2002).

O joelho no momento do toque do calcanhar está próximo da extensão total e inicia um momento de flexão que alcança um pico de $20^{\circ}$ no momento da resposta a carga, com a finalidade de absorção do choque mecânico. Logo após, inicia-se a extensão que marca o médio apoio e apoio terminal. No momento do pré-balanço, surge uma flexão passiva em razão da hiperextensão dos dedos. $\mathrm{Na}$ fase de balanço, o joelho estende para posicionar a tíbia à frente e preparar o pé para o contato com o solo (WINTER, 1991). O quadril e a pelve avançam o membro inferior à frente, no final da fase de balanço, graças à máxima flexão do quadril que ocorre durante a fase terminal do balanço e início do apoio. Essa flexão é mantida durante a resposta à carga e, no médio apoio, a flexão de aproximadamente $30^{\circ}$ vai para $10^{\circ}$. Em seguida, a extensão continua e alcança o valor máximo no momento do desprendimento do pé. No pré-balanço, o quadril encontra-se em uma posição neutra e a partir daí inicia um período de flexão que alcança seu pico no momento do toque do calcanhar com o solo (WINTER, 1983). 
Ao analisar o comportamento das variáveis cinéticas, nota-se que a componente vertical tem característica marcante na marcha, caracterizada por dois picos de força com magnitudes semelhantes. O primeiro pico de força ocorre imediatamente após o contato do calcanhar com o solo e possui magnitude média de aproximadamente 1,5 vezes o peso corporal. Neste instante, o centro de massa é acelerado para cima. A relação entre o pico de força e o tempo que ele demora é a taxa de crescimento, variável que apresenta alta correlação com o choque mecânico sofrido durante esta fase inicial do apoio. No médio apoio da marcha, quando o joelho está mais flexionado, o centro de massa terá aceleração para baixo e, conseqüentemente, a força será menor que o peso corporal. O segundo pico ocorre na fase final do apoio, no momento do desprendimento do pé com o solo, instante em que ocorre a aceleração do centro de massa para cima (AMADIO \& DUARTE, 1996; ZATSIORSKY, 2002; WINTER, 1990).

A componente ântero-posterior é caracterizada por uma fase inicial conhecida como frenagem, demonstrada graficamente de forma padronizada por um período negativo, no qual a força externa atua na direção oposta ao movimento. Caso a magnitude dessa força seja muito pequena, significa que o pé pode estar escorregando para frente. $\mathrm{Na}$ fase de médio-apoio, essa força inexiste, e logo após inicia-se a fase da propulsão do segmento, a qual coincide com uma força na direção do movimento do corpo para frente, demonstrada graficamente com uma magnitude positiva. Durante a marcha, os impulsos de frenagem e de propulsão possuem magnitudes semelhantes (ZATSIORSKY, 2002). A componente médio-lateral apresenta, na marcha, geralmente dois picos mediais e dois picos laterais (FIGURA 1). A força de reação é uma somatória algébrica de todas as acelerações das massas produzidas pelo segmento corporal. Portanto, se uma pessoa ficar posicionada de forma estática em cima de uma plataforma de força, teremos como quantificar com exatidão seu peso corporal. 


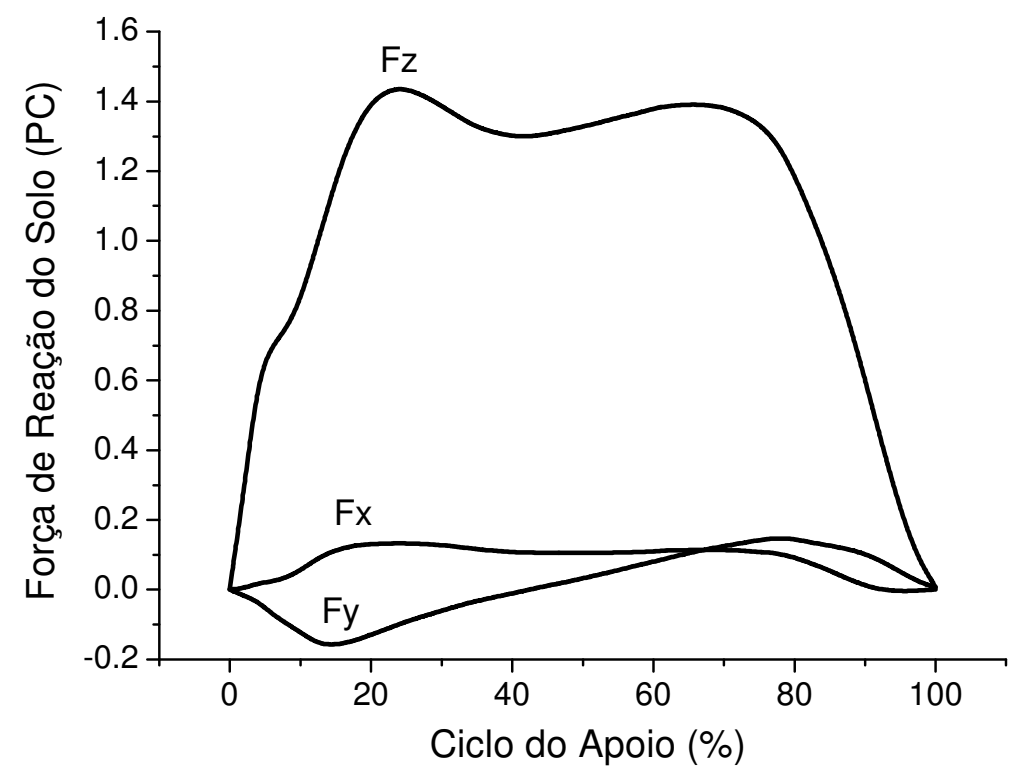

FIGURA 1 - Componentes vertical (Fz), ântero-posterior (Fy) e médio-lateral (Fx) da força de reação do solo, com suas intensidades normalizadas pelo peso corporal (PC).

Os músculos proporcionam a força necessária para a locomoção humana, sendo ativados de formas peculiares e eficientes. A ação de um dado músculo, durante a marcha é definida dentro da fase de balanço ou apoio. WINTER (1991) e RAB (1998) descrevem as ações musculares durante todo o ciclo de uma passada e mostram a sinergia muscular que resulta em um movimento eficiente. No momento do contato inicial do pé, no instante do toque do calcanhar com o chão, inicia-se um momento de desaceleração do membro e posicionamento do pé no solo. Neste momento, dados eletromiográficos demonstram que a contração dos extensores do quadril desacelera a coxa e auxilia na extensão do joelho. Ao mesmo tempo, o tibial anterior age excentricamente gradualmente para facilitar a descida do pé. Neste momento, ação excêntrica do quadríceps auxilia a desaceleração do membro. Na seqüência, tem-se a resposta à carga, para transferir o peso ao membro de apoio e estabilizar a pelve. Neste momento, o quadríceps finaliza a desaceleração e, posteriormente, age de forma concêntrica e inicia a extensão do joelho. 
Conjuntamente inicia-se a flexão plantar do tornozelo, por meio da contração concêntrica do tríceps sural, e a pelve é estabilizada, neste momento, pela contração concêntrica dos glúteos. No médio apoio, o centro de gravidade atinge o ponto mais alto à medida que é deslocado para frente. Neste instante, o joelho permanece estendido, e a massa corporal é deslocada para frente com o pé fixo no solo. A ação do sóleo mantém o antepé pressionado contra o solo, e permite que $o$ joelho continue estendido sem a ação do quadríceps. Na fase terminal do apoio, as forças de extensão do joelho e flexão plantar do tornozelo continuam a manter o joelho passivamente estendido. Então ocorre a ação concêntrica do tríceps sural que acelera o corpo à frente e inicia-se o momento de maior geração de energia da marcha. Pode acontecer, um disparo de descarga do músculo iliopsoas indicando o início da atividade e inicia-se o pré-balanço. Logo após, surge o silêncio dos flexores plantares e os flexores do quadril (iliopsoas e reto femoral). A fase de balanço é praticamente passiva e o membro funciona como um pêndulo, com uma pequena energia consumida nesta fase. $O$ início do balanço ocorre com o final da atividade do iliopsoas e reto femoral e os músculos flexores dorsais começam a contrair de forma concêntrica para tirar o pé do chão. A liberação do pé continua durante a fase de balanço médio pela atividade do músculo tibial anterior, e o membro inferior presencia a continuação da ação de pêndulo passivo. Na fase de balanço terminal, o membro começa a desaceleração ativa pela contração excêntrica dos músculos flexores do joelho. O músculo tibial continua sua atividade, mas muda para uma contração excêntrica e faz com que o pé pouse suave e imediatamente antes do contato do pé com o solo (CHAMBERS \& SUTHERLAND, 2002).

As características dos parâmetros biomecânicos relacionados com a corrida são similares aos da marcha; porém, com característica têmporo-espacial e de magnitudes diferentes. Exemplos são as características de magnitude para o primeiro pico da FRS vertical, as quais são maiores e podem chegar de três a quatro vezes o peso corporal, além existir uma taxa de crescimento para esta magnitude máxima maior. No entanto, a característica marcante da corrida é a inexistência da fase de duplo apoio, marcante na marcha. Com relação à atividade muscular, o quadríceps tem seu período total de tempo de ativação alterada de 
forma considerável com o aumento da velocidade (WINTER, 1983). Durante a caminhada, o quadríceps torna-se ativo nos últimos $10 \%$ da fase do balanço e permanece ativo durante os primeiros $15 \%$ da fase de apoio. Durante a corrida, sua atividade inicia-se nos últimos $20 \%$ do balanço e permanece ativo durante os primeiros $50 \%$ da fase de apoio. No sprint, o quadríceps torna-se ativo durante aproximadamente os primeiros $80 \%$ do apoio e os últimos 50 a $60 \%$ do balanço. $O$ reto femoral, além de sua normal atividade junto com os demais músculos do quadríceps, demonstra um período precoce de ativação no balanço, sendo notado de forma maior nas velocidades mais rápidas (WINTER, 1983).

O salto vertical é relevante em atividades funcionais do dia a dia, bem como na reabilitação. Na preparação do salto vertical com contra-movimento, por exemplo, a magnitude da força vertical torna-se menor do que o peso corporal, pois o centro de massa do corpo está em aceleração para baixo, com a característica de maior flexão do joelho e quadril, e dorsiflexão do tornozelo. Seqüencialmente, com a extensão do joelho, quadril e flexão plantar do tornozelo, - centro de massa inicia uma aceleração para cima até o momento de desprendimento do pé do solo, o que faz com que se inicie a fase aérea. Durante a aterrissagem, o controle multiarticular é induzido por amplas reações e forças intersegmentares controladas pelo sistema neuromuscular, que adequa o aparelho locomotor para uma diminuição da carga após o contato do pé no solo. Estratégias de ativações musculares bem como de tecidos não contráteis periarticulares contribuem para a estabilidade local e conseqüente redução do momento corporal total, fazendo com que exista um adequado pico da FRS vertical, seguido de uma fase de estabilização do movimento (FIGURA 2).

O sistema neuromuscular tem grande ação sobre o aparelho locomotor na fase da aterrissagem do salto, sendo responsável pelos mecanismos protetores que envolvem os segmentos corporais antes do início do contato do segmento inferior com o solo. Tais mecanismos estão relacionados à adequada pré-ativação muscular associada ao melhor posicionamento articular, que promovem o maior controle do choque mecânico no contato do segmento corporal com o solo (PAIN \& CHALLIS, 2006). 


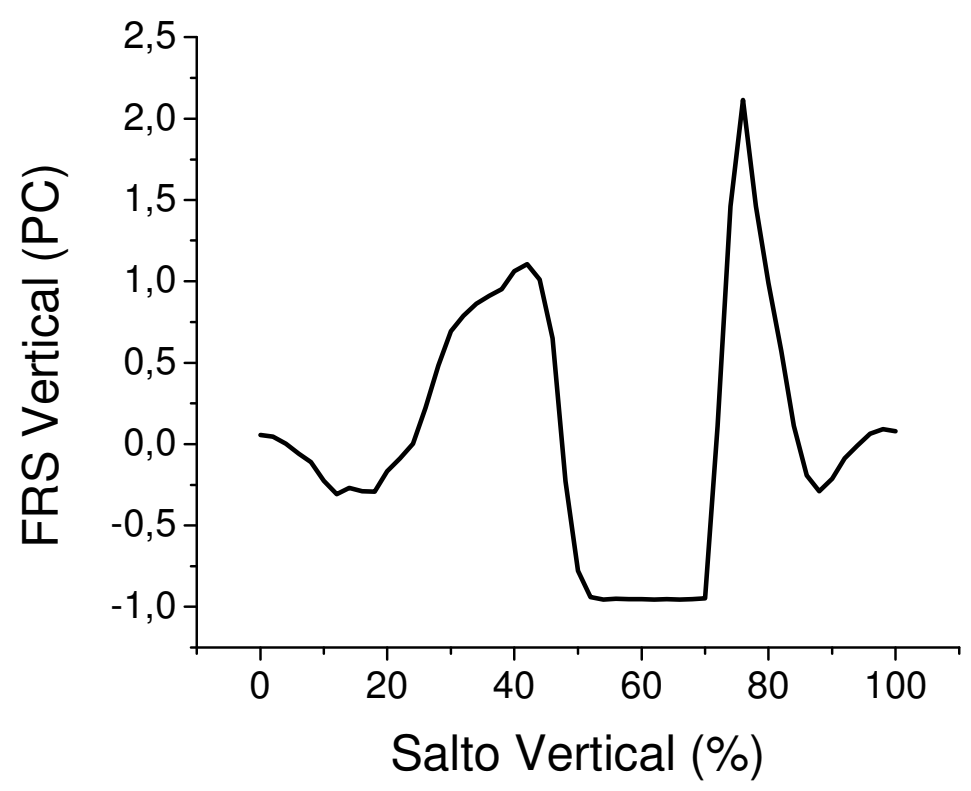

FIGURA 2 - llustração da FRS vertical durante o movimento de salto vertical com contra-movimento, normalizado pelo peso corporal (PC).

Após esse contato, tal proteção continua, o que permite a diminuição das ações de forças externas que agem no segmento corporal (LIEBERMANN \& GOODMAN, 2006).

Estudos demonstram que músculos da perna e coxa agem na aterrissagem de forma a estabilizar as articulações dos membros inferiores, protegendo, conseqüentemente, estruturas articulares e periarticulares (McNITT, HESTER, MATHIYAKOM \& MUNKASY, 2001; PAIN \& CHALLIS, 2006).

De acordo com McNITT et al. (2001), o posicionamento do pé e tornozelo possui uma grande ação nas diferentes cargas sofridas durante a aterrissagem. Segundo esses autores, um adequado momento líquido articular de flexão plantar é necessário para controlar o contato do segmento inferior no solo. No entanto, podem existir outras estratégias, como por exemplo, o contato de toda planta do pé no início dessa fase de aterrissagem (DUFEK \& BATES, 1990).

Discute-se também se possíveis alterações do alinhamento do pé podem influenciar nas sobrecargas sofridas pelo aparelho locomotor durante atividades que geram maiores cargas no aparelho locomotor. Teoricamente, um 
indivíduo que possua características extremas de pronação do pé pode gerar uma diminuição da mobilidade nas articulações da região, o que faz com exista uma rigidez articular acentuada e conseqüente dificuldade de absorção de energia gerada no contato do pé com o solo. HARGRAVE, CARCIA, GANSNEDER e SHULTZ (2003) investigaram a influência do posicionamento da articulação subtalar na FRS vertical durante a aterrissagem. Para isso, selecionaram indivíduos que possuíam, em sua postura estática, características supinadoras, pronadoras e neutras dessa articulação e solicitaram a eles que saltassem com um só pé de uma altura de 0,3 metros sobre uma plataforma de força. Verificaram que o pico da máxima FRS vertical e sua taxa de crescimento, além das características angulares do joelho, quantificadas por um eletrogoniômetro, não foram diferentes entre os grupos. Portanto, segundo os autores, essas características de alterações estáticas do alinhamento do pé não geram alterações na absorção de choque mecânico durante a aterrissagem (TABELA 1).

TABELA 1 - Descrição dos parâmetros encontrados na aterrissagem de sujeitos com diferentes características do posicionamento subtalar: supinadores $(\mathrm{N}=16)$, pronadores ( $\mathrm{N}=16)$ e neutros $(\mathrm{N}=16)$. (Adaptado de HARGRAVE, CARCIA e GANSNEDER, 2003).

\begin{tabular}{lccc}
\hline Parâmetros Analisados & Supinadores & Neutros & Pronadores \\
\hline Flexão do Joelho (Graus) & $15,89 \pm 4,95$ & $14,98 \pm 5,51$ & $16,52 \pm 6,48$ \\
\hline Pico da FRS vertical (PC) & $3,57 \pm 0,73$ & $3,65 \pm 1,01$ & $3,44 \pm 0,68$ \\
\hline $\begin{array}{l}\text { Taxa de Crescimento do } \\
\text { pico da FRS vertical (PC/ms) }\end{array}$ & $0,06 \pm 0,02$ & $0,06 \pm 0,02$ & $0,05 \pm 0,02$ \\
\hline
\end{tabular}

McNITT-GRAY (1991) relatou que a habilidade de atenuar o impacto mecânico durante a fase de aterrissagem pode estar ligada ao nível da tarefa requisitada. Esse autor verificou que atletas recreacionais realizam menor flexão do quadril durante a aterrissagem de uma altura pequena e aumentam a amplitude quando saltam de uma altura maior. Portanto, a identificação de estratégias de controle, durante a aterrissagem, pode revelar como o sistema locomotor operaciona na diminuição das cargas, durante essa fase. 


\subsubsection{A locomoção infantil}

Parâmetros biomecânicos da locomoção são estáveis quando existe a maturação do sistema nervoso central (SNC) e do sistema músculo-esquelético. Portanto, a locomoção dos adultos pode ser diferente das crianças em fase de desenvolvimento. Assim, tem-se que se preocupar com o entendimento das eventuais mudanças biomecânicas na locomoção, em diferentes atividades, durante as fases de desenvolvimento dessas crianças (BECK, ANDRIACCHI, KUO, FERMIER \& GALANTE, 1981; KYRIAZIS, 2002; TINGLEY, WILSON, BIDEN \& KNIGHT, 2002).

Estudos buscam, muitas vezes, o melhor entendimento dos processos de evolução da locomoção das crianças até sua fase adulta, baseados em temáticas desenvolvimentalistas, em aspectos relacionados com a aquisição da coordenação motora e nas adaptações à imposição de diferentes sobrecargas (LOBO DA COSTA, 2000; TAKEGAMI, 1992).

Há grande discussão acerca do controle neural da locomoção, no qual são questionados aspectos relacionados à função reflexa. A capacidade da medula espinhal de gerar estímulos e o controle dessa pelos centros superiores demonstram a existência de certa autonomia da rede neural denominada de gerador central de padrões, na qual neurônios superiores têm grande função na manutenção do controle e coordenação dos movimentos. Dessa forma, aspectos que envolvem os reflexos da marcha, demonstram padrões alternados de coordenação entre os membros. Esses padrões são dificultados durante a fase de desenvolvimento de uma criança, a qual possui várias restrições mecânicas para sua locomoção. Dentre essas restrições, destaca-se a ação da gravidade sobre os segmentos corporais que estão em constante ganho de massa e força. A partir do momento que o sistema locomotor esteja apto para controlar as ações da gravidade, com um controle do equilíbrio de sustentação e de propulsão, surge o estímulo para o movimento rítmico e coordenado, característicos da marcha humana, o que evolui gradativamente por meio do ganho da experiência nessa atividade. Portanto, tanto estímulos vindos do córtex cerebral, cerebelo e tronco encefálico, quanto do sistema de gerador central de padrões, favorecem o 
aperfeiçoamento da locomoção na fase do desenvolvimento motor de uma criança (VAAL, VAN SOEST \& HOPKINS, 1995).

Durante esse desenvolvimento, a criança busca, gradativamente, por meio de uma adequada sustentação do corpo durante a fase de apoio, uma marcha independente, coordenada e com menos gasto energético. Além disso, necessita de uma perfeita geração de energia para a retirada do pé do solo, de um controle da trajetória do pé na fase de balanço e de uma adequada absorção de energia no início do apoio (WINTER, 1991).

Todavia, SUTHERLAND (1997) aponta a necessidade de conhecer melhor os aspectos que envolvem o entendimento de quais são os fatores que controlam a maturação da marcha, tendo ainda muitas perguntas sem respostas.

A discussão a respeito dos aspectos de diferenciações entre a locomoção da criança e do adulto e dos fatores que controlam a maturação da marcha tem sido amplamente enfatizada na literatura. Autores defendem que o processo de maturação que leva a estabilização das características da marcha ocorre até os cinco anos de idade (BECK et al., 1981; SUTHERLAND, 1997). Tanto o próprio crescimento quanto a maturação do SNC controlam as mudanças na marcha até essa faixa etária. No entanto, ainda podem ser encontradas algumas diferenças dessas características de maturação da locomoção com o avançar da idade (HAUSDORFF, ZEMANY, PENG \& GOLDBERGER, 1999; KYRIAZIS, 2002; TAKEGAMI, 1992).

As principais mudanças que ocorrem depois dessa faixa etária manifestam-se em parâmetros têmporo-espaciais, os quais são correlacionados com o comprimento do membro inferior ou altura corporal. Para o melhor entendimento dessa relação, há necessidade de compreender que a velocidade da marcha é o produto da freqüência do passo e do comprimento do passo, bem como da freqüência da passada e o comprimento da passada. Para se considerar a influência do crescimento da criança nos parâmetros temporais e de distância da marcha, pode-se aplicar as bases de conhecimento do sistema de pêndulo. Os membros inferiores agem como um pêndulo na fase de balanço da marcha; os músculos controlam basicamente o início do balanço bem como as ações da perna. Sendo o movimento de um pêndulo dependente do comprimento das 
estruturas desse pêndulo e do seu centro de massa, nota-se que o comprimento do membro inferior e o posicionamento do centro de massa corporal, combinados com as ações musculares, irão influenciar diretamente nas rotações angulares articulares e no tempo de balanço (SUTHERLAND, 1997).

Quando a criança inicia a marcha independente, por volta de um ano de idade, existe uma diminuição da flexão plantar na fase de apoio da marcha e uma diminuição da dorsiflexão na fase de balanço. O início do contato do calcanhar torna-se apenas significativo quando a criança encontra-se em torno de um ano e meio de idade. Para a articulação do joelho, sua flexão encontrada no início do contato do pé com o solo, só é visível a partir dos quatro anos de idade. No momento da retirada do pé do solo, inicia-se uma maior flexão do joelho com o objetivo de preparar o segmento inferior para o balanço, com amplitude de $65^{\circ}$ para crianças com um ano, sendo aumentada para uma média de $72^{\circ}$ em crianças com sete anos. $\mathrm{Na}$ articulação do quadril, as mudanças são muito pequenas com - avançar da idade, tendo uma diferença de apenas $9^{\circ}$ na amplitude de flexo/extensão até os sete anos de idade. Vale ressaltar que, em crianças, existe uma maior variabilidade inter-sujeitos de dados de variação angular, que são minimizadas com o avançar da idade (SUTHERLAND, 1997).

Com relação aos dados da FRS, verifica-se uma grande dificuldade em suas mensurações em crianças abaixo de dois anos. Todavia, em crianças entre dois e sete anos, existe o aumento da fase de duplo apoio e o segundo pico da FRS vertical não chega a $100 \%$ do peso corporal. TAKEGAMI (1992) encontrou aumento das magnitudes da FRS vertical e ântero-posterior na fase final do apoio em crianças acima de sete anos. Isto ocorre pois, para gerar potência na marcha, crianças novas usam mais músculos flexores e extensores de quadril do que flexores plantares de tornozelo (TAKEGAMI, 1992; WINTER, 1991).

Poucos estudos mostram as características eletromiográficas em crianças devido às suas limitações metodológicas inerentes. Verifica-se que o vasto medial tem ativação muscular precoce na fase de balanço em crianças com até dois anos de idade. A atividade do tibial anterior é prolongada na fase de apoio e tem ativação mais tardia no balanço nesta faixa etária (SUTHERLAND, 1997). 
As investigações da pressão plantar também servem para caracterizar parâmetros biomecânicos em crianças saudáveis (HENNIG \& ROSENBAUM, 1991; KELLIS, 2001; MACHADO, HENNIG \& RIEHLE, 2001); e em situações patológicas (FAVRE, EXNER, DRERUP, SCHIMID, WETZ \& JABOB, 2007; WIDHE \& BERGGREN, 1994). Entretanto, estes trabalhos apresentaram resultados diferentes (FIGURA 3). Tal fato pode estar relacionado a vários fatores, como as amostras de cada trabalho. Ressalta-se que as crianças avaliadas por HENNIG e ROSENBAUM (1991) e de KELLIS (2001) são mais novas e não atingiram a maturação da marcha (BECK et al., 1981; SUTHERLAND, 1997).

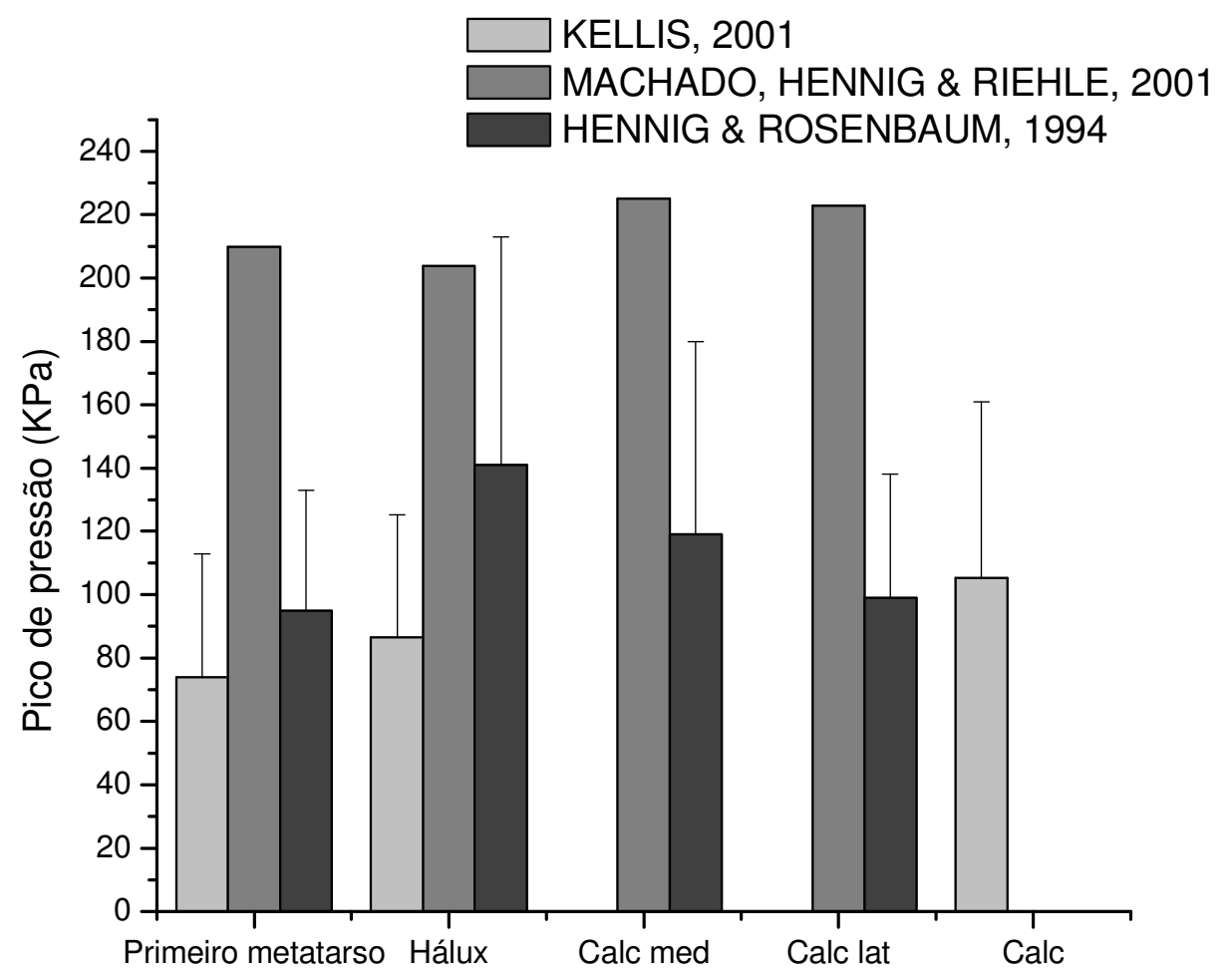

FIGURA 3 - Valores do pico de pressão nas regiões do primeiro metatarso, hálux e calcanhar durante a marcha nas comparações entre os trabalhos de KELLIS (2001), MACHADO, HENNIG e RIEHLE (2001) e HENNIG e ROSENBAUM (1991). O primeiro autor considerou o calcanhar (calc) como um todo, os outros dividiram o calcanhar em duas áreas: medial (calc med) e lateral (calc lat). 
Pouca literatura científica relata características de parâmetros biomecânicos relacionadas com outras atividades funcionais da locomoção de crianças, como o salto (SWARTZ, DECOSTER, RUSSEL \& CROCE, 2005). A análise da preparação do salto com contra-movimento contribui para a compreensão de como o sistema locomotor opera no gerenciamento da execução da tarefa. A simetria entre os membros inferiores e o adequado movimento angular contribuem para a melhor restituição de energia, a qual tem como princípio o melhor desempenho da tarefa (SWARTZ et al., 2005).

$\mathrm{O}$ entendimento de características referentes à fase de aterrissagem também é de fundamental importância e serve para traçar diretrizes utilizadas na reabilitação e no treinamento esportivo. No entanto, ainda não existe uma caracterização homogênea na literatura para essa atividade em crianças.

BAUER, FUCHS e SMITH (2001) encontraram a magnitude máxima média da FRS vertical na fase de aterrissagem de 8,5 vezes o peso corporal; enquanto McKAY, TSANG, HEINONEM, MACKELVIE, SANDERSON e KHAN (2005) encontraram 4,7 vezes o peso corporal. Tal diferença pode estar relacionada ao nível de aptidão física e ao nível de dificuldade entre as tarefas.

SWARTZ et al. (2005) compararam aspectos do salto vertical em 15 meninos (9,6 60,9 anos) e 15 meninas $(9,1 \pm 1,0$ anos) na fase de pré-puberdade,

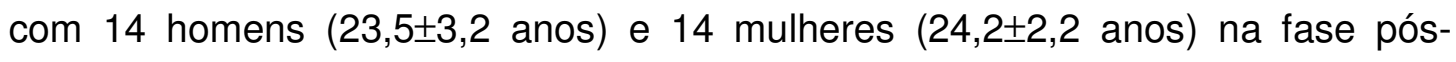
puberdade. Para isso, utilizaram dados da variação angular das articulações do joelho e quadril (TABELA 2), além da FRS vertical durante a fase de aterrissagem. Não foi encontrada nenhuma diferença significativa nas comparações entre os sexos. Porém, na comparação entre os grupos de criança e adulto, o primeiro demonstrou maior valgismo no joelho e menor flexão do quadril no início do contato com o solo. Durante a máxima FRS vertical, foi encontrada uma menor flexão do joelho associada a uma maior magnitude da FRS vertical junto com um tempo menor para atingir essa magnitude. Portanto, o desenvolvimento maturacional influencia os padrões da aterrissagem. 
TABELA 2 - Média e desvio padrão de parâmetros de variação angular do joelho e do quadril, em graus, de crianças $(\mathrm{N}=30)$ e adultos $(\mathrm{N}=28)$ durante dois momentos da aterrissagem do salto vertical: início do contato (IC) e máxima magnitude da FRS vertical (M FRS). $\left.{ }^{*} P<0,05\right)$ (adaptado de SWARTZ et al., 2005).

\begin{tabular}{ccc}
\hline & \multicolumn{2}{c}{ Grupos } \\
\hline Flexão do Joelho no IC & Crianças & Adultos \\
\hline Flexão do Joelho no M_FRS & $10,47 \pm 6,39$ & $12,65 \pm 5,7$ \\
\hline Valgismo do Joelho no IC & $29,6 \pm 8,51^{*}$ & $38,73 \pm 16,13$ \\
\hline Valgismo do Joelho no M_FRS & $12,02 \pm 4,77^{*}$ & $8,14 \pm 3,91$ \\
\hline Flexão do Quadril no IC & $10,23 \pm 5,3^{*}$ & $5,64 \pm 5,91$ \\
\hline Flexão do Quadril no M_FRS & $6,81 \pm 5,65^{\star}$ & $12,6 \pm 5,02$ \\
\hline
\end{tabular}

Diferentemente de SWARTZ et al. (2005), YU, McCLURE, ONATE, GUSKIEWICS, KIRKENDALL e GARRETT (2005) identificaram que características de parâmetros biomecânicos na atividade de salto podem ser diferentes quando comparados o sexo das crianças. Apesar de não ser a mesma atividade avaliada, esses autores investigaram características biomecânicas da aterrissagem na tarefa de parar e saltar em voluntários jogadores recreacionais de futebol entre 11 e 16 anos, divididos em seis diferentes grupos de faixa etária com uma proporção igual entre meninos e meninas nos grupos. Essa atividade consiste em saltar com apoio dos dois membros inferiores, imediatamente após uma corrida, e aterrissar também com os dois pés.

Os autores verificaram que tanto a idade quanto o sexo afetaram alguns parâmetros analisados. Dentre outros achados, o ângulo de flexão do joelho, no início do contato com o solo, e a máxima angulação do joelho, nesta fase de preparação para o salto, nos meninos, permaneceram os mesmos com o aumento da idade. Entretanto, nos grupos das meninas, esses ângulos diminuíram com o aumento da idade, principalmente após os 14 anos. Adicionalmente, ambos os grupos tiveram, nesta fase de preparação, um ângulo de valgismo presente até os 12 anos. 
Após essa idade, o ângulo do joelho tornou-se varo nos meninos e manteve-se valgo nas meninas. Essas características de valgismo e varismo se mantiveram no momento de máxima flexão do joelho nesta fase de preparação para as meninas e meninos, respectivamente. Durante a aterrissagem, as meninas tiveram uma tendência de aumentar o ângulo valgo com o aumento da idade, ao passo que os meninos mantiveram suas características de varismo do joelho com o decorrer da idade. Além disso, após os 12 anos de idade, as meninas tiveram uma menor angulação de flexão do joelho e do quadril, fazendo com que, durante a fase da aterrissagem, elas se posicionassem com os membros inferiores mais estendidos. Segundo YU et al. (2005), esta última característica pode explicar um possível maior índice de lesões no joelho no sexo feminino.

McKAY et al. (2005) estudaram 12 tipos de saltos em crianças com idade média de 10,2 20,7 anos. Dentre os tipos de saltos analisados, destacam-se as análises do salto com quedas de $10 \mathrm{~cm}, 30 \mathrm{~cm}$ e $50 \mathrm{~cm}$ de altura $(S 10, S 30$, S50, respectivamente), de quedas com características para o salto pliométrico saindo das alturas de $10 \mathrm{~cm}, 30 \mathrm{~cm}$ e $50 \mathrm{~cm}$ (P10, P30, P50), do salto lateral sobre uma barra de $10 \mathrm{~cm}$ e outra de $20 \mathrm{~cm}$ de altura (L10 e L20, respectivamente), além do salto com contra-movimento (SCM) e o salto à frente alternando os pés (SAP). Os resultados mostraram que os saltos SCM, P10, P30, P50 e S50 foram acima de cinco vezes o peso corporal (média de 5,2 PC) para a máxima magnitude da FRS. Para as atividades de $S 10, S 30, L 10$ e L20, a FRS máxima foi entre três a quatro vezes o peso corporal (média de 3,6 PC). A única atividade que foi abaixo de três vezes o peso corporal foi o SAP, com média de 2,1 PC. Os saltos pliométricos e o com contra-movimento apresentaram as mais altas taxas de crescimento para o pico máximo da aterrissagem (maiores do que $400 \mathrm{PC} / \mathrm{s}$ ), com os menores valores encontrados no salto à frente com os pés alternados (média de $126 \mathrm{PC} / \mathrm{s}$ ) (TABELA 3). 
TABELA 3 - Resultados de parâmetros da FRS vertical para diferentes tipos de saltos em crianças. Intensidades dos sinais normalizadas pelo peso corporal (PC). Adaptado de McKAY et al. (2005).

\begin{tabular}{ccc}
\hline Tarefas $^{*}$ & $\begin{array}{c}\text { Magnitude máxima da FRS } \\
\text { Vertical (PC) }\end{array}$ & $\begin{array}{c}\text { Taxa de Crescimento para a } \\
\text { máxima FRS Vertical (PC/s) }\end{array}$ \\
\hline SCM & $5,3 \pm 1,6$ & $496 \pm 306$ \\
\hline S10 & $3,2 \pm 1,1$ & $241 \pm 198$ \\
\hline S30 & $3,9 \pm 1,2$ & $299 \pm 203$ \\
\hline S50 & $4,7 \pm 1,7$ & $388 \pm 281$ \\
\hline P10 & $5,5 \pm 2,0$ & $514 \pm 347$ \\
\hline P30 & $5,2 \pm 1,5$ & $440 \pm 263$ \\
\hline P50 & $5,4 \pm 1,6$ & $457 \pm 257$ \\
\hline L10 & $3,7 \pm 0,6$ & $229 \pm 75$ \\
\hline L20 & $3,8 \pm 0,6$ & $251 \pm 99$ \\
\hline SAP & $2,1 \pm 0,3$ & $126 \pm 59$ \\
\hline
\end{tabular}

* SCM - salto com contra-movimento, $\mathrm{S} 10$ (salto de $10 \mathrm{~cm}$ de altura), $\mathrm{S} 30$ (salto de $30 \mathrm{~cm}$ de altura), S50 (salto de $50 \mathrm{~cm}$ de altura), P10 (salto pliométrico com queda de $10 \mathrm{~cm}$ de altura), P30 (salto pliométrico com queda de $30 \mathrm{~cm}$ de altura), P50 (salto pliométrico com queda de $50 \mathrm{~cm}$ de altura), L10 (salto lateral sobre uma barreira de $10 \mathrm{~cm}$ de altura), L20 (salto lateral sobre uma barreira de $20 \mathrm{~cm}$ de altura), SAP (salto à frente alternando os pés).

\subsubsection{A influência dos receptores plantares na locomoção}

Como visto, a locomoção tem sido amplamente estudada com objetivo de um melhor entendimento das características funcionais do ser humano. Contudo, pesquisadores se preocupam em entender quais mecanismos, anatômicos ou puramente mecânicos, podem influenciar na normalidade ou anormalidade da locomoção.

Temáticas de estudos buscam entender se a função sensitiva aferente sensorial da planta do pé influencia na característica motora da locomoção. Tem sido proposto que esta função de aferência de informações oriundas da planta do pé pode ser parte integrada do comportamento dinâmico da região e, conseqüentemente, de todo o comportamento de proteção durante a locomoção (CHEN, NIGG, HULLIGER \& DE KONING, 1995). 
Sabe-se que o limiar sensitivo entre indivíduos pode ter um índice de variação alto por ter influências de vários aspectos. A pergunta que se faz é o quanto esta variação pode mudar a marcha ou outras atividades funcionais do ser humano. Adicionalmente, pergunta-se o quanto pacientes com disfunções nestes receptores plantares podem ter sua marcha comprometida. CHEN et al. (1995) mostraram que mudanças nos estímulos aferentes sensoriais da planta do pé alteram a distribuição de pressão plantar. PRÄTORIUS, KIMMESKAMP e MILANI (2003) identificaram tanto deficiências na identificação da vibração quanto de pressão em parkinsonianos. Segundo esses autores, tais achados podem influenciar nas habilidades motoras dessa população e contribuir para outros desequilíbrios que favoreçam novas lesões. NURSE e NIGG (1999) realizaram um trabalho semelhante ao anterior e quantificaram a relação entre a sensibilidade tátil e vibratória na região plantar do pé com a distribuição da pressão plantar na marcha e corrida. Para isso, utilizaram um instrumento de avaliação do limiar tátil plantar, conhecido como monofilamento de Semmes-Weistein. A amplitude e freqüência do limiar vibratório foram estudadas. A investigação da pressão plantar dinâmica na marcha e corrida foi realizada por palmilhas sensorizadas de pressão. Os resultados mostraram a existência da correlação entre um alto limiar vibratório na região do hálux com picos de pressão sobre a região, tanto na marcha quanto na corrida. Portanto, sujeitos com aumento da sensibilidade tiveram uma tendência de aumentar os picos de pressão no hálux na fase final do apoio durante os movimentos avaliados. Esse achado pode indicar que indivíduos com tal característica de sensibilidade no hálux têm uma função importante funcional no momento da retirada do pé do solo, estabilizando o pé com o centro de pressão, movendo-se para frente. Outra possibilidade é que o corpo move o centro de pressão para um ponto no qual o pé é mais sensível aos estímulos mecânicos. AHMED, AHMED, KHAN, UMER, RASHID, HASHMI e UMAR (2004) verificaram a redução de fibras nervosas sensoriais maduras na região sinovial da articulação subtalar em crianças com PTC. Todavia, ainda não se tem descrito, na literatura, se há relações entre possíveis alterações dos mecanismos sensoriais da planta do pé em crianças com PTC (decorrentes da própria patologia ou de intercorrências no ato cirúrgico) com os mecanismos de locomoção delas. 


\subsection{Sobre o pé torto congênito}

O PTC é considerado a condição mais comum ortopédica de causa congênita. Sua incidência no Reino Unido é de aproximadamente um para cada 1000 nascidos vivos e com acometimento bilateral em cerca de $50 \%$ dos casos (WAINWRIGHT, AULD, BENSON \& THEOLOGIS, 2002). Como mencionado, no Brasil acomete cerca 2:1000 nascidos vivos (SODRÉ, 1998).

Historicamente, o PTC foi primeiramente registrado pintado numa tumba Egípcia. Uma das primeiras descrições sobre o assunto foi feita por Hipócatres (400 d.C.), o qual acreditava que a causa de tal deformidade era devido às pressões mecânicas intra-uterinas e que o tratamento realizado deveria ser feito por meio de manipulações repetitivas corretivas nos primeiros anos de vida da criança (DOBBS, MORCUENDE, GURNETT \& PONSETI, 2000). Até hoje, ainda não há o conhecimento da causa de tal deformidade e alguns autores acreditam que seja multifatorial.

A denominação mais comum encontrada na literatura é a de pé torto eqüinovaro congênito, ou talipes eqüinovarus. O termo "talipes" refere-se à centralização da deformidade no tálus, o "eqüino" à flexão plantar fixa e o "varo" à rotação medial do médio e antepé (RICHARDS, 2002; SODRÉ, 1998).

Portanto, essa deformidade caracteriza-se por apresentar uma inversão e eqüinismo do retropé associados à inversão e adução do mediopé e antepé, conforme demonstrado na FIGURA 4 (SODRÉ, 1998; RICHARDS, 2002).

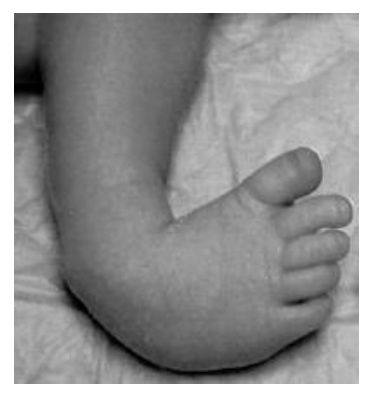

FIGURA 4 - Ilustração de um pé torto congênito unilateral em um recém nascido sem tratamento corretivo (MORCUENDE, DOLAN, DIETZ e PONSETI, 2004). 


\subsubsection{Tipos de classificações para o pé torto congênito}

Muitos pesquisadores e clínicos usam classificações para melhor entender tal problema. Tais procedimentos exigem um formato mais padronizado, pois assim há maior facilidade de definição das características neste grupo de indivíduos. As classificações mais comuns encontradas na literatura são as baseadas na etiologia da doença. SODRÉ (1998) classificou o PTC em alguns tipos, dentre eles destacam-se:

I) Idiopática: deformidade isolada, sem acometimento de outras estruturas, que pode ser unilateral ou bilateral;

II) Sindrômica: deformidade associada a alguma síndrome pré-definida, geralmente bilateral;

III) Postural: deformidade conhecida como "falso pé torto". Redutível, sem apresentar as deformidades clássicas do PTC, que pode ser unilateral ou bilateral.

A TABELA 4 mostra uma classificação baseada em achados clínicos (BANSAL, DANIEL e RAI, 1988).

TABELA 4 - Classificação dos pacientes com pé torto congênito segundo características de avaliação clínica. Adaptado de BANSAL, DANIEL e RAI (1988).

\begin{tabular}{|c|c|c|}
\hline & $\begin{array}{c}\text { Tipo I - Extrínseco ou não } \\
\text { rígido }\end{array}$ & Tipo II - Intrínseco ou rígido \\
\hline Pé & $\begin{array}{l}\text { Tamanho normal. } \\
\text { Suave varismo. }\end{array}$ & $\begin{array}{l}\text { Tamanho menor. } \\
\text { Varismo. }\end{array}$ \\
\hline Calcanhar & $\begin{array}{l}\text { Tamanho normal. } \\
\text { Boa mobilidade. } \\
\text { Mínimo varismo. }\end{array}$ & $\begin{array}{c}\text { Pequeno. } \\
\text { Elevado. } \\
\text { Diminuição da mobilidade. } \\
\text { Varismo. }\end{array}$ \\
\hline Pregas & $\begin{array}{c}\text { Maior ou menor do que o } \\
\text { normal. }\end{array}$ & $\begin{array}{c}\text { Profundidade póstero-medial e } \\
\text { pregas plantares. } \\
\text { Redução das pregas laterais. }\end{array}$ \\
\hline Teste de Telescopagem & Negativo. & Positivo. \\
\hline
\end{tabular}

Entretanto, esses próprios autores relatam que a característica de classificação desse tipo pode ser um método de difícil diferenciação entre esses pacientes por basearem em dados subjetivos. 
Alguns pesquisadores utilizam classificações de acordo com características radiológicas do pé desses indivíduos. Tais classificações podem ser baseadas no tamanho e na forma das estruturas ósseas existentes na região, além das características angulares existentes entre as articulações da região em amplitudes máximas articulares ou em posição neutra.

Segue, na TABELA 5, as características metodológicas de avaliação radiográfica utilizada por alguns autores. Tais avaliações podem ser realizadas com ou sem descarga de peso além de variarem as angulações de posicionamento do tornozelo e de captação da imagem. Em algumas vezes, os autores realizam uma somatória de ângulos, caracterizando alguns índices. Exemplo disso é o índice talocalcaneano, que é a somatória dos ângulos talocalcaneanos da vista lateral e ântero-posterior.

Com objetivo de identificação das características morfológicas, radiográficas e funcionais associadas às deformidades de pacientes com PTC, ARONSON e PUSKARICH (1990) utilizaram uma classificação de acordo com o tratamento médico utilizado: I - Apenas utilização de órtese imobilizadora; II Utilização de órtese imobilizadora associado ao alongamento do tendão do calcâneo; III - Utilização de órtese imobilizadora associado à liberação posterior; IV - Utilização de órtese imobilizadora associada à liberação póstero-medial.

OTIS e BOHNE (1986) classificaram crianças com PTC, dividindo-as em quatro categorias, de acordo com critérios anatômicos, radiológicos e funcionais. No entanto, no artigo, não foram descritos detalhes de como foram feitas tais análises, apresentadas apenas de forma resumida, demonstradas conforme TABELA 6.

LAAVEG e PONSETI (1980) idealizaram um questionário com objetivo de fazer uma quantificação por meio de pontuação baseada em características de função que envolve tal patologia, com enfoque na própria opinião do sujeito com relação ao nível de dor, às características funcionais, às deformidades locais, à avaliação da movimentação passiva, além da análise da marcha. Apesar de tal questionário ser referenciado em outras literaturas, os pesquisadores não realizaram maiores discussões sobre os princípios metodológicos utilizados. 
TABELA 5 - Características metodológicas da utilização de radiografia em pacientes com pé torto congênito.

\begin{tabular}{|c|c|c|}
\hline Pesquisadores & Incidências das Imagens & Parâmetros Analisados \\
\hline \multirow{2}{*}{ SIMONS (1977) } & Ântero-posterior & Ângulos talocalcaneano e talo-primeiro metatarso \\
\hline & Lateral & Ângulo talocalcaneano \\
\hline \multirow{3}{*}{ LAAVEG e PONSETI (1980) } & Ântero-posterior & Ângulos talocalcaneano e calcâneo-primeiro metatarso \\
\hline & Lateral & Ângulos talocalcaneano e primeiro-quinto metatarsos \\
\hline & & Índice talocalcaneano \\
\hline \multirow{2}{*}{$\begin{array}{l}\text { PONSETI, EL-KHOURY, } \\
\text { IPPOLITO e WEINSTEIN } \\
\text { (1981) }\end{array}$} & Ântero-posterior & $\begin{array}{l}\text { Ângulo do colo do tálus com seu corpo; Ângulos calcâneo-cuboide, } \\
\text { navicular-primeiro cuneiforme, talo-primeiro metatarso e calcâneo-primeiro } \\
\text { metatarso; comprimento do primeiro e quinto metatarsos }\end{array}$ \\
\hline & Lateral & $\begin{array}{l}\text { Ângulo: colo do tálus com seu corpo; tamanho do tubérculo lateral do tálus; } \\
\text { deslocamento medial do navicular; comprimento do calcâneo e do tálus }\end{array}$ \\
\hline \multirow{3}{*}{ BANSAL, DANIEL e RAI (1988) } & $\begin{array}{l}\text { Lateral:máxima dorsiflexão } \\
\quad \text { e flexãoplantar }\end{array}$ & $\begin{array}{l}\text { Ângulos talocalcaneano, talo-metatarsal e tíbio-talar na dorsiflexão e flexão } \\
\text { plantar }\end{array}$ \\
\hline & Ântero-posterior & Ângulo talocalcaneano \\
\hline & & Índice talocalcaneano; índice do retropé; arco talar; escore radiológico \\
\hline \multirow{3}{*}{$\begin{array}{l}\text { ARONSON e PUSKARICH } \\
\text { (1990) }\end{array}$} & Ântero-posterior & Ângulo talocalcaneano \\
\hline & Lateral & Ângulo talocalcaneano \\
\hline & & Índice talocalcaneano \\
\hline
\end{tabular}

TARECO, SALA, SCHER, LEHMAN e FELDMAN (2002)

IPPOLITO, FRARACCI, CATERINI, DI MARIO e FARSETTI (2003b)
Lateral

Ântero-posterior

Lateral
Ângulos talocalcaneano e talo-primeiro metatarso

Ângulos talocalcaneano, navicular-primeiro cuneiforme, calcâneo-quinto metatarso e talo-primeiro metatarso

Ângulos talocalcaneano, talo-primeiro metatarso, calcâneo-primeiro metatarso e quinto-primeiro metatarso; comprimento do tálus e calcâneo; distância entre o maléolo medial e tuberosidade medial do navicular 
TABELA 6 - Classificação de crianças portadoras de pé torto congênito, de acordo com aspectos anatômicos, radiológicos e funcionais, segundo OTIS e BOHNE (1986).

\begin{tabular}{|c|c|c|c|}
\hline Classificação & Anatomia & Avaliação Radiográfica & $\begin{array}{l}\text { Avaliação } \\
\text { Funcional }\end{array}$ \\
\hline Excelente & $\begin{array}{l}\text { Alinhamento e } \\
\text { amplitude de } \\
\text { movimento normais. }\end{array}$ & $\begin{array}{c}\text { Normal configuração e } \\
\text { alinhamento dos ossos } \\
\text { constituintes do pé. } \\
\text { Maior do que } 15^{\circ} \text { de dorsiflexão } \\
\text { na vista em estresse lateral. }\end{array}$ & $\begin{array}{c}\text { Força e padrões } \\
\text { de marcha } \\
\text { normais. }\end{array}$ \\
\hline Bom & $\begin{array}{l}\text { Menor do que } 5^{\circ} \text { de } \\
\text { flexibilidade em } \\
\text { adução do antepé. }\end{array}$ & $\begin{array}{c}\text { Topo do tálus aplanado; pouca } \\
\text { adução do antepé (menor do } \\
\left.\text { que } 5^{\circ}\right) \text {. }\end{array}$ & $\begin{array}{l}\text { Diminuição da } \\
\text { flexão plantar. }\end{array}$ \\
\hline Satisfatório & $\begin{array}{l}\text { Maior do que } 5^{\circ} \text { de } \\
\text { rigidez em adução do } \\
\text { antepé. } \\
\text { Menor do que } 15^{\circ} \text { de } \\
\text { dorsiflexão e } 20^{\circ} \text { de } \\
\text { flexão plantar. }\end{array}$ & $\begin{array}{l}15^{\circ} \text { de adução do antepé. } \\
\text { Topo do tálus aplanado. } \\
\text { Menor ou igual a } 15^{\circ} \text { de } \\
\text { dorsiflexão na vista em } \\
\text { estresse lateral. }\end{array}$ & $\begin{array}{l}\text { Menos do que } 15 \\
\text { passos e com as } \\
\text { pontas dos } \\
\text { dedos. } \\
\text { Leve claudicação }\end{array}$ \\
\hline Ruim & Varo e/ou eqüino. & $\begin{array}{l}\text { Alinhamento em varo dos } \\
\text { ossos do retropé. } \\
\text { Menor do que } 0^{\circ} \text { de } \\
\text { dorsiflexão. }\end{array}$ & $\begin{array}{l}\text { Debilidade; } \\
\text { dificuldade na } \\
\text { marcha. }\end{array}$ \\
\hline
\end{tabular}

\subsubsection{Conduta clínica utilizada para o pé torto congênito}

O PTC pode resultar em deficiências graves caso as deformidades existentes não sejam corrigidas. Portanto, o objetivo da conduta clínica será retornar ao posicionamento normal do pé de forma precoce (FIGURA 5).

Durante anos, o destaque para o tratamento dessa patologia voltou-se para os métodos cirúrgicos que objetivam a correção das eventuais deformidades da região por meio de liberações de tecidos moles e transposições de tendões e ligamentos. Utilizam-se técnicas que realizam um alongamento do tendão do calcâneo, liberação capsular posterior das articulações tibiotalar e subtalar. Outras realizam adicionalmente a liberação dos ligamentos calcaneofibular e talofibular. 

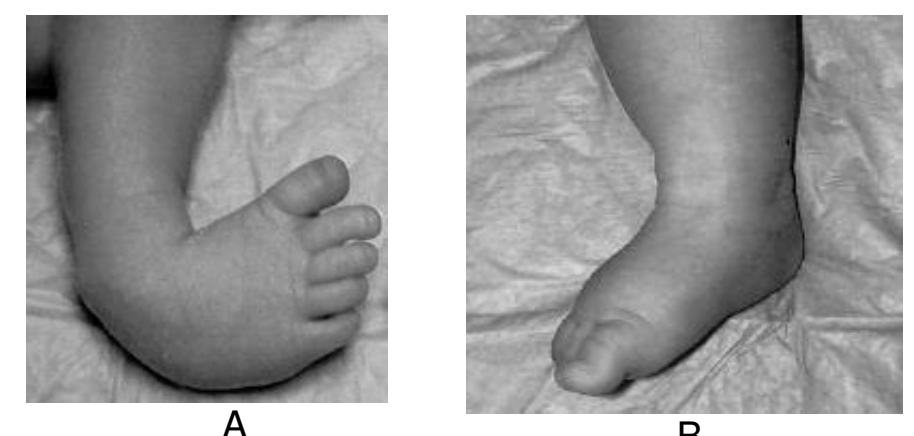

FIGURA 5 - Evolução de um tratamento para correcão da deformidade do pé torto congênito. A) deformidade instalada. B) correção de tal deformidade (MORCUENDE et al., 2004).

Uma das primeiras cirurgias descritas foi a de "Turco", com a realização de uma liberação em tecidos moles da região póstero-medial de forma ampla do pé, associada a uma tenotomia do tibial posterior e fixação do tálus no navicular. Entretanto, atualmente existem várias outras técnicas cirúrgicas com particularidades próprias, dentre elas destacam-se a de "Carroll", de "Goldner" e a de "McKay" (HEILIG, MATERN, ROSENZWEIG \& BENNETT, 2003; NIMITYONGSKUL, ANDERSON \& HEBERT, 1992).

Alguns pesquisadores acreditam que o melhor tratamento para o PTC é o tratamento conservador precoce, pois, nos primeiros dias de vida, há facilidade de adaptação do tecido conectivo denso aos estímulos externos aplicados na região, devido às suas características fibroelásticas (HEILIG et al., 2003; IPPOLITO, FARSETT, CATERINI \& TUDISCO, 2003a; MORCUENDE, WEINSTEIN, DIETZ \& PONSETI, 1994). Nas diferentes técnicas de tratamento conservador, destacam-se as utilizações de órteses corretivas para deformidades na região ou bandagens funcionais, acompanhadas de mobilizações freqüentes nas articulações mais comumente envolvidas (IPPOLITO et al., 2003b). No entanto, tanto as técnicas de mobilização articular quanto as metodologias para colocação de órteses, diferem-se entre as técnicas conservadoras mais utilizadas para esse tratamento (HERZENBERG, RADLER \& BOR, 2002). Alguns métodos de tratamento conservador realizam também 0 alongamento do tendão do calcâneo após alguns meses de tratamento (COLBURN \& WILLIAMS, 2003; HEILIG et al., 2003). 
No entanto, ainda não existe um consenso na literatura com relação à melhor técnica a ser empregada no tratamento dessa deformidade em decorrência do PTC. Todavia, há uma tendência para o tratamento conservador seguido do cirúrgico, caso exista a persistência de deformidades na região (WAINWRIGHT et al., 2002).

Mesmo no tratamento cirúrgico, é preciso acompanhamento fisioterapêutico para estimular o desenvolvimento da locomoção dessas crianças e evitar recidivas de deformidades que eventualmente podem ocorrer.

Muitas complicações podem estar associadas aos diversos métodos de tratamento do PTC. Dentre elas, destacam-se a deformidade em flexão plantar, que faz com que a criança realize uma marcha apenas com o contato da região do antepé no solo, além de uma residual deformidade em adução metatarsal. Pode também existir um aumento de rotação tibial interna ou até mesmo um excesso de correção da deformidade pré-existente. Encontra-se também a subluxação dorsal da articulação talonavicular ou até uma necrose avascular do tálus (HEILIG et al., 2003; NIMITYONGSKUL, ANDERSON \& HEBERT, 1992).

Alguns estudos se preocupam com o entendimento da movimentação acessória nos membros inferiores em atividades funcionais. Define-se movimentação acessória como o movimento dentro de uma articulação necessária para a amplitude de movimento normal e fisiológica (KISNER \& COLBY, 1992). Pesquisadores utilizam-se de diversos métodos para tal investigação; dentre eles, como já mencionado, destaca-se a avaliação fluoroscópica tridimensional, a qual tem sido empregada para análise da movimentação acessória em atividades funcionais de pacientes que realizam diferentes tipos de cirurgias para a colocação de prótese total de joelho (FANTOZZI, BENEDETTI, LEARDINI, BANKS, CAPELLO, CAPELLO, ASSIRELLI \& CATANI, 2002; KANEKASU et al., 2004). Já POWERS et al. (2003) utilizaram a ressonância nuclear magnética dinâmica, a qual contribuiu para o entendimento da movimentação acessória fêmoro patelar durante exercícios realizados em cadeia cinética aberta e fechada em adultos com disfunção fêmoro-patelar. No entanto, tal método não foi encontrado na literatura para identificação dessas características em crianças com PTC. 


\subsubsection{A análise biomecânica da locomoção em crianças com pé torto congênito}

Apesar de estudos abordarem caracterizações subjetivas relacionadas à análise da locomoção em crianças com patologias nos membros inferiores (KAMEGAYA \& SHINOHARA, 2002), alguns artigos tratam de assuntos pertinentes às análises biomecânicas da marcha de crianças com tais disfunções.

KAROL, CONCHA e JOHNSTON (1997) avaliaram características biomecânicas em 23 crianças com história de PTC idiopática que realizaram tratamento cirúrgico unilateral. Para isso, realizaram análise cinemática tridimensional, análise cinética com plataforma de força e investigação eletromiográfica dos músculos tibial anterior, gastrocnêmio, além do fibular longo e curto, durante a marcha auto-selecionada. Adicionalmente, foi realizado teste isocinético de flexo-extensão do joelho $(60 \%)$ e flexão plantar/dorsiflexão do tornozelo $(30 \%)$ na posição sentada. Os dados referentes ao lado comprometido foram comparados com o lado contra lateral. Como resultados, não foram encontradas diferenças significativas em características de comprimento e tempo do passo, além do tempo de apoio simples e duplo. No entanto, dados de variação angular no plano sagital mostraram diferenças em 20 crianças avaliadas. Em algumas crianças, foi encontrado um aumento da flexão plantar no início do apoio e, em outras, uma diminuição da dorsiflexão no médio apoio. Existiu também limitação da flexão plantar na fase final do apoio e uma deficiência da dorsiflexão na fase de balanço. Para a articulação do joelho, houve a hiperextensão no médio apoio, além de uma diminuição da flexão do joelho no contato inicial com o solo do lado com PTC. No plano frontal, existiu uma tendência de valgismo do joelho, além de uma diminuição no movimento pélvico. No plano transversal, houve a progressão interna do pé, além de uma rotação tibial interna. Adicionalmente, foi encontrada uma diminuição da potência plantiflexora do lado acometido em cerca de $20 \%$. Com relação aos dados eletromiográficos, foram encontradas em 11 crianças uma anormal atividade do músculo tibial anterior na fase do médio apoio no lado acometido. Ressalta-se que os autores não apresentaram que tipo de anormalidade do sinal eletromiográfico foi encontrado nesse músculo. Na fase de 
balanço, foi encontrada uma diminuição da atividade do músculo tibial anterior em seis crianças. Vinte e uma crianças apresentaram alterações no tempo de ativação dos músculos fibular longo e curto também na fase de balanço. Foram também encontradas diminuições do torque isocinético para a flexão e extensão de joelho e flexão plantar do tornozelo.

OTIS e BOHNE (1986) avaliaram características eletromiográficas em

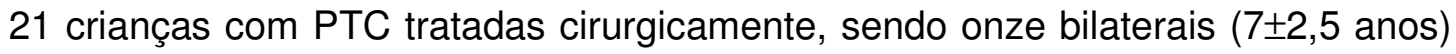

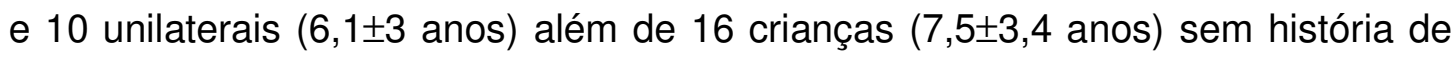
tal alteração. Para isso, realizaram a investigação na marcha auto-selecionada da atividade dos músculos gastrocnêmio medial (GM) e do tibial anterior (TA) por meio de eletrodos de superfície. Foi verificado que, quando comparado o tempo de duração da ativação muscular, o GM do grupo com PTC bilateral teve uma média de duração de ativação maior comparado com o controle, no qual o primeiro foi de $48 \%$ e o segundo $36 \%$ do ciclo da marcha (FIGURA 6 ).

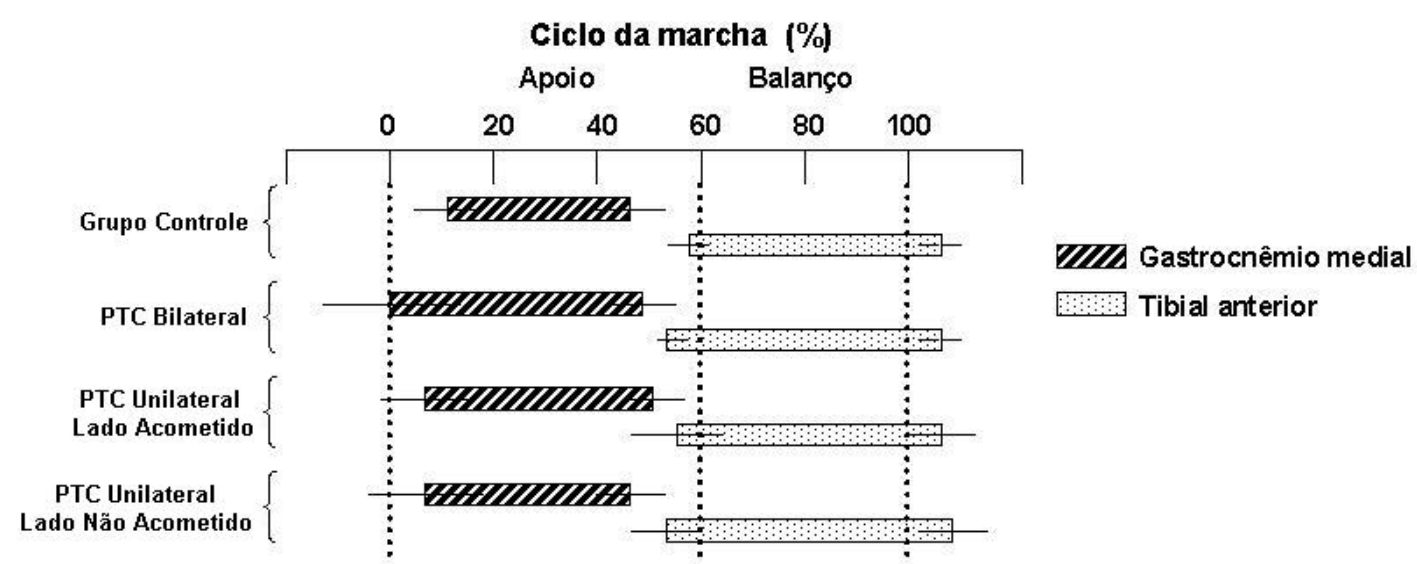

FIGURA 6 - Características do tempo e duração da ativação dos músculos gastrocnêmio medial e tibial anterior na marcha de crianças com pé torto congênito, comparado com um grupo controle (adaptado de OTIS \& BOHNE, 1986).

Entretanto, essas diferenças de duração da ativação dos gastrocnêmios não interferiram na variação angular avaliadas, pois tais parâmetros dos pacientes foram similares aos das crianças sem alterações (TABELA 7). 
TABELA 7 - Características de variação angular da marcha com pé torto congênito, com respectivas médias e desvios padrão (adaptado de OTIS \& BOHNE, 1986).

\begin{tabular}{cccc}
\hline & \multicolumn{2}{c}{ PTC } \\
\cline { 2 - 4 } & Grupo Controle & Bilateral & Unilateral \\
\hline Número de Sujeitos & 16 & 11 & 10 \\
\hline Idade (anos) & $7,5( \pm 3,4)$ & $7,0( \pm 2,5)$ & $6,1( \pm 3,0)$ \\
\hline Velocidade (m/min) & $58,6( \pm 13,7)$ & $53,0( \pm 11,1)$ & $59,5( \pm 9,0)$ \\
\hline Comprimento da passada $(\mathbf{m})$ & $0,96( \pm 0,26)$ & $0,85( \pm 0,13)$ & $0,88( \pm 0,70)$ \\
\hline Cadência (passos/min) & $123( \pm 15)$ & $126( \pm 24)$ & $137( \pm 23)$ \\
\hline
\end{tabular}

ARONSON e PULKARICH (1990), além de avaliarem características antropométricas, radiológicas e de torque isocinético em sujeitos com PTC, analisaram também a trajetória do centro de pressão durante a marcha e o padrão do centro de pressão durante o apoio unipodal antes e depois da fadiga induzida com caminhada em esteira. Para isso, selecionaram 29 voluntários com PTC unilateral do tipo idiopático que estavam no mínimo três anos de alta do tratamento reabilitacional, dividindo-os em grupos de acordo com a faixa etária e conforme o tipo de tratamento médico. Como resultado, no membro inferior acometido, foi encontrada lateralização da trajetória do centro de pressão em direção à região do mediopé, próximo à base do quinto metatarso, além de um maior tempo de contato nesta região durante a marcha. No teste de apoio unipodal, foi constatado um aumento da instabilidade quando os sujeitos realizavam o teste no membro acometido, com uma tendência de existir um melhor controle desse desequilíbrio nos voluntários mais velhos. A fadiga não influenciou nos resultados destes dados.

WIDHE e BERGGREN (1994) avaliaram características da marcha em 42 crianças com PTC, entre quatro e 15 anos; 22 tinham acometimento unilateral e 20, bilateral, com realização tanto de tratamento conservador quanto cirúrgico. Características da pressão, durante a marcha, foram registradas em uma freqüência de $25 \mathrm{~Hz}$ por meio de uma plataforma com 1300 sensores de pressão. Para essas análises, os pés foram divididos em três áreas: região dos dedos $(0 \%$ a $15 \%$ do comprimento do pé), ante-mediopé (15\% até $50 \%$ do comprimento do 
pé) e retropé ( $50 \%$ até $100 \%$ do comprimento do pé). Além disso, foram realizadas análises da marcha $(1,16 \pm 0,21 \mathrm{~m} / \mathrm{s})$ com duas câmeras de vídeo sincronizadas entre si e com uma plataforma de força. Adicionalmente, foram realizadas avaliações radiográficas e antropométricas. Em crianças com comprometimento unilateral, foi identificada, no lado comprometido, uma diminuição do comprimento da perna e do pé, além da existência de um diâmetro menor da panturrilha. Além disso, a amplitude de movimento no tornozelo foi diminuída, com diferença média entre o lado afetado e o contralateral de $24,7^{\circ} \pm 18,1^{\circ}$ no plano sagital. Foi encontrada diminuição da FRS máxima no membro comprometido, comparado com o lado íntegro $(112 \% \pm 14 \%$ e $124 \% \pm 11 \%$ do peso corporal, respectivamente). Foram encontradas menores pressões por $\mathrm{cm}^{2}$, e o COP foi mais lateralizado nas regiões do ante-mediopé e retropé no lado acometido. Para as crianças com comprometimento bilateral, os autores analisaram os dados com a realização da divisão dessas crianças em dois grupos de acordo com suas habilidades: um grupo sem queixas e outro com queixas de falta de habilidades em atividades funcionais. O grupo com queixas teve uma alteração do COP para lateral do pé comparado com o outro grupo. Nenhuma relação foi encontrada entre os parâmetros radiológicos analisados comparados com os demais dados coletados.

DAVIES, KIEFER e ZERNICKE (2001) investigaram características de variação angular e cinéticas das articulações do quadril, joelho e tornozelo na marcha em crianças com PTC, tratadas de forma cirúrgica com liberação pósteromedial. Em adição, foram avaliadas características do torque isocinético nas articulações do joelho (flexão e extensão) e do tornozelo (dorsiflexão e flexão plantar), nas velocidades de $60 \%$ e $30 \%$, respectivamente para cada articulação. Para isso, avaliaram 10 crianças com acometimento bilateral e 15 com acometimento unilateral (12,1 \pm 3 anos), além do grupo controle de 16 crianças da mesma faixa etária dos grupos anteriores. Não existiram diferenças entre os lados direito e esquerdo dos grupos controle e de PTC bilateral. Diante disso, os dados foram divididos em quatro grupos: PTC unilateral lado acometido, PTC unilateral lado não acometido, PTC bilateral e Controle. 
$\mathrm{Na}$ avaliação dinamométrica, os autores encontraram a diminuição do torque isocinético na flexão plantar, para o lado acometido do grupo com PTC unilateral e para o grupo com PTC bilateral. Para a variação angular do joelho, foi encontrado um aumento do varo para os grupos PTC unilateral acometido e bilateral. Adicionalmente, para os lados das crianças com PTC unilateral, a rotação interna dessa articulação foi maior, comparada com os outros. Foi encontrada menor flexão plantar nos grupos com acometimento do PTC, sendo $9,3 \pm 1,2^{\circ}$ e $7,8 \pm 1,4^{\circ}$ respectivamente para os grupos PTC unilateral acometido e bilateral, comparados com os grupos PTC unilateral lado não acometido e controle $\left(10,2 \pm 2^{\circ}\right.$ e $15,1 \pm 1,4^{\circ}$, respectivamente). Para a articulação do quadril, nenhuma diferença foi encontrada na variação angular entre os grupos. Com relação à FRS, a componente vertical foi maior no grupo com PTC bilateral, quando comparado com os demais grupos. Com relação à FRS ântero-posterior, foram menores para o lado acometido do grupo PTC unilateral. Na FRS médio-lateral, foram encontrados maiores valores para os membros acometidos do grupo com acometimento bilateral e para o lado acometido do unilateral (TABELA 8). Ressalta-se que tanto a variação angular quanto a cinética foram representadas pela média ao longo de todo ciclo da marcha, não sendo, portanto, identificadas fases específicas.

TABELA 8 - Dados referentes à média e desvio padrão da força de reação do solo (FRS), normalizados pelo peso corporal, encontrados na marcha de diferentes grupos avaliados no trabalho de DAVIES et al. (2001).

\begin{tabular}{ccccc}
\hline & $\begin{array}{c}\text { PTC unilateral } \\
\text { lado não } \\
\text { acometido }\end{array}$ & $\begin{array}{c}\text { PTC unilateral } \\
\text { lado } \\
\text { acometido }\end{array}$ & PTC bilateral & Controle \\
\hline FRS vertical & $1,36 \pm 0,04^{* \star *}$ & $1,3 \pm 0,04^{* \star \star}$ & $1,44 \pm 0,03^{* \star *}$ & $1,59 \pm 0,07$ \\
FRS ântero-posterior & $0,263 \pm 0,011$ & $0,239 \pm 0,011^{*}$ & $0,282 \pm 0,008$ & $0,248 \pm 0,016$ \\
FRS médio-lateral & $0,067 \pm 0,005^{* * ; * * *}$ & $0,091 \pm 0,008$ & $0,076 \pm 0,004$ & $0,096 \pm 0,004$ \\
\hline
\end{tabular}

${ }^{*}$ diferença significativa comparada com o Controle; ${ }^{* *}$ diferença significativa comparada com PTC unilateral lado acometido; ${ }^{* *}$ diferença significativa comparada com PTC bilateral. 
HEE, LEE e LEE (2001) avaliaram características biomecânicas durante a locomoção em 58 crianças após correção cirúrgica de PTC. Foram divididos em dois grandes grupos: um com crianças de cinco anos ou menos (total de 32 sujeitos) e outro com mais de cinco anos (total de 26 sujeitos). Para comparação, dados de normalidade foram retirados da literatura, divididos em dois grupos com a mesma faixa etária anterior (22 e 18 sujeitos respectivamente). Foi realizada análise cinética (componentes vertical, médio-lateral e ântero-posterior da FRS) e de variação angular (planos frontal e sagital) de forma sincronizada durante a marcha auto-selecionada. Além disso, foram avaliadas características da pressão plantar nas regiões do antepé, mediopé e retropé. De modo geral, características relacionadas com a cadência, velocidade de marcha, tempo de apoio, comprimento do passo e dados da FRS não tiveram diferenças significativas comparadas com dados de normalidade encontrados na literatura em suas específicas faixas etárias. No entanto, alguns dados foram destacados, dentre eles: a inexistência de um aumento do tempo de apoio nas crianças com PTC bilateral com o aumento da idade; uma rotação da perna exagerada durante a marcha no lado acometido das crianças com PTC; redução da flexão plantar durante o ciclo da marcha do tornozelo em $60 \%$ das crianças com PTC; aumento da pressão plantar nas regiões do mediopé e antepé nas crianças com PTC.

THEOLOGIS et al. (2002) analisaram as características dinâmicas do movimento dos pés durante a marcha em crianças com PTC tratadas cirurgicamente. Para isso, foram selecionadas 20 crianças entre seis e 16 anos que realizaram tal cirurgia corretiva com o mesmo protocolo de tratamento e que não tinham perspectivas de novas intervenções devido à estabilização do quadro clínico. A marcha foi avaliada por meio da velocidade auto-selecionada ao longo de uma pista de 10 metros, sendo adquiridos dados de variação angular e cinéticos. Para isso, foram utilizados um sistema de captura de imagens e duas plataformas de força. Foram verificadas, no membro acometido, uma diminuição da potência durante a flexão plantar, uma redução da mobilidade do retropé e uma alteração no modo de colocação do pé, no início do contato inicial com o solo com um excesso de rotação interna do pé. Os pesquisadores relacionaram esse último aspecto com um aumento da rotação tibial associada a uma rotação externa 
exacerbada femoral durante a marcha das crianças com PTC. Verificaram que pacientes com boas evoluções clínicas, avaliadas por questionários funcionais, mostraram características de normalidade de marcha com apenas algumas alterações residuais.

BEYAERT et al. (2003) relataram a existência de compensações em outros segmentos dos membros inferiores pós-tratamento do PTC. Tal afirmação foi realizada após a avaliação da marcha em 20 crianças com história de PTC tratadas cirurgicamente, comparada com um grupo controle formado por 13 crianças. Para isso, utilizaram um sistema de captação de imagens composto por sete câmeras de vídeo e freqüência de amostragem de $50 \mathrm{~Hz}$, além de três plataformas de forças, com freqüência de amostragem de $200 \mathrm{~Hz}$. Foi analisado o ângulo de progressão do pé, definido como ângulo entre a linha de progressão e o eixo longitudinal do pé em cada instante da fase de apoio (FIGURA 7).

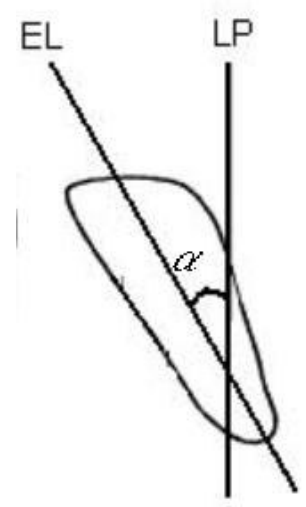

FIGURA 7 - Ângulo de progressão do pé em um instante da fase de apoio na marcha: ângulo $(\alpha)$ entre a linha de progressão (LP) e o eixo longitudinal do pé (EL) (Adaptado de BEYAERT et al., 2003).

Para entender as possíveis alterações decorrentes dos diferentes ângulos de progressão do pé nos momentos articulares, foi analisada a distância do vetor resultante da FRS até o centro articular do joelho durante a fase de apoio da marcha. Segundo os pesquisadores, essa análise é importante, pois o aumento ou diminuição da distância do vetor resultante pode alterar os momentos da articulação do joelho (FIGURA 8). 
Baseados nos resultados das análises do ângulo de progressão, as crianças com PTC foram subdivididas em dois grupos: 13 com o ângulo de progressão do pé maior do que $7^{\circ}$ e 15 com ângulo menor do que $7^{\circ}$.

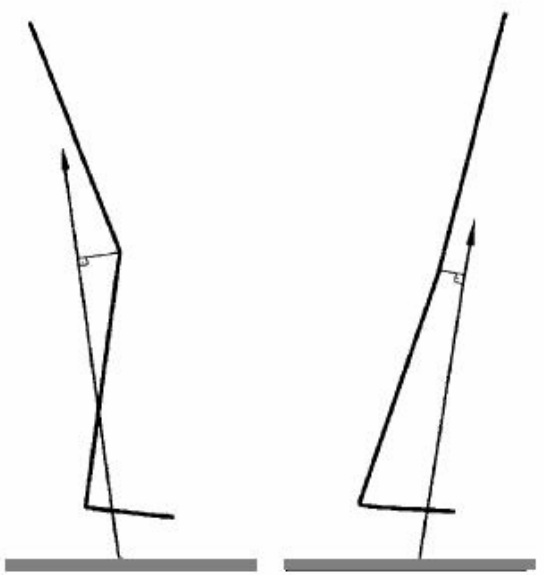

FIGURA 8 - Relação do ângulo do joelho com o vetor resultante da força de reação ao solo (Adaptado de BEYAERT et al., 2003).

Os autores encontraram que, na fase de apoio, o grupo com aumento do ângulo de progressão do pé teve um aumento do momento interno extensor do joelho. Segundo os autores, tais resultados contribuem para o aumento do momento interno extensor durante o médio apoio. Conseqüentemente, podem ocorrer alterações patológicas nas articulações do joelho, como, a predisposição do desenvolvimento de osteoartrose na região.

KAROL, O'BRIEN, WILSON, JOHNSTON e RICHARDS (2005), investigaram 90 crianças com história de PTC, entre dois e três anos de idade. Essas crianças foram divididas em quatro grupos: grupo 1 - composta por 36 crianças que tiveram sucesso no tratamento conservador e que realizaram fisioterapia com exercícios de alongamento e manipulação cinco vezes por semana, com aplicação de uma bandagem corretiva em todo o término de terapia; grupo 2 - cinco crianças que realizaram programa de fisioterapia associado com a tenotomia do tendão do calcâneo devido a persistência da deformidade em eqüino do tornozelo; grupo 3 - 14 crianças que realizaram a liberação cirúrgica posterior associada com tenotomia do tendão do calcâneo, seguido de fisioterapia; grupo 4 - nove crianças que realizaram tratamento cirúrgico com liberação póstero-medial 
ampla após tentativa sem bons sucessos do tratamento conservador. Para isso, foram realizadas análises de variação angular da marcha auto-selecionada com a utilização de um sistema de captação de imagens com oito câmeras de vídeo. Os dados encontrados nessa população foram comparados com os de 15 crianças da mesma faixa etária (grupo 5).

Como resultados desse trabalho, não foram encontradas diferenças nas características de cadência, velocidade de marcha e no comprimento do passo entre os grupos avaliados.

No entanto, dentre vários resultados apresentados, os autores verificaram que $30,8 \%$ das crianças do grupo 1 tiveram limitação de dorsiflexão na fase de apoio e 9,6\% limitações da flexão plantar na retirada do pé do solo. Nenhuma das crianças que realizou a tenotomia do calcâneo teve limitação na dorsiflexão e flexão plantar. Cerca de $20 \%$ das crianças do grupo 3 tiveram diminuição da dorsiflexão, sem limitação, no entanto, na flexão plantar. No grupo que realizou liberação póstero-medial ampla, 17,6\% obteve diminuição da dorsiflexão e 7,8\% obteve características de limitação da flexão plantar.

Algumas crianças apresentaram uma excessiva dorsiflexão na segunda fase do apoio e uma diminuição da flexão plantar na retirada do pé do solo. Essa característica foi considerada pelos autores como "marcha de calcâneo" e foi encontrada em apenas $7,7 \%$ no grupo 1 e $10,5 \%$ no grupo 3 . No entanto, no grupo 4, 29,4\% das crianças apresentaram esse tipo de marcha. Segundo os autores, essa característica pode estar vinculada com o excesso de alongamento do tendão do calcâneo, além de uma liberação cirúrgica exagerada de tecidos moles da região. Em adição, todos os grupos possuíram crianças que apresentaram dificuldades em manter a posição neutra da articulação do tornozelo na fase de balanço (34,6\% para o grupo $1 ; 20 \%$ para o grupo $2 ; 21,1$ para o grupo $3 ; 25,5$ para o grupo 4). A característica de rotação interna da perna na fase de apoio foi encontrada com maior incidência nos grupo $4(45,1 \%)$ e $3(42,2 \%)$, tendo $30,8 \%$ nas crianças do grupo 1. Ao realizar a comparação de vários parâmetros analisados, os melhores índices de normalidade da marcha foram vistos para o grupo $1(32,7 \%)$, comparado com as demais crianças (grupo 2 - 20\%; grupo 3 10,5\%; grupo 4 - 13,7\%). 
MURATLI, DAGLI, YAVUZER, ÇELEBI e BIÇIMOGLU (2005)

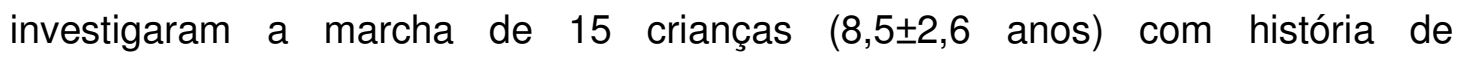
acometimento bilateral de PTC tratadas de forma cirúrgica com liberação pósteromedial. Para comparação dos dados, foram selecionadas 24 crianças sem história de PTC e com características etárias semelhantes ao grupo anterior. Para essa investigação, foram sincronizados dados oriundos de cinco câmeras de vídeo com duas plataformas de força inseridas no solo. Características de velocidade da marcha, cadência, tempo de passada e comprimento de passada não tiveram diferenças entre os grupos avaliados. No entanto, foi encontrada em $57 \%$ das crianças com história de PTC, uma característica de hiperextensão do joelho na fase de apoio da marcha. Para a articulação do tornozelo, verificou-se uma excessiva dorsiflexão em toda fase da marcha e uma diminuição da flexão plantar na retirada do pé do solo. Com relação às características cinéticas, observou-se que o momento e potência na flexão plantar foram menores para o grupo com PTC, além da existência de uma FRS vertical também diminuida para esse grupo no momento da retirada do pé do solo.

WIRCART, RICHARDSON e MATON (2006) realizaram um estudo com a investigação biomecânica na locomoção de crianças com PTC tratadas de forma conservadora. Para isso, investigaram as características do início da marcha em 10 crianças com história de acometimento idiopático de PTC (10 $\pm 8,3$ anos), comparando os dados com um grupo controle da mesma faixa etária. As crianças foram orientadas a se posicionarem em cima de uma plataforma de força e, após um comando verbal, iniciavam a marcha. Os autores avaliaram a fase antecipatória e a fase de execução do movimento em três velocidades: autoselecionada, lenta e rápida. Foram calculados, a partir dos dados da FRS, o posicionamento do centro de pressão, a velocidade do centro de gravidade corporal e a aceleração. Nas crianças com PTC, a velocidade do centro de gravidade, no final da fase de iniciação da marcha, não foi diferente da encontrada no grupo controle. A velocidade do centro de gravidade, no final da fase antecipatória, foi menor nas crianças com PTC quando o pé do balanço era o afetado, o que indicou que a propulsão foi menos eficiente nessa condição. 
FAVRE et al. (2007) investigaram características biomecânicas da marcha, durante velocidade auto-selecionada, em 16 crianças, com idade entre quatro e oito anos, com história de PTC unilateral e tratadas cirurgicamente. Para comparação dos dados, foram selecionadas 68 crianças, sem história de tal acometimento e com idades semelhantes ao grupo anterior. O objetivo dos autores foi investigar as características do membro inferior contra-lateral do PTC, com intuito de analisar se os dados encontrados nesse segmento podem ser considerados como controle. Portanto, compararam o lado contralateral do PTC com o grupo controle. Para isso, utilizaram uma plataforma de pressão com quatro sensores por centímetro quadrado e com freqüência de aquisição de $50 \mathrm{~Hz}$. Foram analisadas características da FRS vertical e da pressão em dez regiões predeterminadas do pé das crianças.

Para ambos grupos, verificou-se um maior pico de pressão na região do calcanhar, seguido do hálux. Na comparação entre os grupos, foram encontradas diferenças significaticas para o pico de pressão entre o grupo controle e o lado contralateral ao acometido nas regiões do calcanhar e regiões do primeiro ao quarto metatarsos. O pico de pressão demonstrou mais homogêneo na região dos metatarsos para o grupo controle; para o lado contralateral do PTC, essa magnitude foi maior na fase lateral plantar. Em todas as áreas avaliadas, com excessão das regiões do terceiro ao quinto dedos, os picos de pressões foram maiores no grupo controle. Em adição, encontrou-se, na fase final do apoio, um aumento da magnitude da FRS vertical no grupo controle.

Portanto, as diferenças encontradas na pressão plantar e na FRS vertical, durante a marcha, no lado contralateral ao PTC, mostraram que esse segmento não pode servir de controle para as análises comparativas do lado acometido e, portanto, há necessidade de um grupo controle com crianças sem história de tal acometimento. 


\section{METODOLOGIA}

\subsection{Amostra}

Inicialmente, foi realizada uma busca nos prontuários médicos do setor de Ortopedia e Traumatologia do Hospital Pediátrico Casas Maria Pia da cidade do Porto em Portugal. Tal investigação teve como objetivo localizar crianças nascidas entre os anos de 1996 e 1998, com histórico de PTC com acometimento tanto bilateral quanto unilateral, sem nenhuma patologia associada e com realização de tratamento cirúrgico corretivo das deformidades por meio de liberação póstero-medial ampla até o primeiro ano de vida.

Após isso, foi agendada uma prévia avaliação no Hospital para seleção da amostra experimental, com participação do médico responsável pelas crianças, do pesquisador e das crianças acompanhadas pelos pais ou responsáveis. Foram convidadas a participar da pesquisa crianças sem lesões músculo-esqueléticas nos últimos seis meses, que não apresentavam relato de dor no pé, nem dificuldades funcionais nas atividades de vida diária, o que totalizou 14 crianças: sete com acometimento unilateral (6,8 $\pm 0,9$ anos, $30 \pm 5,1 \mathrm{~kg}, 1,30 \pm 0,05 \mathrm{~m})$ e sete

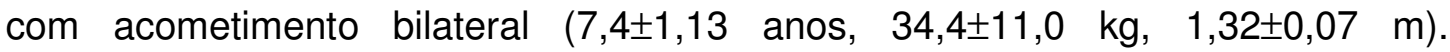
Seqüencialmente, para compor o grupo controle, foram selecionadas 11 crianças (7,6 $\pm 0,6$ anos, $26,3 \pm 4,3 \mathrm{~kg}, 1,30 \pm 0,06 \mathrm{~m})$ sem história de acometimento do PTC e sem lesões músculo-esqueléticas nos últimos seis meses que participavam de atividades recreacionais desenvolvidas na FADE-UP.

\subsection{Instrumentos de medição}

Foi utilizada uma plataforma de força de reação do solo (Bertec \#k80204, tipo 4060-15), com transdutores de força do tipo strain gauge (sensores de deformação). Portanto, uma unidade elétrica foi usada para captação, registro e amplificação dos dados, que, ligada aos transdutores de força, permitem obter as tensões proporcionais às cargas em cada transdutor. Essas tensões foram digitalizadas numa placa de conversão analógico/digital de 16 bits (Biopac) e 
convertidas, por meio da matriz de calibração, nos registros das três componentes da FRS adquiridas (vertical - FZ, médio-lateral - FX e ântero-posterior - FY). Para o registro dos dados, utilizou-se $1000 \mathrm{~Hz}$ como freqüência de amostragem. Esses dados foram adquiridos no programa Aknowledge III.

Com um software específico para captura das imagens (APAS Ariel Dynamics - Módulo Capture), foram sincronizados dados de variação angular provenientes de uma câmera de vídeo digital (Readlake Motion Scope PCI 8000), demonstrada na FIGURA 9A, além de serem utilizadas adicionalmente duas câmeras de vídeo JVC, modelo SVHS (FIGURA 9B). Todos os equipamentos cinemáticos tiveram como freqüência de amostragem de $50 \mathrm{~Hz}$ e foram reguladas para uma velocidade do obturador de 1:100.

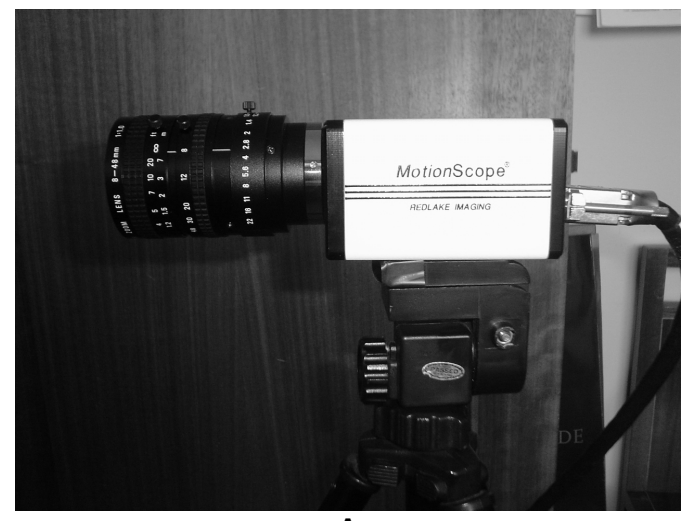

A

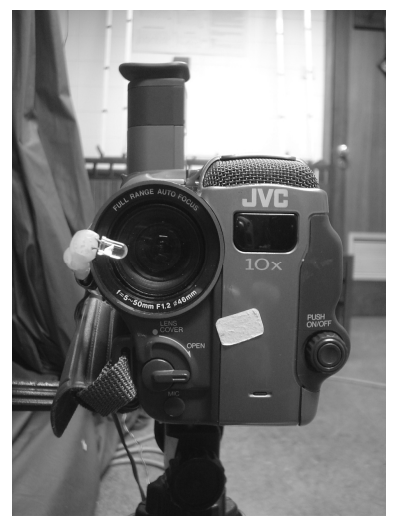

$\mathrm{B}$

FIGURA 9 - Ilustração das câmeras de vídeo utilizadas para o experimento. A) câmera digital; B) câmera analógica com o posicionamento do diodo emissor de luz.

Foi também utilizado um eletromiógrafo, construído pelo Laboratório de Biomecânica da FADE-UP, que possui como características uma unidade de amplificação principal com ganho de 100 vezes e eletrodos de superfície, bipolares e ativos, pré-amplificados em 11 vezes e com a presença de um eletrodo de referência (FIGURA 10). Com isso, a pré-amplificação dos eletrodos foi somada ao ganho do amplificador de sinais e resultou em um ganho total de 1100 vezes. $A$ freqüência de amostragem foi de $1000 \mathrm{~Hz}$. Os dados eletromiográficos também foram digitalizados numa placa de conversão analógico/digital de 16 bits (Biopac). Para a fixação da área de captação do sinal elétrico no músculo, foram utilizados eletrodos descartáveis autocolantes e que contém gel condutor. 


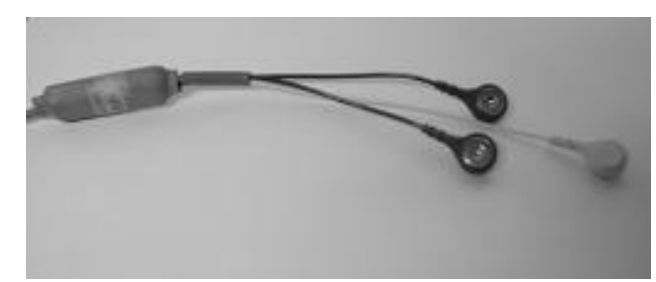

FIGURA 10 - Eletrodos utilizados no experimento. Nota-se a existência do préamplificador, dos dois eletrodos de captação do sinal elétrico muscular e do eletrodo de referência (Laboratório de Biomecânica da FADE-UP, Porto).

Para a sincronização dos dados da variação angular, dinamométricos e eletromiográficos, foi utilizado um software da BIOPAC. Esse sistema foi conectado a um hardware de interface de sincronização, desenvolvido no Laboratório de Biomecânica da FADE-UP. Os dados adquiridos das duas câmeras analógicas foram sincronizados por meio dessa placa eletrônica, a qual foi ativada por um trigger manual, que iniciava os registros dos outros equipamentos utilizados e enviava um sinal para dois diodos emissores de luz (leds) posicionados no campo visual de cada câmera de vídeo (FIGURA 9B). Para calibração dos dados cinemáticos, foi utilizado um quadrilátero com medidas conhecidas na área da coleta de dados, previamente ao início dos testes.

Adicionalmente, foi utilizado um método clássico de avaliação da sensibilidade cutânea para investigação do limiar tátil e de pressão plantar, por meio de estesiômetros (FIGURA 11), conhecidos também por monofilamento de Semmes-Weistein (SORRI, Inc.). Esse instrumento consiste em um kit de seis monofilamentos, representados por cores diferentes, confeccionados em náilon com $38 \mathrm{~mm}$ de comprimento e com diâmetros diferentes. Tais alterações do diâmetro fazem com que cada monofilamento, quando aplicado na superfície da pele de acordo com método padrão, exerça uma pressão equivalente a um peso $(0,05 \mathrm{~g}, 0,2 \mathrm{~g}, 2,0 \mathrm{~g}, 4,0 \mathrm{~g}, 10,0 \mathrm{~g}$ e $300 \mathrm{~g})$, conforme o diâmetro do náilon (CLIFFORD, JAMES \& MARK, 2000). 


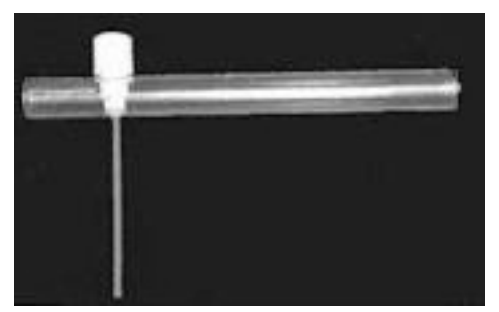

FIGURA 11 - Demonstração de um monofilamento de Semmes-Weistein (SORRI, Inc.).

A percepção de cada monofilamento está associada a um nível específico de sensibilidade, representado abaixo, de acordo com VON PRINCE e BUTLER (1967) ${ }^{1}$ apud SOUZA, NERY, MARCIANO e GARBINO (2005) (TABELA 9).

TABELA 9 - Representação da interpretação da sensibilidade cutânea plantar por meio do uso dos monofilamentos de Semmes-Weistein (VON PRINCE \& BUTLER, 1967, apud SOUZA et al., 2005).

\begin{tabular}{cc}
\hline Monofilamentos & Interpretação \\
\hline $\begin{array}{c}\text { Verde } \\
\text { (nominal: } 0,05 \mathrm{~g}) \\
\text { Azul } \\
(\text { nominal: } 0,2 \mathrm{~g}) \\
\text { Violeta } \\
\text { (nominal: } 2,0 \mathrm{~g})\end{array}$ & Sensibilidade normal no pé \\
$\begin{array}{c}\text { Vermelho escuro } \\
\text { (nominal } 4,0 \mathrm{~g}) \\
\text { Laranja } \\
\text { (nominal: } 10,0 \mathrm{~g})\end{array}$ & Sensibilidade normal no pé \\
$\begin{array}{c}\text { Vermelho magenta } \\
\text { (nominal: } 300,0 \mathrm{~g})\end{array}$ & Sensibilidade protetora diminuída \\
\hline
\end{tabular}

Segundo esses autores, caso não relate nenhuma sensação tátil e de pressão com o monofilamento com maior diâmetro (vermelho magenta, 300,0g), a interpretação será como perda total da sensação de pressão profunda.

${ }^{1}$ K., VON PRINCE; B.J.R., BUTLER, Measuring sensory function of the hand in peripheral nerve injuries. American Journal of Occupational Therapy, Bethesda, v.21, n.6, p.385-95, 1967. 


\subsection{Protocolo experimental}

Para definição do protocolo de investigação final, resumido no fluxograma final da FIGURA 12, foram realizados cinco pré-experimentos (ANEXO I): os três primeiros foram realizados no Laboratório de Biomecânica da Escola da Educação Física e Esporte da Universidade de São Paulo (EEFE-USP), e os dois últimos, no Laboratório de Biomecânica da Faculdade de Desporto da Universidade do Porto (FADE-UP).

Tais pré-experimentos auxiliaram para o delineamento do método baseado neste estudo, baseado na identificação das tarefas e nas características de adaptações do grupo populacional com os instrumentais biomecânicos disponíveis.

Portanto, diante das experiências adquiridas nesses estudos preliminares, foram concebidos os protocolos de avaliação, realizados neste estudo.

As implicações éticas que envolveram os procedimentos destes estudos foram analisadas e aprovadas pela Comissão de Ética em Pesquisa (CEP) da Escola de Educação Física e Esporte da USP, Brasil (Parecer CEP - Projeto ${ }^{\circ}$ 054). As descrições do Termo de Consentimento Livre e Esclarecido utilizado para os experimentos encontram-se no ANEXO II. 


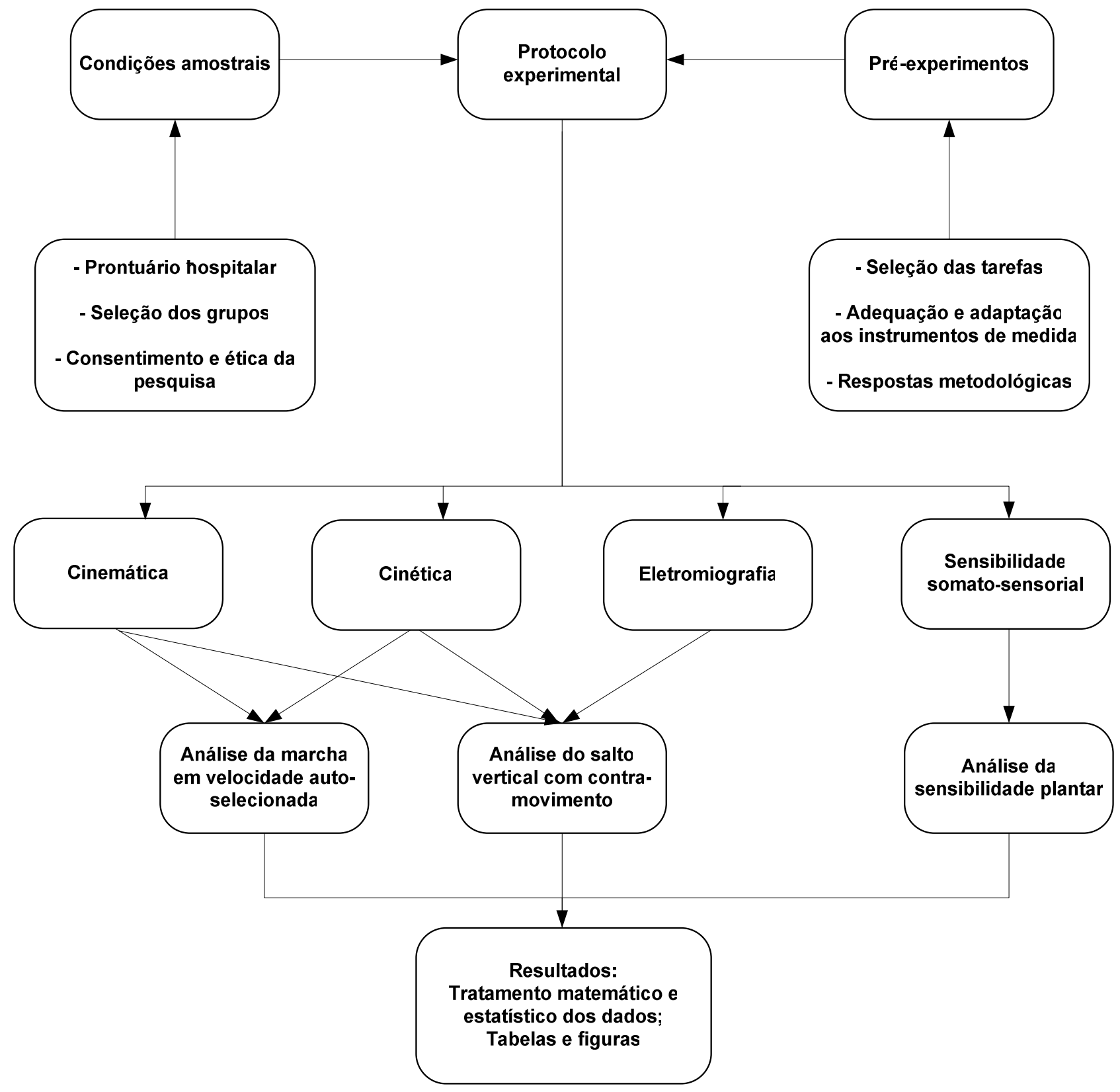

FIGURA 12 - Diagrama de blocos representando o fluxograma das etapas metodológicas seguindo protocolo experimental. 


\subsubsection{Análise da marcha auto-selecionada}

\subsubsection{Procedimento experimental}

Após a leitura do Termo de Consentimento Livre e Esclarecido pelos responsáveis e de todo o processo ter sido explicado às crianças, foram iniciados os procedimentos de coletas dos dados.

Para melhor visualização, foram fixados marcadores brancos com fundo preto no membro inferior com fita auto-adesiva no pé e tornozelo (tubérculo do quinto metatarso, calcâneo e maléolo lateral), joelho (cabeça da fíbula e côndilo lateral femoral) e quadril (trocânter maior do fêmur) (FIGURA 13).

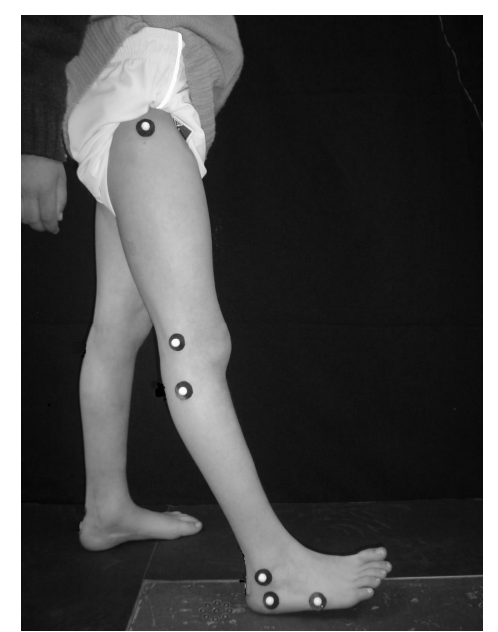

FIGURA 13 - Posicionamento dos marcadores brancos nas regiões predeterminadas do segmento inferior dos voluntários.

As crianças passaram por um tempo de adaptação no ambiente do laboratório e, em seguida, foram instruídas a caminharem em velocidade autoselecionada sobre uma passarela de cinco metros de comprimento, na qual, na porção média, encontrava-se instalada a plataforma de força. A câmera de vídeo digital foi posicionada com o feixe ótico perpendicular à passarela em uma altura de aproximadamente um metro do solo, de tal forma a captar imagens no plano sagital de cada membro inferior das crianças. Foram realizadas cinco coletas registrando-se a FRS e dados cinemáticos da câmera digital apenas para o apoio direito e foi repetido o procedimento com registros para o apoio esquerdo. 
Seqüencialmente, nesta fase, as crianças foram posicionadas em decúbito dorsal, com os olhos fechados. O avaliador aplicou o teste com o monofilamento perpendicular em regiões pré-determinadas da superfície plantar, com força necessária para envergar o fio de náilon (FIGURA 14A). As áreas avaliadas foram baseadas no trabalho de PRÄTORIUS, KIMMESKAMP e MILANI (2003), as quais foram a região central do hálux, bases do primeiro e quinto metatarsos, além da região plantar do tubérculo do quinto metatarso, referente à região do arco plantar, e da área central plantar do calcanhar, definidas como áreas 1, 2, 3, 4 e 5 respectivamente (FIGURA 14B).

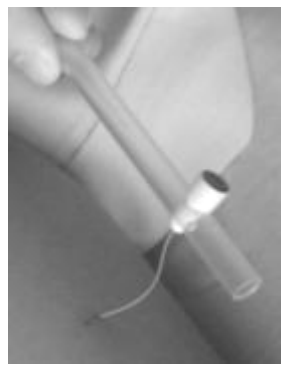

A

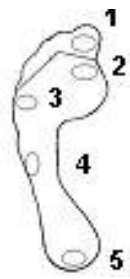

$B$

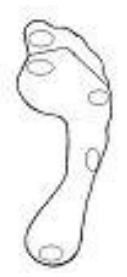

FIGURA 14 - Ilustrações das características da avaliação da sensibilidade plantar: A) Aplicacãa do teste na superfície plantar, com força necessária para envergar o monofilamento; B) Áreas pré-determinadas para avaliação sensitiva: região central do hálux (1), bases do primeiro (2) e quinto metatarsos (3), além das regiões plantar do tubérculo do quinto metatarso, no arco plantar (4) e central plantar do calcanhar (5), tanto do pé esquerdo quanto do direito (PRÄTORIUS, KIMMESKAMP \& MILANI, 2003).

Foi iniciada a avaliação com o filamento de menor diâmetro e, em seguida, com os de maiores diâmetros até a obtenção de resposta positiva. A criança foi orientada a relatar, de forma verbal, ao sentir qualquer sensibilidade no contato do filamento na região avaliada. Caso a criança não se referisse a nenhuma sensibilidade após três tentativas realizadas pelo investigador, imediatamente era utilizado o próximo monofilamento, este com maior diâmetro. $\mathrm{Na}$ existência de resposta positiva, a criança era questionada sobre o local exato do contato e, caso correta, o avaliador avaliava outra região pré-determinada; esta feita de forma aleatória e novamente com o monofilamento de menor diâmetro. 
Previamente ao início do teste, o avaliador explicou todos os procedimentos, com a realização de avaliação demonstrativa na palma da mão das crianças. Para facilitar a interpretação dos dados da análise do limiar de percepção tátil, os estesiômetros foram classificados de 1 a 6 em ordem crescente de acordo com o aumento do diâmetro do filamento.

\subsubsection{Variáveis analisadas}

Foram calculadas variáveis da FRS vertical, ântero-posterior e médiolateral, descritas na TABELA 10.

TABELA 10 - Variáveis calculadas a partir das componentes vertical (Fz), ânteroposterior (Fy) e médio-lateral (Fx) da FRS selecionadas na marcha.

\begin{tabular}{cc}
\hline Variáveis & $\begin{array}{c}\text { Definição das variáveis analisadas } \\
\text { Fz 1 }\end{array}$ \\
TC 1 & $\begin{array}{r}\text { Primeiro valor máximo da FRS vertical } \\
\text { Fz } 2\end{array}$ \\
Fz min & $\begin{array}{r}\text { Taxa de crescimento 1: Razão entre Fz1 e o tempo decorrido do } \\
\text { início do apoio até esta magnitude } \\
\text { Segundo valor máximo da FRS vertical }\end{array}$ \\
TC 2 & Taxa de crescimento 2: Razão entre Fz2 e o tempo decorrido de Fz \\
min até Fz2
\end{tabular}


Seguem os gráficos ilustrativos das variáveis da FRS descritas anteriormente, calculadas a partir dos dados da marcha em velocidade autoselecionada das crianças (FIGURA 15).
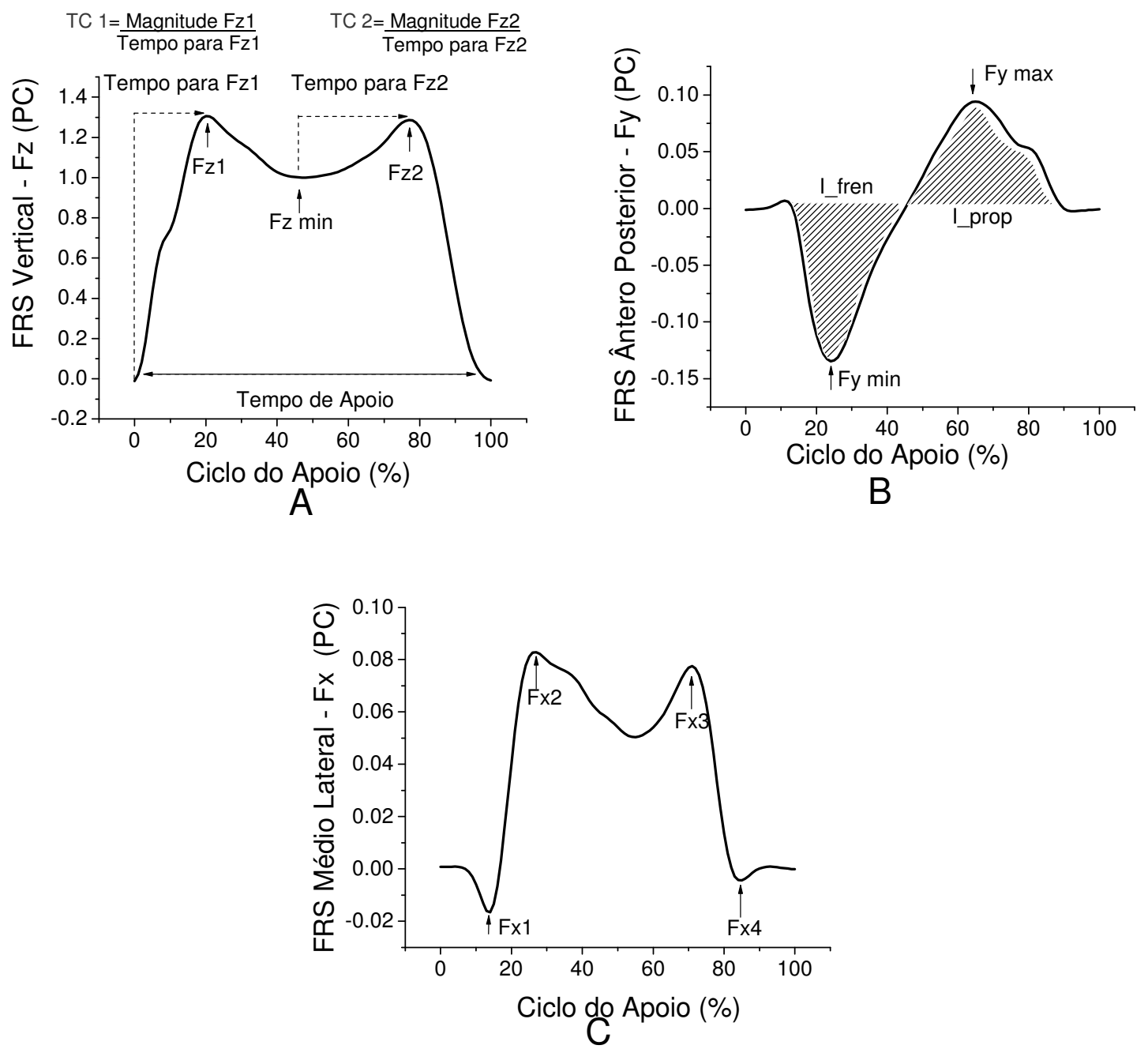

FIGURA 15 - Variáveis calculadas a partir das componentes da FRS adquiridas na marcha das crianças. A) FRS vertical; B) FRS ântero-posterior; C) FRS médio-lateral. 
Adicionalmente, foram analisadas, a partir dos dados recolhidos da câmera digital, a variação angular no plano sagital das articulações do tornozelo e do joelho em cinco momentos, conforme descrito na tabela a seguir (TABELA 11).

TABELA 11 - Variáveis angulares calculadas a partir da componentes vertical, selecionadas dos dados da marcha.

\begin{tabular}{cc}
\hline Variáveis & Definição das variáveis \\
\hline cine_joelho1 & Ângulo do joelho no momento do início da fase de apoio na marcha. \\
cine_joelho2 & Ângulo do joelho no momento de Fz1. \\
cine_joelho3 & Ângulo do joelho no momento de Fz min. \\
cine_joelho4 & Ângulo do joelho no momento de Fz2. \\
cine_joelho5 & Ângulo do joelho no momento final da fase de apoio na marcha. \\
cine_tornozelo1 & Ângulo do tornozelo no momento do início da fase de apoio na marcha. \\
cine_tornozelo2 & Ângulo do tornozelo no momento de Fz1. \\
cine_tornozelo3 & Ângulo do tornozelo no momento de Fz min. \\
cine_tornozelo4 & Ângulo do tornozelo no momento de Fz2. \\
cine_tornozelo5 & Ângulo do tornozelo no momento final da fase de apoio na marcha. \\
\hline
\end{tabular}

Segue gráfico ilustrativo dos parâmetros de variação angular das articulações do joelho e tornozelo descritas anteriormente, baseadas nos dados da FRS vertical adquiridas durante a marcha em velocidade auto-selecionada das crianças.

Nota-se que, para a articulação do tornozelo, o instante de dorsiflexão ocorre quando os valores angulares são acima de $90^{\circ}$. Quando os valores são menores do que $90^{\circ}$, o movimento é caracterizado pela flexão plantar do tornozelo (FIGURA 16). 


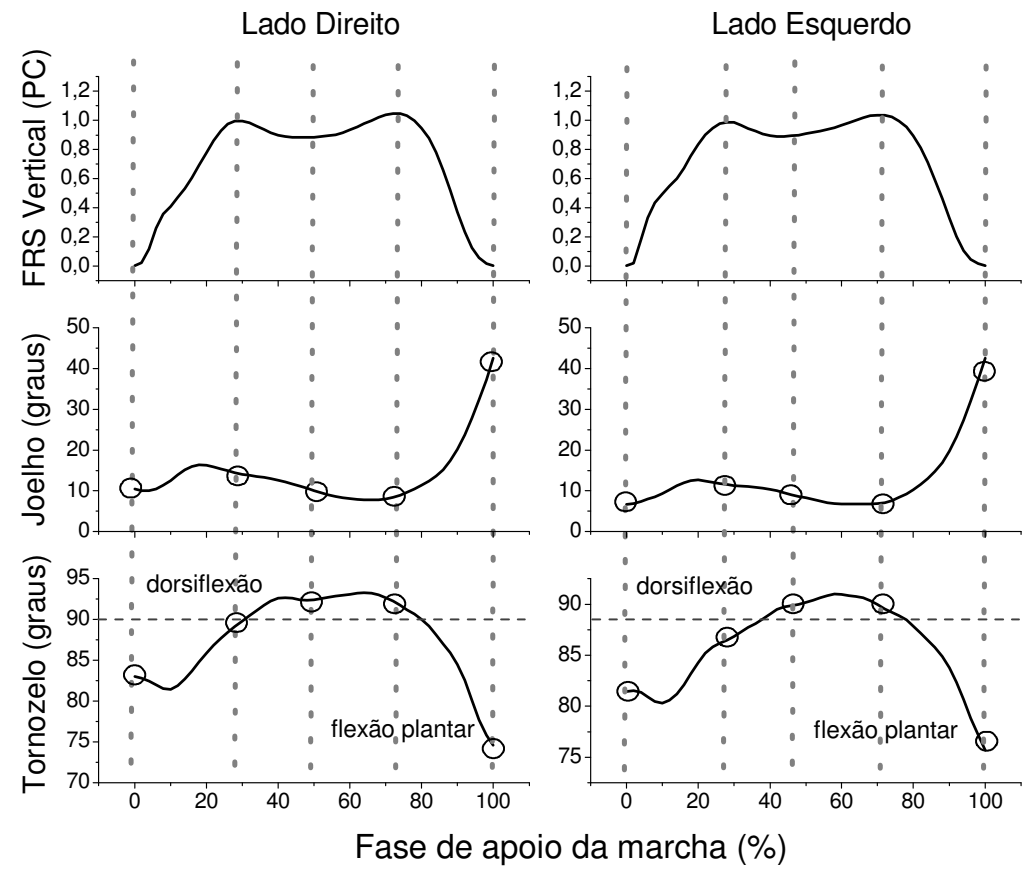

FIGURA 16 - Variáveis angulares, identificadas com um círculo, das articulações do joelho e tornozelo calculadas a partir da componente vertical da FRS adquiridas na marcha de uma criança com acometimento de PTC bilateral.

Para os dados da sensibilidade plantar, foi analisado para cada região pré-determinada da planta do pé, o monofilamento em que a criança primeiro sentiu o estímulo. Os dados adquiridos foram classificados em três diferentes situações: grau 1; grau 2; grau 3 (TABELA 12).

TABELA 12 - Classificação dos monofilamentos em três diferentes situações.

\begin{tabular}{|c|c|}
\hline Monofilamento & Classificação \\
\hline 1 - Verde (nominal 0,05 gr.) & \multirow{2}{*}{ Grau 1.} \\
\hline 2 - Azul (nominal 0.2 gr.) & \\
\hline 3 - Violeta (nominal 2,0 gr.) & \multirow{3}{*}{ Grau 2.} \\
\hline 4 - Vermelho escuro (nominal 4,0 gr.) & \\
\hline 5 - Laranja (nominal 10,0 gr.) & \\
\hline 6 - Vermelho magenta (nominal 300 gr.) & Grau 3. \\
\hline
\end{tabular}




\subsubsection{Análise do salto vertical com contra-movimento}

\subsubsection{Procedimento experimental}

Os marcadores cinemáticos colocados nos dois membros inferiores dos voluntários, no experimento anterior, foram mantidos e, em seguida, conforme recomendações do SENIAN (HERMENS et al., 2000), foram posicionados os eletrodos da eletromiografia nos ventres dos músculos gastrocnêmio medial e tibial anterior bilateralmente. Os eletrodos de referências foram posicionados em cada patela (FIGURA 17).

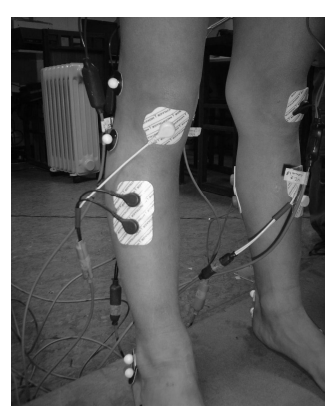

FIGURA 17 - Posicionamento dos eletrodos para o experimento de salto vertical com contra-movimento.

As crianças foram então instruídas a se posicionarem em cima da plataforma de força e, após o comando verbal do avaliador, realizaram um salto vertical com contra-movimento com as mãos apoiadas nas cristas ilíacas (FIGURA 18). Esta tarefa foi repetida cinco vezes. 


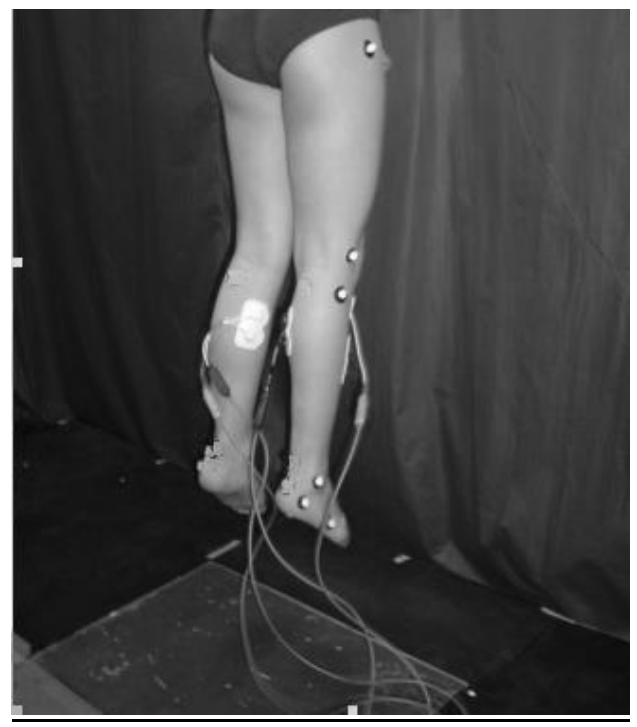

FIGURA 18 - Demonstração de uma coleta do salto vertical com contra-movimento.

Nesta fase, as câmeras JVC foram posicionadas de tal forma a captarem imagens no plano sagital de cada membro inferior das crianças (FIGURA 19).

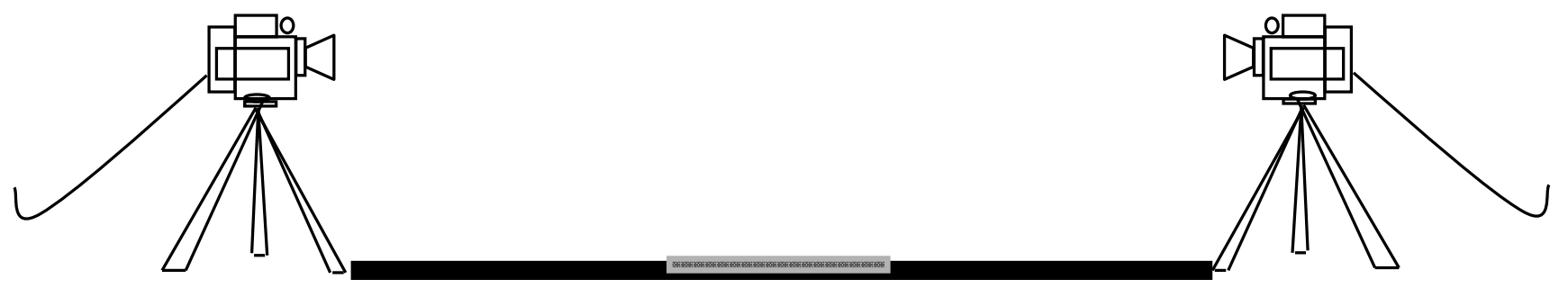

FIGURA 19 - Ilustração do posicionamento das câmeras de vídeo para captarem o plano sagital de movimento das crianças. Entre as câmeras encontrase a plataforma de força. 


\subsubsection{Variáveis analisadas}

Para a investigação dos dados de variação angular e eletromiográficos, o salto vertical foi dividido em duas diferentes fases: preparação (A) e aterrissagem (B). Foram utilizados, para a identificação dessas fases, os parâmetros da FRS vertical.

Foram avaliadas as características do RMS do sinal eletromiográfico para os músculos gastrocnêmio medial e tibial anterior, bilateralmente nas fases do $A$ e $B$.

Foram também analisados os seguintes parâmetros de variação angular:

a) máxima amplitude de flexão do joelho na fase $\mathrm{A}$ (cine1_joelho);

b) amplitude articular do joelho no final da fase A (cine2_joelho);

c) amplitude articular do joelho no início da fase B (cine3_joelho);

d) máxima amplitude de flexão do joelho na fase B (cine4_joelho);

e) máxima amplitude de dorsiflexão do tornozelo na fase $A$ (cine1_tornozelo);

f) amplitude articular do tornozelo no final da fase A (cine2_tornozelo);

g) amplitude articular do tornozelo no início da fase B (cine3_tornozelo);

h) máxima amplitude de tornozelo do joelho na fase $B$ (cine4_tornozelo). 
Segue ilustração dos parâmetros avaliados na análise do salto vertical com contra-movimento (FIGURA 20).
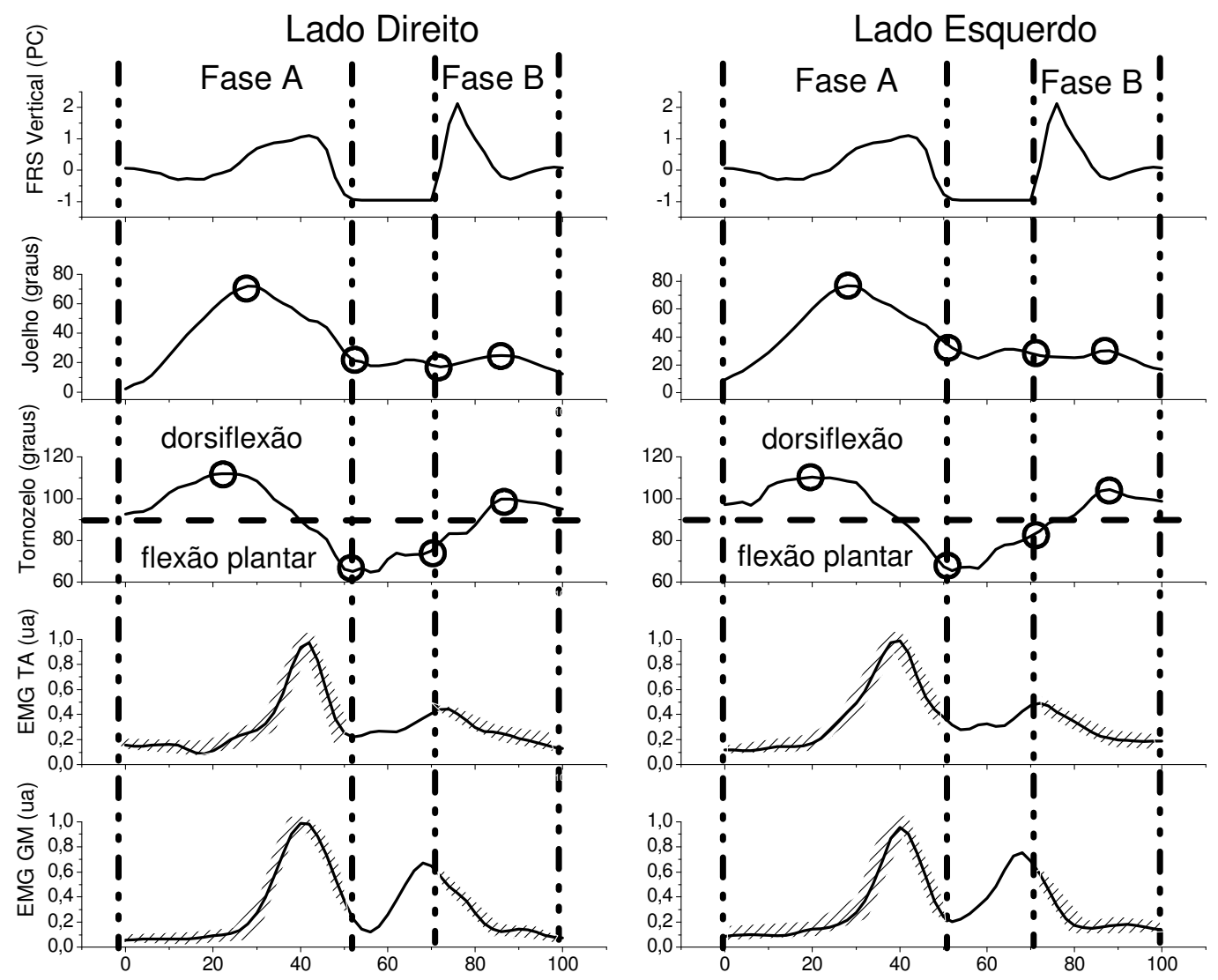

Salto Vertical (\%)

FIGURA 20 - Ilustração das fases analisadas do movimento de salto vertical com contramovimento, baseadas nos dados da FRS vertical. Fase A - preparação. Fase B - aterrissagem; círculos, nos dados angulares das articulacõos do joelho e tornozelo, referem-se aos parâmetros analisados; regiões tracejadas, nos dados eletromiográficos (EMG), referem-se às regiões investigadas.

Conforme demonstrado para os parâmetros da marcha, nota-se que, para a articulação do tornozelo, o instante de dorsiflexão ocorre quando os valores angulares são acima de $90^{\circ}$. Quando os valores são menores do que $90^{\circ}$, 0 movimento é caracterizado pela flexão plantar do tornozelo. 
Analisou-se também parâmetros relacionados com a componente vertical da FRS, as quais se destacam (FIGURA 21):

- máxima $F R S$ vertical na fase $A(F \max 1)$;

- máxima FRS vertical na fase B ( $F$ max2);

- relação entre F max2 com o tempo para atingir essa magnitude a partir do momento do início da aterrissagem - Taxa de Crescimento (TC).

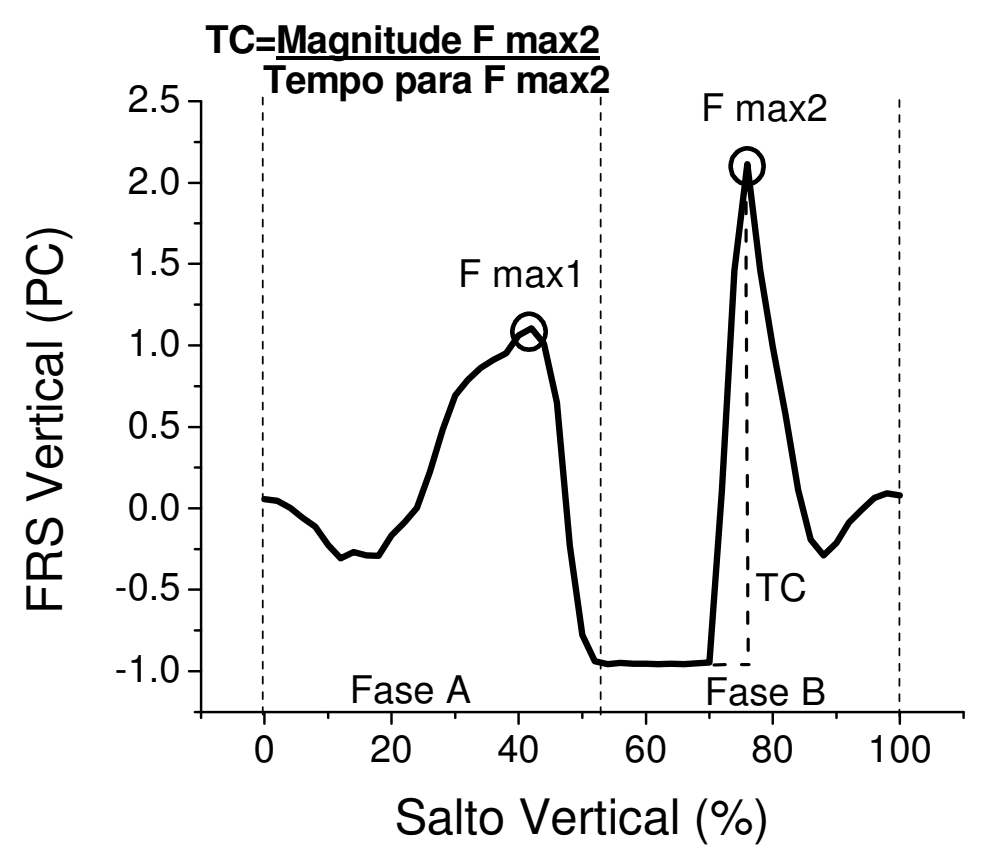

FIGURA 21 - Ilustração dos parâmetros adquiridos da FRS vertical para o experimento: Força máxima na fase $\mathrm{A}(\mathrm{F} \max 1)$, força máxima na fase $\mathrm{B}(\mathrm{F} \max 2)$ e sua respectiva taxa de crescimento (TC).

\subsection{Tratamento matemático dos dados}

\subsubsection{Sincronização dos dados}

Inicialmente foram realizados alguns procedimentos para possibilitar a identificação temporal sincronizada entre os dados da FRS e de variação angular.

Isso foi possível devido a uma placa eletrônica sincronizadora, a qual, após a ativação de um trigger manual, iniciou os registros simultâneos do 
eletromiógrafo, da plataforma de força, da câmera de vídeo digital, além de enviar um sinal para dois diodos emissores de luz posicionados no campo visual de cada câmera de vídeo analógica.

Inicialmente, foram identificadas características temporais da FRS vertical, denominadas de $\mathrm{T} 1$, correspondente ao início das coletas até o início da fase de apoio e de preparação do salto, e T2, referente aos tempos de apoio da marcha e de todo o salto vertical ( $\left.T_{2}\right)$ (FIGURA 22).
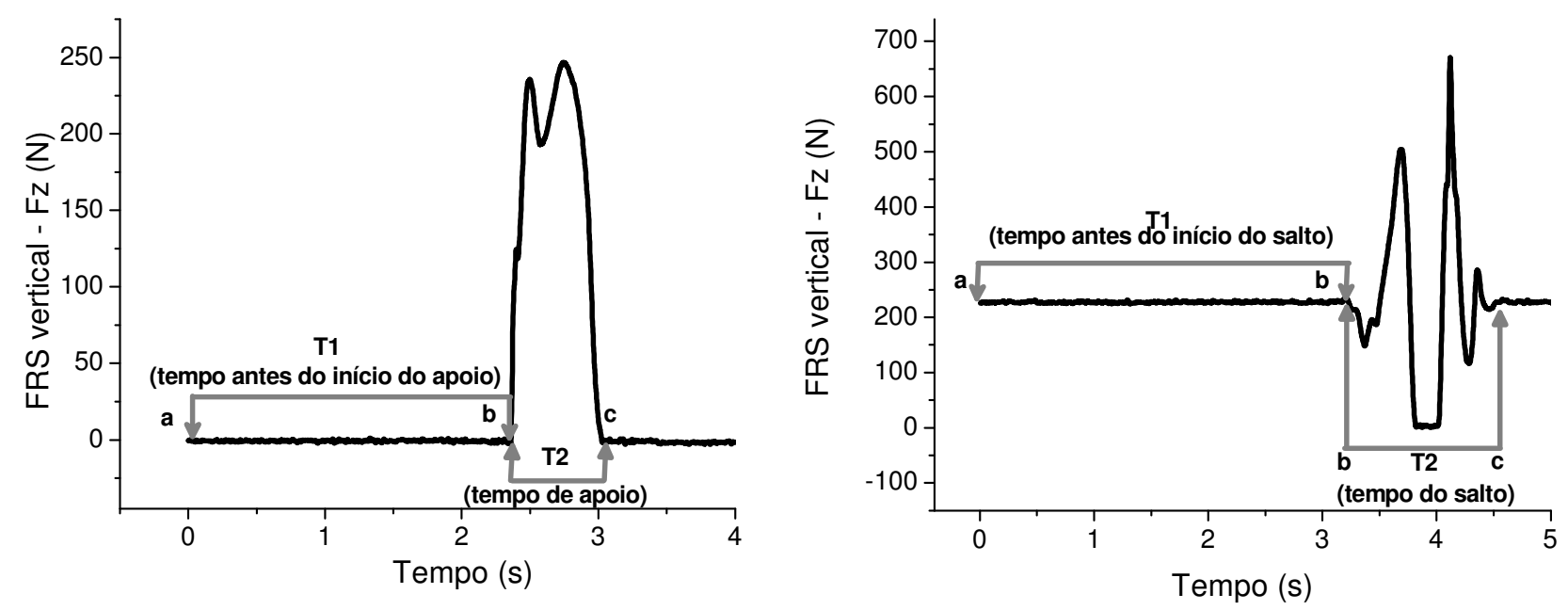

FIGURA 22 - Descrição das características temporais identificadas na marcha e no salto vertical, baseadas nos dados da FRS vertical. Foram analisados os tempos antes do início do apoio e do salto vertical $\left(T_{1}=b-a\right)$ e os tempos de apoio da marcha e de todas as fases do salto $\left(\mathrm{T}_{2}=\mathrm{C}-\mathrm{b}\right)$.

Para encontrar os quadros cinemáticos a serem analisados, foram divididos os valores de $\mathrm{T} 1$ e T2, encontrados na FRS, por 0,02, visto que a cinemática foi adquirida a $50 \mathrm{~Hz}$, ou seja, informações a cada 0,02 segundos.

Tendo, assim, a identificação dos quadros cinemáticos, foi utilizado o programa Trimmer Module (APAS System) para selecionar os dados de variação angular referentes às fases de análise definidas para o estudo. 


\subsubsection{Dados cinéticos}

Os dados cinéticos, tanto da marcha quanto do salto vertical com contra-movimento, foram tratados por meio do software OriginPro 7.0 e por rotinas desenvolvidas em ambiente Matlab 6.5 (The Mathworks Inc.) (ANEXO III).

Inicialmente todos os dados foram filtrados com Butterworth passa baixa de $200 \mathrm{~Hz}$ e removidos os possíveis offsets. Em seguida, as intensidades foram normalizadas pelo peso corporal da criança, sendo iniciadas as identificações dos parâmetros predefinidos de investigação.

Para isso, os dados da FRS foram plotados e, por meio da utilização da função "ginput" no Matlab 6.5 (The Mathworks Inc.), foram identificadas as magnitudes de referência para as identificações dos parâmetros analisados.

\subsubsection{Dados cinemáticos}

Inicialmente, os dados coletados pelas duas câmeras JVC, foram convertidos em arquivos do tipo .AVI com a utilização do programa Capture Module (APAS System). Ressalta-se que os dados de variação angular oriundos das coletas da marcha foram adquiridos por meio de uma câmera digital e, portanto, salvos, imediatamente após as coletas, em arquivo .AVI.

Em seguida, foi utilizado o programa Digitizing Module (APAS System) para criar o modelo para idealização do "stick figure" e a digitalização manual dos dados. Para a reconstrução bidimensional, foi utilizado o programa Transformation Module (APAS System). A filtragem dos dados foi feita no programa Filtering Module (APAS System).

Como a freqüência de amostragem das câmeras de vídeo $(50 \mathrm{~Hz})$ foi diferente da FRS, foi necessário a realização da normalização desses dados na base do tempo.

Foram identificadas a variação angular das articulações do tornozelo e do joelho durante as atividades propostas, por meio do programa Display Module (APAS System). 


\subsubsection{Dados eletromiográficos}

Para análise dos sinais eletromiográficos dos músculos gastrocnêmio medial e tibial anterior durante o salto, inicialmente foram selecionadas atividades eletromiográficas das fases A e B do salto vertical com contra-movimento, baseadas no referencial dinâmico representado pela FRS vertical.

Em seguida, foi passado o filtro Butterworth de segunda ordem, passabanda de 20 a $400 \mathrm{~Hz}$. Adicionalmente foi removido o offset e normalizadas as intensidades dos sinais pelo pico máximo em cada fase analisada (Fases A e B). Posteriormente, foi realizada a análise do RMS em cada uma dessas fases prédeterminadas.

Todos esses procedimentos foram realizados por meio de rotina desenvolvida em ambiente Matlab 6.5 (The Mathworks Inc.) (ANEXO III).

\subsection{Análise estatística dos dados}

Inicialmente foi realizada a análise do coeficiente de variação (CV) para todas as curvas de variação angular, de FRS e de eletromiografia adquiridas nos experimentos.

Para isto, foram selecionados os dados referentes à fase de apoio da marcha e às fases de preparação e de aterrissagem do salto vertical. Em seguida, todos os dados foram normalizados na base do tempo, com ciclo representado por $100 \%$ e interpolados a cada $1 \%$ da duração total de cada fase. Foram selecionados todos os dados de cada grupo e calculados o CV para identificar suas dispersões percentuais em relação a sua respectiva média (WINTER, 1991).

sendo: $\mathrm{DP}=$ Desvio padrão da variável

$$
C V=\frac{D P}{\bar{\chi}} \times 100 \%
$$

$\bar{\chi}=$ Média da variável

Em seguida, iniciaram-se as análises comparativas entre os grupos, com utilização do programa estatístico SPSS, versão 11.5 . 
Foi definido, para este trabalho, um nível de significância de $p \leq 0,05$ (5\%); portanto, todos os intervalos de confiança foram construídos com $95 \%$ de confiança estatística.

Foram utilizados testes e técnicas estatísticas não paramétricas, pois as condições para a utilização de técnicas e testes paramétricos, como a normalidade e homogeneidade das variâncias, não foram encontradas nesse conjunto de dados.

$\mathrm{Na}$ análise dos parâmetros adotados para essa investigação, inicialmente foram comparados os dados das cinco repetições em cada uma das variáveis, tanto para a marcha quanto para o salto vertical. Para tanto, foi utilizado o teste de Friedman, o qual é uma análise não paramétrica aplicada para verificar se as repetições, em cada uma das variáveis analisadas, têm diferenças significativas entre elas. Esse teste é utilizado quando há dados pareados e há necessidade de comparar três ou mais variáveis simultaneamente (MAROCO, 2003). Para este trabalho, o teste de Friedman foi definido em base da hipótese nula $\left(H_{0}\right)$ de que as repetições não têm efeito e hipótese alternativa $\left(H_{1}\right)$ de que existe alguma diferença. Portanto, foram comparadas as cinco repetições em cada uma das variáveis analisadas. Como para a marcha e para o salto vertical a repetição não foi um fator causador de diferença (ANEXO IV), buscou-se investigar todas as observações, de todas as repetições. Isso trouxe uma característica de maior fidedignidade de resultados.

Depois da união de todas as repetições, foi utilizado o teste de Wilcoxon para comparar os lados direito e esquerdo dos indivíduos. Foi selecionado um teste pareado, pois existiu a necessidade de comparar as variáveis duas a duas, relevantes ao mesmo indivíduo (MAROCO, 2003). No caso do presente trabalho, esse teste realizou a comparação dos dados do apoio no lado direito com esquerdo. $O$ teste de Wilcoxon foi definido em base da seguinte hipótese:

$\mathrm{H}_{0}$ : Não há diferença entre os dados dos apoios direito e esquerdo.

$\mathrm{H}_{1}$ : Há diferença entre os dados dos apoios direito e esquerdo. 
Foram encontradas diferenças entre os lados tanto no grupo com PTC bilateral, quanto no unilateral, para os dados da marcha e do salto vertical (ANEXO IV).

Portanto, para a seguinte análise, foram considerados cinco grandes grupos:

1. Grupo Controle (Cont.);

2. Grupo PTC bilateral - lado direito (Bil. D.);

3. Grupo PTC bilateral - lado esquerdo (Bil. E.);

4. Grupo PTC unilateral - lado acometido (Acom.);

5. Grupo PTC unilateral - lado não acometido (Ñ Acom.).

No caso dos parâmetros da FRS vertical adquiridos no salto vertical com contra-movimento, que não são bilaterais, os grupos continuaram classificados apenas como PTC unilateral (Unil.), PTC bilateral (Bil.) e Grupo Controle (Cont.).

Com a existência de muitas variáveis analisadas, há complexidade no entendimento e discussão dos resultados. A investigação por meio da Análise dos Componentes Principais (ACP) é uma técnica estatística que serve para serem criados fatores multivariados por meio da variabilidade e correlações intrínsecas das variáveis. Dessa forma, favorece a união de variáveis, que possuam alguma similaridade entre si, em um único grupo. Com essa técnica, reduz-se a quantidade de variáveis e, portanto, contribui para a simplificação do entendimento das variáveis existentes.

O primeiro passo para a construção dessa análise é a realização dos testes Kaiser-Meyer-Olkin (KMO) e Bartlett, os quais verificam a adequabilidade dos dados para a técnica. Assim, como o intuito é a criação de componentes, o ideal é que haja uma correlação entre as variáveis, portanto, podemos aplicar o $\mathrm{KMO}$, pois esse é um dos testes que tem como objetivo a investigação da medida de adequação da amostragem. $O$ teste de Bartlett mede se a matriz de correlação dos dados é igual ou não à matriz identidade (MAROCO, 2003). 
Portanto, com o objetivo de tentar reduzir a quantidade das variáveis para os parâmetros da marcha, esses foram divididos em dois grandes grupos: um para os dados referentes à FRS e outro para os de variação angular. Foi verificado, pelo teste $\mathrm{KMO}$, que as variáveis possuem uma correlação muito boa, tanto para os dados da FRS quanto para os de variação angular (0,565 e 0,730, respectivamente). Complementando essa análise, foi obtido, pelo teste de Bartlett, um p-valor menor do que 0,001, em ambos os casos. Isso garantiu que a ACP pode ser utilizada para os parâmetros investigados da marcha, pois as correlações entre as variáveis existem.

Diante disso, iniciou-se a ACP e constatou-se que a investigação para os dados da FRS demonstrou que cinco componentes obtiveram valores próprios maiores do que 01 , os quais representam $73,69 \%$ da variabilidade total (TABELA 13).

TABELA 13 - Características dos valores próprios encontrados nas cinco componentes principais, relacionados com os parâmetros da marcha, para os dados da FRS, com valores maiores do que 01 .

\begin{tabular}{ccc}
\hline \multirow{2}{*}{ Componentes } & \multicolumn{2}{c}{ Valores Próprios } \\
\cline { 2 - 3 } & Total & \% da Variância \\
\hline $\mathbf{1}$ & 3,23 & 23,07 \\
\hline $\mathbf{2}$ & 2,86 & 20,48 \\
\hline $\mathbf{3}$ & 1,73 & 12,38 \\
\hline $\mathbf{4}$ & 1,40 & 10,01 \\
\hline $\mathbf{5}$ & 1,08 & 7,73 \\
\hline Total & 10,31 & 73,69 \\
\hline
\end{tabular}


A tabela a seguir descreve a variância de cada uma das variáveis originais nas novas componentes principais em termos das médias dos escores para cada indivíduo registrado na variável. Isso permite identificar quais variáveis são determinantes para cada componente principal (TABELA 14).

TABELA 14 - Variâncias explicadas para cada componente principal em cada parâmetro investigado na marcha. ( ${ }^{*}$ variância $\left.>0,5\right)$.

\begin{tabular}{cccccc}
\hline \multirow{2}{*}{ Parâmetros } & \multicolumn{5}{c}{ Componentes principais } \\
\cline { 2 - 6 } & $\mathbf{1}$ & $\mathbf{2}$ & $\mathbf{3}$ & $\mathbf{4}$ & $\mathbf{5}$ \\
\hline Fz 1 & 0,13 & 0,24 & 0,05 & 0,13 & 0,40 \\
Fz 2 & $0,61^{*}$ & 0,10 & 0,10 & 0,04 & 0,07 \\
Fz_min & 0,13 & 0,35 & 0,03 & 0,21 & 0,06 \\
T_apoio & 0,32 & 0,42 & 0,21 & 0,09 & 0,02 \\
TC 1 & 0,05 & $0,68^{*}$ & 0,13 & 0,18 & 0,04 \\
TC 2 & 0,30 & 0,21 & 0,06 & 0,28 & 0,02 \\
Fy_min & 0,17 & $0,54^{*}$ & 0,06 & 0,18 & 0,05 \\
Fy_max & 0,50 & 0,04 & 0,05 & 0,06 & 0,15 \\
I_fren & 0,33 & 0,09 & 0,17 & 0,32 & 0,02 \\
I_prop & $0,62^{*}$ & 0,05 & 0,10 & 0,04 & 0,08 \\
Fx 1 & 0,12 & 0,06 & 0,16 & 0,07 & 0,35 \\
Fx 2 & 0,17 & 0,35 & 0,27 & 0,08 & 0,01 \\
Fx 4 & 0,12 & 0,16 & 0,39 & 0,15 & 0,06 \\
Fx 5 & 0,22 & 0,09 & 0,32 & 0,05 & 0,17 \\
\hline
\end{tabular}

Portanto, para a componente 1, que explica $23,07 \%$ da variância, os parâmetros que se destacam são Fz 2 e I_prop. Para a componente 2, que explica 20,48\% da variância, os parâmetros que se destacam são TC1 e Fy_min. Esses parâmetros estão em componentes que respondem a 43,6\% da variância.

Os dados de variação angular mostraram que três componentes, relacionadas aos parâmetros da marcha, obtiveram valores próprios maiores do que 01 , os quais representam $73,8 \%$ da variabilidade total (TABELA 15). 
TABELA 15 - Características dos valores próprios encontrados nas três componentes principais, para os dados de variação angular, com valores maiores do que $\underline{01 .}$

\begin{tabular}{ccc}
\hline \multirow{2}{*}{ Componentes } & \multicolumn{2}{c}{ Valores Próprios } \\
\cline { 2 - 3 } & Total & \% da Variância \\
\hline $\mathbf{1}$ & 4,38 & 43,77 \\
\hline $\mathbf{2}$ & 1,89 & 18,86 \\
\hline $\mathbf{3}$ & 1,12 & 11,17 \\
\hline Total & 7,38 & 73,80 \\
\hline
\end{tabular}

A tabela a seguir descreve a variância de cada uma das variáveis originais de variação angular nas novas componentes principais em termos das médias dos escores para cada indivíduo registrado na variável. Isso permite identificar quais as variáveis são determinantes para cada componente principal (TABELA 16).

TABELA 16 - Variâncias explicadas para cada componente principal em cada parâmetro de variação angular investigado na marcha auto-selecionada. ( ${ }^{*}$ variância $>$ $\underline{0,5)}$.

\begin{tabular}{cccc}
\hline & \multicolumn{3}{c}{ Componentes principais } \\
Parâmetros & $\mathbf{1}$ & $\mathbf{2}$ & $\mathbf{3}$ \\
\hline cine_joelho1 & 0,25 & 0,04 & 0,28 \\
cine_joelho2 & $0,76^{*}$ & 0,01 & 0,02 \\
cine_joelho3 & $0,74^{*}$ & 0,02 & 0,04 \\
cine_joelho4 & $0,68^{*}$ & 0,04 & 0,02 \\
cine_joelho5 & 0,07 & $0,89^{*}$ & 0,04 \\
cine_tornozelo1 & 0,04 & 0,02 & $0,78^{*}$ \\
cine_tornozelo2 & $0,57^{*}$ & 0,02 & 0,02 \\
cine_tornozelo3 & $0,72^{*}$ & 0,05 & 0,06 \\
cine_tornozelo4 & $0,65^{\star}$ & 0,06 & 0,08 \\
cine_tornozelo5 & 0,04 & $0,91^{*}$ & 0,02 \\
\hline
\end{tabular}


Como a componente principal 1 responde a $43 \%$ das variâncias dos dados de variação angular na marcha, semelhante à porcentagem encontrada para a FRS, serão utilizados, para análises mais precisas, apenas os parâmetros que se destacaram nesse grupo, os quais foram: cine_joelho2, cine_joelho3, cine_joelho4, cine_tornozelo2, cine_tornozelo3 e cine_tornozelo4.

Dessa forma, foram avaliados os seguintes parâmetros para a marcha (TABELA 17):

TABELA 17 - Variáveis calculadas a partir das componentes vertical (Fz), ânteroposterior (Fy) e médio-lateral ( $F x$ ) da FRS selecionadas dos dados da marcha, após a análise das componentes principais.

\begin{tabular}{|c|c|}
\hline Variáveis analisadas & Definição das variáveis \\
\hline TC 1 & $\begin{array}{l}\text { Taxa de crescimento 1: Razão entre Fz1 e o tempo decorrido do } \\
\text { início do apoio até esta magnitude }\end{array}$ \\
\hline Fz 2 & Segundo valor máximo da FRS vertical \\
\hline Fy $\min$ & Primeiro pico negativo da FRS ântero-posterior \\
\hline I_prop & $\begin{array}{l}\text { Impulso de propulsão: Integral do sinal da FRS ântero-posterior } \\
\text { na fase de propulsão do movimento }\end{array}$ \\
\hline cine_joelho2 & Ângulo do joelho no momento de Fz1 \\
\hline cine_joelho3 & Ângulo do joelho no momento de Fz min \\
\hline cine_joelho4 & Ângulo do joelho no momento de Fz2 \\
\hline cine_tornozelo2 & Ângulo do tornozelo no momento de Fz1 \\
\hline cine_tornozelo3 & Ângulo do tornozelo no momento de Fz min \\
\hline cine_tornozelo4 & Ângulo do tornozelo no momento de Fz2 \\
\hline
\end{tabular}


Segue a ilustração das variáveis investigadas para a marcha a partir da ACP (FIGURA 23).
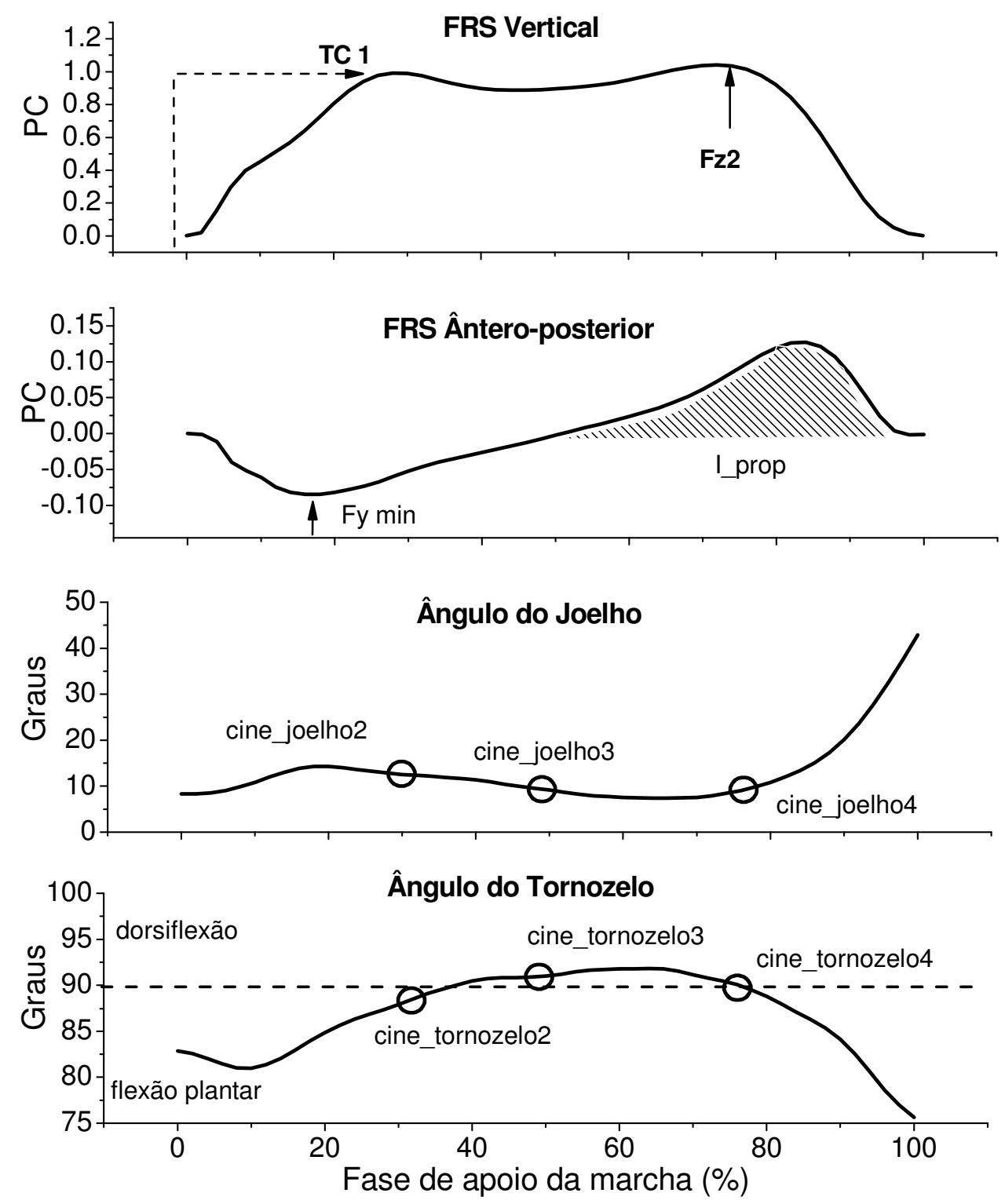

FIGURA 23 - Variáveis calculadas para a marcha auto-selecionada, após a análise das componentes principais. 
Para os dados adquiridos no salto vertical com contra-movimento, também foram realizados os testes de KMO e de Bartlett para verificação da adequação dos dados na utilização do teste de ACP para os parâmetros da FRS, eletromiografia e de variação angular. Entretanto, constatou-se que esses dados não têm uma adequação para a utilização da análise por meio das componentes principais, visto que foi encontrado um $p$-valor maior do que 0,001 para o teste de Bartlett $(0,014)$, além de uma não muito boa correlação dos dados no teste de KMO $(0,439)$. Portanto, não foi realizado o teste de ACP.

Após isso, tanto para os dados da marcha quanto para os do salto vertical, foi utilizado o teste de Kruskal-Wallis, o qual é aplicado quando há necessidade de comparar mais de duas variáveis simultaneamente; ou seja, mede-se apenas se existe diferença entres os grupos, mas não se conclui em qual grupo está a diferença (MAROCO, 2003). A hipótese para esse teste foi a seguinte:

$H_{0}$ : As médias dos grupos são iguais.

$H_{1}$ : pelo menos uma das médias é diferente.

Por meio desse teste, foram encontradas diferenças estatísticas em todos os parâmetros relacionados com os dados da marcha.

Para o salto vertical com contra-movimento, foi observado que para as variáveis "F max2", "RMS_TA_pos", "RMS_TA_pre", "cine1_joelho" e "cine4_joelho", as diferenças entre os grupos não podem ser consideradas estatisticamente significantes. Para as demais variáveis, pode-se dizer que há diferenças entre os grupos e, dessa forma, foram selecionados os seguintes parâmetros para futura investigação (TABELA 18): 
TABELA 18 - Variáveis das componentes vertical da FRS, eletromiografia e de variação angular que foram avaliadas no salto vertical e que obtiveram diferenças significativas entre os grupos.

\begin{tabular}{cr}
\hline Variáveis analisadas & Definição das variáveis \\
\hline F max1 & $\begin{array}{c}\text { Relação entre a máxima força da fase B com o tempo para atingir } \\
\text { esta magnitude a partir do momento do início da aterrissagem }\end{array}$ \\
RMS_GM_pre & Análise do sinal eletromiográfico do gastrocnêmio medial por meio \\
do RMS na fase A do salto vertical
\end{tabular}


Segue a ilustração das variáveis analisadas, a partir do salto vertical, após a utilização do teste de Kruskal-Wallis (FIGURA 24).

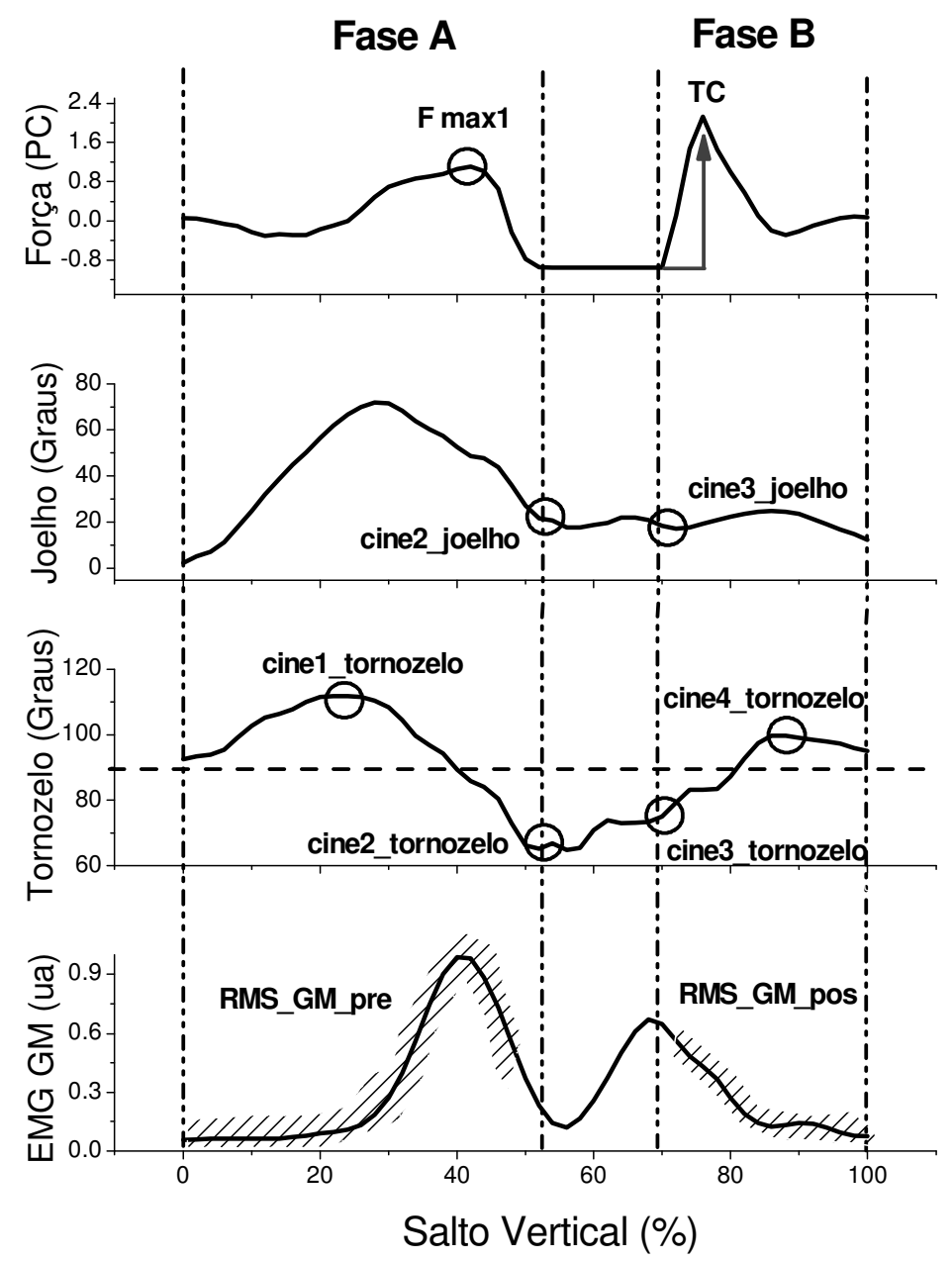

FIGURA 24 - lustração das variáveis das componentes vertical da FRS, eletromiografia e de variação angular que foram avaliadas no salto vertical que obtiveram diferenças significativas entre os grupos; regiões tracejadas, nos dados eletromiográficos (EMG), referem-se às regiões investigadas. 
Para a identificação precisa das diferenças entre essas variáveis da marcha e do salto vertical, foi utilizado o teste de Mann-Whitney. Esse é um teste não paramétrico, utilizado em baixas amostragens e usado quando há amostras independentes (MAROCO, 2003). Os resultados desse teste encontram-se descritos posteriormente no item resultados.

Para a avaliação com monofilamentos, foram utilizados os testes Kruskal-Wallis e Mann-Whitney, citados anteriormente, além do teste de lgualdade de duas Proporções. Esse é um teste não paramétrico que compara se a proporção de respostas de duas determinadas variáveis e/ou seus níveis é estatisticamente significante (MAROCO, 2003).

\subsection{Controle do erro experimental e limitações metodológicas}

Os procedimentos metodológicos estão sempre susceptíveis às limitações e a tentativa de controle destas torna-se imprescindível, mesmo com a consciência de que, em algumas ocasiões, isso seja impossível. Tais aspectos são inerentes a qualquer investigação quase-experimental em um ambiente laboratorial; no entanto, a identificação dessas possíveis limitações é inevitável, pois, com isso, tem-se um maior cuidado na discussão dos resultados.

Ressalta-se que, com o objetivo de controlar o erro experimental, foram delineados estudos preliminares que auxiliaram no direcionamento do método empregado no atual trabalho. Exemplo disso foi a verificação prévia de que a investigação por meio da marcha em esteira rolante seria inviável para esse grupo populacional, conforme demonstrado no Estudo Piloto 1. Nesse estudo foi

verificado que, apesar das tentativas de familiarização com o ambiente experimental, a criança avaliada demonstrou dificuldades de adaptação durante a locomoção na esteira rolante, com desequilíbrios constantes e necessidade de segurar nas barras de suporte do equipamento durante as coletas.

Entre as limitações metodológicas existentes neste trabalho, encontram-se aspectos relevantes que se referem à amostra, ao ambiente experimental, à instrumentação utilizada e ao método de tratamento dos sinais biológicos. 


\subsubsection{Amostra}

Quanto ao grupo da amostra investigado, em específico o com PTC, a primeira limitação metodológica encontrada foi a dificuldade da melhor caracterização dos aspectos pré-cirúrgicos dessas crianças. Apesar de todas as crianças terem características etiológicas idiopáticas e de não apresentarem patologias associadas ou qualquer aspecto sindrômico, não foi possível definir se os pés delas possuíam características de um pé rígido ou não rígido. Essa informação não se encontrava nos prontuários das crianças. Conforme classificado por BANSAL, DANIEL e RAI (1988), essas características são clinicamente identificadas e podem influenciar na facilidade de correção da deformidade. No entanto, não existe nenhum dado na literatura que compare esses dois tipos de características com aspectos diferenciais funcionais. Além disso, todos foram corrigidos cirurgicamente, mesmo que tenham tido pés rígidos e não rígidos.

Adicionalmente, com relação ao próprio ato cirúrgico, certamente há variações nesse procedimento, baseadas nas necessidades de cada indivíduo. Um método de controle para tal aspecto torna-se inviável, pois o ato cirúrgico é específico para as necessidades da criança. O método do controle desse eventual erro foi que a cirurgia tenha sido realizada mediante a liberação póstero-medial até o primeiro ano de vida das crianças e que elas estivessem em alta médica e com realização de apenas acompanhamentos periódicos.

\subsubsection{Ambiente experimental}

Com relação ao ambiente experimental, verificou-se que, por mais que as crianças passassem por um processo de adaptação no ambiente laboratorial, certamente não estavam em seus ambientes do dia-a-dia. Isso pode levar a efeitos retroativos com características de locomoção diferenciadas do convencional.

Para investigação da marcha, a qual necessita de um deslocamento maior da criança, a conexão de cabos pode gerar certo desconforto. Dessa forma, 
um modo de minimizar os efeitos retroativos durante a marcha foi a opção da não colocação dos eletrodos de eletromiografia e, conseqüentemente, a não existência de cabos fixados nos segmentos inferiores, visto que as crianças caminhavam de um lado para o outro em comprimento de cinco metros. Portanto, as coletas eletromiográficas foram realizadas apenas no salto vertical, o que foi possível visto que as crianças não necessitavam de se locomover de um lado para o outro com tal instrumental, o que não gerou o aumento de efeitos retroativos na coleta.

Um possível método para aumentar a familiarização das crianças com o ambiente laboratorial e com os instrumentos de coleta seria a realização de um reteste após alguns dias. Contudo, essa opção tornou-se inviável em decorrência da dificuldade dos pais em levar as crianças para uma re-avaliação.

Destaca-se também que, para a análise da marcha, as crianças tinham que realizar o contato do pé com apenas um segmento sobre a plataforma de força. Como as crianças não eram informadas a respeito dessa necessidade, em alguns casos o tempo de coleta se estendia, pois existia uma seqüência de testes que tinham que ser descartados. Com isso, o controle do tempo total de coleta não foi realizado. Para minimizar os erros, previamente ao início das coletas, o avaliador treinava com a criança a marcha, observando sempre com qual membro inferior geralmente a criança iniciava a locomoção e, assim, ele conseguia ajustar a melhor distância da plataforma em que iria ser iniciada a marcha.

\subsubsection{Instrumentação e metodologia}

A precisão dos sistemas de aquisição de dados utilizados neste trabalho está diretamente dependente da calibragem dos equipamentos. Por meio da calibração desses equipamentos, é possível identificar a diferença de potencial elétrico gerado na plataforma e, em seguida, identificar as forças existentes. Por se tratar de um transdutor de comportamento estável, a plataforma de força utilizada não necessita ser calibrada freqüentemente $\mathrm{e}$, conseqüentemente, os limites de erro de medida para os sinais de saída da plataforma de força foram de $\pm 2 \%$. 
A plataforma de força, como qualquer material, possui uma característica específica de histerese, a qual é definida como a diferença entre a amplitude de deformação dada no material versus a amplitude de recuperação dessa deformação elástica (HERZOG, 2000). Portanto, quanto menor esse histerese, maior é a fidedignidade dos dados. Geralmente os valores de histeresse das plataformas de força são menores do que 0,5. A plataforma de força utilizada no procedimento experimental, da marca Bertec, possui um índice de histeresse menor do que 0,2 .

Para a variação angular, calibrou-se o sistema antes do início das coletas, com a utilização de um objeto de medidas conhecidas posicionado no local da investigação. A acurácia do sistema de captação cinemática é dependente de fatores como a localização das câmeras do objeto de estudo. No atual trabalho, preocupou-se em manter a câmera nivelada paralelamente ao solo e perpendicular ao plano sagital de coleta dos dados.

Uma das etapas associada a possíveis erros no tratamento dos dados cinemáticos é o rastreamento dos marcadores durante a digitalização manual dos dados, pois ruídos podem ser atribuídos aos dados quando os marcadores que definem o modelo não são identificados com precisão. Fator minimizador desse erro foi a realização de tal procedimento por um único sujeito.

Quanto ao método, para a análise do salto vertical, foi utilizada apenas uma plataforma de força, o que limitou a descrição da FRS, com a impossibilidade de comparações desses dados entre os segmentos inferiores direito e esquerdo. No entanto, vale ressaltar que dados de variação angular e eletromiográficos possibilitaram as análises entre os segmentos dos sujeitos.

Atualmente, a melhor forma de identificar o comportamento muscular é por meio da EMG (SUTHERLAND, 2001). Contudo, sabe-se de vários fatores que influenciam a captação desse sinal elétrico muscular e causam interferências no sinal eletromiográfico captado (CLANCY, MORIN \& MERLETTI, 2002). Por isso, foram tomadas algumas medidas para minimizar tais ruídos. Foi utilizado um sistema de EMG com eletrodos pré-amplificados e bipolares. A pele foi preparada para diminuir possíveis artefatos ao sinal provenientes da interface pele/eletrodo com a realização da tricotomia e limpeza com álcool do local, além de ter a 
preocupação com o posicionamento dos eletrodos os quais foram posicionados de acordo com referenciais anatômicos e seguindo as recomendações do SENIAM. Adicionalmente, foram preconizados cuidados com a freqüência de amostragem e com métodos do tratamento dos dados.

Outro fato a ser considerado é a não utilização, neste protocolo experimental, da análise da distribuição de pressão plantar. Sabemos que a pressão plantar é afetada por vários fatores, dentre eles características de movimentos articulares e aspectos estruturais anatômicos das extremidades inferiores (KELLIS, 2001). Diante do fato de que crianças com história de PTC, mesmo após tratamentos corretivos de tal deformidade, possam apresentar alterações anatômicas, tal investigação poderia nos auxiliar numa melhor compreensão de possíveis características próprias nesse grupo populacional. De fato, foram encontrados, nos estudos piloto 2 e 3, a relevância da investigação desses parâmetros. Um ponto a considerar relaciona-se com a limitação técnica existente para as coletas de dados nessas crianças, o que se refere ao tamanho das palmilhas utilizadas. As discrepâncias geométricas entre o pé acometido com o não acometido e a inexistência de tamanhos de palmilhas instrumentadas diversificadas, dificultou as coletas de dados no estudo piloto 3. Atualmente, para a análise da pressão plantar, têm-se disponíveis, no mercado, diferentes instrumentos com o mesmo princípio das palmilhas sensorizadas, os quais também possuem pequenos sensores ou matrizes de múltiplos sensores que mensuram a força que age durante seu contato com uma superfície. Dentre eles, destacam-se as plataformas de pressão, as quais podem ser mais úteis nas avaliações de crianças com PTC, visto a não necessidade de adaptação do pé a uma palmilha. Outra vantagem do uso das plataformas é que seus sensores estão sempre posicionados paralelamente à superfície de contato, o que provê uma fidedignidade maior na mensuração da FRS vertical (ORLIN \& McPOIL, 2000).

Porém, para a realização da análise adicional com uma plataforma de pressão, o tempo de coleta seria estendido, fazendo com que a criança ficasse mais tempo no ambiente de laboratório. Para evitar tal característica, a qual poderia gerar desconforto às crianças, não foi realizado tal método. 
RESULTADOS

\subsection{Análise da marcha auto-selecionada}

O CV para as curvas da FRS vertical variaram de 13 a $16,8 \%$. Para a médio-lateral, de 34,1 a $45,9 \%$; e os para a ântero-posterior, de 53,5 a 57,4\%. Portanto, esses valores foram maiores para a FRS ântero-posterior, seguido da médio-lateral e vertical (TABELA 19).

TABELA 19 - Apresentação do coeficiente de variação (CV) das curvas da FRS vertical, médio-lateral e ântero-posterior na fase de apoio da marcha autoselecionada dos grupos avaliados: Controle (Cont.), PTC bilateral lado direito (Bil. D.), PTC bilateral lado esquerdo (Bil. E.), PTC unilateral lado

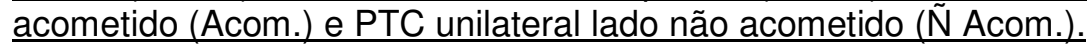

\begin{tabular}{cccc}
\hline Grupos & FRS Vertical (\%) & FRS médio-lateral (\%) & FRS ântero-posterior (\%) \\
\hline Cont. & 13,8 & 45,9 & 57 \\
Acom. & 15,4 & 34,1 & 53,5 \\
Ñ Acom. & 13 & 40,4 & 57,4 \\
Bil. D. & 16,8 & 44,5 & 54,4 \\
Bil. E. & 13,2 & 37,1 & 55,7 \\
\hline
\end{tabular}

$\mathrm{Na}$ análise do CV das curvas médias dos dados de variação angular, não foram identificadas diferenças entre os grupos avaliados para a articulação do tornozelo (TABELA 20).

TABELA 20 - Apresentação do coeficiente de variação (CV) das curvas de variação angular da articulação do tornozelo na fase de apoio da marcha dos grupos avaliados: Controle (Cont.), PTC bilateral lado direito (Bil. D.), PTC bilateral lado esquerdo (Bil. E.), PTC unilateral lado acometido (Acom.) e PTC unilateral lado não acometido (Ñ Acom.).

\begin{tabular}{cc}
\hline Grupos & Tornozelo (\%) \\
\hline Cont. & 6,9 \\
Acom. & 7,5 \\
Ñ Acom. & 7,8 \\
Bil. D. & 5,3 \\
Bil. E. & 4,8 \\
\hline
\end{tabular}


Foram encontrados maiores valores do CV para a articulação do joelho, na comparação com os valores encontrados no tornozelo.

Para a articulação do joelho, foram identificados maiores valores do CV para o grupo PTC bilateral (lado direito $=52,9$; lado esquerdo $=52,4$ ), comparados com os demais grupos, conforme demonstrado na TABELA 21.

TABELA 21 - Apresentação do coeficiente de variação (CV) das curvas de variação angular da articulação do joelho na fase de apoio da marcha dos grupos avaliados: Controle (Cont.), PTC bilateral lado direito (Bil. D.), PTC bilateral lado esquerdo (Bil. E.), PTC unilateral lado acometido (Acom.) e PTC unilateral lado não acometido ( $\tilde{N}$ Acom.).

\begin{tabular}{cc}
\hline Grupos & Joelho (\%) \\
\hline Cont. & 35,8 \\
Acom. & 35,4 \\
Ñ Acom. & 39,9 \\
Bil. D. & 52,4 \\
Bil. E. & 52,9 \\
\hline
\end{tabular}

Todos os grupos com história de PTC apresentaram, de forma geral, características das curvas da FRS vertical (FIGURA 25), ântero-posterior (FIGURA 26) e médio-lateral (FIGURA 27), em toda fase de apoio da marcha, similares aos encontrados no grupo Controle e ao descrito na literatura (STANSFIELD, HILLMAN, HAZLEWOOD, LAWSON, MANN, LOUDON \& ROBB, 2001; TAKEGAMI, 1992). 
A curva média da componente vertical da FRS foi composta por dois picos e um vale entre esses (FIGURA 25).

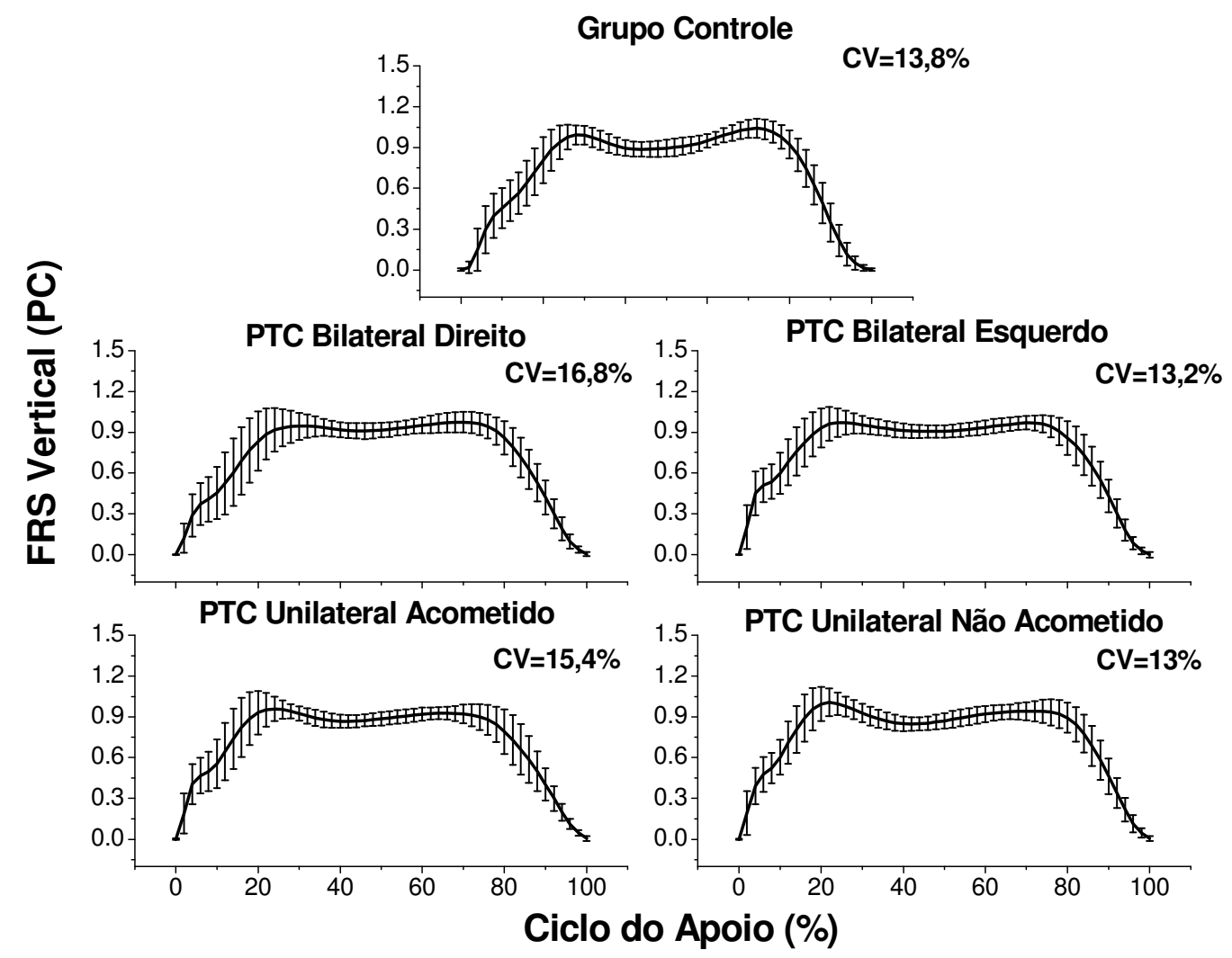

FIGURA 25 - Ilustracão das médias e desvios-padrão da FRS Vertical, com sua intensidade normalizada pelo peso corporal (PC), além do coeficiente de variação (CV), para a marcha auto-selecionada em todos os grupos analisados. Dados normalizados na base do tempo, tendo todo o ciclo da fase de apoio $100 \%$. 
A curva média da componente ântero-posterior da FRS apresentou características de normalidade de acordo com a literatura (WINTER, 1983), com um inicial pico, representado por uma intensidade negativa, relacionado com a fase de frenagem. Em torno de $50 \%$ da fase de apoio da marcha, iniciou-se uma nova fase, representada por valores positivos, na qual se encontra o pico de propulsão (FIGURA 26).

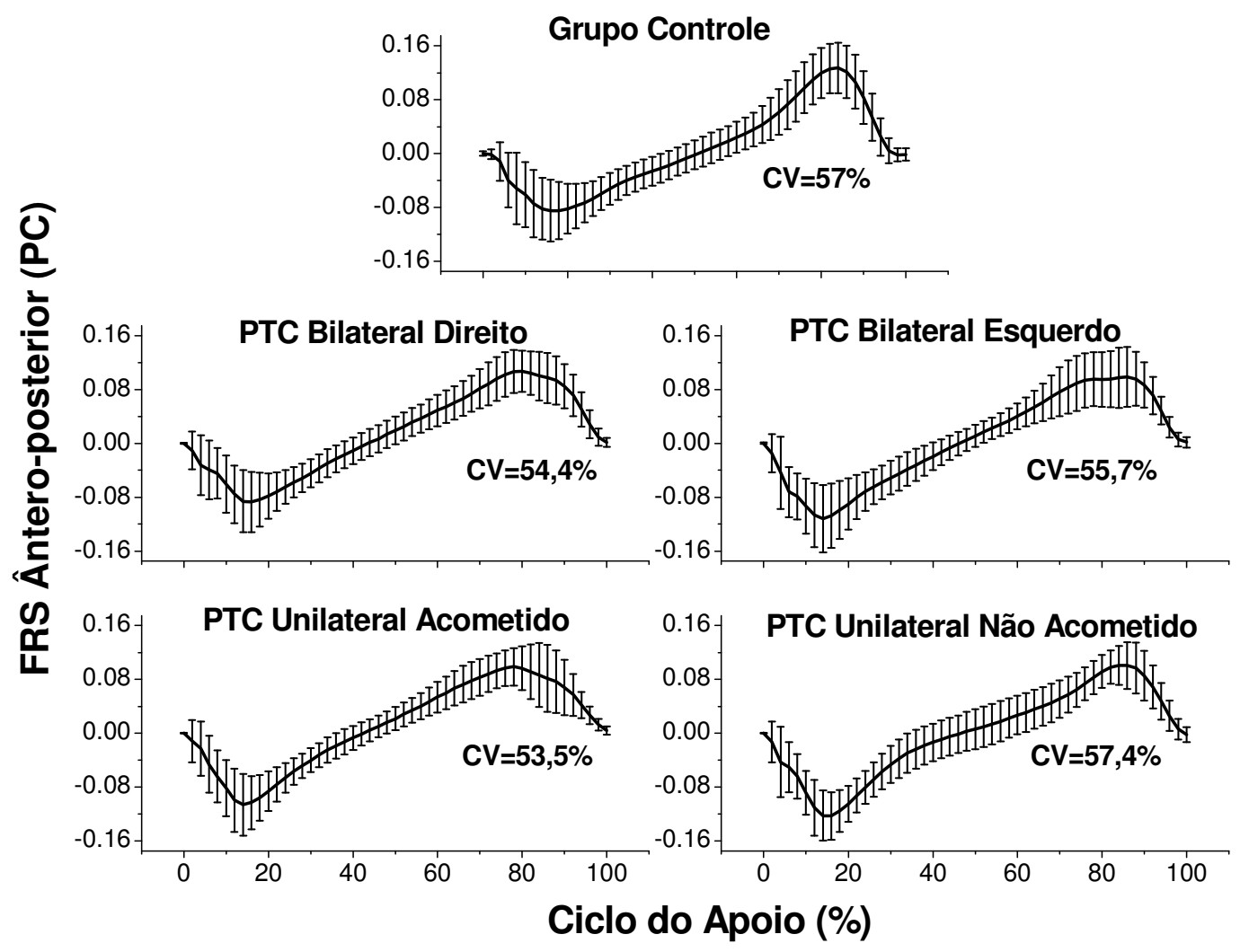

FIGURA 26 Ilustração das médias e desvios-padrão da FRS Ântero-posterior, com sua intensidade normalizada pelo peso corporal (PC), além do coeficiente de variação (CV), para a marcha auto-selecionada em todos os grupos analisados. Dados normalizados na base do tempo, tendo todo o ciclo da fase de apoio $100 \%$. 
A componente médio-lateral apresentou dois picos de força durante o apoio, representados por valores positivos, com uma pequena fase negativa na retirada do pé do solo, de acordo com o descrito por STANSFIELD et al. em 2001. (FIGURA 27).

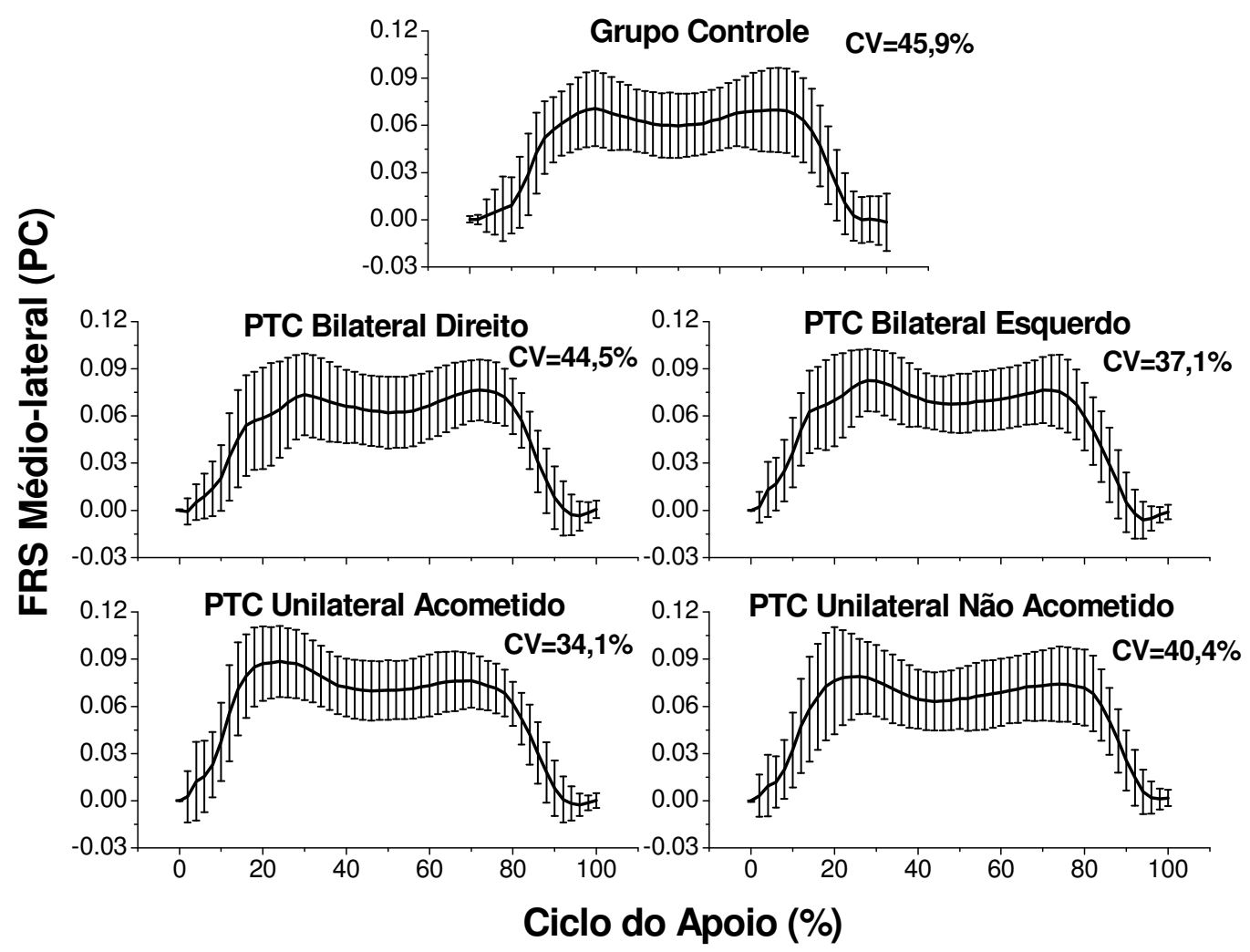

FIGURA 27 - Ilustração das médias e desvios-padrão da FRS Médio-lateral, com sua intensidade normalizada pelo peso corporal (PC), além do coeficiente de variação (CV), para a marcha auto-selecionada em todos os grupos analisados. Dados normalizados na base do tempo, tendo todo o ciclo da fase de apoio $100 \%$. 
A FIGURA 28 apresenta as curvas médias e desvios-padrão da variação angular na articulação do tornozelo. A partir do início do contato com o solo, há um aumento da flexão plantar até, em média, 10\% do ciclo do apoio, momento este em que se inicia a dorsiflexão. Na fase final do contato do pé com o solo, pode-se notar novamente uma característica de flexão plantar, não evidenciado, nessa curva média, para os grupos com acometimento unilateral.

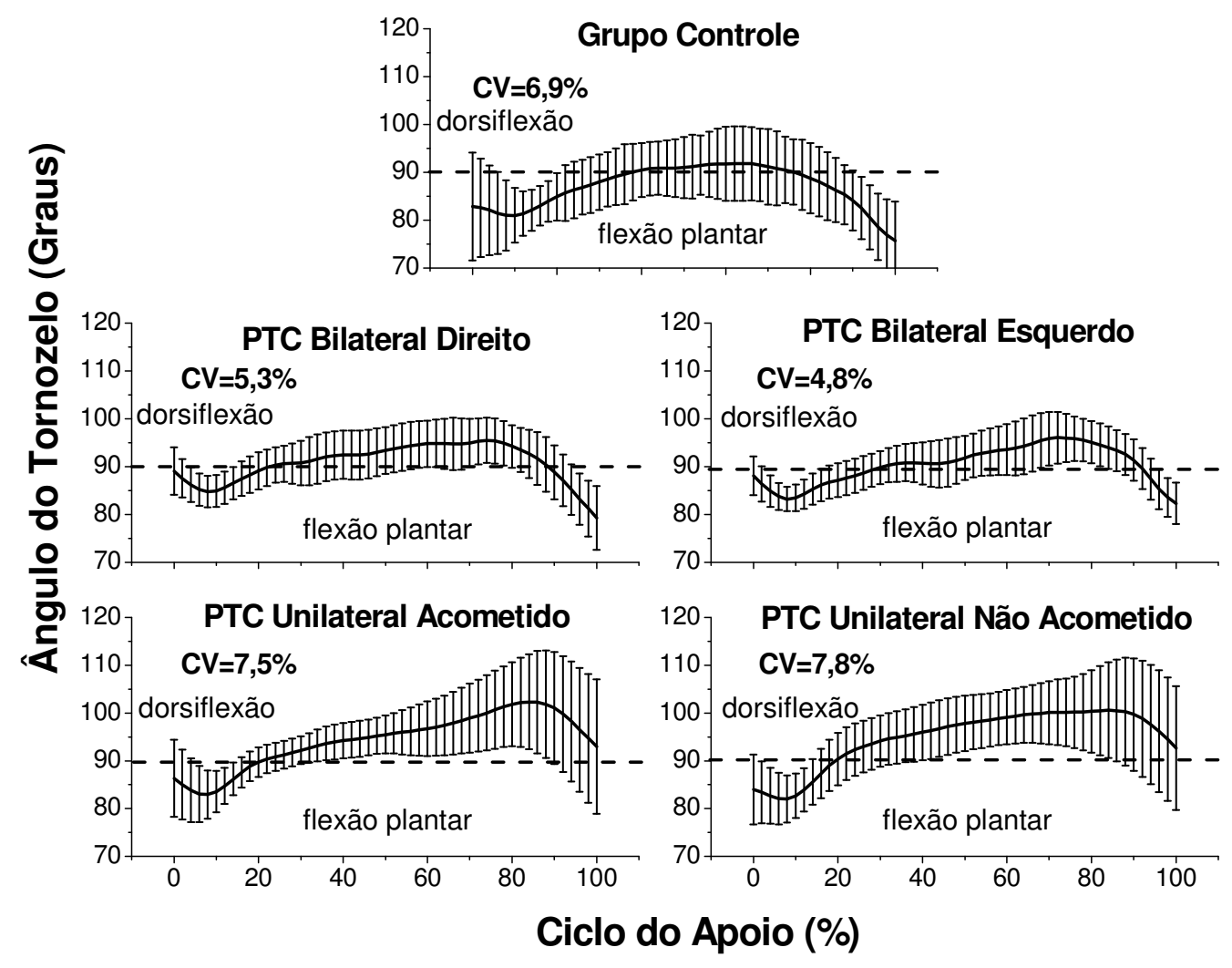

FIGURA 28 - Ilustração das médias e desvios-padrão da variação angular da articulação do tornozelo, além do coeficiente de variação (CV), para a marcha autoselecionada em todos os grupos analisados. 
Como encontrado na articulação do tornozelo, nota-se que as curvas de variação angular da articulação do joelho apresentaram um formato muito similar entre os grupos (FIGURA 29). De forma geral, no momento de contato do pé com o solo, as crianças possuem um posicionamento articular do joelho em torno de $10^{\circ}$ de flexão, aumentando essa angulação ainda nessa fase inicial do apoio. Após, o joelho estende e, em seguida, atinge o máximo de flexão no final do apoio.

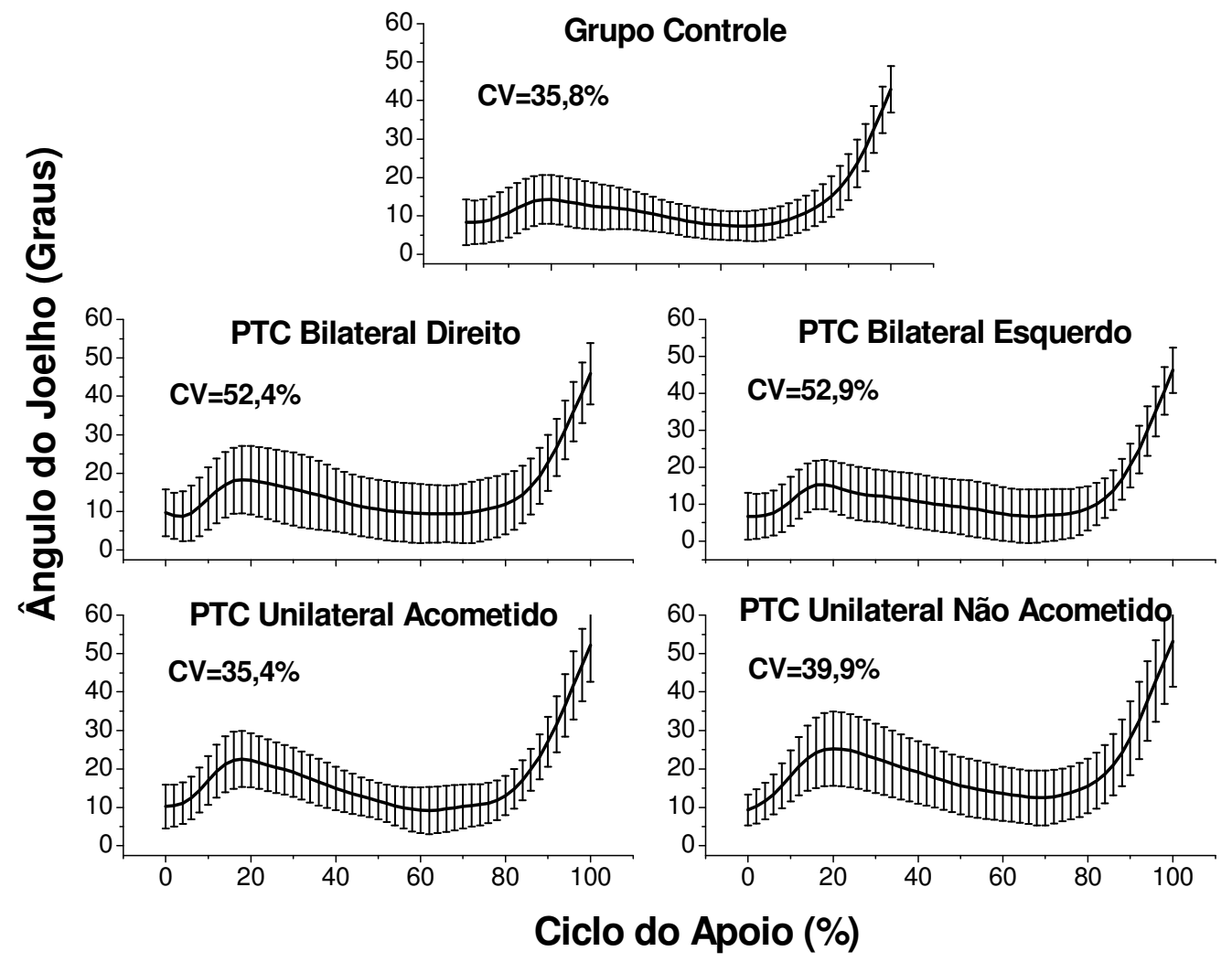

FIGURA 29 - Ilustração das médias e desvios-padrão da variação angular da articulação do joelho, além do coeficiente de variação (CV), para a marcha autoselecionada em todos os grupos analisados. 
Por meio do teste Kruskal-Wallis, foram encontradas diferenças significativas para todas as variáveis selecionadas da marcha (TABELA 22).

TABELA 22 - Dados referentes aos parâmetros analisados, após a análise dos componentes principais, da marcha auto-selecionada, nas comparações entre os grupos: Controle (Cont.), PTC com acometimento bilateral lado direito (Bil. D.), PTC com acometimento bilateral lado esquerdo (Bil. E.), PTC com acometimento unilateral lado acometido (Acom.) e PTC com acometimento unilateral lado não acometido ( $\tilde{\mathrm{N}}$ Acom.).

\begin{tabular}{|c|c|c|c|c|c|}
\hline Variáveis & Grupos & Média & Desvio Padrão & Tamanho & $p$-valor \\
\hline \multirow{5}{*}{$\begin{array}{l}\text { Fz } 2 \\
\text { (PC) }\end{array}$} & Acom. & 0,960 & 0,055 & 35 & \multirow{5}{*}{$<0,001^{*}$} \\
\hline & Bil. D. & 1,008 & 0,077 & 35 & \\
\hline & Bil. E. & 0,996 & 0,045 & 35 & \\
\hline & Cont. & 1,063 & 0,064 & 100 & \\
\hline & $\tilde{\mathrm{N}}$ Acom. & 0,979 & 0,066 & 35 & \\
\hline \multirow{5}{*}{$\begin{array}{l}\mathrm{TC} 1 \\
(\mathrm{PC} / \mathrm{s})\end{array}$} & Acom. & 9,06 & 2,39 & 35 & \multirow{5}{*}{$<0,001^{*}$} \\
\hline & Bil. D. & 7,67 & 2,44 & 35 & \\
\hline & Bil. E. & 8,55 & 2,18 & 35 & \\
\hline & Cont. & 6,14 & 3,42 & 100 & \\
\hline & $\tilde{\mathrm{N}}$ Acom. & 9,48 & 2,11 & 35 & \\
\hline \multirow{5}{*}{$\begin{array}{l}\text { Fy_min } \\
(P C)\end{array}$} & Acom. & $-0,1117$ & 0,044 & 35 & \multirow{5}{*}{$0,001^{*}$} \\
\hline & Bil. D. & $-0,0959$ & 0,039 & 35 & \\
\hline & Bil. E. & $-0,1246$ & 0,046 & 35 & \\
\hline & Cont. & $-0,1114$ & 0,049 & 100 & \\
\hline & $\tilde{\mathrm{N}}$ Acom. & $-0,1332$ & 0,035 & 35 & \\
\hline \multirow{5}{*}{$\begin{array}{l}\text { I_prop } \\
\text { (PC.s) }\end{array}$} & Acom. & 0,0163 & 0,003 & 35 & \multirow{5}{*}{$<0,001^{*}$} \\
\hline & Bil. D. & 0,0162 & 0,006 & 35 & \\
\hline & Bil. E. & 0,0157 & 0,005 & 35 & \\
\hline & Cont. & 0,0229 & 0,006 & 100 & \\
\hline & $\tilde{N}$ Acom. & 0,0140 & 0,004 & 35 & \\
\hline \multirow{5}{*}{$\begin{array}{c}\text { cine_joelho2 } \\
\text { (Graus) }\end{array}$} & Acom. & 20,94 & 6,78 & 35 & \multirow{5}{*}{$<0,001^{*}$} \\
\hline & Bil. D. & 15,80 & 8,94 & 35 & \\
\hline & Bil. E. & 13,26 & 7,16 & 35 & \\
\hline & Cont. & 13,19 & 5,97 & 100 & \\
\hline & $\tilde{\mathrm{N}}$ Acom. & 25,53 & 9,29 & 35 & \\
\hline
\end{tabular}

${ }^{*} \mathrm{p}$-valor considerado estatisticamente significativo perante o nível de significância adotado $(\mathrm{p} \leq$ $0,05)$; No anexo IV, encontram-se os resultados para as outras variáveis não selecionadas a partir da ACP. 
TABELA 22 - Dados referentes aos parâmetros analisados, após a análise dos componentes principais, da marcha auto-selecionada, nas comparações entre os grupos: Controle (Cont.), PTC com acometimento bilateral lado direito (Bil. D.), PTC com acometimento bilateral lado esquerdo (Bil. E.), PTC com acometimento unilateral lado acometido (Acom.) e PTC com acometimento unilateral lado não acometido (Ñ Acom.). (cont.).

\begin{tabular}{|c|c|c|c|c|c|}
\hline Variáveis & Grupos & Média & Desvio Padrão & Tamanho & p-valor \\
\hline \multirow{5}{*}{ cine_joelho3 } & Acom. & 12,93 & 5,02 & 35 & \multirow{5}{*}{$<0,001^{*}$} \\
\hline & Bil. D. & 9,42 & 5,53 & 35 & \\
\hline & Bil. E. & 8,84 & 6,48 & 35 & \\
\hline & Cont. & 9,72 & 4,58 & 100 & \\
\hline & $\tilde{\mathrm{N}}$ Acom. & 17,58 & 8,08 & 35 & \\
\hline \multirow{5}{*}{$\begin{array}{l}\text { cine_joelho4 } \\
\text { (Graus) }\end{array}$} & Acom. & 10,39 & 6,17 & 35 & \multirow{5}{*}{$<0,001^{*}$} \\
\hline & Bil. D. & 9,20 & 7,47 & 35 & \\
\hline & Bil. E. & 7,58 & 6,69 & 35 & \\
\hline & Cont. & 8,71 & 4,10 & 100 & \\
\hline & $\tilde{N}$ Acom. & 14,25 & 7,41 & 35 & \\
\hline \multirow{5}{*}{$\begin{array}{c}\text { cine_tornozelo2 } \\
\text { (Graus) }\end{array}$} & Acom. & 90,66 & 3,58 & 35 & \multirow{5}{*}{$<0,001^{*}$} \\
\hline & Bil. D. & 91,09 & 4,22 & 35 & \\
\hline & Bil. E. & 88,05 & 3,39 & 35 & \\
\hline & Cont. & 87,97 & 3,94 & 100 & \\
\hline & $\tilde{N}$ Acom. & 91,69 & 4,97 & 35 & \\
\hline \multirow{5}{*}{$\begin{array}{c}\text { cine_tornozelo3 } \\
\text { (Graus) }\end{array}$} & Acom. & 94,26 & 4,03 & 35 & \multirow{5}{*}{$<0,001^{*}$} \\
\hline & Bil. D. & 93,18 & 5,44 & 35 & \\
\hline & Bil. E. & 91,02 & 4,51 & 35 & \\
\hline & Cont. & 91,03 & 4,18 & 100 & \\
\hline & $\tilde{N}$ Acom. & 96,27 & 5,85 & 35 & \\
\hline \multirow{5}{*}{$\begin{array}{c}\text { cine_tornozelo4 } \\
\text { (Graus) }\end{array}$} & Acom. & 97,66 & 7,47 & 35 & \multirow{5}{*}{$<0,001^{*}$} \\
\hline & Bil. D. & 95,75 & 5,91 & 35 & \\
\hline & Bil. E. & 95,17 & 5,21 & 35 & \\
\hline & Cont. & 91,24 & 5,95 & 100 & \\
\hline & $\tilde{\mathrm{N}}$ Acom. & 99,72 & 7,07 & 35 & \\
\hline
\end{tabular}

${ }^{*} \mathrm{p}$-valor considerado estatisticamente significativo perante o nível de significância adotado $(\mathrm{p} \leq$ $0,05)$; No anexo IV, encontram-se os resultados para as outras variáveis não selecionadas a partir da ACP. 
Diante disso, foi determinado, com exatidão, qual grupo foi diferente dos demais e, para isso, foi utilizado o teste de Mann-Whitney. Todos esses resultados (p-valor) entre os grupos, apresentados no ANEXO IV (TABELA 44) estão descritos a seguir.

Para a Taxa de crescimento 1, foi encontrado um menor valor para o grupo Controle $(6,14 \pm 3,42 \mathrm{PC} / \mathrm{s})$, comparado com os demais grupos. $\mathrm{Na}$ comparação entre os grupos com PTC, nota-se que tanto o lado acometido $(9,06 \pm 2,39 \mathrm{PC} / \mathrm{s})$, quanto o não acometido $(9,48 \pm 2,11 \mathrm{PC} / \mathrm{s})$ do grupo PTC unilateral são maiores do que o PTC bilateral direito $(7,67 \pm 2,44$ PC/s) (FIGURA 30).

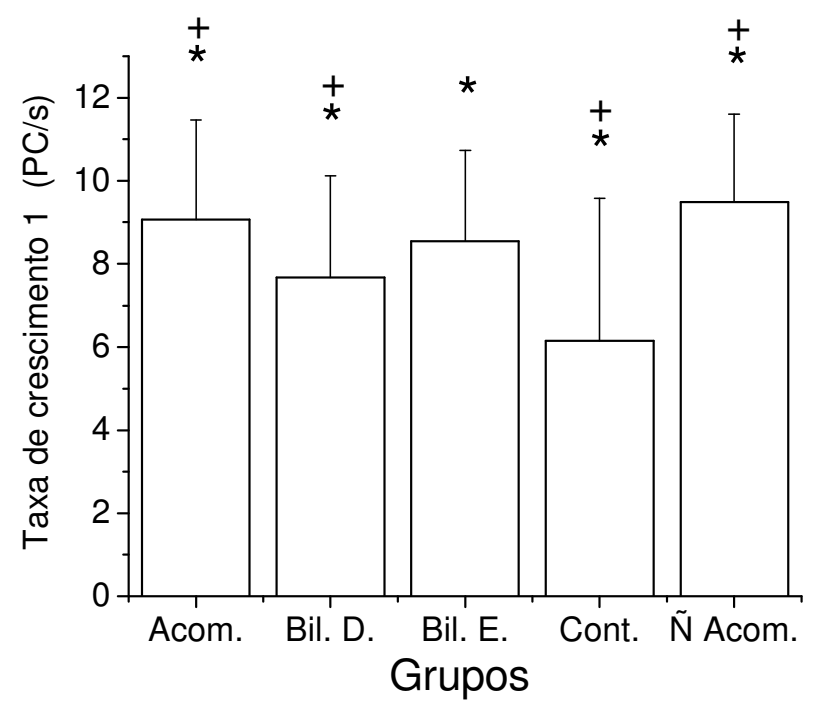

FIGURA 30 - Gráfico referente ao parâmetro taxa de crescimento 1 (TC 1) da FRS vertical para os grupos avaliados: Controle (Cont.), PTC com acometimento bilateral lado direito (Bil. D.), PTC com acometimento bilateral lado esquerdo (Bil. E.), PTC com acometimento unilateral lado acometido

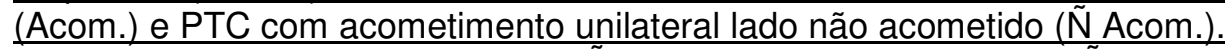
${ }^{*}$ Cont. < Acom. / Bil.D. / Bil.E. / Ñ Acom.; ${ }^{+}$Bil. D. < Acom./ Ñ Acom. $(\mathrm{p}<0,05)$. 
No primeiro pico da FRS ântero-posterior (Fy_min), os maiores valores

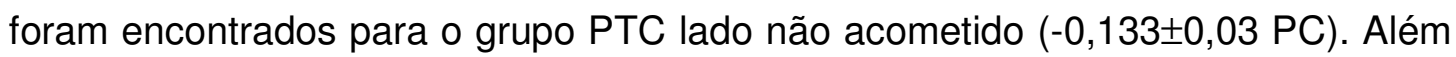
disso, foram encontradas diferenças significativas entre os lados do grupo PTC bilateral, com valores maiores para o lado esquerdo $(-0,125 \pm 0,04 \mathrm{PC})$, comparado

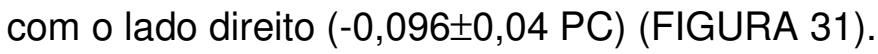

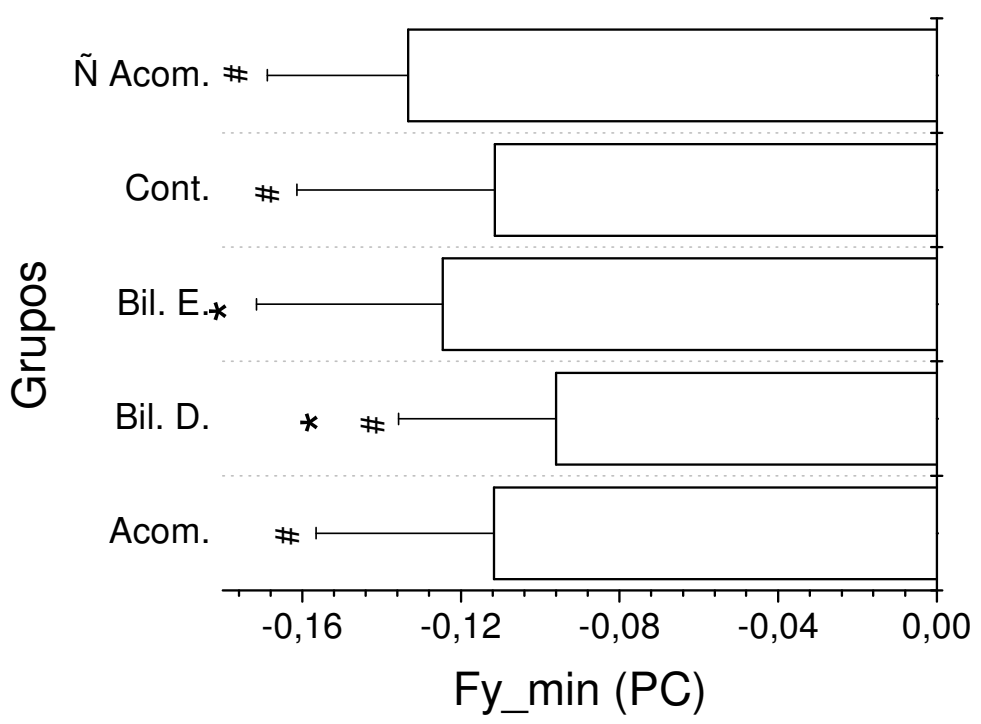

FIGURA 31 - Gráfico referente ao parâmetro Fy min da FRS ântero-posterior para os grupos avaliados: Controle (Cont.), PTC com acometimento bilateral lado direito (Bil. D.), PTC com acometimento bilateral lado esquerdo (Bil. E.), PTC com acometimento unilateral lado acometido (Acom.) e PTC com

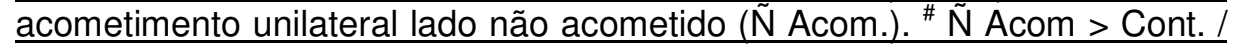
Acom. / Bil. D.; * Bil. D. < Bil. E. $(p<0,05)$. 
Ainda referente à fase inicial do apoio, no instante de máxima magnitude de força vertical $(F z 1)$, os grupos PTC unilateral (lado acometido = $90,7 \pm 3,6^{\circ}$ e lado não acometido $\left.=91,7 \pm 4,9^{\circ}\right)$ e PTC bilateral direito $\left(91,1 \pm 4,2^{\circ}\right)$ tiveram uma característica angular em posição neutra do tornozelo. Os grupos Controle $\left(88 \pm 3,9^{\circ}\right)$ e PTC bilateral esquerdo $\left(88^{\circ} \pm 3,4\right)$ tiveram uma catacterística de pequena flexão plantar (FIGURA 32).

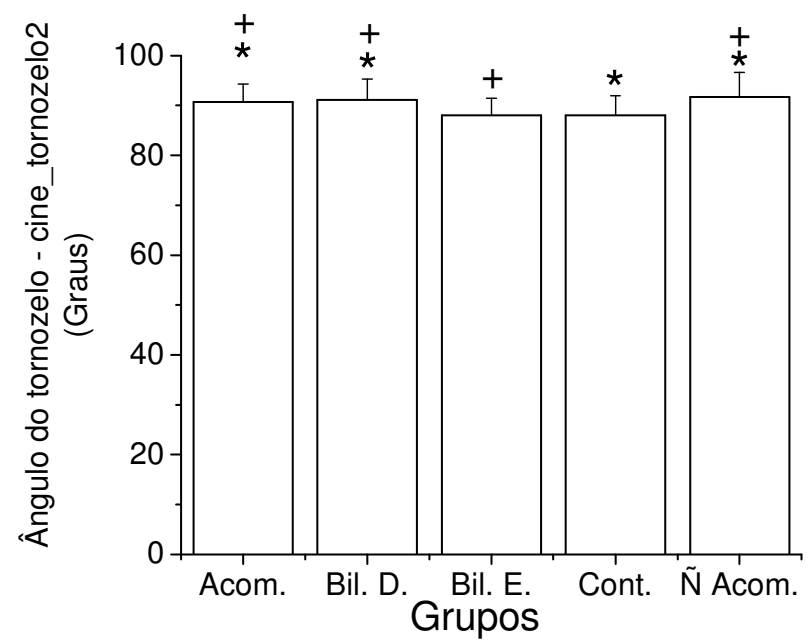

FIGURA 32 - Gráfico referente ao ângulo do tornozelo no instante de máxima magnitude de força vertical na fase inicial do apoio da marcha (cine tornozelo2) para os grupos avaliados: Controle (Cont.), PTC com acometimento bilateral lado direito (Bil. D.), PTC com acometimento bilateral lado esquerdo (Bil. E.), PTC com acometimento unilateral lado acometido (Acom.) e PTC com

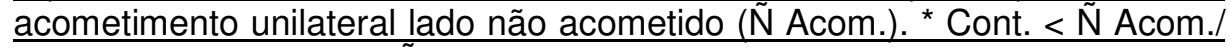
Acom./ Bil.D.; ${ }^{+}$Bil. E. < Ñ Acom./ Acom./ Bil.D. $(p<0,05)$. 
$\mathrm{Na}$ articulação do joelho, os maiores valores encontrados foram para os Grupos de PTC unilateral (lado acometido $=20,9 \pm 6,8^{\circ}$; lado não acometido $=$ $25,5 \pm 9,2^{\circ}$ ), quando comparados com os demais grupos (Controle $=13,2 \pm 5,9^{\circ}$; PTC bilateral lado direito $=15,8 \pm 9,0^{\circ}$ e lado esquerdo $\left.=13,3 \pm 4,9^{\circ}\right)($ FIGURA 33).

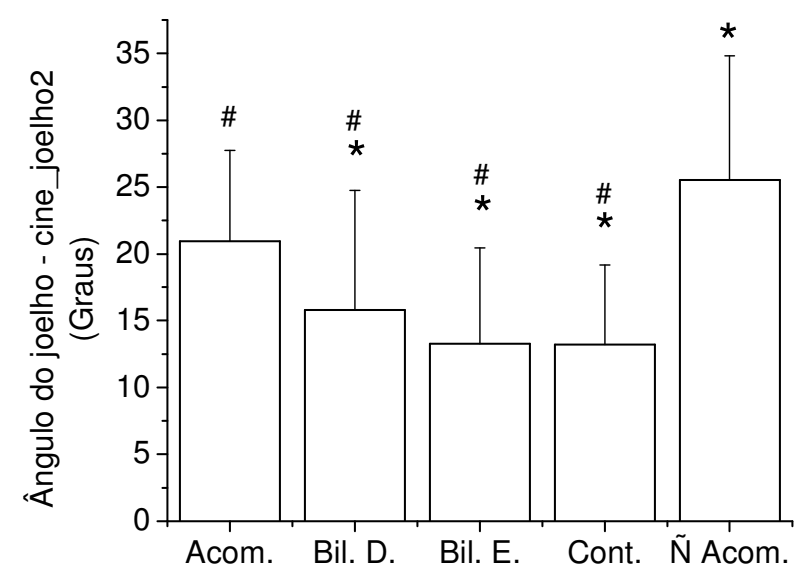

Grupos

FIGURA 33 - Gráfico referente ao ângulo do joelho no instante de máxima magnitude de força vertical na fase inicial do apoio da marcha (cine joelho2) para os grupos avaliados: Controle (Cont.), PTC com acometimento bilateral lado direito (Bil. D.), PTC com acometimento bilateral lado esquerdo (Bil. E.), PTC com acometimento unilateral lado acometido (Acom.) e PTC com

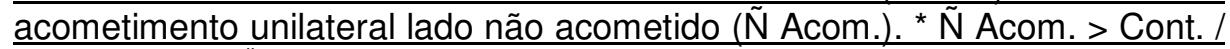
Bil. D./ Bil. E.; ${ }^{\#}$ Acom. > Cont. / Bil. D./ Bil. E $(p<0,05)$. 
Na fase de médio apoio, quando acontece a deflexão da FRS vertical (Fz min), as crianças com PTC unilateral apresentaram maior dorsiflexão (lado não acometido $=96,3 \pm 5,8^{\circ}$, lado acometido $=94,3 \pm 4^{\circ}$ ), quando comparados com o Controle $\left(91 \pm 4^{\circ}\right)$ e com o grupo PTC bilateral esquerdo $\left(91 \pm 5^{\circ}\right)$; esses dois praticamente permaneceram em posição neutra (FIGURA 34).

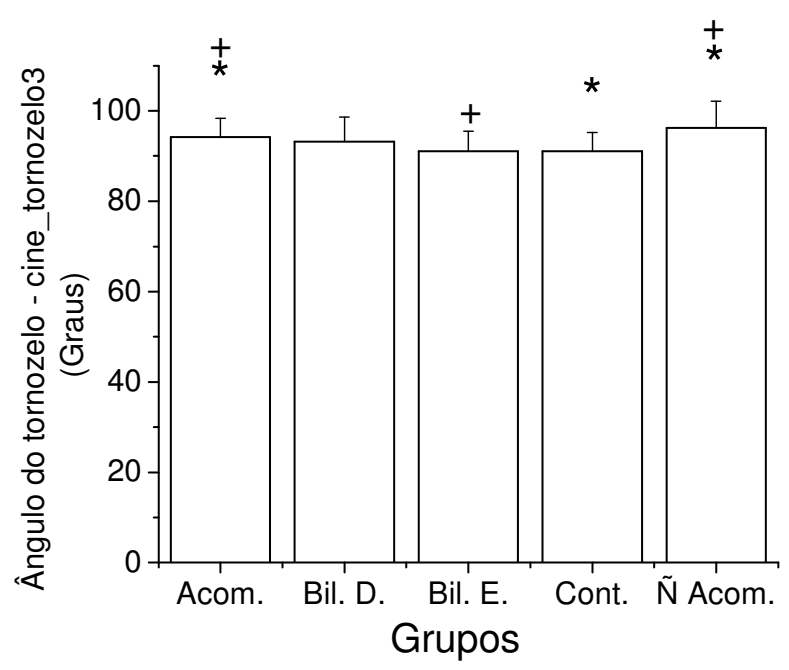

FIGURA 34 - Gráfico referente ao ângulo do tornozelo no instante de deflexão da força vertical na fase de médio apoio da marcha (cine tornozelo3) para os grupos avaliados: Controle (Cont.), PTC com acometimento bilateral lado direito (Bil. D.), PTC com acometimento bilateral lado esquerdo (Bil. E.), PTC com acometimento unilateral lado acometido (Acom.) e PTC com

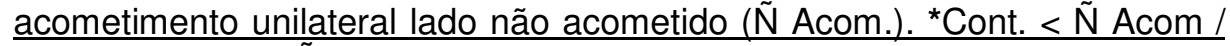
Acom; ${ }^{+}$Bil. E. $<\tilde{N}$ Acom / Acom $(p<0,05)$. 
Nessa fase, para a articulação do joelho, também foram encontrados maiores valores angulares para os grupos com PTC unilateral (lado não acometido $=17,6 \pm 8,1^{\circ}$ e lado acometido $=12,9 \pm 5^{\circ}$ ), quando comparados com o Controle $\left(9,7 \pm 4,5^{\circ}\right)$ e com os grupos PTC bilateral (direito $=9,4 \pm 5,6^{\circ}$ e esquerdo $=8,8 \pm 6,4^{\circ}$ ) (FIGURA 35).

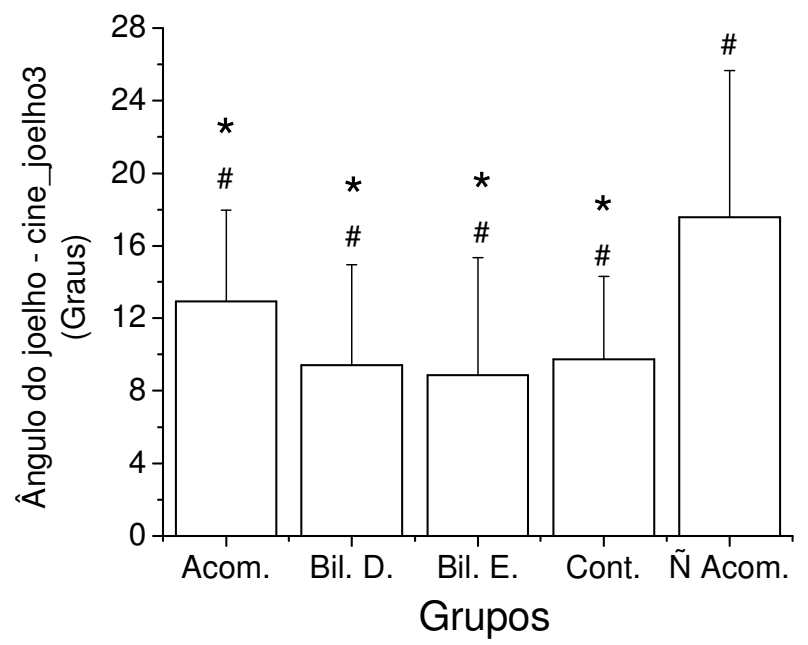

FIGURA 35 - Gráfico referente ao ângulo do joelho no instante de deflexão da força vertical na fase de médio apoio da marcha (cine joelho3) para os grupos avaliados: Controle (Cont.), PTC com acometimento bilateral lado direito (Bil. D.), PTC com acometimento bilateral lado esquerdo (Bil. E.), PTC com acometimento unilateral lado acometido (Acom.) e PTC com acometimento

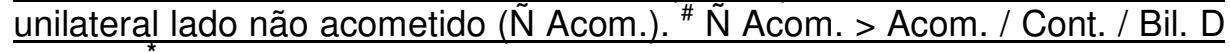
/ Bil. E.; ${ }^{*}$ Acom > Cont. / Bil. D. / Bil. E. $(p<0,05)$. 
Para o segundo pico da FRS vertical ( $F z$ 2), o grupo Controle $(1,063 \pm 0,06$ PC) apresentou maiores valores quando comparado com os demais grupos. Na comparação entre os grupos de PTC, nota-se que o resultado apresentado para o lado acometido do Grupo PTC unilateral $(0,96 \pm 0,05$ PC) foi menor do que para o lado direito e esquerdo do grupo Bilateral $(1,01 \pm 0,07$ PC e 1,0 $\pm 0,04$ PC, respectivamente) (FIGURA 36).

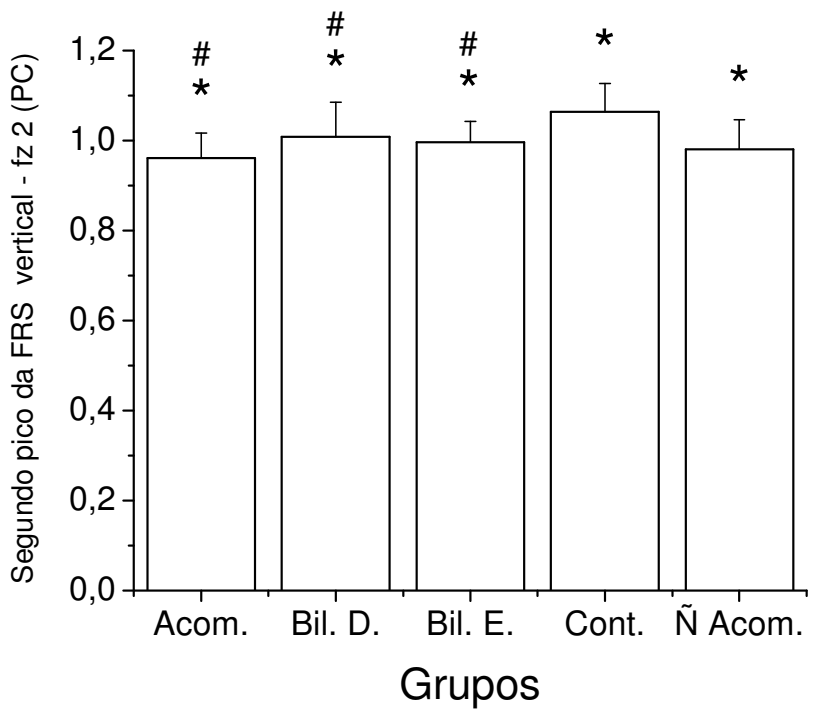

FIGURA 36 - Gráfico referente segundo pico da FRS vertical (fz 2) da FRS ânteroposterior para os grupos avaliados: Controle (Cont.), PTC com acometimento bilateral lado direito (Bil. D.), PTC com acometimento bilateral lado esquerdo (Bil. E.), PTC com acometimento unilateral lado acometido (Acom.) e PTC com acometimento unilateral lado não acometido

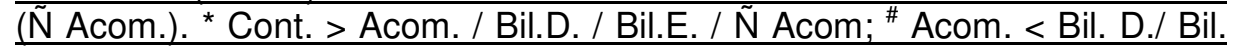
E. $(p<0,05)$. 
Durante esta fase propulsiva, foram encontrados maiores valores no parâmetro impulso de propulsão (I_prop) no grupo Controle $(0,023 \pm 0,006$ PC.s), quando comparado com os outros grupos: PTC bilateral direito $(0,016 \pm 0,006$ PC.s), PTC bilateral esquerdo (0,016 $\pm 0,005$ PC.s), PTC unilateral lado acometido

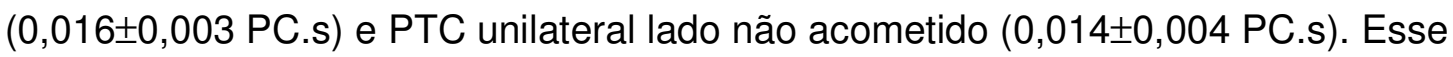
último apresentou o menor valor (FIGURA 37).

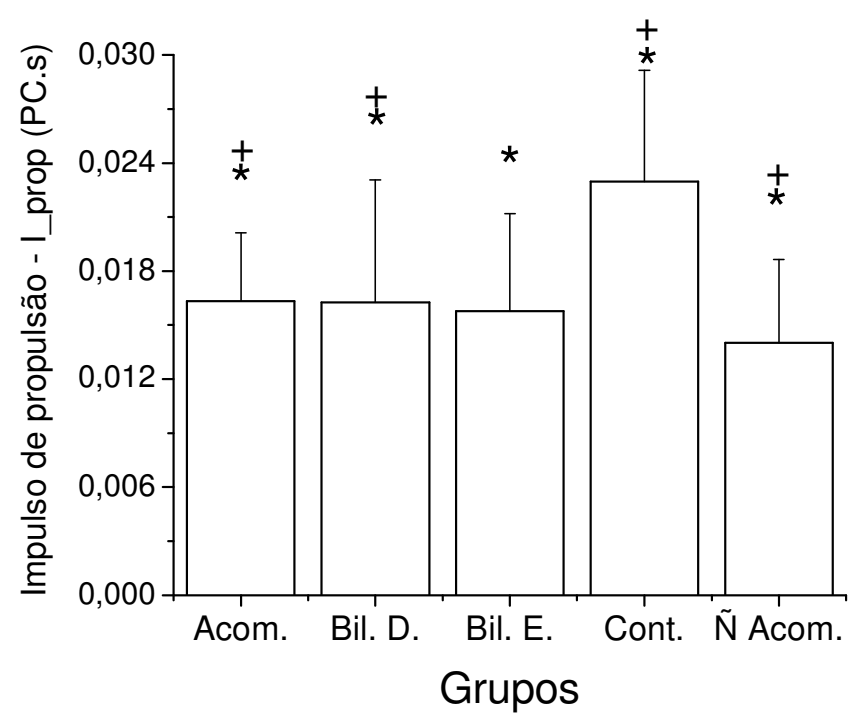

FIGURA 37 - Gráfico referente ao impulso de propulsão (I prop) da FRS ântero-posterior para os grupos avaliados: Controle (Cont.), PTC com acometimento bilateral lado direito (Bil. D.), PTC com acometimento bilateral lado esquerdo (Bil. E.), PTC com acometimento unilateral lado acometido (Acom.) e PTC com acometimento unilateral lado não acometido ( $\tilde{N}$ Acom.). ${ }^{*}$ Cont. > N Acom/ Acom. / Bil.D. / Bil.E.; ${ }^{+} \tilde{N}$ Acom < Acom. / Bil.D / Cont. $(p<0,05)$. 
No instante do segundo pico da FRS vertical, o ângulo do tornozelo obteve maior dorsiflexão para os grupos com PTC unilateral (lado não acometido = $99,7 \pm 5,9^{\circ}$ e lado acometido $=97,7 \pm 7,5^{\circ}$ ) e PTC bilateral (lados direito $=95,8 \pm 6^{\circ} \mathrm{e}$ lado esquerdo $\left.=95 \pm 5^{\circ}\right)$, comparados com o Controle $\left(91,2 \pm 5,9^{\circ}\right)$, o qual permaneceu praticamente em posição neutra. Nota-se também que o lado não acometido do grupo com PTC unilateral obteve maior dorsiflexão do que os grupos com PTC bilateral (FIGURA 38).

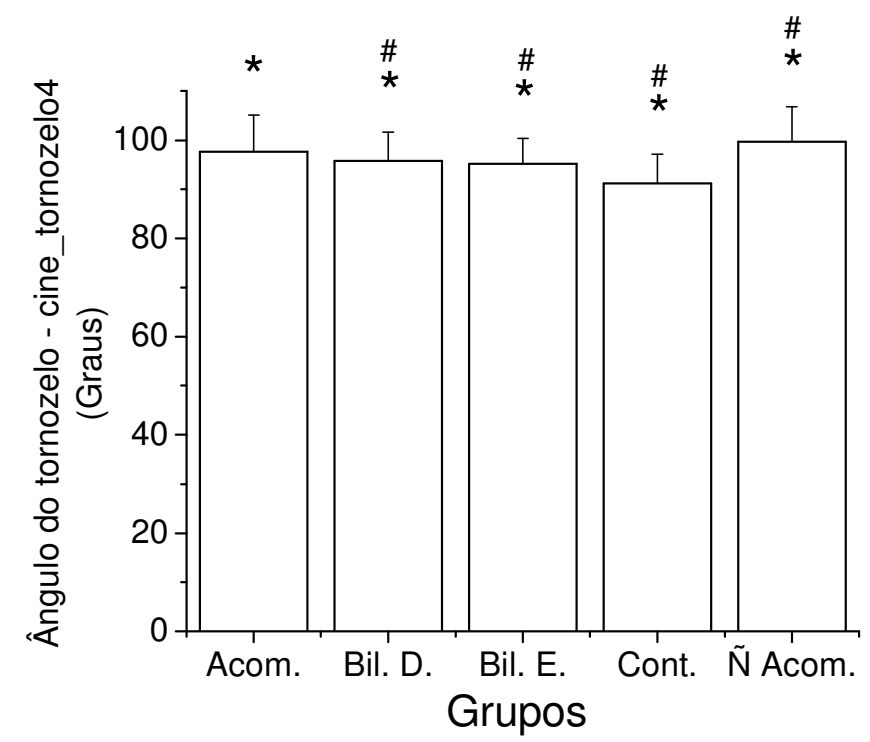

FIGURA 38 - Gráfico referente ao ângulo do tornozelo no instante do segundo pico da FRS vertical na fase de apoio da marcha (cine tornozelo4) para os grupos avaliados: Controle (Cont.), PTC com acometimento bilateral lado direito (Bil. D.), PTC com acometimento bilateral lado esquerdo (Bil. E.), PTC com acometimento unilateral lado acometido (Acom.) e PTC com acometimento

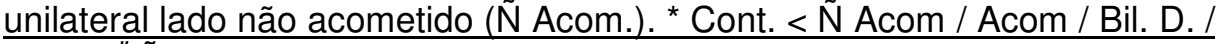
Bil. E.; "N. N Acom. > Bil. D. / Bil. E. / Cont. $(p<0,05)$. 
Para a articulação do joelho, a maior flexão foi encontrada no grupo PTC unilateral lado não acometido $\left(14,2 \pm 7,4^{\circ}\right)$, quando comparado com todos os demais grupos: Controle $\left(8,7 \pm 4,1^{\circ}\right)$, PTC unilateral lado acometido $\left(10,4 \pm 6,2^{\circ}\right)$, PTC bilateral direito $\left(9,2 \pm 7,5^{\circ}\right)$ e PTC bilateral esquerdo $\left(7,6 \pm 6,7^{\circ}\right)$. Esse último obteve o menor valor (FIGURA 39).

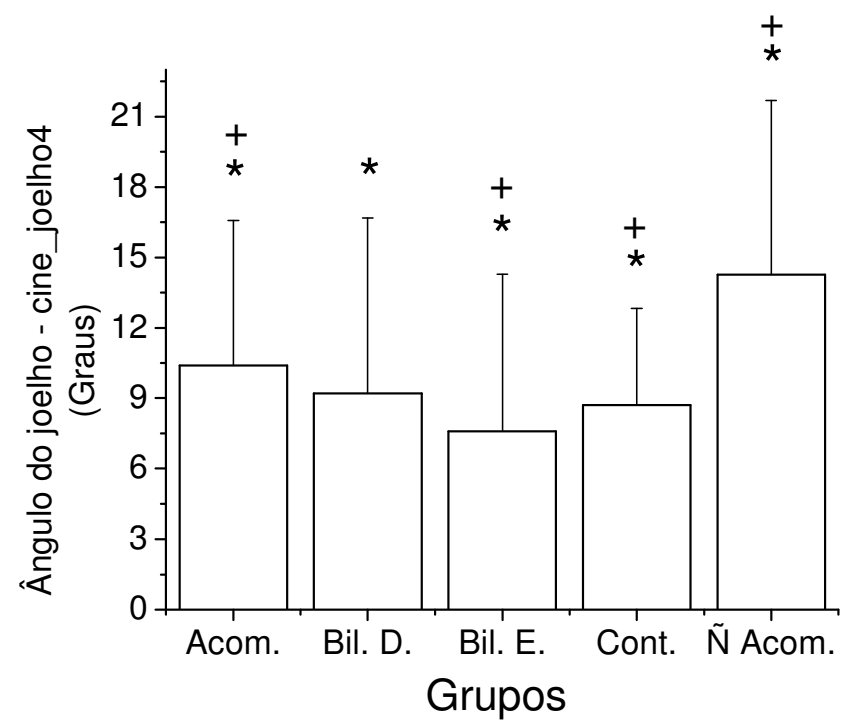

FIGURA 39 - Gráfico referente ao ângulo do joelho no instante do segundo pico da FRS vertical na fase de apoio da marcha (cine joelho4) para os grupos avaliados: Controle (Cont.), PTC com acometimento bilateral lado direito (Bil. D.), PTC com acometimento bilateral lado esquerdo (Bil. E.), PTC com acometimento unilateral lado acometido (Acom.) e PTC com acometimento

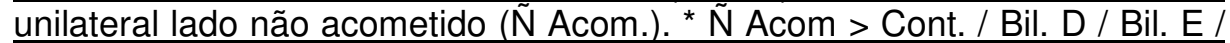
Acom.; ${ }^{+}$Bil. E. < Acom. / Cont. / Ñ Acom. $(p<0,05)$. 


\subsection{Análise do salto vertical com contra-movimento}

O CV, para os dados da FRS vertical, foram semelhantes entre os grupos; maiores na fase de aterrissagem se comparados com a fase de preparação (TABELA 23).

TABELA 23 - Apresentação do coeficiente de variação (CV) das curvas da FRS vertical nas fases de preparação e aterrissagem do salto vertical com contramovimento dos grupos avaliados.

\begin{tabular}{ccc}
\hline & \multicolumn{2}{c}{ CV FRS Vertical (\%) } \\
Grupos & Fase de Preparação & Fase de Aterrissagem \\
\hline Controle & 56,5 & 94,5 \\
PTC bilateral & 66,7 & 111,6 \\
PTC unilateral & 58,7 & 93,2 \\
\hline
\end{tabular}

Para os dados eletromiográficos, o CV foi semelhante entre os grupos, tanto para a fase de aterrissagem quanto para a preparação (TABELA 24).

TABELA 24 - Apresentação dos coeficientes de variação (CV) das atividades dos músculos gastrocnêmio medial e tibial anterior, nas fases de preparacão e aterrissagem do salto vertical com contra-movimento dos grupos avaliados: Controle (Cont.), PTC bilateral lado direito (Bil. D.), PTC bilateral lado esquerdo (Bil. E.), PTC unilateral lado acometido (Acom.) e PTC unilateral lado não acometido (Ñ Acom.).

\begin{tabular}{ccccc}
\hline & \multicolumn{2}{c}{ CV Músculo Gastrocnêmio Medial (\%) } & \multicolumn{2}{c}{ CV Músculo Tibial Anterior (\%) } \\
& Preparação & Aterrissagem & Preparação & Aterrissagem \\
\hline Cont. & 42,6 & 37,5 & 48,7 & 39,6 \\
Acom. & 44 & 37,9 & 44,2 & 28,8 \\
N Acom. & 39,5 & 47,8 & 44,8 & 39,7 \\
Bil. D. & 35,7 & 35,7 & 28,4 & 22,8 \\
Bil. E. & 41,1 & 51,4 & 31,2 & 30,8 \\
\hline
\end{tabular}


O CV para os dados de variação angular, seguiram as mesmas características das encontradas para a FRS, com maiores valores na fase de aterrissagem comparados com a fase de preparação, em ambas as articulações e para todos os grupos (TABELA 25).

TABELA 25 - Apresentação dos coeficientes de variação (CV) para as curvas de variação angular do joelho e tornozelo, nas fases de preparação e aterrissagem do salto vertical com contra-movimento dos grupos avaliados: Controle (Cont.), PTC bilateral lado direito (Bil. D.), PTC bilateral lado esquerdo (Bil. E.), PTC unilateral lado acometido (Acom.) e PTC unilateral lado não acometido (N Acom.).

\begin{tabular}{ccccc}
\hline & \multicolumn{2}{c}{ CV Ângulo Joelho (\%) } & \multicolumn{2}{c}{ CV Ângulo Tornozelo (\%) } \\
& Preparação & Aterrissagem & Preparação & Aterrissagem \\
\hline Cont. & 24,9 & 55 & 9 & 42,6 \\
Acom. & 22,4 & 39,4 & 10,7 & 44 \\
$\tilde{\mathbf{N}}$ Acom. & 23,1 & 42,7 & 8,3 & 39,5 \\
Bil. D. & 33,8 & 40,7 & 10,1 & 35,7 \\
Bil. E. & 38,3 & 46,2 & 10,3 & 41,1 \\
\hline
\end{tabular}


O comportamento das curvas médias de FRS e da variação angular em todos os grupos com história de PTC foram semelhantes às encontradas no grupo Controle. As características eletromiográficas apontam diferenças entre os grupos na fase de preparação para o músculo tibial anterior.

$\mathrm{Na}$ fase inicial da preparação do salto, a FRS vertical possui valores negativos. A partir de $50 \%$ dessa fase, iniciam-se valores positivos que atingem seu pico, em média, aos $80 \%$ do ciclo. Após isso, há diminuição da força, o que representa a retirada gradativa do contato dos pés com o solo (FIGURA 40).

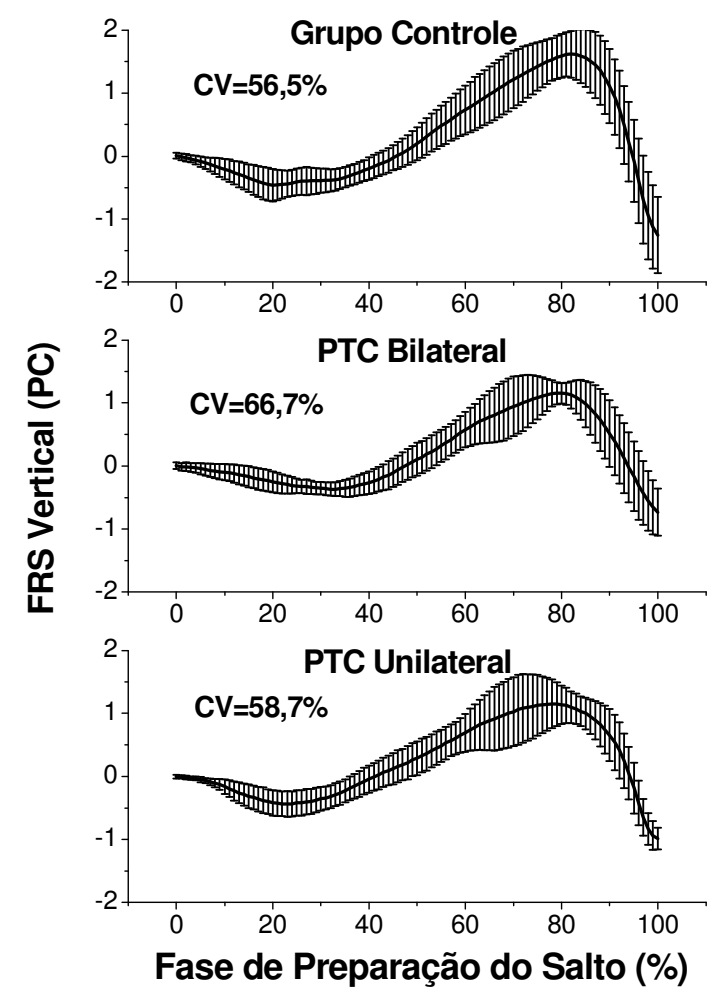

FIGURA 40 - Ilustração das médias e desvios padrão da FRS vertical, com suas intensidades normalizadas pelo peso corporal (PC), além do coeficiente de variação (CV), na fases de preparação do salto vertical com contramovimento, em todos os grupos analisados. 
Nessa fase de preparação, há um aumento gradativo da flexão do joelho e logo após, inicia-se a extensão até atingir sua máxima amplitude na fase final desse ciclo (FIGURA 41).

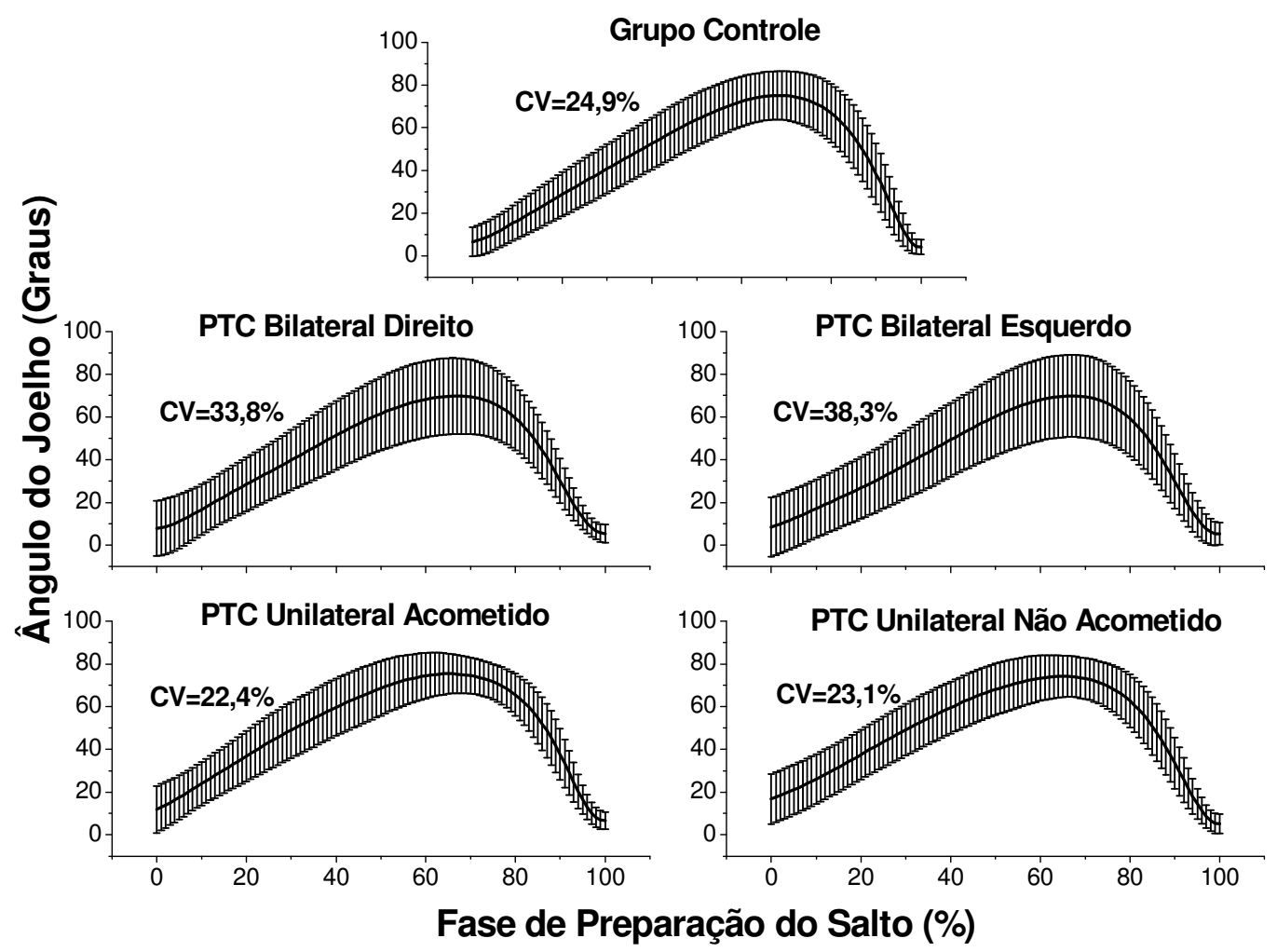

FIGURA 41 - Ilustração das médias e desvios padrão da variação angular na articulação do joelho durante a fase de preparação do salto vertical com contramovimento, além do coeficiente de variação (CV), em todos os grupos analisados. 
Acompanhando a flexão do joelho, no início do movimento do salto, há o aumento da dorsiflexão do tornozelo e no final do ciclo, inicia-se a flexão plantar que alcança seu valor máximo no final desse evento (FIGURA 42).

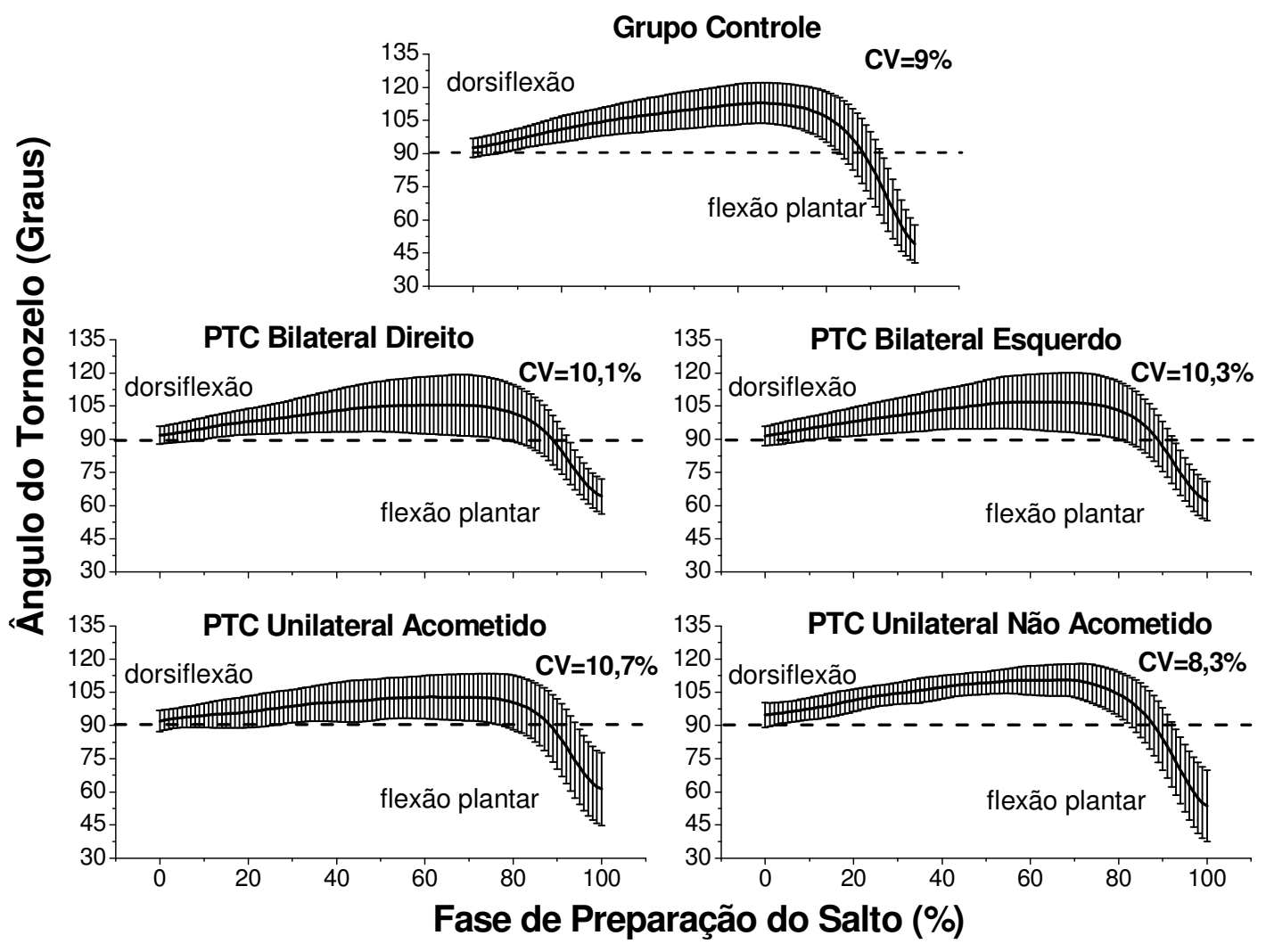

FIGURA 42 - Ilustração das médias e desvios padrão da variação angular na articulação do tornozelo durante a fase de preparação do salto vertical com contramovimento, além do coeficiente de variação (CV), em todos os grupos analisados. 
O músculo gastrocnêmio medial, na fase de preparação, apresenta um único pulso de ação a partir de $50 \%$ do ciclo, com o pico de sua atividade próximo a $80 \%$ desse ciclo (FIGURA 43).

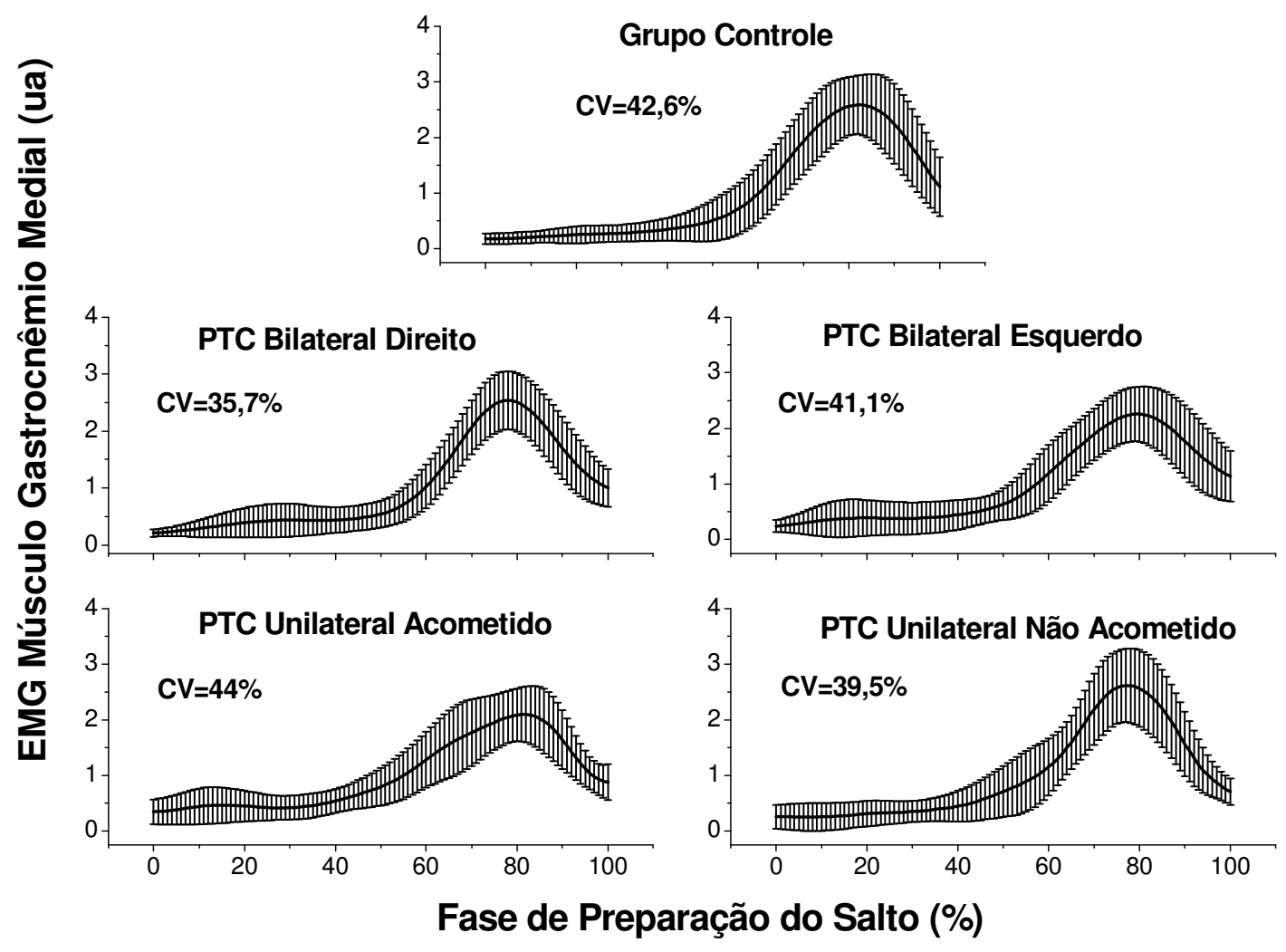

FIGURA 43 - Ilustração das médias e desvios padrão da atividade eletromiográfica do músculo gastrocnêmio medial, normalizados pela média do sinal, na fase de preparação do salto vertical com contra-movimento, além do coeficiente de variação (CV), em todos os grupos analisados. 
O músculo tibial anterior, na fase de preparação, apresenta características semelhantes na comparação entre os resultados do grupo Controle e PTC bilateral. Nesses casos, o músculo encontra-se ativo no início dessa fase; logo após, atinge o pico de ação e, a partir desse momento, há um decréscimo de sua intensidade que alcança seus menores valores em torno de $50 \%$ do ciclo. No lado acometido do grupo PTC unilateral, não há uma ativação aparente no início do movimento, com um pulso apenas a partir de $70 \%$ do ciclo. O grupo PTC unilateral, lado não acometido, inicia-se nessa fase ativo e mantém-se até $80 \%$ do ciclo; logo após, inicia-se um segundo pulso o qual dura até o fim desta fase (FIGURA 44).

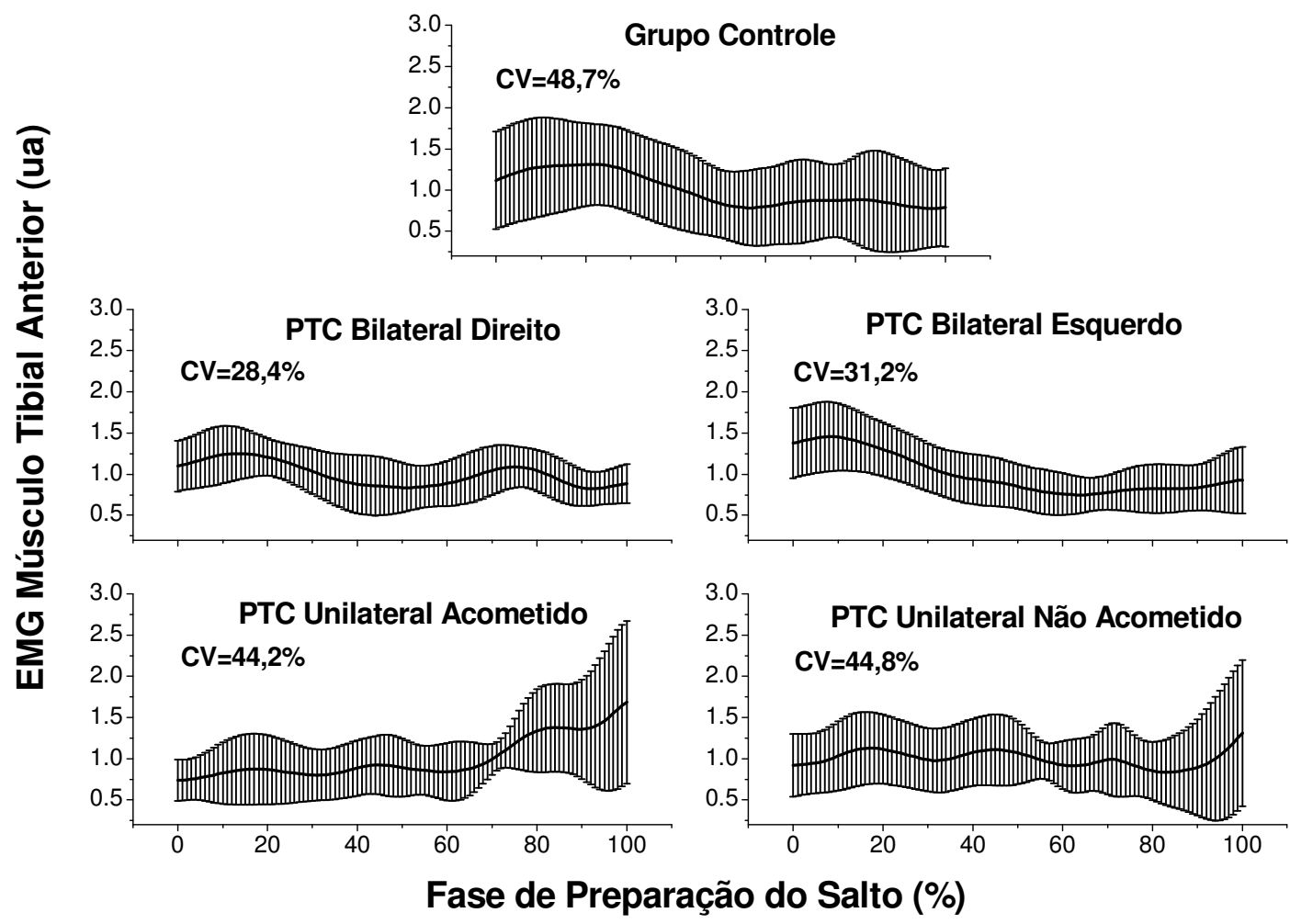

FIGURA 44 - Ilustração das médias e desvios padrão da atividade eletromiográfica do músculo tibial anterior, normalizados pela média do sinal, na fase de preparação do salto vertical com contra-movimento, além do coeficiente de variação (CV), em todos os grupos analisados. 
$\mathrm{Na}$ aterrissagem, o pico da componente vertical é alcançado, em média, a $20 \%$ do ciclo; logo após, sua intensidade diminui até o final desse evento (FIGURA 45).

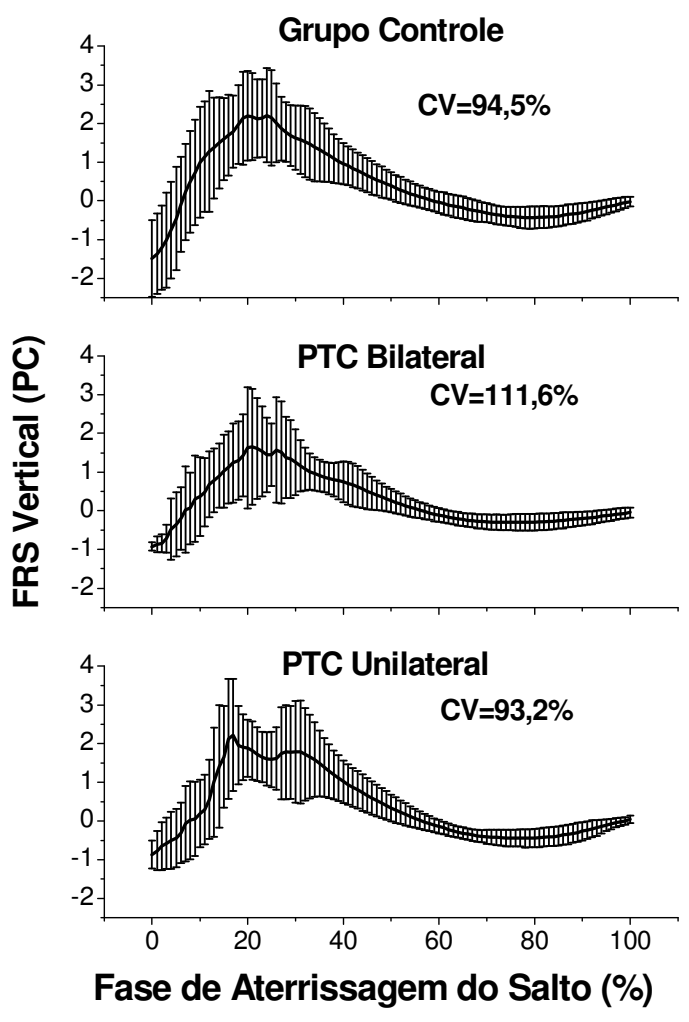

FIGURA 45 - Ilustracão das médias e desvios padrão da FRS vertical, com suas intensidades normalizadas pelo peso corporal (PC), além do coeficiente de variação (CV), na fase de aterrissagem do salto vertical com contramovimento, em todos os grupos analisados. 
Nessa fase de aterrissagem, no instante inicial do contato com o solo, a articulação do joelho está próxima a extensão total; contudo, logo em seguida, inicia-se a flexão, com o retorno gradativo à posição de extensão da articulação até o final desse evento (FIGURA 46).

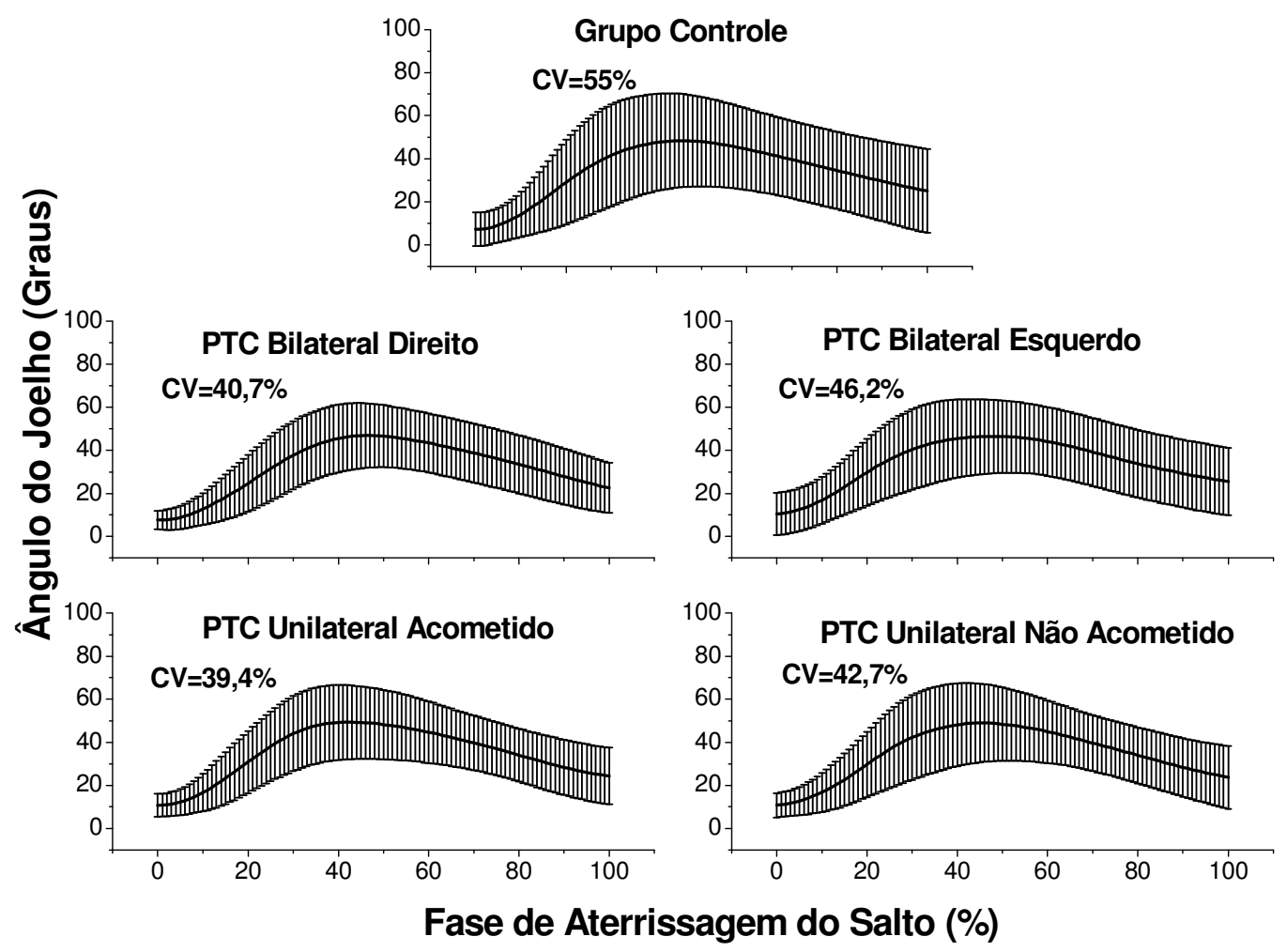

FIGURA 46 - Ilustração das médias e desvios padrão da variação angular na articulação do joelho durante a fase de aterrissagem do salto vertical com contramovimento, além do coeficiente de variação (CV), em todos os grupos analisados. 
A articulação do tornozelo inicia a fase de aterrissagem em flexão plantar e gradativamente passa para dorsiflexão, a qual alcança valor máximo antes de $50 \%$ do ciclo. Em seguida, há uma diminuição dessa angulação, e a articulação retorna para posição neutra (FIGURA 47).

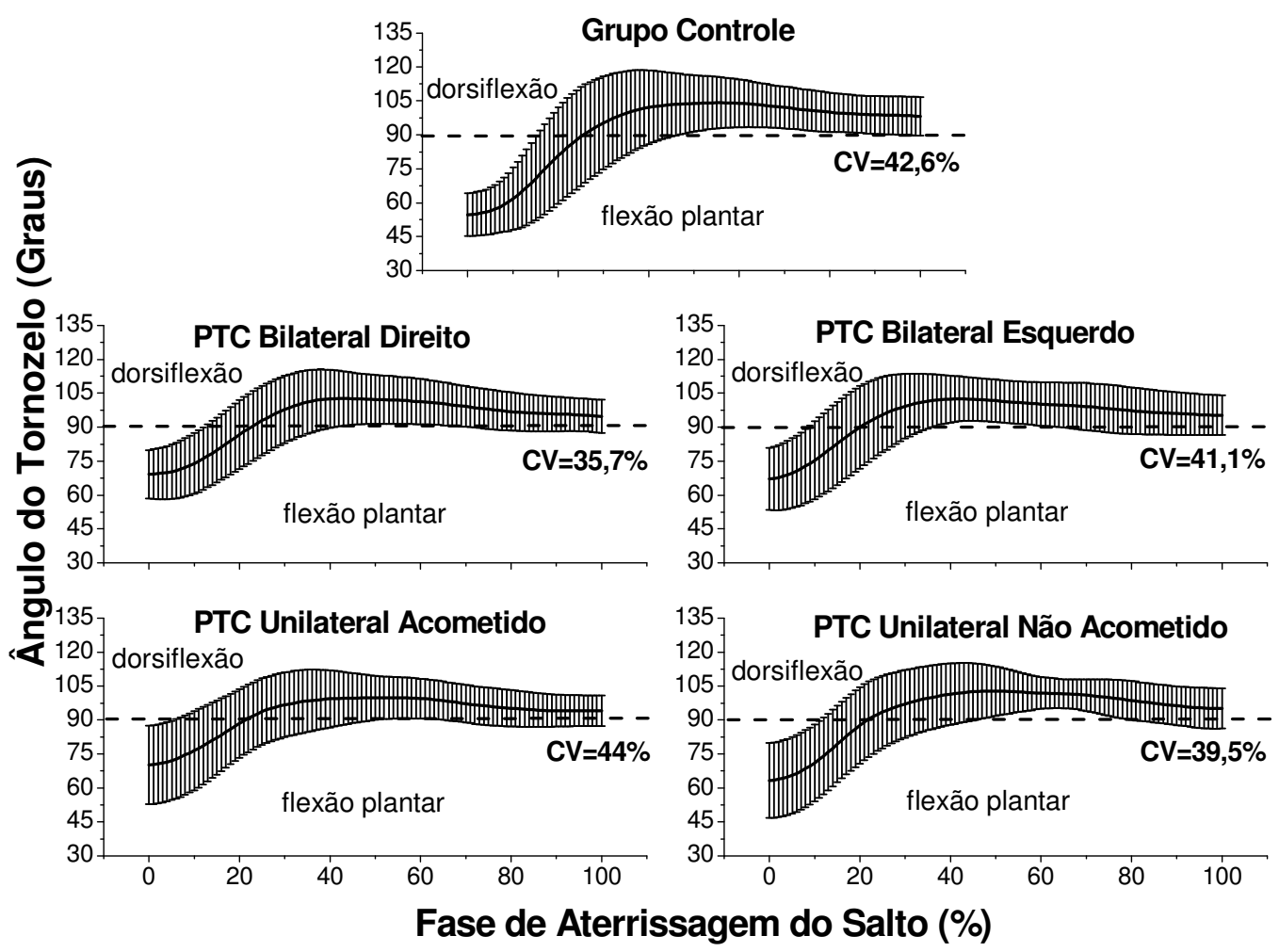

FIGURA 47 - Ilustração das médias e desvios padrão da variação angular na articulação do tornozelo durante a fase de aterrissagem do salto vertical com contramovimento, além do coeficiente de variação (CV), em todos os grupos analisados. 
O músculo gastrocnêmio medial está ativo no início do contato com o solo na fase de aterrissagem e, de forma progressiva, diminui sua atividade até 0 final do ciclo (FIGURA 48).

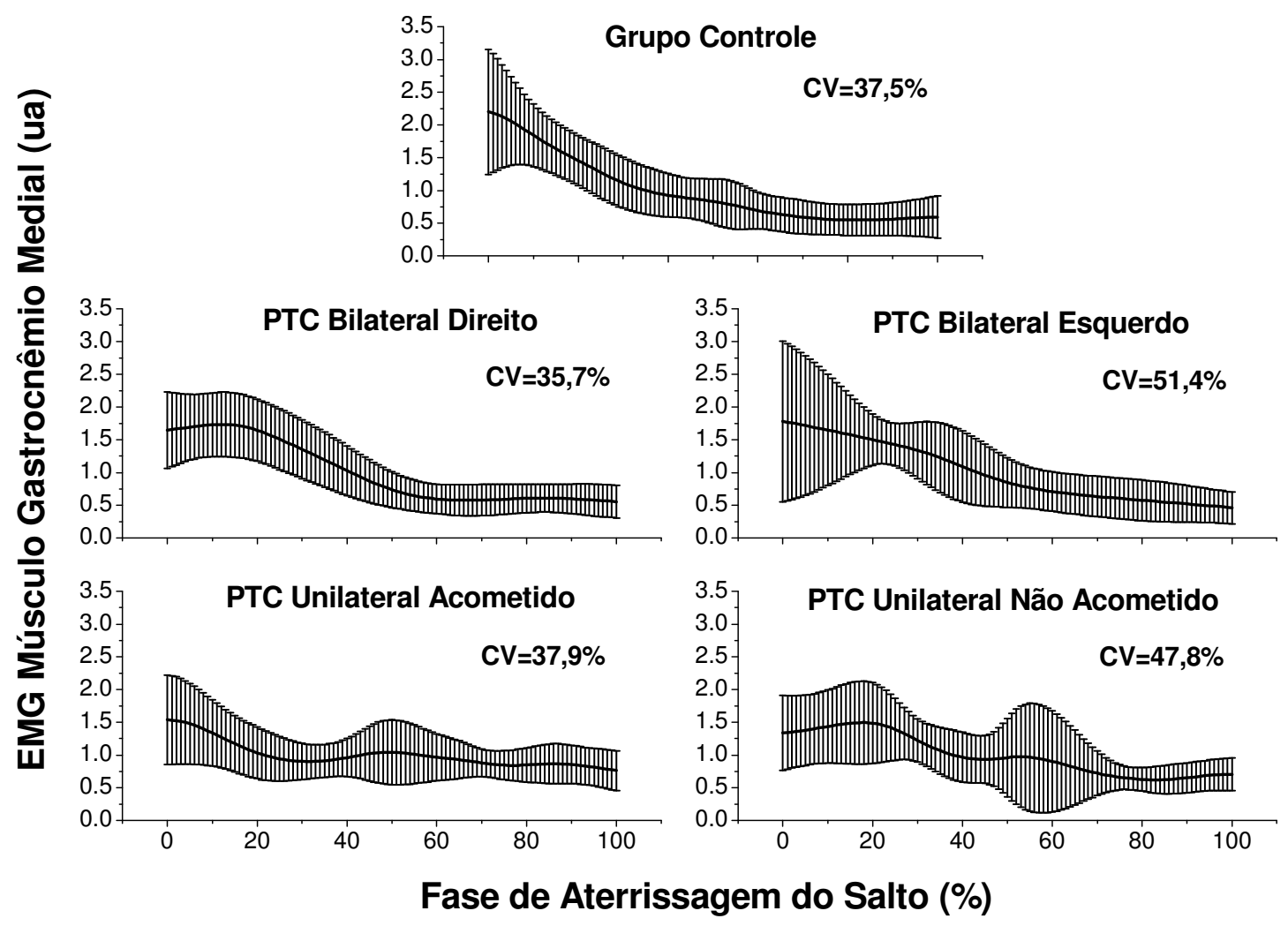

FIGURA 48 - Ilustracão das médias e desvios padrão da atividade eletromiográfica do músculo gastrocnêmio medial, normalizados pela média do sinal, na fase de aterrissagem do salto vertical com contra-movimento, além do coeficiente de variação (CV), em todos os grupos analisados. 
Para o músculo tibial anterior, há um único pulso que ocorre no início do contato e que diminui sua intensidade até o final do ciclo, semelhante ao músculo gastrocnêmio medial (FIGURA 49).

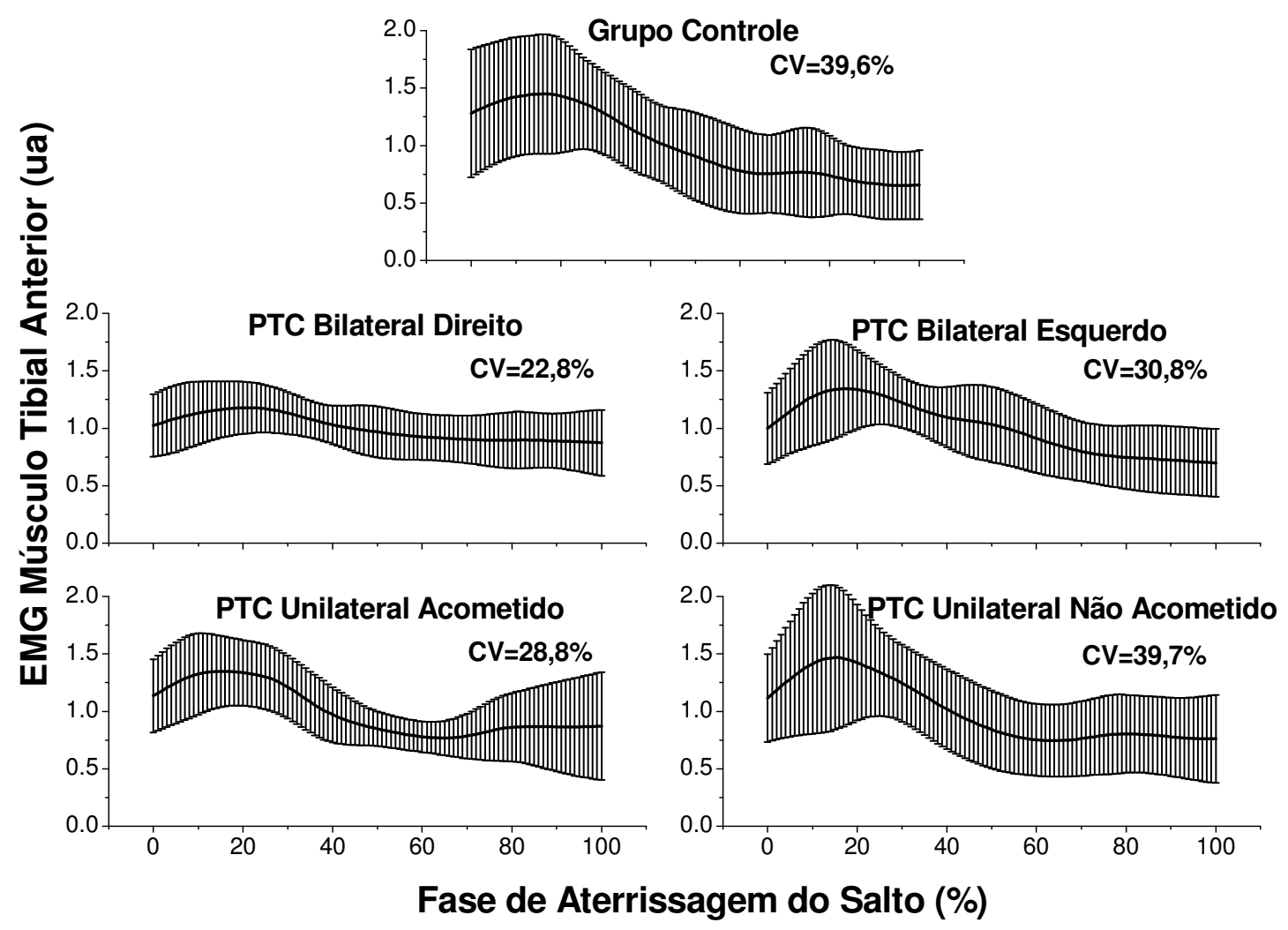

FIGURA 49 - Ilustracão das médias e desvios padrão da atividade eletromiográfica do músculo tibial anterior, normalizados pela média do sinal, na fase de aterrissagem do salto vertical com contra-movimento, além do coeficiente de variação (CV), em todos os grupos analisados.

Por meio do teste Kruskal-Wallis, foram encontradas diferenças significativas em variáveis selecionadas do salto vertical (TABELA 26). 
TABELA 26 - Dados referentes aos parâmetros analisados do salto vertical o, nas comparações entre os grupos: Controle (Cont.), PTC com acometimento bilateral lado direito (Bil. D.), PTC com acometimento bilateral lado esquerdo (Bil. E.), PTC com acometimento unilateral lado acometido (Acom.) e PTC com acometimento unilateral lado não acometido (Ñ Acom.). Dados da força foram classificados como: PTC unilateral (Unil.), PTC bilateral (Bil.) e Grupo Controle (Cont.).

\begin{tabular}{|c|c|c|c|c|c|}
\hline Variáveis & Grupos & Média & Desvio Padrão & Tamanho & $p$-valor \\
\hline \multirow{3}{*}{$\begin{array}{c}F \max 1 \\
(P C)\end{array}$} & Unil. & 1,21 & 0,42 & 24 & \multirow{3}{*}{$0,019^{*}$} \\
\hline & Bil. & 1,55 & 0,44 & 27 & \\
\hline & Cont. & 1,46 & 0,62 & 48 & \\
\hline \multirow{3}{*}{$\begin{array}{c}\mathrm{TC} \\
(\mathrm{PC} / \mathrm{s})\end{array}$} & Unil. & 58,65 & 41,78 & 24 & \multirow{3}{*}{$0,002^{*}$} \\
\hline & Bil. & 63,21 & 39,91 & 27 & \\
\hline & Cont. & 40,46 & 30,83 & 48 & \\
\hline \multirow{5}{*}{$\underset{\text { (ua) }}{R M S \text { _G }}$} & Acom. & 0,081 & 0,03 & 24 & \multirow{5}{*}{$0,013^{*}$} \\
\hline & Bil. D. & 0,091 & 0,016 & 29 & \\
\hline & Bil. E. & 0,126 & 0,016 & 29 & \\
\hline & Cont. & 0,100 & 0,029 & 98 & \\
\hline & Ñ. Acom. & 0,097 & 0,017 & 24 & \\
\hline \multirow{5}{*}{$\underset{\text { (ua) }}{\text { RMS_GM_pos }}$} & Acom. & 0,091 & 0,040 & 24 & \multirow{5}{*}{$<0,001^{*}$} \\
\hline & Bil. D. & 0,117 & 0,027 & 29 & \\
\hline & Bil. E. & 0,107 & 0,046 & 29 & \\
\hline & Cont. & 0,092 & 0,033 & 98 & \\
\hline & Ñ. Acom. & 0,155 & 0,050 & 24 & \\
\hline \multirow{5}{*}{$\begin{array}{l}\text { cine2 joelho } \\
\text { (Graus) }\end{array}$} & Acom. & 6,21 & 4,35 & 25 & \multirow{5}{*}{$0,025^{*}$} \\
\hline & Bil. D. & 5,15 & 4,35 & 27 & \\
\hline & Bil. E. & 4,69 & 4,97 & 27 & \\
\hline & Cont. & 3,20 & 2,79 & 110 & \\
\hline & N. Acom. & 5,20 & 4,83 & 25 & \\
\hline \multirow{5}{*}{$\begin{array}{l}\text { cine3_joelho } \\
\text { (Graus) }\end{array}$} & Acom. & 8,89 & 3,54 & 25 & \multirow{5}{*}{$0,004^{*}$} \\
\hline & Bil. D. & 7,09 & 4,81 & 27 & \\
\hline & Bil. E. & 8,14 & 7,69 & 27 & \\
\hline & Cont. & 6,96 & 7,72 & 110 & \\
\hline & Ñ. Acom. & 9,39 & 4,90 & 25 & \\
\hline
\end{tabular}

* $\mathrm{p}$-valor considerado estatisticamente significativo perante o nível de significância adotado $(\mathrm{p} \leq$ $0,05)$. 
TABELA 26 - Dados referentes aos parâmetros analisados do salto vertical com contramovimento, nas comparacões entre os grupos: Controle (Cont.), PTC com acometimento bilateral lado direito (Bil. D.), PTC com acometimento bilateral lado esquerdo (Bil. E.), PTC com acometimento unilateral lado acometido (Acom.) e PTC com acometimento unilateral lado não acometido (Ñ Acom.). Dados da força que não são bilaterais foram classificados como: PTC unilateral (Unil.), PTC bilateral (Bil.) e Grupo Controle (Cont.). (cont.)

\begin{tabular}{|c|c|c|c|c|c|}
\hline Variáveis & Grupos & Média & Desvio Padrão & Tamanho & $p$-valor \\
\hline \multirow{5}{*}{$\begin{array}{c}\text { cine1_tornozelo } \\
\text { (Graus) }\end{array}$} & Acom. & 104,54 & 11,36 & 25 & \multirow{5}{*}{$0,001^{*}$} \\
\hline & Bil. D. & 106,23 & 13,23 & 27 & \\
\hline & Bil. E. & 107,97 & 13,18 & 27 & \\
\hline & Cont. & 114,08 & 8,96 & 110 & \\
\hline & N. Acom. & 113,15 & 5,80 & 25 & \\
\hline \multirow{5}{*}{$\begin{array}{c}\text { cine2 tornozelo } \\
\text { (Graus) }\end{array}$} & Acom. & 59,35 & 17,88 & 25 & \multirow{5}{*}{$<0,001^{*}$} \\
\hline & Bil. D. & 61,54 & 7,67 & 27 & \\
\hline & Bil. E. & 59,51 & 8,59 & 27 & \\
\hline & Cont. & 43,08 & 7,38 & 110 & \\
\hline & N. Acom. & 50,55 & 16,84 & 25 & \\
\hline \multirow{5}{*}{$\begin{array}{c}\text { cine3 tornozelo } \\
\text { (Graus) }\end{array}$} & Acom. & 67,38 & 17,81 & 25 & \multirow{5}{*}{$<0,001^{*}$} \\
\hline & Bil. D. & 66,49 & 9,66 & 27 & \\
\hline & Bil. E. & 63,60 & 11,60 & 27 & \\
\hline & Cont. & 53,73 & 9,76 & 110 & \\
\hline & N. Acom. & 58,75 & 15,61 & 25 & \\
\hline \multirow{5}{*}{$\begin{array}{c}\text { cine4_tornozelo } \\
\text { (Graus) }\end{array}$} & Acom. & 102,67 & 11,41 & 25 & \multirow{5}{*}{$0,007^{*}$} \\
\hline & Bil. D. & 105,05 & 10,92 & 27 & \\
\hline & Bil. E. & 105,28 & 9,89 & 27 & \\
\hline & Cont. & 110,17 & 8,12 & 110 & \\
\hline & Ñ. Acom. & 108,79 & 6,90 & 25 & \\
\hline
\end{tabular}

* $p$-valor considerado estatisticamente significativo perante o nível de significância adotado $(p \leq$ $0,05)$.

Diante disso, foi determinado, com exatidão, qual grupo foi diferente de qual e para isso foi utilizado o teste de Mann-Whitney. Todos esses resultados ( $p$ valor), entre os grupos apresentados no ANEXO IV (TABELAS 50 e 51), estão descritos a seguir. 
Vale ressaltar que, nesses parâmetros investigados, em nenhum momento existiram diferenças significativas entre os dados do PTC bilateral direito quando comparado com o esquerdo.

Os resultados serão descritos primeiramente para a fase $A$ e, em seguida, para a fase $B$.

Portanto, em relação ao instante de máxima dorsiflexão plantar na fase A, foram encontrados menores valores para o lado acometido do PTC unilateral $\left(104,54 \pm 11,36^{\circ}\right)$ e para o lado direito do PTC bilateral $\left(106,23 \pm 13,23^{\circ}\right)$, comparados com o Controle $\left(114,08 \pm 8,96^{\circ}\right)$. Nota-se também que o lado acometido do grupo PTC unilateral apresentou valor menor do que o não acometido $\left(113,15 \pm 5,8^{\circ}\right)$ (FIGURA 50).

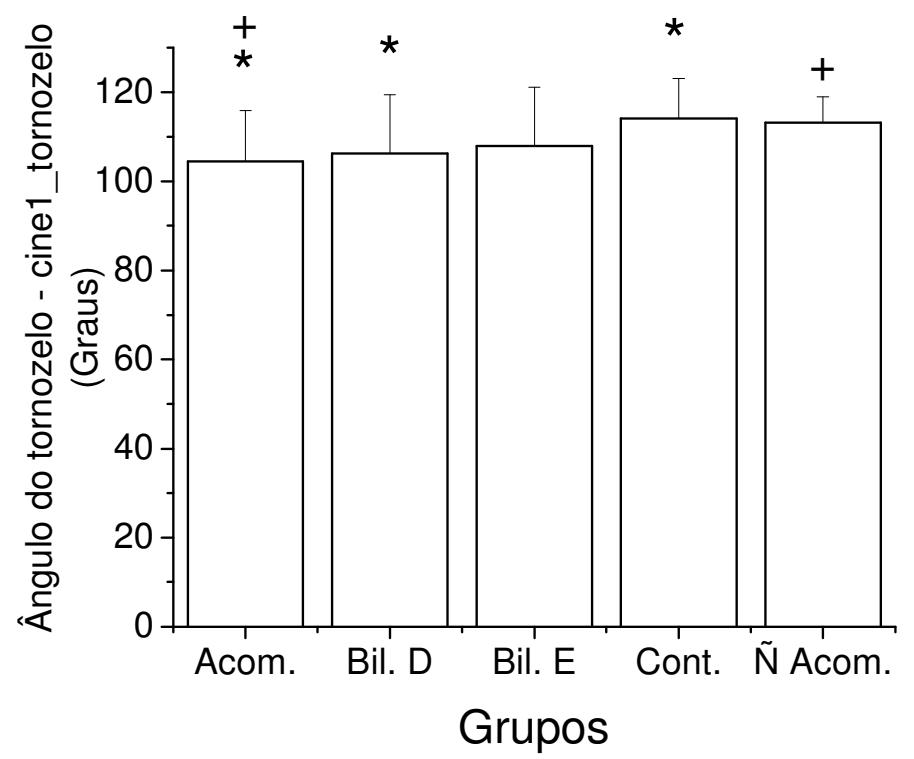

FIGURA 50 - Gráfico referente máxima dorsiflexão plantar da fase A do salto vertical (Cine1 tornozelo) para os grupos avaliados: Controle (Cont.), PTC com acometimento bilateral lado direito (Bil. D.), PTC com acometimento bilateral lado esquerdo (Bil. E.), PTC com acometimento unilateral lado acometido (Acom.) e PTC com acometimento unilateral lado não acometido

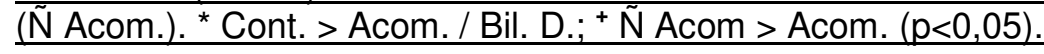


Com relação à maior intensidade de $F R S$ na fase $A(F \max 1)$, foi

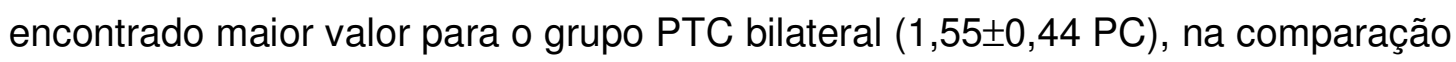
com grupo PTC unilateral $(1,21 \pm 0,42$ PC). Em adição, foi encontrado uma tendência $(p=0,052)$ de menor valor para o grupo PTC unilateral, quando

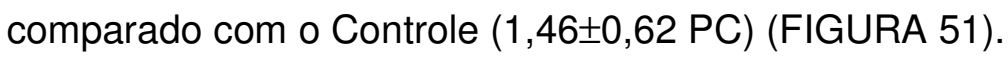

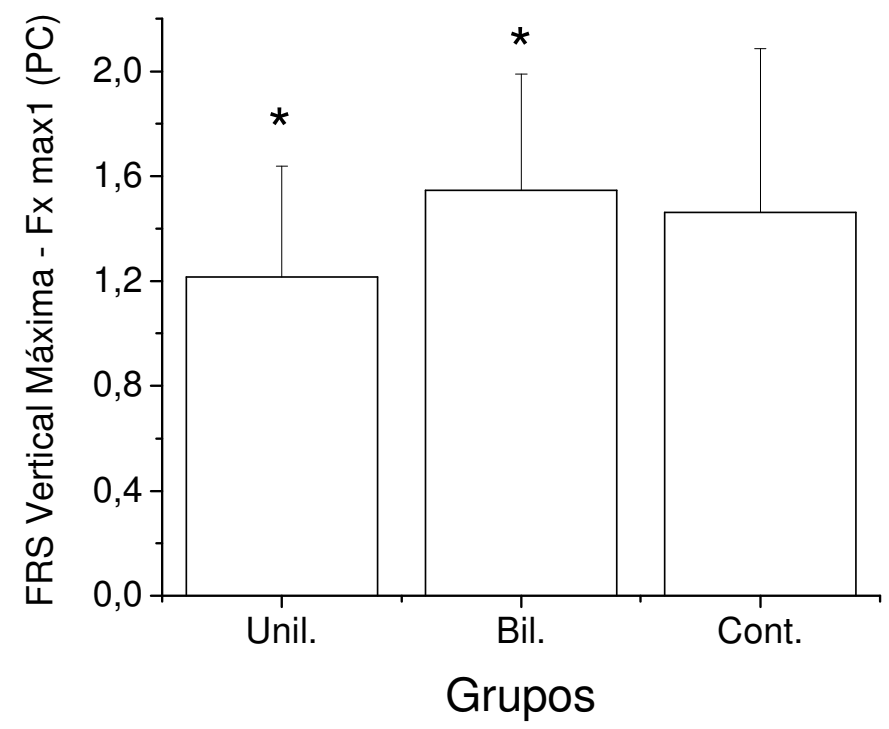

FIGURA 51 - Gráfico referente ao parâmetro $F \max 1$ da FRS vertical para os grupos avaliados: Controle (Cont.), PTC bilateral (Bil.), PTC unilateral (Unil.). *Unil. $\leq$ Bil. $(p<0,05)$. 
Considerando as características de ativação muscular nessa fase, foi verificado que o músculo gastrocnêmio medial apresentou ativação menor para o lado acometido do PTC unilateral $(0,081 \pm 0,03$ ua), quando comparado com os demais grupos (Bil.D. $=0,091 \pm 0,016$ ua; Bil. E. $=0,126 \pm 0,016$ ua; N. Acom. $=$ 0,097 $\pm 0,017$ ua; Cont. $=0,100 \pm 0,029$ ua) (FIGURA 52).

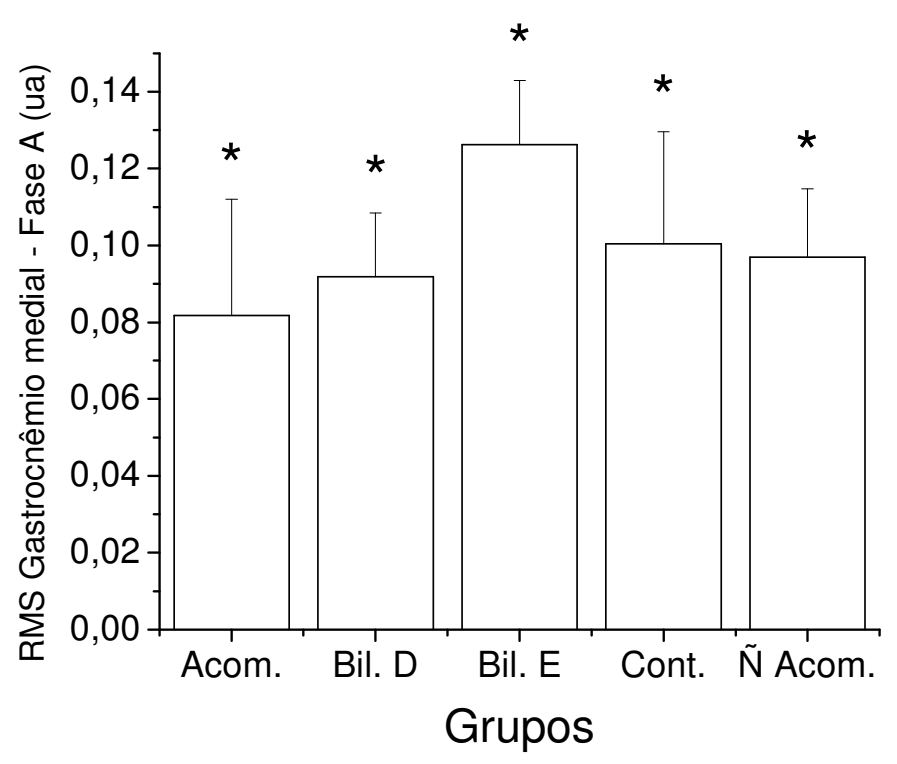

FIGURA 52 - Gráfico referente às características do sinal RMS eletromiográfico da fase A para o gastrocnêmio medial para os grupos avaliados: Controle (Cont.), PTC com acometimento bilateral lado direito (Bil. D.), PTC com acometimento bilateral lado esquerdo (Bil. E.), PTC com acometimento unilateral lado acometido (Acom.) e PTC com acometimento unilateral lado não acometido (N Acom.). ${ }^{*}$ Acom. < N Acom/ Bil. D./ Bil. E./ Cont. $(p<0,05)$. 
$\mathrm{Na}$ fase de retirada do contato dos pés do solo, os grupos com PTC apresentaram uma menor flexão plantar (Bil.D. $=61,54 \pm 7,67^{\circ}$; Bil. E. = $59,51 \pm 8,59^{\circ} ; \tilde{N}$. Acom. $=50,55 \pm 16,84^{\circ} ;$ Acom. $=59,35 \pm 17,88^{\circ}$ ) quando comparados com o Controle $\left(43,08 \pm 7,38^{\circ}\right)$. Na comparação entre os grupos de PTC, verificou-se que o grupo que mais se aproximou das características de normalidade foi o grupo PTC unilateral lado não acometido. Vale lembrar que $90^{\circ}$ é o ângulo considerado como posição neutra; quanto menor este ângulo, maior é a flexão plantar (FIGURA 53).

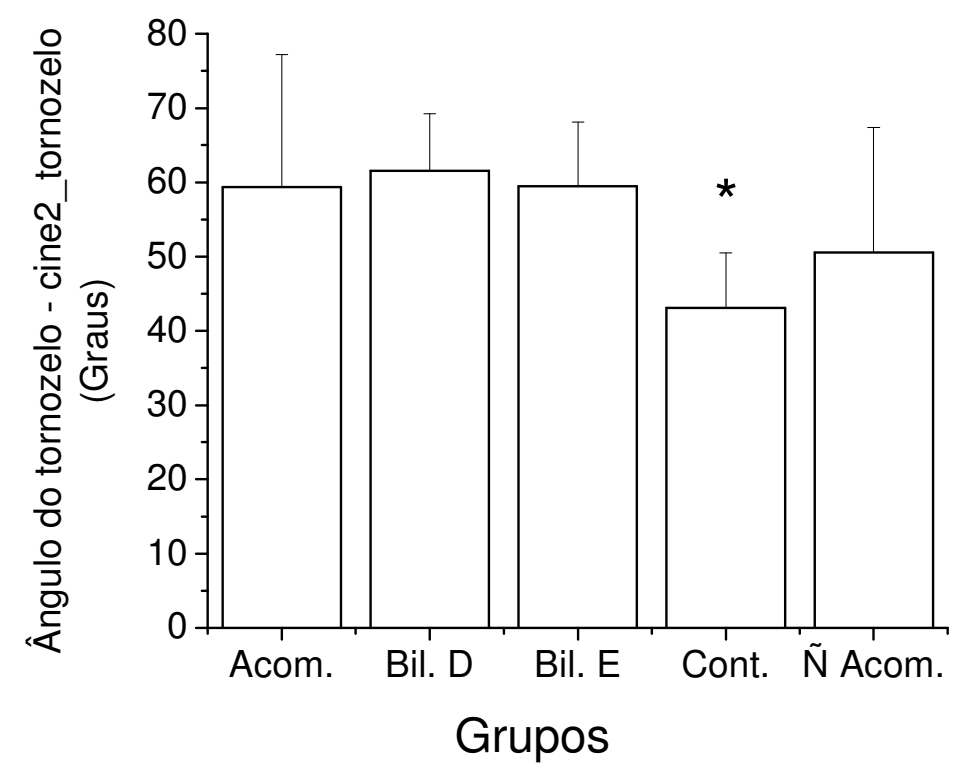

FIGURA 53 - Gráfico referente às características de variação angular do tornozelo (cine2 tornozelo) na fase de retirada do contato do pé com o solo para os grupos avaliados: Controle (Cont.), PTC com acometimento bilateral lado direito (Bil. D.), PTC com acometimento bilateral lado esquerdo (Bil. E.), PTC com acometimento unilateral lado acometido (Acom.) e PTC com acometimento unilateral lado não acometido ( $\tilde{\mathrm{N}}$ Acom.). ${ }^{*}$ Cont. $<$ Acom. $/ \tilde{N}$ Acom/ Bil. D./ Bil. E.; ${ }^{+} \tilde{N}$ Acom < Acom. / Bil. D. / Bil. E. $(p<0,05)$. 
A articulação do joelho neste momento, tanto o lado não acometido $\left(5,20 \pm 4,83^{\circ}\right)$ quanto 0 acometido $\left(6,21 \pm 4,35^{\circ}\right)$ do grupo PTC unilateral tiveram maiores valores angulares quando comparados com o Controle $\left(3,20 \pm 2,79^{\circ}\right)$ (FIGURA 54).

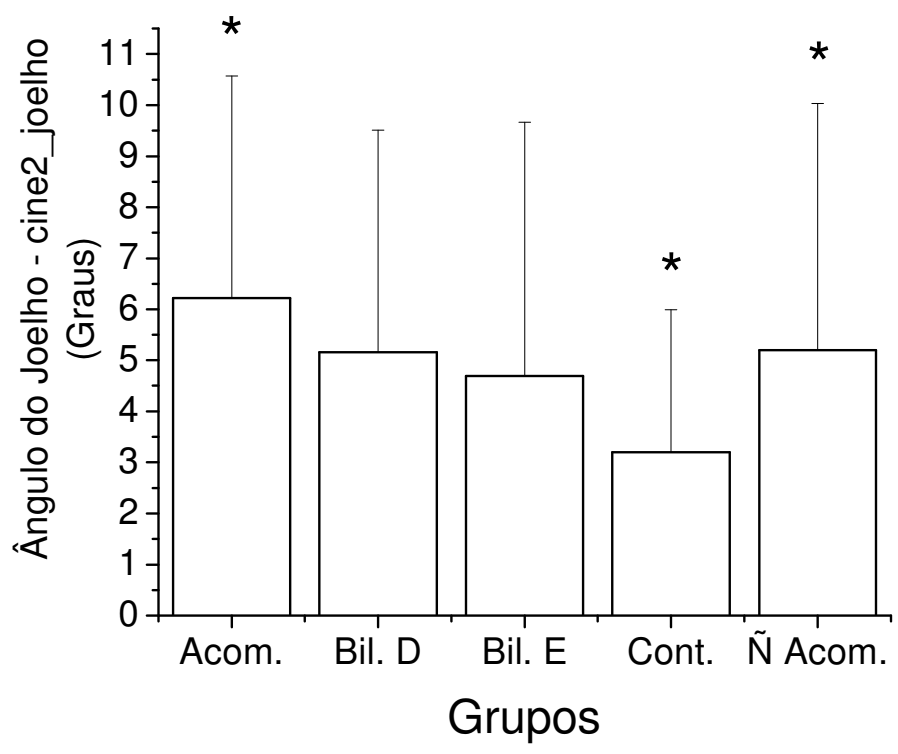

FIGURA 54 - Gráfico referente às características angulares do joelho (cine2 joelho) na fase de retirada do contato do pé com o solo para os grupos avaliados: Controle (Cont.), PTC com acometimento bilateral lado direito (Bil. D.), PTC com acometimento bilateral lado esquerdo (Bil. E.), PTC com acometimento unilateral lado acometido (Acom.) e PTC com acometimento unilateral lado não acometido (N Acom.). * Cont. < Acom. / N Acom. $(\mathrm{p}<0,05)$. 
No momento da aterrissagem (início da fase B), a articulação do joelho encontrou-se mais flexionada no grupo Unilateral $\left(\right.$ Acom. $=8,89 \pm 3,54^{\circ} ; \tilde{N}$. Acom. $=$ $\left.9,39 \pm 4,90^{\circ}\right)$, comparado com o Controle $\left(6,96 \pm 7,72^{\circ}\right)$ (FIGURA 55).

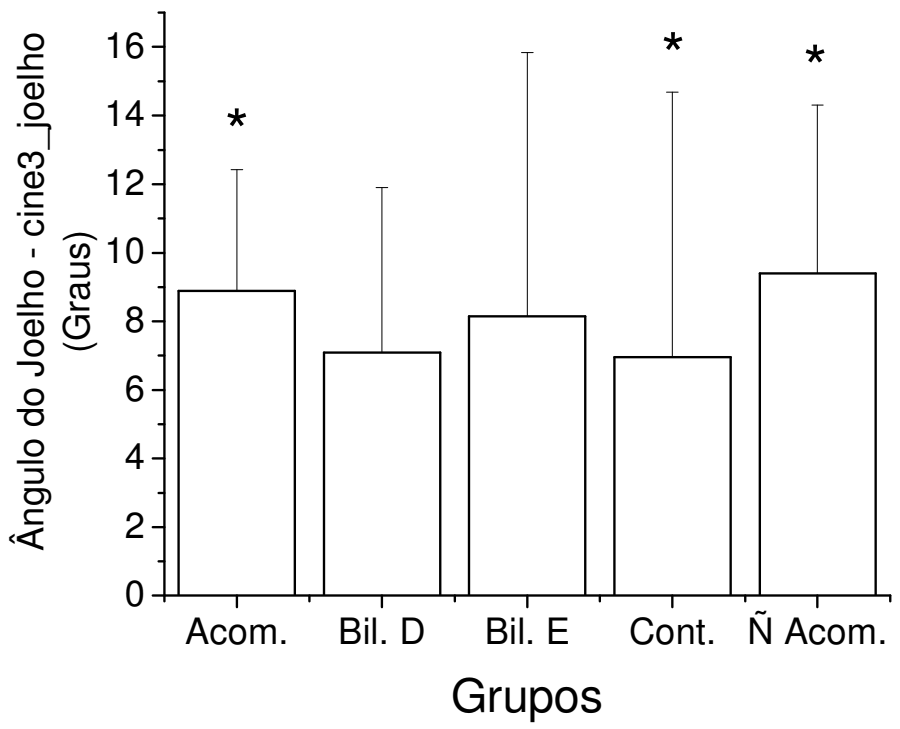

FIGURA 55 - Gráfico referente às características angulares do joelho (cine3 joelho) no momento da aterrissagem (fase B) para os grupos avaliados: Controle (Cont.), PTC com acometimento bilateral lado direito (Bil. D.), PTC com acometimento bilateral lado esquerdo (Bil. E.), PTC com acometimento unilateral lado acometido (Acom.) e PTC com acometimento unilateral lado

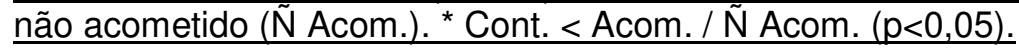


Neste momento, os dois lados do grupo PTC bilateral (Bil. D. = $66,49 \pm 9,66^{\circ}$; Bil. E. $\left.=63,60 \pm 11,60^{\circ}\right)$ e o lado acometido do PTC unilateral $\left(67,38 \pm 17,81^{\circ}\right)$ obtiveram menor flexão plantar do que o Controle $\left(53,73 \pm 9,76^{\circ}\right)$ (FIGURA 56).

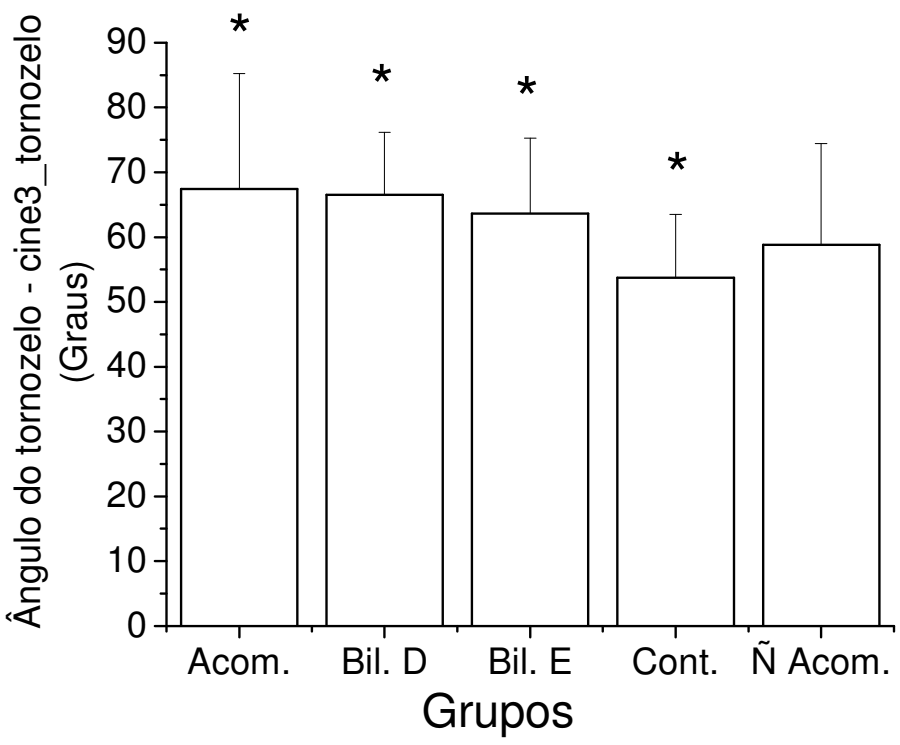

FIGURA 56 - Gráfico referente às características angulares do tornozelo (cine3 tornozelo) no momento da aterrissagem (fase B), para os grupos avaliados: Controle (Cont.), PTC com acometimento bilateral lado direito (Bil. D.), PTC com acometimento bilateral lado esquerdo (Bil. E.), PTC com acometimento unilateral lado acometido (Acom.) e PTC com acometimento unilateral lado não acometido (Ñ Acom.). ${ }^{*}$ Cont. < Acom. / Bil. D./ Bil. E. $(p<0,05)$. 
A Taxa de Crescimento nessa fase foi aumentada em ambos os grupos com PTC, unilateral $(58,6 \pm 41,7 \mathrm{PC} / \mathrm{s})$ e bilateral $(63,2 \pm 39,9 \mathrm{PC} / \mathrm{s})$, quando comparado com o Controle $(40,4 \pm 30,8 \mathrm{PC} / \mathrm{s})$ (FIGURA 57).

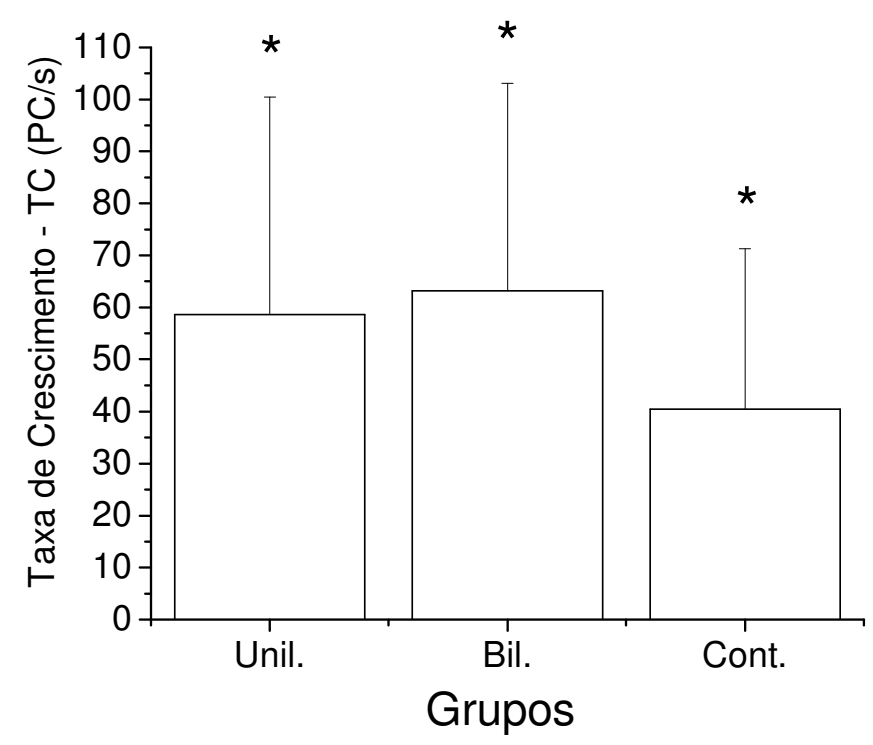

FIGURA 57 - Gráfico referente taxa de crescimento da FRS avaliada no salto vertical para os grupos avaliados: Controle (Cont.), PTC bilateral (Bil.), PTC unilateral (Unil.). * Cont. < Unil. / Bil. $(p<0,05)$. 
Com relação à ativação muscular do gastrocnêmio medial, nessa fase final do salto vertical, foi encontrado maior valor para o grupo PTC lado não acometido $(0,155 \pm 0,050$ ua), comparado com os demais grupos (Cont. = 0,092 $\pm 0,033$ ua; Acom. $=0,091 \pm 0,040$ ua; Bil. D. $=0,117 \pm 0,027$ ua; Bil. E. $=$ $0,107 \pm 0,046$ ua). Nota-se também que no grupo PTC bilateral direito foi encontrado valor maior do que o controle (FIGURA 58).

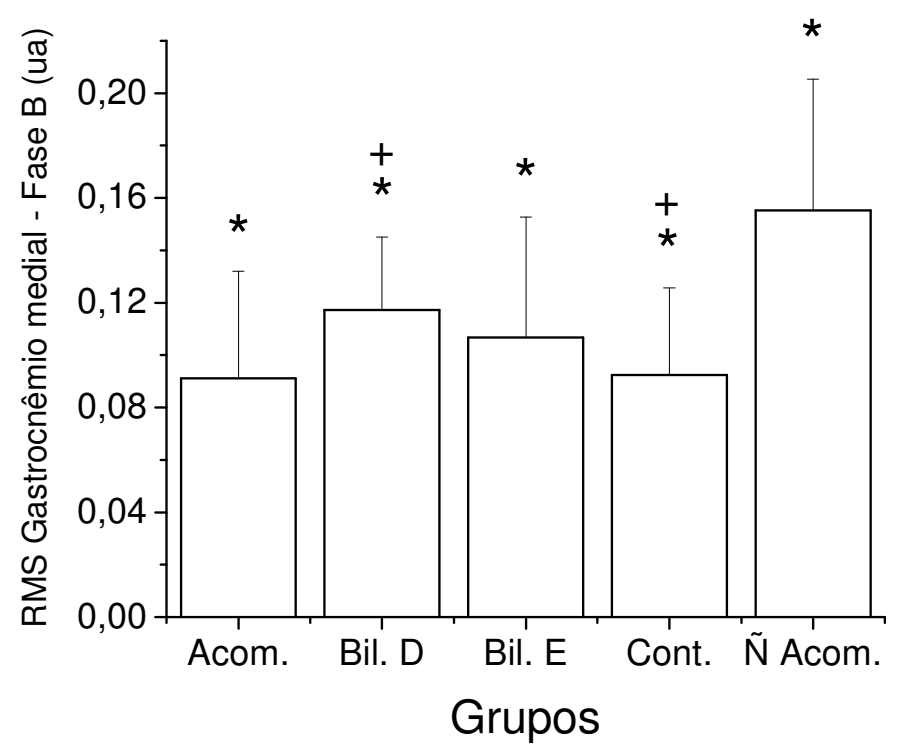

FIGURA 58 - Gráfico referente às características do sinal RMS eletromiográfico do gastrocnêmio medial, na fase $\mathrm{B}$, para os grupos avaliados: Controle (Cont.), PTC com acometimento bilateral lado direito (Bil. D.), PTC com acometimento bilateral lado esquerdo (Bil. E.), PTC com acometimento unilateral lado acometido (Acom.) e PTC com acometimento unilateral lado não acometido (N Acom.). ${ }^{*} \tilde{N}$ Acom. > Acom. / Bil. D./ Bil. E./ Cont.; ${ }^{+}$Bil. D. $>$ Cont. $(p<0,05)$. 
No momento de maior dorsiflexão plantar na fase B (cine4_tornozelo), menores valores foram encontrados para os grupos com PTC unilateral acometido $\left(102,67 \pm 11,41^{\circ}\right)$, bilateral direito $\left(105,05 \pm 10,92^{\circ}\right)$ e bilateral esquerdo $\left(105,28 \pm 9,89^{\circ}\right)$, quando comparado com o Controle $\left(110,17 \pm 8,12^{\circ}\right)$ (FIGURA 59).

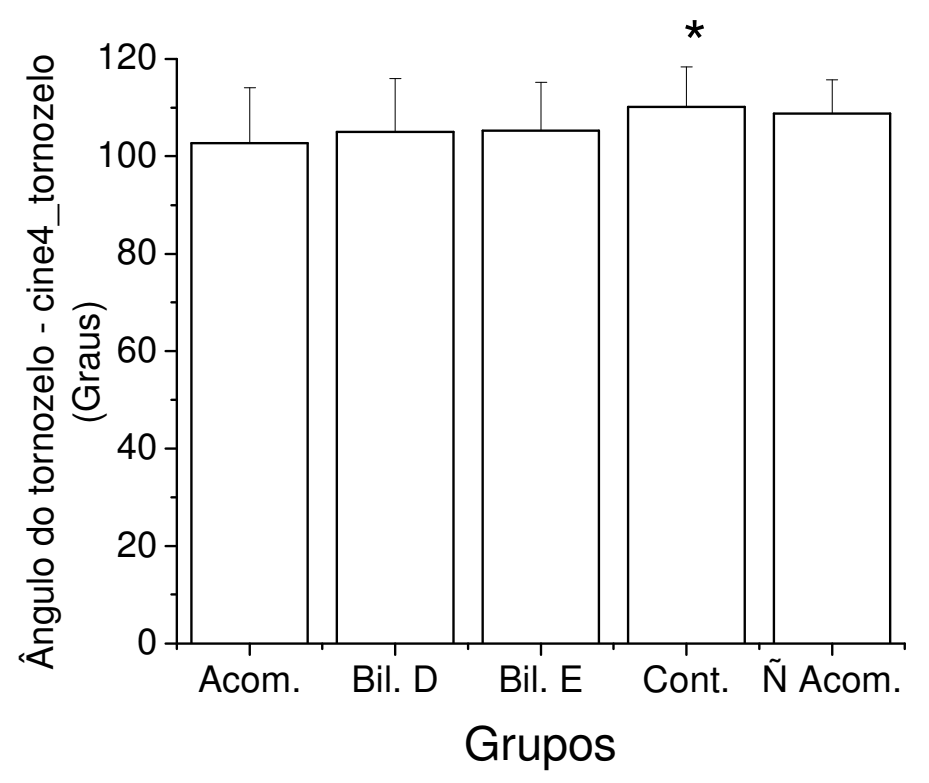

FIGURA 59 - Gráfico referente às características de maior dorsiflexão plantar na fase B (Cine4 tornozelo), para os grupos avaliados: Controle (Cont.), PTC com acometimento bilateral lado direito (Bil. D.), PTC com acometimento bilateral lado esquerdo (Bil. E.), PTC com acometimento unilateral lado acometido (Acom.) e PTC com acometimento unilateral lado não acometido (Ñ Acom.). * Cont. < Acom. / Bil. D./ Bil. E. $(p<0,05)$. 


\subsection{Análise da sensibilidade plantar}

Os dados adquiridos por meio da avaliação com os monofilamentos foram classificados como: 1) sensibilidade normal (cores verde e azul); 2) predisponentes a alterações sensitivas (violeta e vermelho escuro); e 3) alteração sensitiva (laranja e vermelho magenta). Segue a distribuição percentual entre os grupos para as categorias criadas e cada local de aplicação (TABELA 27).

TABELA 27 - Distribuição percentual (\%) entre os grupos PTC unilateral lado acometido

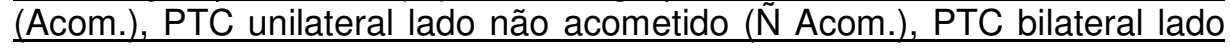
direito (Bil. Dir.), PTC bilateral lado esquerdo (Bil. Esq.) e grupo controle (Cont.), para as categorias criadas $(1=$ sensibilidade normal; $2=$ predisposiccão de alteração sensitiva; 3 = alteração sensitiva).

\begin{tabular}{|c|c|c|c|c|c|c|c|c|c|c|c|}
\hline \multirow{2}{*}{\multicolumn{2}{|c|}{ Monofilamentos }} & \multicolumn{2}{|c|}{$1^{\circ}$ metatarso } & \multicolumn{2}{|c|}{$3^{\circ}$ metatarso } & \multicolumn{2}{|c|}{$5^{\circ}$ metatarso } & \multicolumn{2}{|c|}{ calcanhar } & \multicolumn{2}{|c|}{ mediopé } \\
\hline & & Qtde & $\%$ & Qtde & $\%$ & Qtde & $\%$ & Qtde & $\%$ & Qtde & $\%$ \\
\hline \multirow{2}{*}{ Acom. } & 1 & 6 & $17,1 \%$ & 5 & $14,3 \%$ & 5 & $14,3 \%$ & 5 & $14,3 \%$ & 6 & $17,1 \%$ \\
\hline & 2 & 1 & $2,9 \%$ & 2 & $5,7 \%$ & 2 & $5,7 \%$ & 2 & $5,7 \%$ & 1 & $2,9 \%$ \\
\hline \multirow{3}{*}{ Bil. Dir. } & 3 & 0 & $0,0 \%$ & 0 & $0,0 \%$ & 1 & $2,9 \%$ & 0 & $0,0 \%$ & 1 & $2,9 \%$ \\
\hline & 1 & 6 & $17,1 \%$ & 5 & $14,3 \%$ & 5 & $14,3 \%$ & 5 & $14,3 \%$ & 4 & $11,4 \%$ \\
\hline & 2 & 1 & $2,9 \%$ & 2 & $5,7 \%$ & 1 & $2,9 \%$ & 2 & $5,7 \%$ & 2 & $5,7 \%$ \\
\hline \multirow{2}{*}{ Bil. Esq. } & 1 & 7 & $20,0 \%$ & 6 & $17,1 \%$ & 7 & $20,0 \%$ & 6 & $17,1 \%$ & 6 & $17,1 \%$ \\
\hline & 2 & 0 & $0,0 \%$ & 1 & $2,9 \%$ & 0 & $0,0 \%$ & 1 & $2,9 \%$ & 1 & $2,9 \%$ \\
\hline \multirow{2}{*}{ Cont. } & 1 & 21 & $19,1 \%$ & 21 & $19,1 \%$ & 21 & $19,1 \%$ & 18 & $16,4 \%$ & 21 & $19,1 \%$ \\
\hline & 2 & 1 & $0,9 \%$ & 1 & $0,9 \%$ & 1 & $0,9 \%$ & 4 & $3,6 \%$ & 1 & $0,9 \%$ \\
\hline \multirow{2}{*}{$\tilde{\mathbf{N}}$ Acom. } & 1 & 6 & $17,1 \%$ & 5 & $14,3 \%$ & 6 & $17,1 \%$ & 5 & $14,3 \%$ & 6 & $17,1 \%$ \\
\hline & 2 & 1 & $2,9 \%$ & 2 & $5,7 \%$ & 1 & $2,9 \%$ & 2 & $5,7 \%$ & 1 & $2,9 \%$ \\
\hline
\end{tabular}

Em seguida, foi investigado o $p$-valor de todas as comparações, duas a duas, entre os grupos em cada situação. Foram analisadas somente as comparações para as categorias 1 e 2, uma vez que a 3 ocorreu somente no grupo PTC bilateral lado direito apenas uma vez (ANEXO IV - TABELA 52). Conclui-se, portanto, que não existem diferenças entre os grupos para as categorias de monofilamentos em quaisquer dos locais de aplicação. 


\section{DISCUSSÃO}

A locomoção humana apresenta movimentos complexos. O estudo de suas especificidades, por meio dos métodos deste trabalho, pode contribuir para 0 entendimento dos mecanismos que garantem um movimento eficiente e que favorecem condutas na reabilitação funcional de crianças com PTC.

Sabe-se que a locomoção torna-se estável na existência da maturação do SNC e do sistema músculo-esquelético (BECK et al., 1981; KYRIAZIS, 2002; TINGLEY et al., 2002). Dessa forma, este trabalho se preocupou em selecionar uma amostra de crianças que estejam praticamente com suas características de locomoção estáveis, com objetivo de minimizar a variabilidade dos dados biológicos adquiridos. Todavia, como a origem do PTC não está totalmente esclarecida, não podemos afirmar que as diferenças entre essa população e o grupo controle não possam ser minimizadas em virtude do atraso da maturação do SNC e/ou do sistema músculo-esquelético. ARONSON e PULKARICH (1990), ao analisarem crianças com história de acometimento unilateral, verificaram o aumento da instabilidade postural quando os sujeitos realizavam o teste de apoio unipodal no membro acometido, com uma tendência de existir o melhor controle desse desequilíbrio nos voluntários mais velhos.

Portanto, recomenda-se que trabalhos devem ser desenvolvidos com o objetivo de delinear a evolução da estabilização dos parâmetros biomecânicos da locomoção de portadores de PTC por meio de investigações longitudinais dessa população. Com isso, será possível identificar as diferenças dos parâmetros biomecânicos relacionados com o PTC em função do desenvolvimento motor das crianças e conhecer suas características até a sua fase adulta.

Os procedimentos cirúrgicos para tratamento de portadores de PTC buscam correções das deformidades presentes. Ainda que esses procedimentos proporcionem a diminuição dessas alterações e que todas as crianças avaliadas possuam uma vida ativa sem dificuldades funcionais aparentes, muitos parâmetros biomecânicos, tanto relativos à marcha quanto ao salto vertical com contramovimento, encontram-se alterados. Seguem, portanto, considerações específicas de cada situação experimental investigada no presente trabalho. 


\subsection{Marcha auto-selecionada}

De forma geral, as curvas médias da FRS na marcha, tanto na componente vertical quanto ântero-posterior e médio-lateral, bem como as curvas médias da variação angular do joelho e do tornozelo apresentaram-se similares aos resultados encontrados no grupo Controle (FIGURAS 25, 26 e 27), bem como às descritas na literatura de indivíduos sem acometimento de PTC (LOBO DA COSTA, 2000; WINTER, 1983).

Os dados do CV contribuem para o entendimento da variabilidade dos dados biomecânicos e, conseqüentemente, favorecem a melhor caracterização global das variáveis por meio da compreensão de possíveis inconsistências existentes nos dados coletados.

Os dados do CV foram baseados nas investigações inter-sujeitos do mesmo grupo e mostraram algumas particularidades interessantes. Baseado no fato de que o grupo Controle não possui nenhuma história de lesão no sistema locomotor, variações encontradas nesse grupo representam o desempenho típico encontrado no comportamento motor infantil, e podem respaldar o melhor entendimento das características encontradas nos grupos com PTC.

Os trabalhos de WINTER (1991) e de DAVID (2000) formam as bases fundamentais para comparação com os dados do CV da FRS encontrados no presente estudo. Os resultados de LOBO DA COSTA (2000) também são relevantes, mas ela se utilizou da investigação do CV intra-sujeitos, diferente dos trabalhos anteriores.

Nota-se que o CV para a componente vertical da FRS variou nos grupos investigados de 13 a 16,8 \% (TABELA 19), similar aos encontrados na literatura, uma vez que WINTER (1991) encontrou o CV de 18\% e DAVID (2000) $13 \%$. LOBO DA COSTA (2000) encontrou variação intra-sujeito de $21,1 \%$ a $51,1 \%$.

No presente estudo, foi encontrado um CV para a componente ânteroposterior de 53,5 a 57,7\% (TABELA 19), com poucas diferenças entre os grupos. Valores menores foram descritos nos trabalhos de WINTER (1991) e DAVID (2000), $43 \%$ e $34 \%$ respectivamente. As variações intra-sujeitos encontradas por LOBO DA COSTA foram de 31,9 a $115 \%$. 
Para a FRS médio-lateral, foi verificado um CV entre $34,1 \%$ e $45,9 \%$ (TABELA 19), sendo os menores valores para os grupos com PTC, em especial o lado acometido do grupo com acometimento unilateral. Tal fato pode ser reflexo das alterações residuais do próprio pé dessas crianças. Vale ressaltar que DAVID (2000) encontrou variação de $54 \%$ no lado esquerdo e $66 \%$ no direito em crianças sem nenhum acometimento músculo-esquelético, o que contribui para afirmar que esse grupo com PTC teve baixos valores de CV para esta componente da FRS.

De forma geral, na marcha, os resultados do presente estudo relacionados ao CV para a FRS, foram semelhantes entre os grupos analisados; os maiores valores foram encontrados para a componente ântero-posterior, seguido da médio-lateral e da vertical (TABELA 19). Tanto o trabalho de DAVID (2000) quanto o de LOBO DA COSTA (2000) apresentam valores para o CV maiores para a componente médio-lateral, comparados com os valores das outras duas componentes. Como a componente médio-lateral ainda é pouco estudada, talvez em razão de sua baixa magnitude se comparada com as demais forças, não existe um consenso sobre suas particularidades.

Em relação à variação angular, verificou-se um maior CV na articulação do joelho quanto comparado com a do tornozelo (TABELAS 20 e 21), fato que representa inconsistência dessa variável daquela articulação. Inconsistência maior foi encontrada no CV do grupo com PTC bilateral na articulação do joelho.

Para maior entendimento das características da marcha dessas crianças, há necessidade de uma discussão mais aprofundada relacionada às comparações das variáveis selecionadas em cada grupo. Ambos os grupos com PTC tiveram diferenças nas variáveis calculadas a partir dos parâmetros cinéticos e de variação angular ao serem comparados com o grupo Controle.

No inicio da fase de apoio da marcha, representada pela resposta à carga ( $10 \%$ do ciclo da passada), a taxa de crescimento para o primeiro pico da FRS vertical foi maior em ambos os grupos com PTC, sendo que o grupo com acometimento unilateral obteve os maiores valores (TABELAS 22 e 44; FIGURA 30).

Além disso, foi encontrada, no lado não acometido do grupo com PTC unilateral, diferença no início do apoio representada pela maior magnitude do pico 
na fase de frenagem da FRS ântero-posterior (TABELAS 22 e 44; FIGURA 31).

Tais eventos podem ser explicados pela alteração do controle protetor das crianças com PTC na fase inicial do apoio, em especial do grupo com comprometimento unilateral. A TC 1 tem sido utilizada para quantificar possíveis características relacionadas à força aplicada no aparelho locomotor no instante de maior impacto durante a marcha, o que demonstra ser um parâmetro interessante para diagnosticar sobrecargas e, conseqüentemente, a inabilidade na proteção corporal. KAROL, CONCHA e JOHNSTON (1997) encontraram, nessa fase, uma diminuição da flexão do joelho no contato inicial com o solo do lado com PTC, o que pode explicar essa deficiência no gerenciamento da colocação do pé com a superfície no início da fase de apoio da marcha. Normalmente, no instante do toque do calcanhar, o joelho encontra-se próximo da extensão total e chega a uma flexão em torno de $20^{\circ}$ no momento da resposta à carga, com a finalidade de controle do choque mecânico (WINTER,1991). O presente trabalho encontrou nessa fase, no grupo Controle, flexão de $13,2 \pm 5,9^{\circ}$ na articulação do joelho, com dados semelhantes aos encontrados nas crianças com PTC bilateral (TABELAS 22 e 44; FIGURA 33). Contudo, ainda que tais valores sejam semelhantes, as estratégias desenvolvidas pelos grupos com PTC levam ao aumento da TC1. Comportamento, ainda mais marcante, foi visto no grupo com PTC unilateral, com maiores valores angulares de flexão do joelho e maiores magnitudes na TC1 (TABELAS 22 e 44).

Possivelmente, os maiores valores angulares do joelho no momento de resposta à carga acarretou o maior pico encontrado na componente ânteroposterior na fase de frenagem no lado não acometido. O gerenciamento da força no sentido vertical leva a maior sobrecarga neste sentido, contudo, no sentido horizontal o grau de flexão do joelho pode ter colaborado para o maior valor do pico de frenagem na componente ântero-posterior.

Deve-se ainda considerar que os resultados relacionados à FRS vertical e ântero-posterior, no instante inicial do apoio, podem estar relacionados à variação angular do tornozelo. Foram encontradas diferenças na variação angular dessa articulação, em ambos os grupos de PTC unilateral e no grupo PTC bilateral, quando comparados com o grupo Controle (TABELAS 22 e 44; FIGURA 
32). Em todos os casos, o tornozelo encontra-se próximo a posição neutra. Contudo, no grupo Controle, existiu uma pequena flexão plantar, e nos demais grupos citados anteriormente, caracterizaram-se por uma pequena dorsiflexão. Portanto, essa alteração do comportamento da variação angular pode ser um dos fatores determinantes para o aumento da TC1.

$\mathrm{Na}$ fase de médio apoio da marcha, na qual existe o balanço da perna contralateral e uma conseqüente deflexão da FRS vertical, os grupos com PTC unilateral, em ambos os apoios, apresentaram as maiores angulações de dorsiflexão no tornozelo (TABELAS 22 e 44; FIGURA 34). KAROL, CONCHA e JOHNSTON (1997) encontraram resultados diferentes daqueles encontrados no presente estudo. Os autores verificaram uma diminuição da dorsiflexão no lado não acometido de crianças com PTC. Entretanto, esses pesquisadores avaliaram apenas crianças com comprometimento unilateral e, portanto, compararam seus dados com o lado não comprometido. No presente estudo, por ter adicionalmente um grupo controle, verificou-se que tanto o lado acometido quanto o lado não acometido obtiveram angulações de dorsiflexão maiores do que o grupo Controle.

Adicionalmente, como possível meio de compensação, nesta fase de médio apoio, foi encontrada maior flexão do joelho no grupo com PTC unilateral, com maiores ângulos para o lado não acometido, seguido do acometido (TABELAS 22 e 44; FIGURA 35). Essas alterações de posicionamento articular podem ser devido à fraqueza de músculos estabilizadores da região. Segundo uma das teorias descritas por MURATLI et al. (2005), quando o músculo gastrocnêmio está fraco e perde seu controle protetor articular, a tíbia move-se para frente e induz à flexão do joelho. No entanto, os mesmos autores verificaram que, cerca da metade das crianças apresentaram hiperextensão do joelho, em membros inferiores com acometimento do PTC, na fase do apoio da marcha. Segundo suas explicações, isso pode ocorrer nos casos em que existe uma limitação grande de movimentação do tornozelo, o que evita o deslocamento excessivo da tíbia e aumenta, como conseqüência, a extensão do joelho.

O aumento da dorsiflexão de tornozelo, associado com o aumento de flexão do joelho, pode justificar a diminuição da magnitude da FRS vertical no médio apoio no lado não acometido de crianças com PTC unilateral. A variável 
FZ_min, apesar de não ser selecionada na análise dos componentes principais, demonstrou valores menores nas crianças com PTC unilateral do lado não acometido (TABELAS 41 e 44). Isso demonstra que essas crianças abaixam o Centro de Massa além do normal.

Pode-se notar que em alguns parâmetros as crianças com PTC unilateral apresentam diferenças em relação ao grupo Controle do que as com PTC bilateral. O comportamento da variação angular do tornozelo e joelho neste instante está ligado a esta afirmação.

Deve-se considerar que a presença da maior dorsiflexão do tornozelo e flexão do joelho no médio apoio, apresentadas nos grupos com PTC unilateral, podem facilitar o maior abaixamento do centro de massa, o que contribui para a maior dificuldade em vencer a ação da gravidade na fase de propulsão.

De fato, foi verificado que ambos os grupos com PTC, indiferentemente do lado, têm deficiência na fase de propulsão da marcha, de acordo com os dados de impulso de propulsão da FRS ântero-posterior (TABELAS 22 e 44; FIGURA 37) e do segundo pico da FRS vertical (TABELAS 22 e 44; FIGURA 36), os quais mostraram déficit ainda maior para o lado acometido do grupo PTC unilateral. Esses achados foram semelhantes aos encontrados por FAVRE et al. (2007), DAVIES et al. (2001), MURATLI et al. (2005), THEOLOGIS et al. (2002) e WIDHE e BERGGREN (1994), os quais verificaram uma ineficiência na fase de propulsão da marcha em crianças com PTC.

Parâmetros angulares também foram diferenciados nas crianças com PTC; na articulação do tornozelo existiu uma menor flexão plantar para os lados não acometido e acometido do grupo com PTC unilateral, comparados com o Controle (TABELAS 22 e 44; FIGURA 38). Esses achados são semelhantes aos encontrados nos trabalhos de KAROL, CONCHA e JOHNSTON (1997), WIDHE e BERGGREN (1994) e HEE, LEE e LEE (2001). DAVIES et al. (2001), os quais avaliaram crianças com uma idade mais avançada do que as do presente estudo, verificaram uma maior deficiência no lado acometido de crianças com PTC, quando comparado com o lado contralateral.

Muito se discute sobre as causas desses desequilíbrios, as quais podem estar relacionadas com a hipotrofia do músculo tríceps sural, associada 
aos procedimentos cirúrgicos adotados e provenientes das próprias deformidades residuais existentes após tratamento. OTIS e BOHNE (1986) verificaram uma alteração na ativação muscular do gastrocnêmio medial durante a marcha de crianças com acometimento bilateral. KAROL, CONCHA e JOHNSTON (1997) verificaram alterações nas ativações do músculo tibial anterior e dos fibulares. Isso pode auxiliar para o entendimento de fatores musculares que contribuem para as características diferenciadas da marcha encontradas nos grupos com PTC. No presente estudo, optou-se por não analisar a atividade eletromiográfica na marcha para não gerar possível efeito retroativo durante o procedimento experimental.

$O$ presente trabalho não avaliou a variação angular no plano transversal. No entanto, HEE, LEE e LEE (2001), THEOLOGIS et al. (2002) e DAVIES et al. (2001) verificaram que crianças com história de PTC tratadas cirurgicamente possuem um excesso de rotação da perna na fase de apoio da marcha.

De forma geral, o presente estudo identificou que as crianças com história de acometimento de PTC unilateral, comparadas com as de acometimento bilateral, possuíram mais características de desequilíbrios nos parâmetros biomecânicos investigados durante a marcha. Esse resultado está de acordo com os de WIDHE e BERGGREN (1994) e de DAVIES et al. (2001) e pode estar relacionado com os maiores desequilíbrios entre os segmentos nessa população, o que faz com que essas crianças tenham necessidade de maiores compensações entre os membros inferiores acometidos e não acometido.

\subsection{Salto vertical com contra-movimento}

Os estudos à respeito da locomoção em crianças são geralmente associados à marcha e corrida (LOBO DA COSTA, 2000). Poucas referências da literatura científica abordam outras atividades funcionais da locomoção em crianças. O salto vertical, por exemplo, tem sua importância em virtude de ser uma atividade funcional aplicada tanto no treinamento quanto na reabilitação (SWARTZ et al., 2005). Tais atividades geram cargas mecânicas diferenciadas que podem ter importante função no desenvolvimento osteo-mio-articular infantil. Mas a 
quantidade ideal e a forma precisa de estímulos para que tal atividade física possa produzir resultados positivos ainda são pouco caracterizadas (McKAY et al., 2005).

Existem descrições de tal atividade em crianças sem nenhuma história de patologia, as quais se relacionam com aspectos tanto cinéticos quanto de variação angular. KELLIS (2001) preocupou-se em caracterizar a pressão plantar durante a aterrissagem e relatou a importância de trabalhos como este para futuras comparações com dados de crianças com acometimento músculoesquelético. $O$ autor faz tal afirmação, pois relata que essa atividade gera grandes valores de pressão. Outros trabalhos, principalmente nos últimos anos, utilizaramse de diversas formas de salto para quantificar a variação angular e da FRS com preocupações na fase de aterrissagem do movimento (SWARTZ et al., 2005; McKAY et al., 2005). Tal fase, segundo esses autores, é caracterizada por apresentar valores elevados da FRS vertical e, conseqüentemente, favorecer a predisposição de lesões musculo-esqueléticas.

Todavia, tais investigações não são comumente vistas em crianças com seqüelas de patologias músculo-esqueléticas. $O$ presente estudo investigou parâmetros biomecânicos relacionados com 0 salto vertical com contramovimento, tanto em sua fase de preparação quanto da aterrissagem. Como mencionado na revisão de literatura, ainda não existe uma caracterização homogênea dos achados para dados referentes a tal atividade em crianças. Autores investigam a aterrissagem, em diversas atividades e de diferentes formas, desde quedas de alturas padronizadas até quedas a partir do salto saindo do solo. Autores buscam padronizar a altura da queda com escopo de minimizar as variações inter-sujeitos, visto que, dessa forma, todos têm um comportamento mais similar de início do movimento. No presente estudo, foi decidido realizar uma atividade mais funcional, com todas as etapas envolvidas em um salto, pois, dessa forma, consegue-se entender as particulariedades da preparação para o evento, não tendo a pesquisa vinculanda apenas ao estudo de aspectos que envolvem a fase de absorção da energia referente à aterrissagem.

Foram investigadas, além de características de variação angular e cinéticas, destacadas no experimento anterior, particularidades eletromiográficas.

Ressalta-se que não foram encontrados valores na literatura de CV 
referentes aos dados de variação angular, de FRS vertical e de eletromiografia no salto vertical com contra-movimento. Verificou-se, no presente estudo, que o CV foi semelhante entre os grupos, tanto para a FRS vertical quanto para a eletromiografia e para a variação angular (TABELAS 23, 24 e 25).

Verificou-se, para os dados da FRS vertical e da variação angular, valores aumentados para a fase de aterrissagem, comparados com a de preparação (TABELA 23 e 25). Isso demonstra que, em tal atividade, existiu importante variação no controle da queda em todas as crianças investigadas.

No momento da preparação do salto, foram encontrados menores valores angulares para a dorsiflexão, tanto para o grupo PTC unilateral lado acometido, quanto para os dos lados do grupo Bilateral (TABELAS 26 e 51; FIGURA 50). Isso mostra que, em atividades que necessitam de um movimento angular amplo do tornozelo, característico da preparação do salto, crianças com PTC possuem limitações para tal, o que pode prejudicar a restituição de energia e adequada contração muscular de flexores plantares.

Essa característica pode estar associada à tendência encontrada no grupo PTC unilateral de diminuição do pico da FRS vertical ( $F$ max1) na fase propulsiva do salto vertical (TABELAS 26 e 50; FIGURA 51). No momento da retirada do pé, na fase final do salto, existiu, adicionalmente, uma menor angulação de flexão plantar para ambos os grupos com PTC (TABELAS 26 e 51; FIGURA 53), que são acompanhados por uma maior angulação de flexão do joelho nesta fase (TABELAS 26 e 51; FIGURA 54). Nessa fase, há característica de maior extensão do joelho associada a flexão plantar aumentada, pois, dessa forma, consegue-se maior aproveitamento das forças exercidas para este movimento (SWARTZ et al., 2005). Verificou-se, portanto, que, em toda fase de preparação para o salto vertical, existiu uma deficiência de amplitude articular, tanto do tornozelo quanto do joelho, a qual pode ter contribuído para a menor FRS encontrada nas crianças com PTC.

Tanto no instante de flexão do joelho e dorsiflexão do tornozelo no início da fase preparatória, quanto no momento de impulsão do segmento para cima, com uma extensão do joelho e flexão plantar, a ação muscular é fundamental para a boa efetividade do movimento. Para isso, além de músculos 
da coxa, há necessidade de uma adequada contração de músculos posteriores da perna. Nessa fase de propulsão, existiu a diminuição da atividade do músculo gastrocnêmio medial no lado acometido do grupo com PTC unilateral (TABELAS 26 e 51; FIGURA 52).

Ou seja, os menores valores de variação angular do joelho e tornozelo, associados à menor atividade eletromiográfica do músculo gastrocnêmio medial, são fatores que podem contribuir para diminuição da FRS na fase de preparação. Tais achados mostram as alterações resultantes do PTC e apontam que o comprometimento da amplitude articular e da ação muscular podem gerar um movimento diferente, que resulta em menores valores de força aplicados ao solo. Dessa forma, o movimento resultante destas crianças pode ser caracterizado como ineficiente, quando comparado ao grupo Controle.

Investigações têm como resultados uma máxima FRS vertical na fase da aterrissagem que varia de 8,5 vezes o peso corporal (BAUER, FUCHS \& SMITH, 2001) a 4,7 vezes (McKAY et al., 2005). Nesse último trabalho, foram encontrados, no salto vertical com contra-movimento, valores máximos da FRS vertical no momento da aterrissagem superiores a 5 vezes o peso corporal $(5,3 \pm$ $1,6 \mathrm{PC}$ ). No presente trabalho, as crianças tiveram uma média de 3,2 vezes 0 peso corporal, sendo encontrados valores um pouco menores para o grupo Controle (TABELA 49).

Achados também diferentes foram apresentados por BAUER, FUCHS e SMITH (2001) e McKAY et al. (2005) ao analisar dados relacionados à taxa de crescimento para máxima magnitude da FRS na aterrissagem. McKAY et al. (2005) encontraram valores superiores a $400 \mathrm{PC} / \mathrm{s}(496 \pm 306 \mathrm{PC} / \mathrm{s})$. No presente estudo, encontraram-se valores muito menores, tanto para os grupos com PTC unilateral e bilateral, como para o grupo Controle $(58,6 \pm 41,7 \mathrm{PC} / \mathrm{s}, 63,2 \pm 39,9 \mathrm{PC} / \mathrm{s}$ e 40,4 $\pm 30,8 \mathrm{PC} / \mathrm{s}$, respectivamente). Nota-se que todos esses trabalhos possuem um desvio padrão elevado, o que demonstra que, possivelmente, haja uma inconsistência típica em alguns parâmetros referentes à locomoção infantil. Uma possível justificativa para esses diferentes achados pode estar associada à população investigada. Enquanto McKAY et al. (2005) investigaram crianças com 
idade média de 10,2 $\pm 0,7$ anos; o presente trabalho investigou crianças mais jovens. Portanto, $\mathrm{o}$ desempenho do salto pode ser diferenciado e, conseqüentemente, podem ter contribuído para resultados diferenciais dos encontrados no presente estudo. Adicionalmente, as crianças avaliadas por McKAY et al. (2005) eram vinculadas a atividades esportivas escolares, característica esta não evidenciada no presente trabalho.

$\mathrm{Na}$ fase de aterrissagem, os Grupos com PTC apresentaram menor angulação de flexão plantar (TABELAS 26 e 51; FIGURA 56), sendo acompanhados de uma maior angulação de flexão do joelho no grupo PTC unilateral (TABELAS 26 e 51; FIGURA 55). A taxa de crescimento foi maior para ambos os grupos com PTC (TABELAS 26 e 50; FIGURA 57). A ação do gastrocnêmio medial é fundamental na aterrissagem, com função de desacelerar o segmento do tornozelo no início do contato com o solo. No atual estudo, esperavam-se diferenças relacionadas à sua ação nos dois grupos com PTC. Tal hipótese baseia-se nos procedimentos adotados na cirurgia realizada com as crianças, que passaram por tenotomia e alongamento do tendão calcâneo. No entanto, foi encontrado maior atividade do músculo gastrocnêmio na fase de desaceleração no lado não acometido do grupo PTC unilateral (TABELAS 26 e 51, FIGURA 58). Com a existência de maior desequilíbrio entre os membros inferiores em crianças com PTC unilateral, constata-se que a musculatura que contribui para a desaceleração dos segmentos pé e tornozelo tem maior ação muscular no lado contralateral ao acometido por ter a necessidade de compensar desequilíbrios estruturais encontrados no outro segmento. Esses desequilíbrios talvez não estejam relacionados aos procedimentos cirúrgicos adotados em todas as crianças com PTC, as quais passaram por uma tenotomia e alongamento do tendão do calcâneo. Tal fato deve-se principalmente em razão do achado de que tanto para a perna acometida das crianças com comprometimento unilateral quanto para as com acometimento bilateral não tiveram diferenças significativas comparadas com as encontradas no grupo Controle.

Portanto, de forma geral, crianças com histórico de PTC podem não possuir um adequado gerenciamento, tanto da fase de preparação quanto da fase de aterrissagem, do salto vertical com contra-movimento. 


\subsection{Sensibilidade plantar}

Alterações sensitivas na região plantar podem gerar deficiências na locomoção e, conseqüentemente, influenciar nas diferentes cargas sofridas pelo aparelho locomotor. Diante desse aspecto, nota-se a importância de investigações da sensibilidade do pé em portadores de PTC, visto que até então nenhuma referência da literatura abordou tal avaliação.

O controle postural humano é determinado, dentre outros fatores, pela integridade dos sistemas somatosensorial, visual e vestibular. Desta forma, sabese que os mecanorreceptores plantares, envolvidos no sistema somatosensorial, têm grande influência na postura humana (PRÄTORIUS, KIMMESKAMP \& MILANI, 2003). Portanto, torna-se interessante entender se crianças com PTC têm deficiência sensitiva plantar, pois estas podem estar relacionadas com alterações do controle motor em atividades funcionais. PRÄTORIUS, KIMMESKAMP e MILANI (2003) identificaram que, em pacientes com doença de Parkinson, a alteração da percepção a estímulos plantares gera alteração nas habilidades motoras desses pacientes.

No presente trabalho, as crianças avaliadas não apresentaram deficiências de sensibilidade na pressão plantar (TABELAS 27 e 52). Ou seja, as características da patologia e o ato cirúrgico adotado nas crianças não geraram alterações de sensibilidade. Portanto, acredita-se que as alterações encontradas nos parâmetros biomecânicos das crianças com PTC não estejam relacionadas diretamente às deficiências na sensibilidade tátil e de pressão da planta do pé.

\subsection{Considerações gerais}

Um dos grandes questionamentos do estudo relaciona-se à influência do ato cirúrgico sobre os resultados. Sabe-se que a cirurgia busca as correções estruturais existentes na região. Para isso, são utilizadas técnicas as quais realizam liberações de tecidos moles e transposições de tendões e ligamentos. De fato, em muitos casos, há bons resultados no efeito estético do pé das crianças (HEILIG et al., 2003; NIMITYONGSKUL, ANDERSON \& HEBERT, 1992). 
Contudo, no meio clínico questiona-se se essas correções são funcionais para as crianças.

Atualmente são utilizadas técnicas não-cirúrgicas para o tratamento do PTC e apesar de não interferirem cirurgicamente nas estruturas estabilizadoras estáticas e dinâmicas da região, também geram bons resultados estéticos. Essas técnicas se baseiam no princípio de que, nos primeiros dias de vida da criança, há facilidade de adaptação do tecido conectivo denso aos estímulos externos aplicados na região. No entanto, uma das complicações é a possibilidade maior de recidiva da deformidade conforme o desenvolvimento físico da criança (HEILIG et al., 2003; IPPOLITO et al., 2003a).

Para investigar a influência do ato cirúrgico nessas habilidades, há necessidade de comparar os resultados encontrados no atual trabalho com os de crianças submetidas ao tratamento conservador. Dessa forma, pode-se de fato verificar se tais desequilíbrios são maiores ou menores, dependendo da conduta adotada. WIRCART, RICHARDSON e MATON (2005), por exemplo, encontraram deficiências em crianças tratadas de forma conservadora na fase de propulsão da marcha. Entretanto, não realizaram tal investigação com crianças tratadas de forma cirúrgica, o que impossibilita maiores discussões sobre tal temática. Um dos poucos trabalhos que realizaram comparações entre tipos de tratamento foi o apresentado por KAROL et al. (2005). Nessa pesquisa, foram investigadas características de variação angular na marcha de crianças que passaram por vários tipos de tratamento, e foi verificado que, apesar da existência de deficiências angulares em todos os grupos, as tratadas de forma conservadora tiveram menores desequilíbrios. Ressalta-se que, nesse trabalho, os pesquisadores não se preocuparam em subdividir os grupos em crianças com acometimento bilateral e unilateral. Além disso, não conseguiram manter uma quantidade homogênia de crianças nos grupos, pois de 36 crianças tratadas de forma conservadora, apenas cinco foram tratadas de forma conservadora em adição à tenotomia do calcâneo, 14 crianças realizaram liberação cirúrgica posterior e apenas nove realizaram liberação cirúrgica póstero-medial.

Adicionalmente ao entendimento das características de parâmetros biomecânicas relacionados com a locomoção dessas crianças, há necessidade da 
compreensão do comportamento dos movimentos acessórios articulares da região durante a locomoção. Se a movimentação acessória não estiver adequada, como pode ser o caso em crianças com PTC, automaticamente a movimentação funcional do segmento estará comprometida. Ressalta-se que, no presente trabalho, a variação angular das articulações do joelho e tornozelo, tanto na marcha quanto no salto vertical, encontraram-se diferenciados do grupo Controle. A possível deficiência da movimentação acessória poderá alterar as áreas de contato entre as superfícies ósseas que compõe as articulações. Essa alteração resultará em possíveis sobrecargas em regiões pouco susceptíveis à transferência de forças, o que irá gerar um estresse maior na região e conseqüentemente uma predisposição de osteoartrose. Tal preocupação tem sido descrita por vários autores, dentre eles, destacam-se MAQUET (1976) e BEYAERT et al. (2003), os quais relacionaram as alterações de movimentação acessória no membro inferior com a predisposição de osteoartrose no joelho e tornozelo.

Caso exista uma alteração da movimentação acessória no segmento inferior das crianças com PTC, cuidados devem ser tomados para que elas não tenham maior predisposição de osteoartrose na região. Tal fato deve-se aos achados encontrados no presente estudo, referentes aos elevados índices da taxa de crescimento para as magnitudes de força, tanto no início do apoio da marcha quanto na fase de aterrissagem do salto vertical.

Portanto, crianças com história de PTC tratadas por diferentes métodos podem possuir alterações residuais de posicionamento articular, que comprometem as movimentações acessórias da região e, conseqüentemente, alteram as características de amplitude articular fisiológica natural. Adicionalmente, pode também gerar alterações nas áreas de contato entre as superfícies articulares e facilitar o aumento do estresse na região. No presente trabalho, foram encontradas deficiências na movimentação fisiológica tanto do joelho quanto no tornozelo durante a marcha e salto vertical com contramovimento. Além disso, alterações da FRS, durante tais atividades, também foram diferenciadas nessa população. $O$ fato da existência dessas características faz com que haja preocupação com o excesso de sobrecarga na região por favorecer o aumento do estresse e conseqüente osteoartrose. 


\section{$7 \quad$ CONCLUSÕES}

No presente estudo, foram investigadas características da marcha autoselecionada e do salto vertical com contra-movimento de crianças com história de PTC com acometimentos unilateral e bilateral, tratadas de forma cirúrgica. Apesar da semelhança entre os grupos com PTC e Controle, nas médias das curvas analisadas para a FRS, variação angular e eletromiografia, variáveis biomecânicas mostraram diferenças. A partir da análise e discussão dos resultados, pode-se destacar algumas conclusões:

- existência de uma adaptação do controle protetor das crianças com PTC na fase inicial do apoio da marcha, baseada principalmente nos maiores valores da taxa de crescimento para o primeiro pico da FRS vertical e nas alterações da variação angular encontradas nesta fase;

- alterações nos valores cinéticos e de variação angular na fase do médio apoio da marcha no grupo com PTC unilateral, o qual apresentou a maior flexão do joelho e dorsiflexão do tornozelo, e uma diminuição da FRS vertical;

- existência de uma adaptação na fase de propulsão da marcha dos grupos com PTC, em decorrência da alteração na magnitude da FRS ântero-posterior, do menor segundo pico da FRS vertical, além da diminuição da flexão plantar nesta fase. Este último só encontrado no grupo com PTC unilateral;

- alterações para os grupos com PTC no momento da preparação do salto vertical, com diminuição da dorsiflexão para os segmentos acometidos;

- adaptações na fase de impulsão para o salto vertical nas crianças com história de PTC com menor flexão plantar e maior flexão do joelho, os quais podem ter contribuído para a menor FRS vertical. Destaca-se, nesta fase, a diminuição da atividade do músculo gastrocnêmio medial no lado acometido do grupo com PTC unilateral; 
- adaptação no controle na transferência do choque mecânico na fase de aterrissagem do salto vertical nas crianças com PTC, com uma maior taxa de crescimento para a máxima magnitude da FRS vertical, associada a uma menor angulação de flexão plantar e maior angulação de flexão do joelho, evidenciadas no grupo com PTC unilateral;

- maior atividade elétrica do músculo gastrocnêmio na fase de desaceleração no lado não acometido do grupo PTC unilateral;

- não identificação de alterações relacionadas com a avaliação da sensibilidade plantar, por meio da investigação com estesiômetro, nas crianças com PTC investigadas.

As alterações encontradas entre os parâmetros analisados permitem 0 entendimento de desequilíbrios existentes nessa população e, assim, contribuem para as melhores informações tanto para a conduta da reabilitação quanto na orientação de atividades físicas direcionadas a essa população. No entanto, para melhor definição dessas características, futuras investigações devem utilizar métodos de pesquisa que quantifiquem as forças internas intra-articulares da região afetada para que possa ser entendida a situação real do comprometimento articular em atividades funcionais. Adicionalmente, investigações devem ser realizadas com o intuito de comparar os achados de análises com instumentais da Biomecânica em crianças com história de acometimento do PTC, tratadas com diferentes técnicas cirúrgicas e conservadoras.

O presente estudo tem sua relevância visto que buscou o entendimento do comportamento de como o sistema locomotor opera durante as atividades propostas. Dessa forma, contribuiu para o direcionamento de estímulos adequados durante a prática da atividade física para esse grupo de crianças, fato este que pode contribuir para uma conduta profilática na tentativa de minimizar tais desequilíbrios e, conseqüentemente, prevenir lesões. 


\section{REFERÊNCIAS}

AHMED, M.; AHMED, N.; KHAN, K.M.; UMER, M.; RASHID, H.; HASHMI, P.; UMAR, M. Sensory hypoinnervation in club foot. The Journal of Bone \& Joint Surgery (Br), v.86-B, n.8, p.1163-1169, 2004.

AMADIO, A. C.; COSTA, P. H. L.; SACCO, I. C. N.; SERRÃO, J. C.; ARAÚJO, R. C., MOCHIZUKI, L.; DUARTE, M. Introdução à análise do movimento humano descrição e aplicação dos métodos biomecânicos de medição. Revista Brasileira de Fisioterapia, São Carlos, v.2, n.3, p.41-54, 1999.

AMADIO, A. C.; DUARTE, M. Fundamentos biomecânicos para a análise do movimento humano. São Paulo: Laboratório de Biomecânica / EEFUSP, 1996. p. 9-58.

ANDRIACCHI, T.P.; ALEXANDER, E.J. Studies of locomotion: past, present and future. Journal of Biomechanics, New York, n.33, p.1217-1224, 2000.

ARAÚJO, R.C. Utilização da eletromiografia na análise do movimento humano. São Paulo, 1999. 151p. Tese (Doutorado) - Escola de Educação Física e Esporte, Universidade de São Paulo.

ARONSON, J.; PUSKARICH, C.L. Deformity and disability from treated clubfoot. Journal of Pediatric Orthopaedics. New York, v.10, n.1, p. 109-119, 1990.

BANSAL, V.P.; DANIEL, J.; RAÍ, J. Radiological score in the assessment of clubfoot. International Orthopaedics, Heidelberg, n.12, p.181-185, 1988.

BASMANJIAN, J.V.; DE LUCA, C.J. Muscle alive: their functions revealed by electromyography. 5. ed. Baltimore: Williams \& Wilkins, 1985.

BAUER, J.; FUCHS, R.; SMITH, G. Quantifying force magnitude and loading rate from drop landing that induce osteogenisis. Journal of Applied Biomechanics, Champaign, n.17, p.142-152, 2001. 
BECK, R.J.; ANDRIACCHI, T.P.; KUO, K.N.; FERMIER, R.W.; GALANTE, J.O. Changes in the gait patterns of growing children. Journal of Bone and Joint Surgery, London, v.9, n.63, p.1452-1457, 1981.

BEYAERT, C.; HAUMONT, T.; PAYASANT, J; LASCOMBES, P.; ANDRE, J.M. The effect of inturning of the foot on knee kinematics and kinetics in children with treated idiopathic clubfoot. Clinical Biomechanics, New York, v.18, p.670-676, 2003.

BEYNNON, B.; JOHNSON, R.J.; FLEMING, B.J. The Science of anterior cruciate ligament rehabilitation. Clinical Orthopaedics \& Related Research, lowa City, v.402, p. 9-20, 2002.

BRUDEN, A.; BARTLETT, R. Normalization of EMG amplitude: an evaluation and comparison of old and new methods. Medical Engineering \& Physics, Oxford, n.21, p.247-257, 1999.

CHAMBERS, H.G.; SUTHERLAND, D.H. A practical guide to gait analysis. Journal of the American Academy of Orthopaedics Surgeons, Rosemont, v.10, p.222-231, 2002.

CHAO, E.Y.; LAUGHMAN, R.K.; SCHNEIDER, E.; STAUFFER, R.N. Normative data of knee joint motion and ground reaction forces in adult level walking. Journal of Biomechanics, New York, v.16, n.3, p.219-233, 1983.

CHEN, H.; NIGG, B. M.; HULLIGER, M.; DE KONING, J. Influence of sensory input on plantar pressure distribution. Clinical Biomechanics, New York, v.10, p.271274, 1995.

CLANCY, E. A.; MORIN, E. L.; MERLETTI, R. Sampling, noise-reduction and amplitude estimation issues in surface electromyography. Journal of Electromyography and Kinesiology, Oxford, v.12, p.1-16, 2002.

CLIFFORD, J.; JAMES, M.; MARK M. Sensory thresholds of normal human feet. Foot \& Ankle International, v.21, n.6, p. 501-504, 2000. 
COLBURN, M.; WILLIAMS, M. Evaluation of the treatment of idiopathic clubfoot by using the Ponseti method. The Journal of Foot and Ankle Surgery, Philadelphia, v.42, p.259-267, 2003.

DAVID, A.C. Aspectos biomecânicos do andar em crianças: cinemática e cinética. Santa Maria, 2000. 142p. Tese (Doutorado) - Universidade Federal de Santa Maria.

DAVIES, T.C.; KIEFER, G.K.; ZERNICKE, R.F. Kinematics and kinetics of the hip, knee, and ankle of children with clubfoot after posteromedial release. Journal of Pediatric Orthopaedics, Philadelphia, v.21, n.3, p.366-371, 2001.

DE LUCA, C. J. The use of surface electromyography in biomechanics. Journal of Applied Biomechanics. Champaign, n.13, p.135-163, 1997.

DE LUCA, C.J., VAN DYK, E.J. Derivation of some parameters of myoelectric signals recorded during sustained constant force isometric contractions. Biophsical Journal. Bethesda, v.15, n.2, p.1167-1180, 1975.

DOBBS, M. B.; MORCUENDE, J. A.; GURNETT, C. A.; PONSETI, I. V. Treatment of idiopathic clubfoot: an historical review. The lowa Orthopaedics Journal, lowa City, v.20, p. 59-63, 2000.

DUFEK, J.; BATES, B. The evaluation and prediction of impact forces during landings. Medicine and Science in Sports and Exercise, Madison, v.22, n.2, p.370-377, 1990.

FANTOZZI, S.; BENEDETTI, G. M.; LEARDINI, A.; BANKS, A. S.; CAPELLO, A.; ASSIRELLI, D.; CATANI, F. Fluoroscopic and gait analysis of the functional performance in stair ascent of total knee replacement designs. Gait and Posture, New York, v.17, p.225-234, 2002.

FAVRE, P.; EXNER, G.U.; DRERUP, B.; SCHIMID, D.; WETZ, H.H.; JABOB, H.A. The contralateral foot in children with unilateral clubfoot: a study of pressures and 
forces involved in gait. Journal of Pediatric Orthopedics, Philadelphia, v.27, n.7, p.54-59, 2007.

HARGRAVE, M. D.; CARCIA, C. R.; GANSNEDER, B. M.; SHULTZ, S. J. Subtalar pronation does not influence impact forces or rate of loading during a single-leg landing. Journal of Athletic Training, Columbus, v. 38, n.1, p.18-23, 2003.

HAUSDORFF, J. M.; ZEMANY, L.; PENG, C. K.; GOLDBERGER, A. L. Maturation of gait dynamics: stride-to-stride variability and its temporal organization in children. Journal of Applied Physiology, Bethesda, v.83, n.3, p.1040-1047, 1999.

HEE, H.T.; LEE, E.H.; LEE, G. S. M. Gait and Pedobarographic patterns of surgical treated clubfeet. The Journal of Foot \& Ankle Surgery, New York, v.40, n.5, p.287-294, 2001.

HEILIG, M. L.; MATERN, R. V.; ROSENZWEIG, S. D.; BENNETT, J. T. Current management of idiopathic clubfoot questionnaire: a multicentric study. Journal Pediatric Orthopeadic, Baltimore, v.23, n.6, p.780-787, 2003.

HENNIG, E.M.; ROSENBAUM, D. Pressure distribution patterns under the feet of children in comparison with adults. Foot \& Ankle, v.5, n.11, p.306-311, 1991.

HERD, F.; MACNICOL, M.; ABDOUD, R.J. The need biomechanical evaluation in the assessment of clubfoot. The Foot, New York, n.14, p.72-76, 2004.

HERMENS, H.J.; FRERIKS, B.; DISSELHORST-KLUG, C.; RAU, G. Development of recommendations for SEMG sensors and sensor placement procedures. Journal of Electromyography and Kinesiology, Oxford, v.10, p.361-374, 2000.

HERZENBERG, J.E.; RADLER, C.; BOR, N. Ponseti versus traditional methods of casting for idiopathic clubfoot. Journal Pediatric Orthopaedic, Baltimore, v.22, n.4, p.517-521, 2003.

HERZOG, Walter. Clinical biomechanics of spinal manipulation.New York: Churchill Livingstone, 2000. 
HERZOG, W.; NIGG, B.; READ, L.; OLSSON, E. Asymmetries in ground reaction force patterns in normal human gait. Medicine Science Sports Exercise, v. 21, p.110-114, 1989.

IPPOLITO, E.; FARSETT, P.; CATERINI, R.; TUDISCO, C. Long-term comparative results in patients with congenital clubfoot treated with two different protocols. The Journal of Bone and Joint Surgery, v.85-A, n.7, p.1286-1294, 2003a.

IPPOLITO, E.; FRARACCI, L.; CATERINI, R.; Di MARIO, M.; FARSETTI, P. A radiographic comparative study of two series of skeletally mature clubfeet treated by two different protocols. Skeletal Radiology, v.32, p.446-453, 2003b.

KAMEGAYA, M.; SHINOHARA, S. Gait disorders and leg deformities in children. Journal of Orthopaedic Science, Tokyo, v.7, p.154-159, 2002.

KANEKASU, K.; BANKS, A. S.; HONJO, S.; O.; NAKATA, O.; KATO, H. Fluoroscopic analysis of knee arthroplasty kinematics during deep flexion kneeling. The Journal of Arthroplasty, v.19, n.8, p.998-1002, 2004.

KAROL, L.A.; CONCHA, M.C.; JOHNSTON, C.E. Gait analysis and muscle strength in children with surgically treated clubfeet. Journal Pediatric Orthopaedic, Baltimore, v.17, n.6, p.790-795, 1997.

KAROL, L.A; O'BRIEN, S.E; WILSON, H.; JOHNSTON, C.E.; RICHARDS, B.S. Gait analysis in children with severe clubfeet: early results of physiotherapy versus surgical release. Journal Pediatric Orthopaedic, Baltimore, v.25, n.2, p.236-240, 2005.

KELLIS, E. Plantar pressure distribution during barefoot standing, walking and landing in preschool boys. Gait and Posture, New York, n. 14, p.92-97, 2001.

KISNER, C.; COLBY, A. L. Exercícios terapêuticos: fundamentos e técnicas. 3.ed. São Paulo: Manole, 1998. p.689. 
KYRIAZIS, V. Temporal gait analysis of children aged 9-10 years. Journal of Orthopaedic and Traumatologic, v.3, p.31-34, 2002.

LAAVEG, S.; PONSETI, I.V. Long-term results of treatment of congenital club foot. The Journal of Bone and Joint Surgery, v.62, n.1, p.23-31, 1980.

LIEBERMANN, D.G.; GOODMAN, D. Pre-landing muscle timing and post-landing effects of falling with continuous vision and in blindfold conditions. Journal of Electromyography and Kinesiology, 2006. (in press). Disponível em: http://linkinghub.elsevier.com/retrieve/pii/S1050-6411(06)00029-0. Acesso em: jan. 2006.

LOBO DA COSTA, P.H. Aspectos biomecânicos da locomoção infantil: grandezas cinéticas no andar e no correr. 2000. 189f. Tese (Doutorado) Universidade de São Paulo, Escola de Educação Física e Esporte, São Paulo, 2000.

MACHADO, D. B.; HENNIG, E.; RIEHLE, H. Plantar pressure distribution in children: movement patterns and footwear influences. Brazilian Journal of Biomechanics, São Paulo, n.2, p.19-25, 2001.

MANN, R.A.; HAGY, J.H. Biomechanics of walking, running, and sprinting. American Journal of Sports Medicine, Columbus, v.5, n.8 p.345-350, 1980.

MAQUET, P. G. J. Biomechanics of the knee: with application to the pathogenesis and the surgical treatment of osteoarthritis. New York: SpringerVerlag, 1976. p. 20-101.

MAROCO, J. Análise estatística com utilização do SPSS. 2. ed. Lisboa: Edições Sílabo, 2003.

McKAY, H.; TSANG, G.; HEINONEM, A.; MACKELVIE, K.; SANDERSON, D.; KHAN, K. M. Ground reaction forces associated with an effective elementary school based jumping intervention. British Journal Sports, Vancouver, v. 39, p.10-14, 2005. 
McNITT-GRAY, J. L. Kinematics and impulse characteristics of drop lands from three heights. International Journal Sports Biomechanics, v.7, p.201-224, 1991.

McNITT-GRAY, J.L.; HESTER, D.M.E.; MATHIYAKOM, W.; MUNKASY, B.A. Mechanical demand and multijoit control during landing depend on orientation of the body segments relative to the reaction force. Journal of Biomechanics. New York, v.34, p.1471-1482, 2001.

MORCUENDE, J.A.; DOLAN, L.A.; DIETZ, F.R.; PONSETI, I.V. Radical reduction in the rate of extensive corrective surgery for clubfoot using the Ponseti method. Pediatrics, Elky Grove Village, v.113, n.2, p.376-380, 2004.

MORCUENDE, J.A.; WEINSTEIN, S.L.; DIETZ, F.R.; PONSETI, I.V. Plaster cast treatment of clubfoot: the Ponseti method of manipulation and casting. Journal Pediatric Orthopeadics, Part B, New York, v.2, n.3, p. 161-167, 1974.

MURATLI, H.H; DAGLI, C.; YAVUZER, G.; ÇELEBI, L.; BIÇIMOGLU, A. Gait characteristics of patients with bilateral club feet following posteromedial release procedure. Journal Pediatric Orthopeadics B, v.14, n.3, p. 206-211, 2005.

NIMITYONGSKUL, P.; ANDERSON, L. D.; HEBERT, D. E. Surgical treatment of clubfoot: a comparison of two techniques. Foot and Ankle, v.13, n.3, p.116-124, 1992.

NOVEL. Product information. Emed system. Disponível em: <http://www.novel.de/ roductinfo/ systems - emed.htm> Acesso em: 8 set. 2005.

NURSE, M.; NIGG, B. Quantifying a relationship between tactile and vibration sensitivity of the human foot with plantar pressure distributions during gait. Clinical Biomechanics, New York, n.14, p.667-672, 1999.

ORLIN, N. M.; McPOIL, T. G. Plantar pressure assessment. Physical Therapy, Alexandria, v.80, n.4, p.399-409, 2000. 
OTIS, J.C.; BOHNE, W.H. O. Gait analysis in surgically treated clubfoot. Journal of Pediatric Orthopedics, New York, v.6, n.2, p.162-164, 1986.

PAIN, M.T.G.; CHALLIS, J.H. The influence of soft tissue movement on ground reaction forces, joint torques and joint reaction forces in drop landing. Journal of Biomechanics. New York, v.39, p.119-124, 2006.

PONSETI, I.V.; EL-KHOURY, G.Y.; IPPOLITO, E.; WEINSTEIN,S.L. A radiographic stuty of skeletal deformities in treated clubfeet. Clinical Orthopaedics \& Related Research, lowa City, v.160, p.30-42, 1981.

POWERS, C.M.; WARD, S.R.; FREDERICSON, M.; GUILLET, M.; SHELLOCK, F.G. Patellofemoral kinematics during weight-bearing and non-weight-bearing knee extension in persons with lateral subluxation of the patella: a preliminary study. Journal of Orthopaedic \& Sports Physical Therapy, La Crosse, v.33, n.11, 677685, 2003.

PRÄTORIUS, B; KIMMESKAMP, S.; MILANI, T.L. The sensitivity of the sole of the foot in patients with Morbus Parkinson. Neuroscience Letters, New York, v.346, p.173-176, 2003.

RAB, G.T. Músculos. In: ROSE, J.; GAMBLE, J. Marcha humana. 2.ed. São Paulo: Premier, 1998. p.107-28.

RICHARDS, B. S. Atualização em conhecimentos ortopédicos: pediatria. São Paulo: Atheneu, 2002. p.617-645.

SIMONS, G.W. Analytical radiography of club feet. Journal of Bone and Joint Surgery Br, London, v.59-B, n.4, p.485-489, 1977.

SODERBERG, G.L.; COOK, T.M. Electromyography in biomechanics. Physical Therapy, Alexandria, v.64, n.12, p.1813-1820, 1984. 
SODERBERG, G.L.; KNUTSON, L.M. A guide for use and interpretation of kinesiologic electromyographic data. Physical Therapy, Alexandria, v.80, n. 5, p. 485-498, 2000.

SODRÉ, H. Pé torto eqüinovaro congênito. In: BRUSCHINI, S. Ortopedia pediátrica. 2. ed. São Paulo: Atheneu, 1998. p.124-130.

SOUZA, A.; NERY, C.A.S.; MARCIANO, L.H.S.C.; GARBINO, J.A. Avaliação da neuropatia periférica: correlação entre a sensibilidade cutânea dos pés, achados clínicos e eletroneuromiográficos. Acta Fisiatrica, São Paulo, v.12, n.3, p.87-93, 2005.

STANSFIELD, B.W.; HILLMAN, S.J.; HAZLEWOOD, M.E.; LAWSON, A.A.; MANN, A.M.; LOUDON, I.R.; ROBB, J.E. Normalized speed not age caracterizes ground reaction force patterns in 5- to 12- years-old children walking self-selected speeds. Journal of Pediatric Orthopedics, New York, v.21, n.3, p.395-402, 2001.

SUTHERLAND, D. The development of mature gait. Gait and Posture, New York, v.6, p.163-170, 1997.

SUTHERLAND, D.H. The evolution of clinical gait analysis part 1: kinesiological EMG. Gait and Posture, New York, v.14, p.61-70, 2001.

SWARTZ, E. E.; DECOSTER, L. C.; RUSSEL, P. J.; CROCE, R. V. Effects of developmental stage and sex on lower extremity kinematics and vertical ground reaction forces during landing. Journal of Athletic Training, Columbus, v.40, n.1, p.9-14, 2005.

TAKEGAMI, Y. Wave pattern of ground reaction force growing children. Journal of Pediatric Orthopaedics, New York, v.12, n.4, p.522-526, 1992.

TARECO, J.; SALA, D.A.; SCHER, D.M.; LEHMAN, W.B.; FELDMAN, D.S. Percutaneous fixation in clubfoot surgery: a radiographic and gait study. Journal of Pediatric Orthopaedics, New York, v.2, n.11, p.139-142, 2002. 
THEOLOGIS, T. N.; HARRINGTON, M. E.; THONMPSOM, N.; BENSON, M. K. D. Dynamic foot movement in children treated for congenital talipes equinovarus. The Journal of Bone and Joint Surgery, v.85, n.4, p.572-577, 2003.

TINGLEY, M.; WILSON, C.; BIDENE; KNIGHT, W. R. An index to quantify normality of gait in young children. Gait and Posture, New York, n.16, p.149-158, 2002.

VAAL, J.; VAN SOEST, A. J.; HOPKINS, B. Modeling the early development of bipedal locomotion: a multidisciplinar approach. Human Movement Science, v.14, p.609-636, 1995.

WAINWRIGHT, A. M.; AULD, T.; BENSON, M. K.; THEOLOGIS, T. N. The classification of congenital talipes eqüinovarus. The Journal of Bone and Joint Surgery, Vancouver, n.84, p.1020-1024, 2002.

WIDHE, T.; BERGGREN, L. Gait analysis and dynamic pressure in the assessment of treated clubfoot. Foot \& Ankle International, Baltimore, v.15, n.4, p.186-190, 1994.

WINTER, D.A. Biomechanics and motor control of human movement. 2nd. ed. New York: Wiley, 1990.

WINTER, D.A. Biomechanics motor patterns in normal walking. Journal of Motor Behavior, Washington, v.15, n.4, p.303-330, 1983.

WINTER, D.A. The biomechanics and motor control of human gait: normal, elderly and pathological. Ontario: University of Waterloo Press, 1991.

WIRCART, P.H.; RICHARDSON, J.; MATON, B. Adaptation of gait initiation in children with unilateral idiopathic clubfoot following conservative treatment. Journal of Electromyography and Kinesiology, New Orleans, v.16, n.6, p.650660, 2006. Elsevier Science Ltd. 
YU, B.; McClURE, S. B.; ONATE, J. A.; GUSKIEWICS, K.; KIRKENDALL, D. T.; GARRETT, W. E. Age and gender effects on lower extremity kinematics of youth soccer players in a stop-jump task. The American Journal of Sports Medicine, v.33, n.9, p.1356-1364, 2005.

YUAN, X.; RYD, L.; BLANKEVOORT, L. Error propagation for relative motion determined from marker positions. Journal of Biomechanics. New York, v.30, n.9, p.989-992, 1997.

ZATSIORSKY, V.M. Kinetics of human motion. Champaign: Human Kinetics, 2002. 


\section{ANEXOS}

\section{ANEXO I - Pré-experimentos.}

Após a leitura do Termo de Consentimento Livre Esclarecido realizada pelos responsáveis e explicado para as crianças, foram iniciados os procedimentos para as coletas de dados de todos os estudos descritos a seguir.

8

\section{Pré-experimentos}

\subsection{Estudo piloto 1}

\subsubsection{Objetivos}

Sabendo-se da importância do uso de dados da FRS para caracterização de tarefas funcionais de crianças com PTC, o estudo piloto 1 teve como objetivo identificar qual o melhor metodologia a ser empregada para avaliação desses parâmetros. Tal preocupação foi pertinente, visto que há, atualmente, dois modos de avaliação: locomoção em esteira rolante e em piso fixo.

Portanto, utilizando-se do caminhar como objeto de investigação dinâmica da fase de apoio, registrou-se a FRS na esteira rolante e em deslocamento a piso fixo.

\subsubsection{Amostra}

Neste estudo inicial, foi selecionada uma criança de sete anos de idade, sexo masculino, com acometimento unilateral direito tratada cirurgicamente com técnica de liberação póstero-medial ampla. 


\section{ANEXO I - Pré-experimentos (cont.)}

\subsubsection{Instrumentos de medição}

Foi utilizada uma esteira rolante (TROTTER N01-06560201) que contém duas plataformas de força piezelétricas (KISTLER, 9810S1x), dispostas em séries, que captam a FRS vertical (FZ). Essas estão montadas sob o piso da esteira que possui $0,8 \mathrm{~m}$ de largura e $2 \mathrm{~m}$ de comprimento. Adicionalmente, há um conversor Analógico/Digital (A/D) Keithley MetraByte DAS-1402 e um programa de funções (Gaitway Software, Versão 1.0x). Todo esse conjunto forma o sistema GAITWAY Instrumented - KISTLER (9810S1) (FIGURA 60).

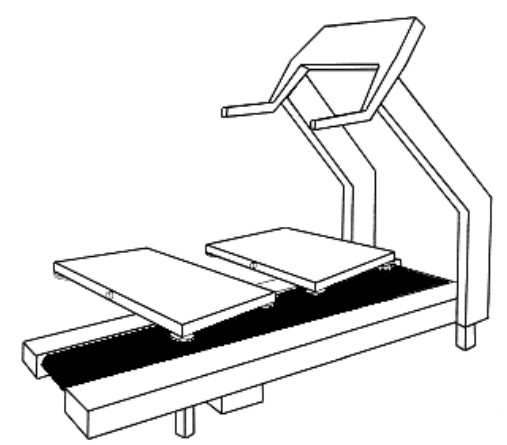

FIGURA 60 - llustração da esteira rolante instrumentada (KISTLER, 9810S1x),

Foi também utilizada uma plataforma com transdutores de força do tipo piezelétrico (KISTLER AG, tipo 9287 A), com superfície de apoio de $600 \times 900 \mathrm{~mm}$ e determina as componentes vertical, médio-lateral e ântero-posterior da FRS.

O gerenciamento dos dados foi realizado pelo programa de funções BIOWARE (Biomechanical Software Analysis System and Performance Module Type 282A1-20), o qual realizou controle da aquisição, análise e armazenamento dos dados.

\subsubsection{Protocolo experimental}

A criança realizou a marcha auto-selecionada na esteira e, em seguida, foram realizadas coletas em piso fixo. As variáveis estão descritas na FIGURA 61. 


\section{ANEXO I - Pré-experimentos (cont.)}

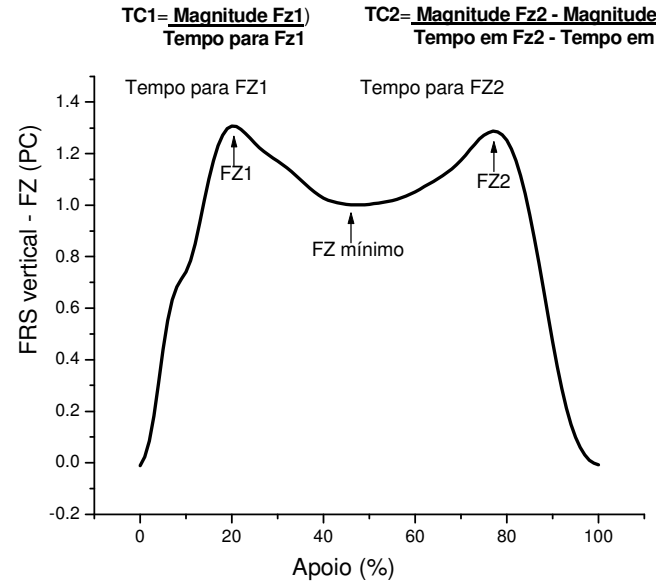

A

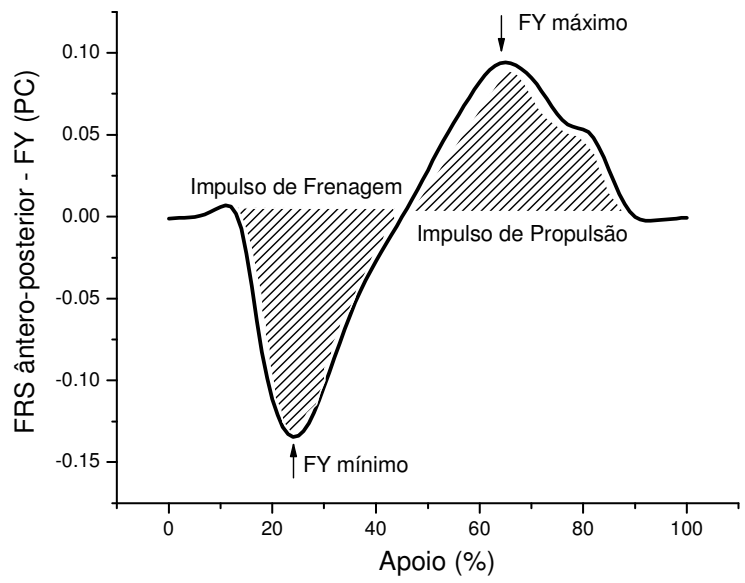

B

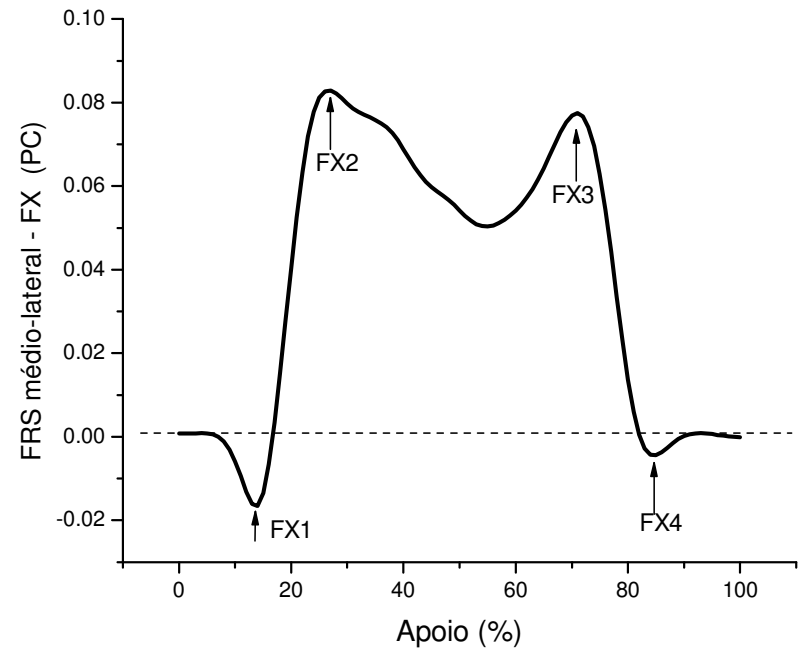

C

FIGURA 61 - Variáveis da FRS normalizadas pelo peso corporal (PC). A) FRS vertical Fz; B) FRS ântero-posterior - Fy; C) FRS médio-lateral - Fx.

\subsubsection{Resultados e discussões}

Apesar das várias tentativas de familiarização com o ambiente experimental, verificou-se que a criança demonstrou grandes dificuldades de adaptação durante a locomoção na esteira rolante, com desequilíbrios constantes e necessidade de segurar nas barras paralelas da esteira durante as coletas. 


\section{ANEXO I - Pré-experimentos (cont.)}

Nota-se na, FIGURA 62, discrepâncias entre as curvas da FRS em sua magnitude vertical, ao comparar a marcha em esteira e em solo.

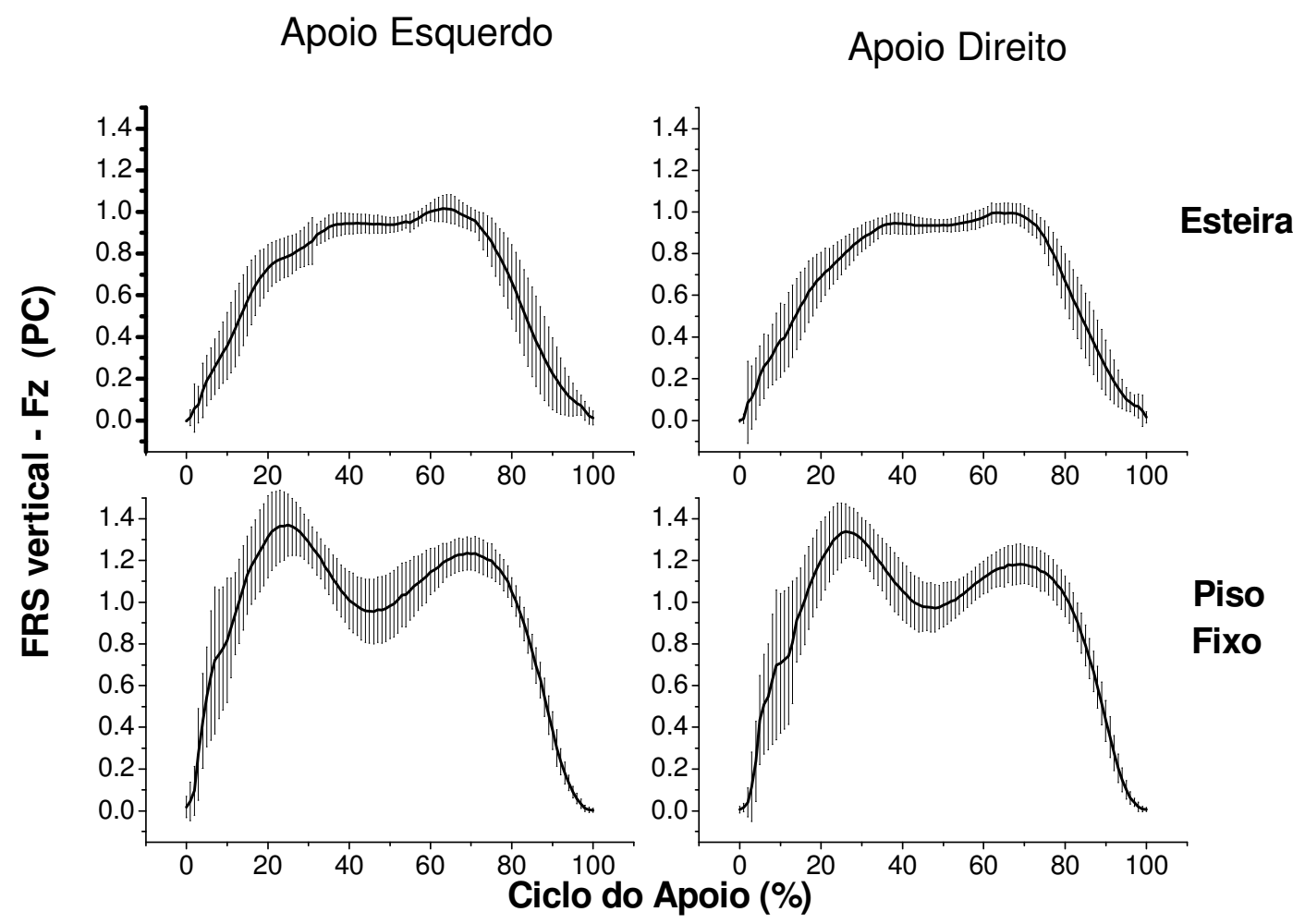

FIGURA 62 - Ilustração da FRS, magnitude vertical, dos apoios direito e esquerdo, durante as coletas de marcha em esteira (apoio esquerdo $n=13$ e direito $n$ $\equiv 16$ ) e em piso fixo (apoio direito e esquerdo $n=12$ ), no estudo piloto 1 . normalizados pelo peso corporal.

Tais diferenças encontradas nessa avaliação prévia qualitativa foram comprovadas mediante as comparações dos dados por meio da análise com 0 teste $t$ para medidas independentes e nível de significância $p \leq 0,05$, com utilização do programa estatístico SPSS, versão 11.5. Os resultados de tais comparações seguem na TABELA 28. 


\section{ANEXO I - Pré-experimentos (cont.)}

TABELA 28 - Dados da força vertical de reação do solo do estudo piloto 1, na esteira instrumentada e piso fixo, normalizados pelo peso corporal $\left({ }^{*} p \leq 0,05\right)$.

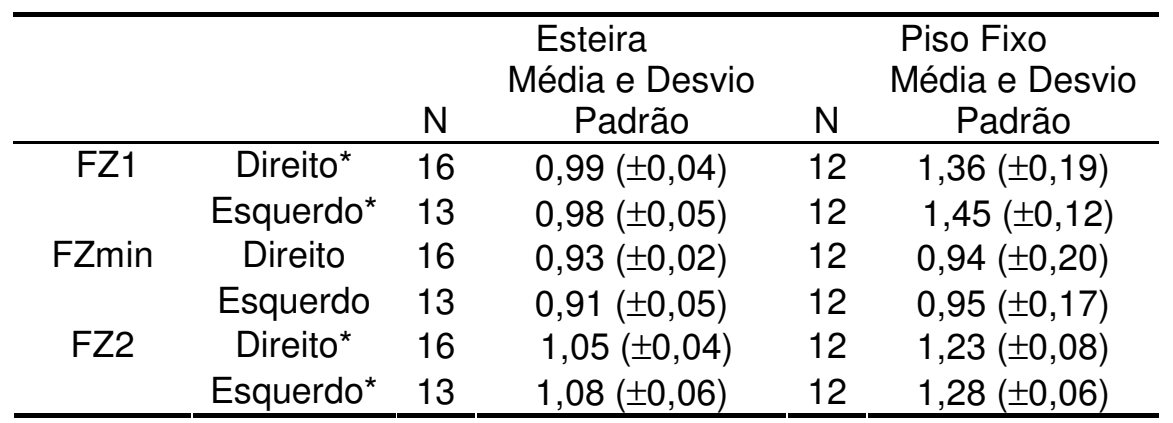

Diante desta constatação, seguiu-se para a análise dos dados da FRS adquiridas no solo fixo, ilustradas na FIGURA 63.

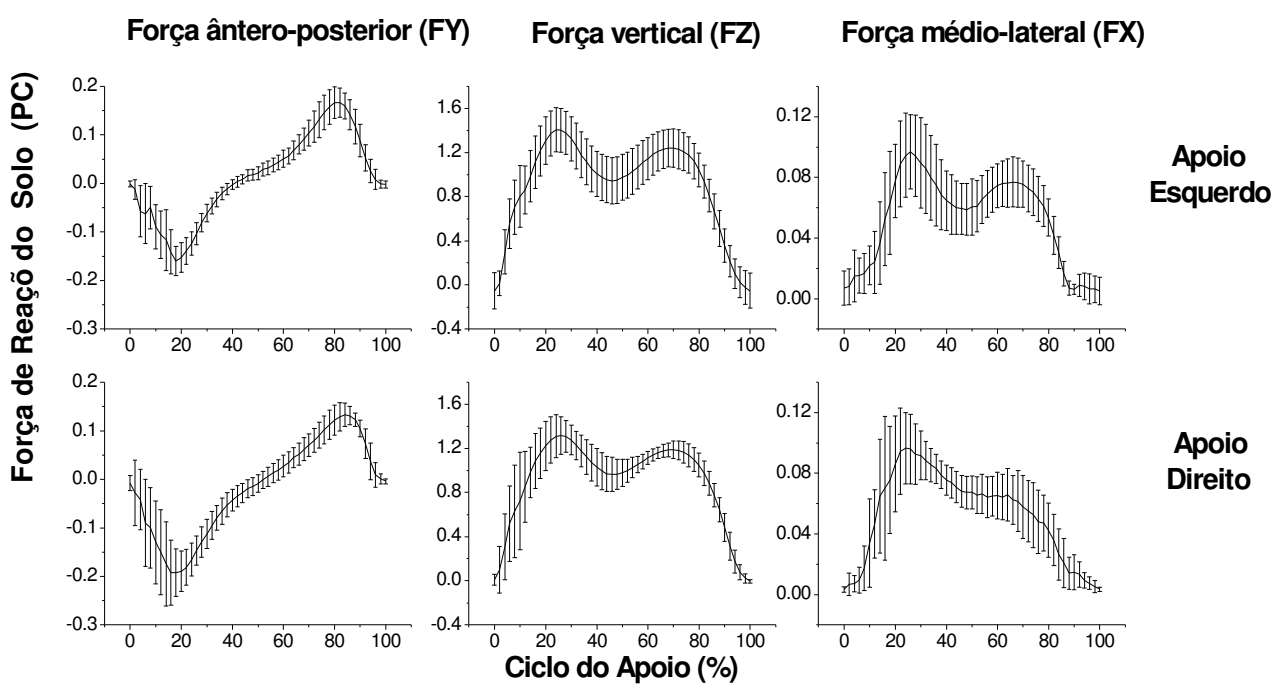

FIGURA 63 - Médias e desvios padrão dos dados da FRS, normalizados pelo peso corporal da criança, adquiridos em piso fixo. $\mathrm{N}=12$. 


\section{ANEXO I - Pré-experimentos (cont.)}

Para as comparações desses dados, foi utilizado o teste t para dados pareados com comparações entre apoio direito com esquerdo e nível de significância $p \leq 0,05$. Previamente a esse teste, foram realizadas investigações exploratórias dos dados, com análises mediante as observações de medidas qualitativas e teste estatístico de Shapiro-Wilk, com utilização do programa estatístico SPSS, versão 11.5.

Foram encontrados valores semelhantes nas comparações entre os apoios direito e esquerdo para FZ1, FZ min, FZ2 e TC2. No entanto, constatou-se uma taxa de crescimento do primeiro pico (TC1) da força vertical maior no lado não acometido (TABELA 29). Isso pode ser explicado pela falta de controle protetor da criança, que desfavorece a aceitação de carga nesse segmento.

TABELA 29 - Dados da força vertical (FZ) de reação do solo do estudo piloto 1, em piso fixo, normalizados pelo peso corporal $\left.{ }^{*} p \leq 0,05\right)$.

\begin{tabular}{|c|c|c|c|}
\hline & & $\mathbf{n}$ & Média e Desvio Padrão \\
\hline \multirow{2}{*}{ FZ1 } & Direito & 12 & $1,35( \pm 0,19)$ \\
\hline & Esquerdo & 12 & $1,45( \pm 0,12)$ \\
\hline \multirow{2}{*}{$\mathrm{TC}^{*}$} & Direito & 12 & $9,09( \pm 2,28)$ \\
\hline & Esquerdo & 12 & $10,78( \pm 3,01)$ \\
\hline \multirow{2}{*}{ FZ min } & Direito & 12 & $0,94( \pm 0,19)$ \\
\hline & Esquerdo & 12 & $0,95( \pm 0,17)$ \\
\hline \multirow{2}{*}{ FZ2 } & Direito & 12 & $1,2( \pm 0,15)$ \\
\hline & Esquerdo & 12 & $1,28( \pm 0,06)$ \\
\hline \multirow{2}{*}{ TC2 } & Direito & 12 & $3,07( \pm 0,44)$ \\
\hline & Esquerdo & 12 & $3,39( \pm 0,32)$ \\
\hline
\end{tabular}

$\mathrm{Na}$ análise da FRS, sentido ântero-posterior (FY), constataram-se diferenças significantes em todas as variáveis analisadas (TABELA 30).

As magnitudes de forças mínimas ( $F Y$ min) e de impulso de frenagem foram maiores no lado acometido. Adicionalmente, apesar da existência de um FY máximo maior no lado acometido, o impulso de propulsão foi menor. 


\section{ANEXO I - Pré-experimentos (cont.)}

TABELA 30 - Dados da força ântero-posterior (FX min e máximo) de reação do solo e dos impulsos de frenagem e propulsão, do estudo piloto 1 , em piso fixo, normalizados pelo peso corporal $\left({ }^{*} \mathrm{p} \leq 0,05\right)$.

\begin{tabular}{cccc}
\hline & & $\mathbf{n}$ & Média e Desvio Padrão \\
\hline \multirow{2}{*}{ FY min* $^{*}$ FY máximo* } & Direito & $\mathbf{1 2}$ & $-0,20( \pm 0,05)$ \\
& Esquerdo & $\mathbf{1 2}$ & $-0,16( \pm 0,02)$ \\
& Direito & $\mathbf{1 2}$ & $0,12( \pm 0,03)$ \\
& Esquerdo & $\mathbf{1 2}$ & $0,17( \pm 0,03)$ \\
Impulso de Frenagem* & Direito & $\mathbf{1 2}$ & $-27,10( \pm 5,52)$ \\
& Esquerdo & $\mathbf{1 2}$ & $-17,92( \pm 2,25)$ \\
Impulso de Propulsão* & Direito & $\mathbf{1 2}$ & $17,29( \pm 5,34)$ \\
& Esquerdo & $\mathbf{1 2}$ & $25,17( \pm 6,84)$ \\
\hline
\end{tabular}

Para os dados da FRS sentido médio-lateral, verificou-se maiores magnitudes para o segundo, terceiro e quartos picos, no apoio esquerdo (TABELA 31). Tais características demonstram a dificuldade de realização dos movimentos de prono-supinação no lado acometido, o que pode estar alterado devido às características da própria patologia ou do ato cirúrgico realizado.

TABELA 31- Dados da força médio-lateral $(F X)$ de reação do solo do estudo piloto 1, em piso fixo, normalizados pelo peso corporal $\left({ }^{*} p \leq 0,05\right)$.

\begin{tabular}{cccc}
\hline & & $\mathbf{N}$ & Média e Desvio Padrão \\
\hline \multirow{2}{*}{$\mathbf{F X}_{1}$} & Direito & $\mathbf{1 2}$ & $-0.018( \pm 0.01)$ \\
& Esquerdo & $\mathbf{1 2}$ & $-0.063( \pm 1,5)$ \\
$\mathbf{F X}_{2}{ }^{*}$ & Direito & $\mathbf{1 2}$ & $0.104( \pm 0.02)$ \\
& Esquerdo & $\mathbf{1 2}$ & $14.85( \pm 15.7)$ \\
\multirow{2}{*}{$\mathbf{F X}_{3}{ }^{*}$} & Direito & $\mathbf{1 2}$ & $0.07( \pm 0.02)$ \\
& Esquerdo & $\mathbf{1 2}$ & $11.9( \pm 12.7)$ \\
& Direito & $\mathbf{1 2}$ & $-0.017( \pm 0.01)$ \\
& Esquerdo & $\mathbf{1 2}$ & $-0.91( \pm 1.2)$ \\
\hline
\end{tabular}




\section{ANEXO I - Pré-experimentos (cont.)}

\subsubsection{Considerações}

A verificação da falta de adaptação de marcha em esteira pôde demonstrar a dificuldade dessa criança em se adaptar às perturbações externas. Essa característica pode inviabilizar futuras avaliações com tal instrumental. Todavia, foi verificado que dados da FRS adquiridos em plataforma de força fixa no solo auxiliam para o entendimento de características dinâmicas da marcha dessas crianças.

A adição da investigação da variação angular, sincronizada com os dados da plataforma de força, pode auxiliar o melhor entendimento de características biomecânicas existentes na locomoção dessa população.

\section{2 $\quad$ Estudo piloto 2}

\subsubsection{Objetivo}

O objetivo deste estudo piloto foi realizar coletas com instrumental que mensura a distribuição da pressão plantar e, dessa forma, identificar a possível relevância de tal mensuração em crianças portadoras de PTC.

\subsubsection{Amostra}

Foi selecionada uma criança de sete anos de idade, sexo masculino, com acometimento unilateral direito tratada cirurgicamente com técnica de liberação póstero-medial ampla. 


\section{ANEXO I - Pré-experimentos (cont.)}

\subsubsection{Instrumentos de medição}

Foram utilizadas palmilhas com sensores resistivos (FIGURA 64), do sistema F-Scan, empresa Tekscan. Esse sistema é composto por palmilhas plantares com conectores para aquisição de dados de pressão que recebem as informações e as transmitem ao computador. Com auxílio do software F-Scan, há a visualização do sinal e análise dos dados. A freqüência de amostragem dos dados da pressão foi $50 \mathrm{~Hz}$.

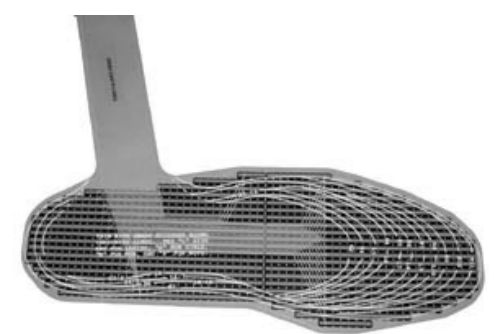

FIGURA 64 - Ilustracão da palmilha com sensores resistivos, do sistema F-Scan, utilizada no estudo piloto 2 , com objetivo de quantificar as características de distribuição da pressão plantar.

\subsubsection{Protocolo experimental}

As palmilhas foram recortadas no tamanho do solado e colocadas na interface do pé com o calçado. Após a adaptação com o instrumental, foram realizadas três coletas de cinco segundos em marcha natural auto-selecionada em linha reta (FIGURA 65). 


\section{ANEXO I - Pré-experimentos (cont.)}

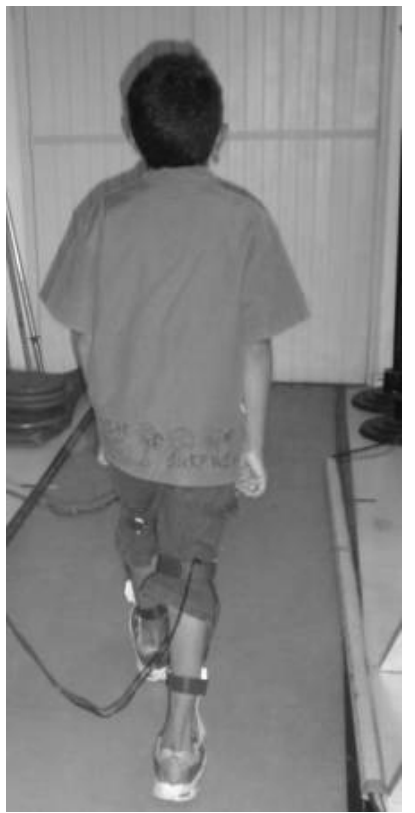

FIGURA 65 - Ilustração da coleta de dados com a utilização do sistema F-Scan, no estudo piloto 2, com a mensuração da pressão plantar na locomoção de crianças com PTC.

Foram descartados os primeiros apoios no início e final de cada coleta.

Para as análises dos dados, os apoios foram divididos em três áreas: região do retropé $(0 \%$ até $30 \%$ do comprimento do pé), mediopé $(30 \%$ até $60 \%$ do comprimento do pé) e antepé (60\% até $100 \%$ do comprimento do pé) (FIGURA 66). 


\section{ANEXO I - Pré-experimentos (cont.)}

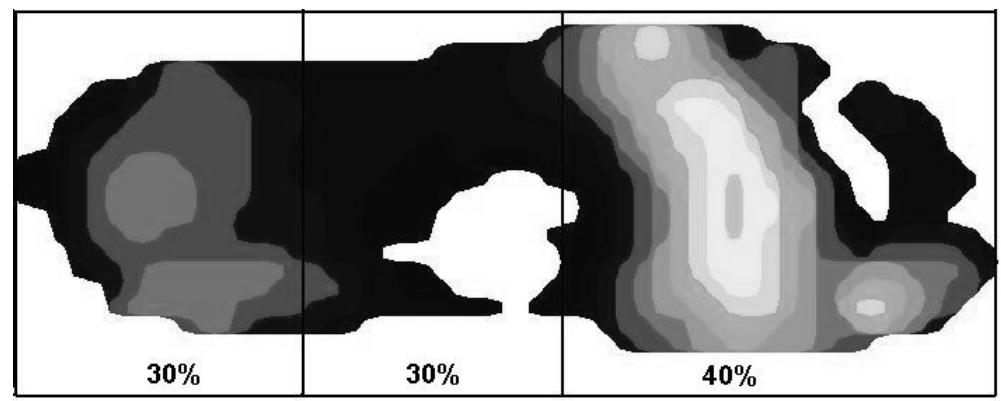

FIGURA 66 - Divisão das áreas da planta do pé: retropé (0\% até 30\% do comprimento do pé), mediopé (30\% até $60 \%$ do comprimento do pé) e antepé $(60 \%$ até $100 \%$ do comprimento do pé).

\subsubsection{Resultados e discussões}

Para análise dos dados, foi utilizado o teste t para dados pareados para as comparações entre apoio direito com esquerdo e nível de significância $p \leq 0,05$.

Verificou-se a existência de diferenças estatisticamente significantes para os dados de pressão plantar para a região do mediopé, com valores elevados no apoio do lado acometido ( $P=0,001)$ (TABELA 32).

TABELA 32 - Dados de pressão plantar $(\mathrm{KPa})$ durante a marcha da criança, no estudo piloto $2\left({ }^{*} p \leq 0,05\right)$.

\begin{tabular}{cccc}
\hline & \multicolumn{3}{c}{ Pressão Plantar (kPa) } \\
& $\mathrm{N}$ & Direito & Esquerdo \\
\hline Retropé & 5 & $136,1( \pm 14,4)$ & $135,8( \pm 31,3)$ \\
Mediopé $^{*}$ & 5 & $279,5( \pm 52,2)$ & $57,3( \pm 6,4)$ \\
Antepé & 5 & $109,9( \pm 10,8)$ & $86,4( \pm 21,8)$ \\
\hline
\end{tabular}

Tais achados estão ilustrados na FIGURA 67. 


\section{ANEXO I - Pré-experimentos (cont.)}

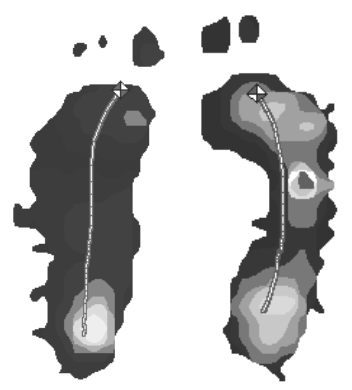

FIGURA 67 - llustração das características de pressão plantar durante os apoios direito e esquerdo na marcha da criança no estudo piloto 2.

\subsubsection{Considerações}

Verificou-se a existência de valores elevados de pressão plantar no apoio do lado acometido. Apesar de ser um estudo preliminar, foi constatada característica particular a essa criança relacionada à distribuição da pressão plantar em sua marcha realizada em velocidade auto-selecionada.

\subsection{Estudo piloto 3}

\subsubsection{Objetivo}

O objetivo deste estudo preliminar foi verificar características da distribuição da pressão plantar na locomoção em diferentes velocidades.

\subsubsection{Amostra}

Foram avaliadas duas crianças (9 e 10 anos de idade) do sexo masculino, com acometimento unilateral direito, tratadas cirurgicamente por meio de liberação póstero-medial ampla no primeiro ano de vida. 


\section{ANEXO I - Pré-experimentos (cont.)}

\subsubsection{Instrumentos de medição}

Foi realizada análise de distribuição da pressão plantar e da FRS com utilização de palmilhas instrumentadas com sensores capacitivos, do sistema PEDAR, Novel GmbH. Previamente às coletas de dados, o instrumental foi calibrado.

O sistema de calibração, da própria Novel $\mathrm{GmbH}$, envolve a utilização de compressão uniforme das palmilhas com demonstração quantitativa da pressão exercida, assim permite que cada sensor possua um referencial idêntico. Para tal calibração, utilizou-se o programa Pedar Mobile Expert Calibration (Novel GmbH).

\subsubsection{Protocolo experimental}

Foram colocadas as palmilhas instrumentadas no calçado de uso habitual das crianças (FIGURA 68) e, após adaptação com o equipamento, as crianças andaram (velocidade natural $3,07 \pm 0,04 \mathrm{~m} / \mathrm{s}$ e rápida $3,5 \pm 0,08 \mathrm{~m} / \mathrm{s}$ ) e correram $(4,8 \pm 0,23 \mathrm{~m} / \mathrm{s})$ em uma passarela de $10 \mathrm{~m}$ de comprimento.

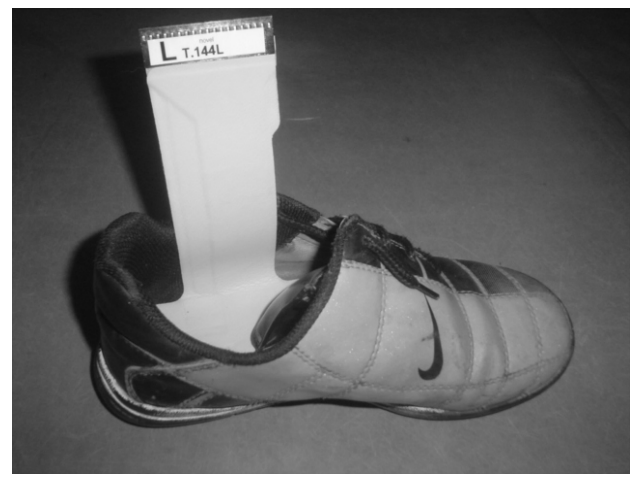

FIGURA 68 - Colocação da palmilha instrumentada PEDAR no calçado do voluntário. 


\section{ANEXO I - Pré-experimentos (cont.)}

As velocidades escolhidas para as coletas foram estipuladas pelos voluntários. Para o cálculo da velocidade, foi feito a razão entre uma distância conhecida pelo tempo percorrido nessa extensão. Com freqüência de amostragem dos dados da pressão de $50 \mathrm{~Hz}$, foram avaliados 42 apoios para o andar natural (21 para cada lado) e 36 para cada uma das outras velocidades (18 para cada lado).

\subsubsection{Resultados e discussões}

Foram analisados dados distintos de três áreas do pé: região do retropé ( $0 \%$ até $30 \%$ do comprimento do pé), mediopé (30\% até $60 \%$ do comprimento do pé) e antepé (60\% até $100 \%$ do comprimento do pé), com o auxílio de um programa da Novel GmbH.

Por meio do programa da Novel, foram analisadas as médias do pico de pressão, da área de contato e da FRS máxima vertical, em cada uma das três áreas pré-determinadas. As intensidades das forças foram normalizadas pelo peso corporal das crianças. Para as comparações entre os apoios, foi utilizado o teste $t$ para dados pareados e nível de significância $p \leq 0,05$. O programa estatístico utilizado foi o SPSS, versão 11.5 .

Com relação aos dados de área de contato analisados, foi encontrada, na região do antepé, uma menor área no lado acometido em todas as velocidades de locomoção analisadas, o que demonstra que, apesar da existência de uma correção cirúrgica no primeiro ano de vida dessas crianças, persistem desequilíbrios quanto à área de contato nessa região em atividades funcionais. $\mathrm{Na}$ região do retropé, foi encontrada menor área de contato plantar do lado acometido apenas durante a corrida (TABELA 33). 


\section{ANEXO I - Pré-experimentos (cont.)}

TABELA 33 - Área de contato $\left(\mathrm{cm}^{2}\right)$ na região do antepé e retropé durante as diferentes velocidades de locomoção analisadas no estudo piloto $3\left({ }^{*} p \leq 0,05\right)$.

\begin{tabular}{cccccc}
\hline & \multicolumn{4}{c}{ Área de contato $\left(\mathbf{c m}^{2}\right)$} \\
& n & \multicolumn{2}{c}{ Antepé } & \multicolumn{2}{c}{ Retropé } \\
& não acometido & acometido & não acometido & acometido \\
\hline Andar Natural & $\mathbf{4 2}$ & $49,5( \pm 1,2)^{*}$ & $42,2( \pm 4,1)^{*}$ & $31,2( \pm 1)$ & $30,9( \pm 1)$ \\
Andar Rápido & $\mathbf{3 6}$ & $48,4( \pm 7,9)^{*}$ & $42,2( \pm 4,6)^{*}$ & $30,5( \pm 3,9)$ & $30,4( \pm 2)$ \\
Correr & $\mathbf{3 6}$ & $50,6( \pm 4,8)^{\star}$ & $43,6( \pm 3,8)^{*}$ & $27,4( \pm 5)^{*}$ & $19,1( \pm 6)^{*}$ \\
\hline
\end{tabular}

Essa característica foi comprovada com uma também diminuição dos valores da FRS máxima vertical e do pico de pressão na região do retropé do lado acometido durante a corrida, sendo semelhantes nas duas velocidades de marcha realizadas (FIGURAS 69 e 70).

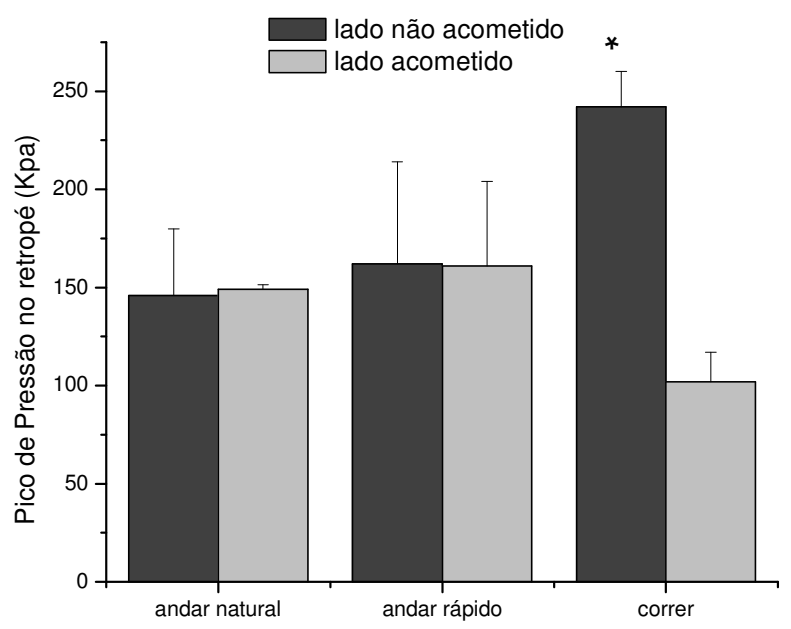

FIGURA 69 - Gráfico da média do pico de pressão (KPa) na região do retropé, durante as diferentes velocidades de locomoção analisadas no estudo piloto 3

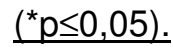




\section{ANEXO I - Pré-experimentos (cont.)}

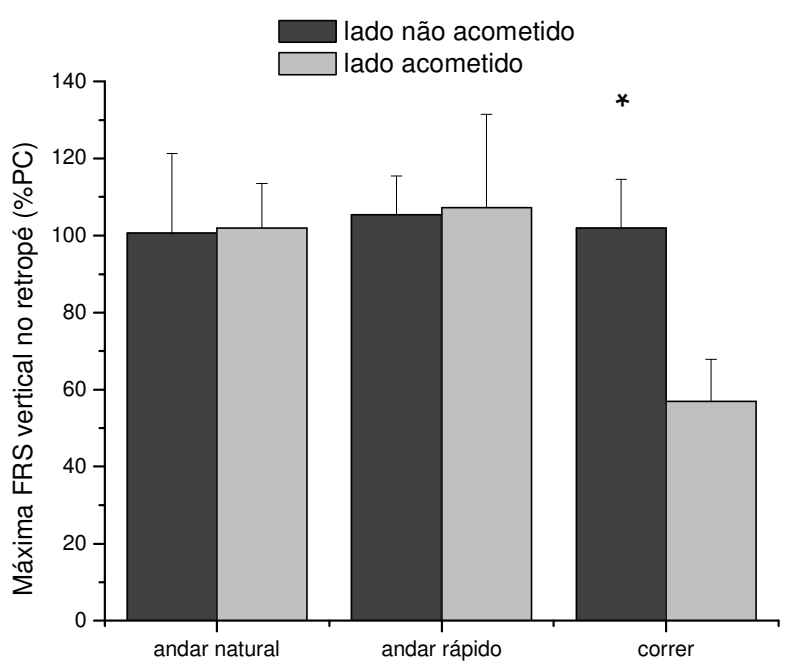

FIGURA 70 - Gráfico da máxima força vertical de reação do solo (porcentagem do peso corporal - \%PC) na região do retropé, durante as diferentes velocidades de locomoção analisadas no estudo piloto 3 ( $\left.^{*} p \leq 0,05\right)$.

Tais dados encontram-se descritos na TABELA 34.

TABELA 34 - Média do pico de pressão $(\mathrm{KPa})$ e máxima força vertical de reação do solo (porcentagem do peso corporal - \%PC) na região do retropé, durante as diferentes velocidades de locomoção analisadas no estudo piloto 3 ( $^{*} \mathrm{p}$ $\leq 0,05)$.

\begin{tabular}{cccccc}
\hline & & \multicolumn{2}{c}{$\begin{array}{c}\text { Pico de pressão (KPa) } \\
\text { Retropé }\end{array}$} & \multicolumn{2}{c}{ Máxima FRS vertical (\%PC) } \\
& $\mathbf{n}$ & \multicolumn{2}{c}{ Retropé } \\
& & não acometido & acometido & não acometido & acometido \\
\hline Andar Natural & $\mathbf{4 2}$ & $146( \pm 34)$ & $149 \pm 24$ & $100,7( \pm 10,6)$ & $102( \pm 11,5)$ \\
Andar Rápido & $\mathbf{3 6}$ & $162( \pm 52)$ & $161 \pm 43$ & $105,4( \pm 10,1)$ & $107,3( \pm 14,2)$ \\
Correr & $\mathbf{3 6}$ & $242( \pm 18)^{*}$ & $102 \pm 15^{*}$ & $102,8( \pm 12,6)^{*}$ & $56,9( \pm 11)^{*}$ \\
\hline
\end{tabular}




\section{ANEXO I - Pré-experimentos (cont.)}

Nota-se a não alteração dos valores de força vertical na região do retropé, com o aumento da velocidade de locomoção. Tal característica não é comumente vista, pois há o aumento da força com o aumento da velocidade de locomoção. Isso pode ser explicado em razão da possível alteração do gerenciamento de colocação do pé das crianças, as quais diminuem o contato do retropé com o aumento da velocidade.

\subsubsection{Considerações}

Foi encontrado, nesse estudo preliminar, que a geometria de colocação do pé foi influenciada pela atividade de locomoção realizada por essas crianças. Assim, investigações adicionais que abordem diversas modalidades de locomoção, como a corrida, devem ser analisadas.

Outro ponto a considerar foi a limitação técnica existente para as coletas de dados, o que se refere ao tamanho das palmilhas utilizadas. As discrepâncias geométricas entre o pé acometido com o não acometido e a inexistência de tamanhos de palmilhas instrumentadas diversificadas dificultaram as coletas de dados.

\subsection{Estudo piloto 4}

\subsubsection{Objetivo}

Apesar da marcha caracterizar-se como uma das atividades funcionais essenciais, há também a necessidade de entendermos como essas crianças se adaptam a situações que exijam esforços diferenciados. Exemplo disso é a análise do salto vertical, que também pode evidenciar distúrbios do controle motor.

Assim, esse estudo preliminar teve como objetivo analisar a viabilidade de análise biomecânica durante o salto vertical em crianças com PTC. 


\section{ANEXO I - Pré-experimentos (cont.)}

\subsubsection{Amostra}

Participaram desse estudo um total de cinco crianças com PTC submetidas a tratamento cirúrgico, com comprometimento bilateral, com idade de $7,4 \pm 1,3$ anos, estatura $1,33 \pm 0,09 \mathrm{~m}$ e massa $36,2 \pm 12,5 \mathrm{~kg}$. Para comparação dos dados foi formado um Grupo Controle constituído por 11 crianças sem história de PTC, saudáveis, com idade de $7,7 \pm 0,8$ anos estatura $1,3 \pm 0,1 \mathrm{~m}$ e massa $26,3 \pm 4,3$ $\mathrm{kg}$.

\subsubsection{Instrumentos de medição}

Para a caracterização da atividade muscular, foi utilizado um eletromiógrafo, construído na FADE-UP com ganho de 100 vezes e eletrodos de superfície, ativos, bipolares e diferenciais, pré-amplificados em 11 vezes. Adicionalmente foi utilizada uma plataforma de força (Bertec \#k80204, tipo 406015), construída com células de carga.

Para captação desses sinais de força, foi utilizada uma unidade elétrica de amplificação, captação e registro de dados, constituída por amplificadores que ligados às células de carga permitem obter tensões proporcionais às cargas em cada célula. A freqüência de amostragem da FRS e da eletromiografia (EMG) foi de $1000 \mathrm{~Hz}$. Os dados foram digitalizados numa placa de conversão analógico/digital de 16 bits (Biopac).

As coletas foram feitas no mesmo sistema (AcqKnowledge ACK 100 da BIOPAC Systems, Inc), e para propiciar um único eixo temporal dos dados coletados, os instrumentos de investigação foram sincronizados por meio de uma placa eletrônica, a qual era ativada por um trigger manual que iniciava os registros dos eventos dinamométricos e eletromiográficos. 


\section{ANEXO I - Pré-experimentos (cont.)}

\subsubsection{Protocolo experimental e metodologia}

Foram posicionados os eletrodos da eletromiografia nos ventres dos músculos gastrocnêmio medial e tibial anterior bilateralmente, conforme recomendações do SENIAM (HERMENS et al., 2000).

As crianças foram instruídas a se posicionarem em cima da plataforma de força e realizaram um salto vertical com contra-movimento e mãos apoiadas nas cristas ilíacas. Foram realizadas cinco coletas para cada criança.

As variáveis relacionadas à EMG foram tratadas por intermédio de rotinas matemáticas em ambiente Matlab 6.5 (The Mathworks Inc.). Para os sinais de EMG, foi utilizado filtro Butterworth de segunda ordem, passa-banda de 20 a $400 \mathrm{~Hz}$. Adicionalmente foi removido o offset e normalizados os sinais pelo pico máximo.

Foram analisadas características eletromiográficas em diferentes fases do salto vertical por meio da avaliação da integral do sinal encontrado em cada músculo avaliado. As fases analisadas do salto foram divididas em dois momentos: preparação (A) e aterrissagem (B). Assim, foram avaliadas as características eletromiográficas dos músculos gastrocnêmio medial e tibial anterior, bilateralmente nas fases pré-determinadas, baseadas nos dados da FRS vertical (FIGURA 71). 


\section{ANEXO I - Pré-experimentos (cont.)}
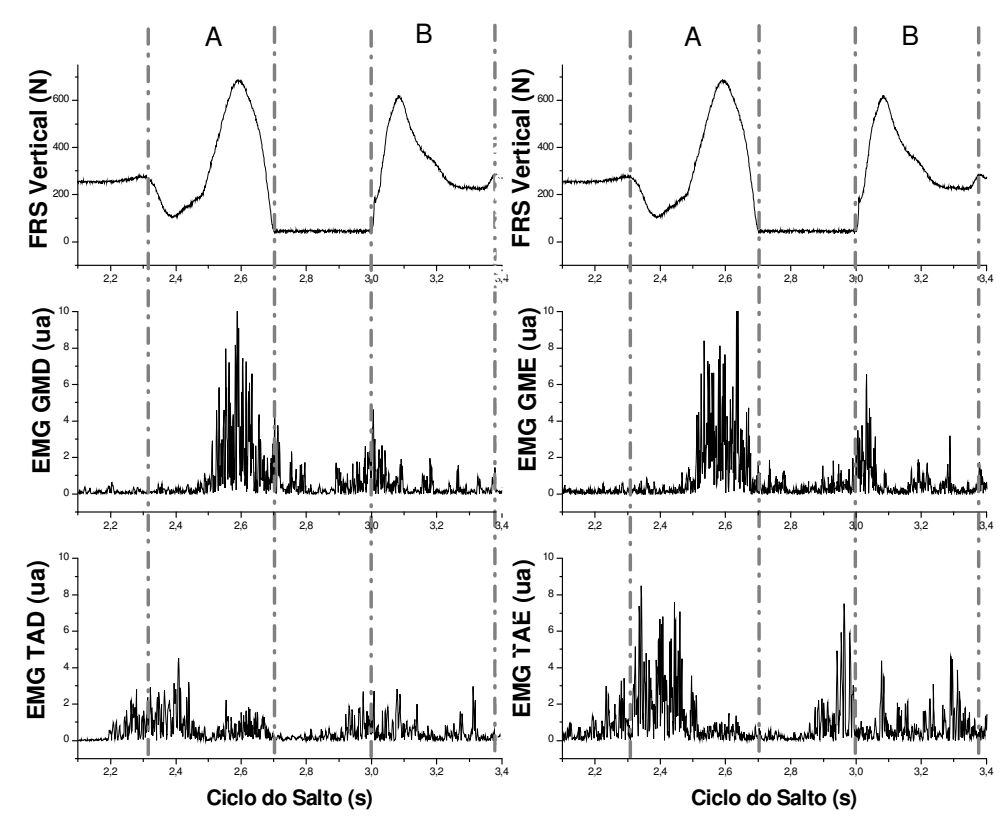

FIGURA 71 - Demonstração das divisões, baseadas na FRS vertical, para análise das características eletromiográficas dos músculos gastrocnêmio medial direito (GMD) e esquerdo (GME) e tibial anterior direito (TAD) e esquerdo (TAE) durante o salto vertical com contra-movimento. A - preparação; B aterrissagem. Foram realizadas cinco tentativas para cada sujeito avaliado.

Com objetivo de descrever o comportamento das variáveis dinâmicas, foi realizada a estatística descritiva dos parâmetros propostos. Para comparação das variáveis, foi utilizado o teste ANOVA com um fator e nível de significância $p \leq$ 0,05, além do post-hoc de TUKEY para amostras desiguais. Foram realizadas as comparações entre PTC lado direito (PTC_D), PTC lado esquerdo (PTC_E) e controle (GC). Para a amostra do grupo controle, foi selecionado aleatoriamente um dos membros inferiores. Previamente a esse teste, foram realizadas análises exploratórias dos dados, com análises investigativas mediante as observações de medidas qualitativas e teste estatístico de Shapiro-Wilk, com utilização do programa estatístico SPSS, versão 11.5. 


\section{ANEXO I - Pré-experimentos (cont.)}

\subsubsection{Resultados e discussões}

Os resultados desses dados parciais mostraram que não existiram diferenças nas características de ativações do músculo gastrocnêmio medial, em ambas as fases analisadas, nas comparações entre o lado direito e esquerdo do grupo com PTC e do controle (TABELAS 35 e 36).

$\mathrm{Na}$ análise das características do sinal para o músculo tibial anterior, foram encontradas diferenças significativas tanto para a fase da preparação/salto quanto para aterrissagem (TABELAS 35 e 36).

TABELA 35 - Média e desvio padrão da integral do sinal eletromiográfico (iEMG) para os músculos tibial anterior (TA) e gastrocnêmio medial (GM), tanto para o grupo controle (C) quanto para o pé torto congênito direito (PTC D) e esquerdo (PTC E) durante a fase da preparação/salto. Dados normalizados pelo pico máximo de ativação muscular $\left({ }^{*} \mathrm{p} \leq 0,05\right)$.

\begin{tabular}{cccc}
\hline & Grupos & N & iEMG (ua) \\
\hline \multirow{4}{*}{ GM } & GC & 46 & $3,96( \pm 1,29$ \\
& PTC_D & 23 & $4,31( \pm 1,86$ \\
& PTC_E & 23 & $4,70( \pm 1,92$ \\
& GC & 46 & $1,13( \pm 0,40$ \\
TA $^{*}$ & PTC_D & 23 & $2,21( \pm 0,60$ \\
& PTC_E & 23 & $2,30( \pm 0,60$ \\
\hline
\end{tabular}




\section{ANEXO I - Pré-experimentos (cont.)}

TABELA 36 - Média e desvio padrão da integral do sinal eletromiográfico (iEMG) para os músculos tibial anterior (TA) e gastrocnêmio medial (GM), tanto para o grupo controle (GC) quanto para o pé torto congênito direito (PTC D) e esquerdo (PTC E) durante a fase de aterrissagem. Dados normalizados pelo pico máximo de ativação muscular $\left.{ }^{*} p \leq 0,05\right)$.

\begin{tabular}{cccc}
\hline & Grupos & N & iEMG (ua) \\
\hline \multirow{3}{*}{ GM } & GC & 46 & $3,96( \pm 1,29$ \\
& PTC_D & 23 & $4,31( \pm 1,86$ \\
& PTC_E & 23 & $4,70( \pm 1,92$ \\
& GC & 46 & $1,14( \pm 0,50$ \\
TA $^{*}$ & PTC_D & 23 & $2,21( \pm 0,50$ \\
& PTC_E & 23 & $2,20( \pm 0,60$ \\
\hline
\end{tabular}

Tais diferenças foram evidenciadas com o aumento da atividade no grupo com PTC, comparado com o controle. Para melhor entendimento dessas características, há necessidade da investigação de variação angular sincronizada com os instrumentos utilizados neste estudo piloto.

\subsubsection{Considerações}

Verificou-se a possibilidade de avaliação funcional por meio do salto vertical em crianças com história de PTC.

A adição da investigação de variação angular, sincronizada com os dados da plataforma de força e da eletromiografia, durante tal atividade, pode auxiliar o melhor entendimento dos desequilíbrios existentes. 


\section{ANEXO I - Pré-experimentos (cont.)}

\subsection{Estudo piloto 5}

\subsubsection{Objetivo}

O objetivo neste estudo piloto foi de avaliar a possibilidade da identificação do limiar de percepção tátil plantar em crianças com história de PTC por meio de estesiômetros.

\subsubsection{Amostra}

Foram avaliadas duas crianças (9 e 10 anos de idade) do sexo masculino, com acometimento unilateral direito, tratadas cirurgicamente por meio de liberação póstero-medial ampla no primeiro ano de vida.

\subsubsection{Instrumentos de medição}

Foi utilizado um kit de monofilamentos de Semmes-Weistein (SORRI,Inc.), que contêm seis estesiômetros. Esses instrumentos são confeccionados com fios de náilon número 612 , de $38 \mathrm{~mm}$ de comprimento, sendo cada um com diâmetro diferente.

\subsubsection{Protocolo experimental}

As crianças foram posicionadas em decúbito dorsal, com os olhos fechados. O avaliador aplicou o teste com o monofilamento perpendicular em regiões pré-determinadas da superfície plantar, com força necessária para envergar o fio de náilon (FIGURA 72). 


\section{ANEXO I - Pré-experimentos (cont.)}

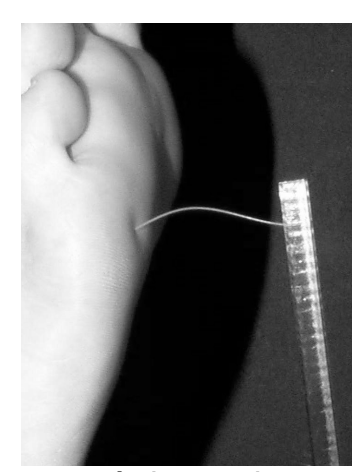

FIGURA 72 - Ilustrações das características da avaliação da sensibilidade plantar. Aplicação do teste na superfície plantar, com força necessária para envergar o monofilamento

\subsubsection{Resultados e discussões}

Pode-se apenas notar que, para um dos voluntários, existiu uma diferença nessa sensibilidade plantar para a avaliação no calcanhar com uma diferença de dois filamentos (TABELA 37). Por não ter encontrado na literatura científica características de normalidade para essa avaliação da sensibilidade plantar em crianças, foi difícil uma melhor discussão sobre os dados encontrados.

TABELA 37 - Dados da avaliação com os monofilamentos de Semmes-Weistein. Para melhor visualização estes estesiômetros, foram classificados de 1 a $6 \mathrm{em}$ ordem crescente de acordo com o aumento do diâmetro do filamento.

\begin{tabular}{|c|c|c|c|c|}
\hline \multirow{2}{*}{ Regiões Plantares Avaliadas } & \multicolumn{2}{|c|}{ Voluntário 1} & \multicolumn{2}{|c|}{ Voluntário 2} \\
\hline & Esquerdo & Direito & Esquerdo & Direito \\
\hline Calcanhar & 3 & 3 & 1 & 3 \\
\hline Base do $1^{\circ}$ metatarso & 3 & 3 & 2 & 2 \\
\hline Base do $5^{\circ}$ metatarso & 3 & 3 & 2 & 3 \\
\hline Tubérculo do $5^{\circ}$ metatarso & 2 & 3 & 2 & 3 \\
\hline Hálux & 3 & 3 & 2 & 3 \\
\hline
\end{tabular}




\section{ANEXO I - Pré-experimentos (cont.)}

\subsubsection{Considerações}

Pôde-se constatar que as crianças não tiveram dificuldades em responder aos estímulos dados durante tal teste; em todas as ocasiões elas foram precisas nas respostas dadas.

Tal avaliação pode ser importante para o entendimento de possíveis alterações sensitivas na região plantar de crianças com história de PTC, assunto este não discutido em literaturas científicas. 
ANEXO II - Termo de consentimento livre e esclarecido:

\section{ESCOLA DE EDUCAÇÃO FÍSICA E ESPORTE DA \\ UNIVERSIDADE DE SÃO PAULO \\ TERMO DE CONSENTIMENTO LIVRE E ESCLARECIDO}

I - DADOS DE IDENTIFICAÇÃO DO SUJEITO DA PESQUISA OU RESPONSÁVEL LEGAL

1. NOME DO INDIVÍDUO:

DOCUMENTO DE IDENTIDADE №: SEXO: $\quad . M \square F \square$

DATA NASCIMENTO:.......................

ENDEREÇO: №.............. APTO.

BAIRRO: CIDADE

CEP:. TELEFONE: DDD

2. RESPONSÁVEL LEGAL:

NATUREZA (grau de parentesco, tutor, curador, etc.):

DOCUMENTO DE IDENTIDADE: SEXO: $M \square F \square$

DATA NASCIMENTO: .................

ENDEREÇO: № APTO:

BAIRRO: CIDADE:

CEP:. TELEFONE: DDD (

II - DADOS SOBRE A PESQUISA CIENTÍFICA TÍTULO DO PROJETO DE PESQUISA:

"Análise de parâmetros biomecânicos na locomoção de crianças portadoras de pé torto congênito" PESQUISADOR RESPONSÁVEL: Professor Doutor Alberto Carlos Amadio

PESQUISADOR GERENTE: Renato José Soares

CARGO/FUNÇÃO: 2) Professor Doutor e 3) Fisioterapeuta.

AVALIAÇÃO DO RISCO DA PESQUISA:

RISCO MÍNIMO RISCO MÉDIO RISCO BAIXO $x$ RISCO MAIOR

(probabilidade de que o indivíduo sofra algum dano como conseqüência imediata ou tardia do estudo)

DURAÇÃO DA PESQUISA: 4 meses (coleta de dados) e todo estudo 4 anos. 


\section{ANEXO II - Termo de consentimento livre e esclarecido (cont.)}

III - EXPLICAÇÕES DO PESQUISADOR AO INDIVÍDUO OU SEU REPRESENTANTE LEGAL SOBRE A PESQUISA:

JUSTIFICATIVA E OS OBJETIVOS DA PESQUISA:

Estas informações estão sendo fornecidas para a participação voluntária neste estudo que tem como objetivo analisar características da locomoção (andar e saltar) em crianças com história de pé torto congênito e crianças sem tal acometimento.

PROCEDIMENTOS QUE SERÃO UTILIZADOS E PROPÓSITOS, INCLUINDO A IDENTIFICAÇÃO DOS PROCEDIMENTOS QUE SÃO EXPERIMENTAIS:

Durante a coleta de dados experimentais, inicialmente a criança passará por uma entrevista com preenchimento de um questionário. Isso servirá para coletar informações sobre atividades do dia-adia e eventuais dores na região. A criança será orientada, pelo médico responsável, a realizar um raio-x dos pés com a finalidade de acompanhamento da evolução do tratamento clínico.

Em seguida, avaliar-se-á as características da sensibilidade do pé, por meio de um equipamento conhecido como estesiômetro, baseado em fios de distintas densidades que tocam diferentes regiões do pé. Para isso, a criança permanecerá deitada e com os olhos fechados. Esses fios não acarretarão em nenhum tipo de dor ou outro desconforto.

A próxima etapa, será a avaliação de características do andar natural. Para a análise dos movimentos das articulações, será utilizada uma câmera de vídeo que irá registrar as imagens durante as atividades requisitadas. Para isso, serão colocados, com fitas adesivas, marcadores nas regiões próximas das articulações, os quais não serão lesivos ao corpo. Após isso, será pedido para a criança andar em uma passarela. Inserido a essa passarela, existe um equipamento chamado plataforma de força de reação do solo que se encontra nivelado ao solo. Portanto, a criança passará por cima dela sem perceber.

Numa outra etapa, a criança ficará em cima dessa plataforma e realizará cinco saltos verticais. Serão utilizadas duas câmeras de vídeo que registrarão as imagens durante as atividades requisitadas. Será também utilizado um equipamento que mede a atividade de alguns músculos da perna. Para isso, serão utilizados pequenos dispositivos chamados de eletrodos que serão posicionados, de forma não invasiva, sobre a pele. 


\section{ANEXO II - Termo de consentimento livre e esclarecido (cont.)}

\section{DESCONFORTOS E RISCOS ESPERADOS:}

Destaca-se que todos os experimentos serão realizados de forma não invasiva, apresentando riscos mínimos à sua integridade física.

BENEFÍCIOS QUE PODERÃO SER OBTIDOS E PROCEDIMENTOS ALTERNATIVOS QUE POSSAM SER VANTAJOSOS PARA O INDIVÍDUO:

Assim que todos os resultados forem tratados e interpretados, um relatório será enviado para 0 médico responsável.

Em qualquer etapa deste estudo, a criança ou responsável terão acesso aos profissionais responsáveis pela pesquisa para esclarecimento de eventuais dúvidas relacionadas ao procedimento experimental realizado e das informações sobre os riscos e benefícios relacionados aos experimentos.

Não há despesas pessoais para o participante em qualquer fase do estudo. Também não há compensação financeira relacionada à sua participação. Será mantido sigilo em relação à identidade de cada um dos participantes durante todo procedimento experimental.

IV - ESCLARECIMENTOS DADOS PELO PESQUISADOR SOBRE GARANTIAS DO SUJEITO DA PESQUISA:

A qualquer momento, os sujeitos terão direito às informações sobre procedimentos, riscos e benefícios relacionados a esta pesquisa.

Você terá liberdade de retirar seu consentimento e a criança pode deixar de participar do estudo a qualquer momento sem que isto lhes traga qualquer prejuízo. 


\section{ANEXO II - Termo de consentimento livre e esclarecido (cont.)}

V - INFORMAÇÕES DE NOMES, ENDEREÇOS E TELEFONES DOS RESPONSÁVEIS PELO ACOMPANHAMENTO DA PESQUISA, PARA CONTATO EM CASO DE INTERCORRÊNCIAS CLÍNICAS E REAÇÕES ADVERSAS.

Alberto Carlos Amadio

Endereço: Rua: Professor Mello Moraes, 65 - Butantã, CEP:05508-900 - São Paulo- SP

Renato José Soares

Endereço: Rua: Professor Mello Moraes, 65 - Butantã, CEP:05508-900 - São Paulo- SP

VI - CONSENTIMENTO PÓS-ESCLARECIDO

Declaro que, após convenientemente esclarecido pelo pesquisador e ter entendido o que me foi explicado, consinto em participar do presente Projeto de Pesquisa.

São Paulo, de de 200

Assinatura do sujeito da pesquisa ou responsável legal

Assinatura do pesquisador responsável 


\section{ANEXO III - Rotinas em ambiente matlab}

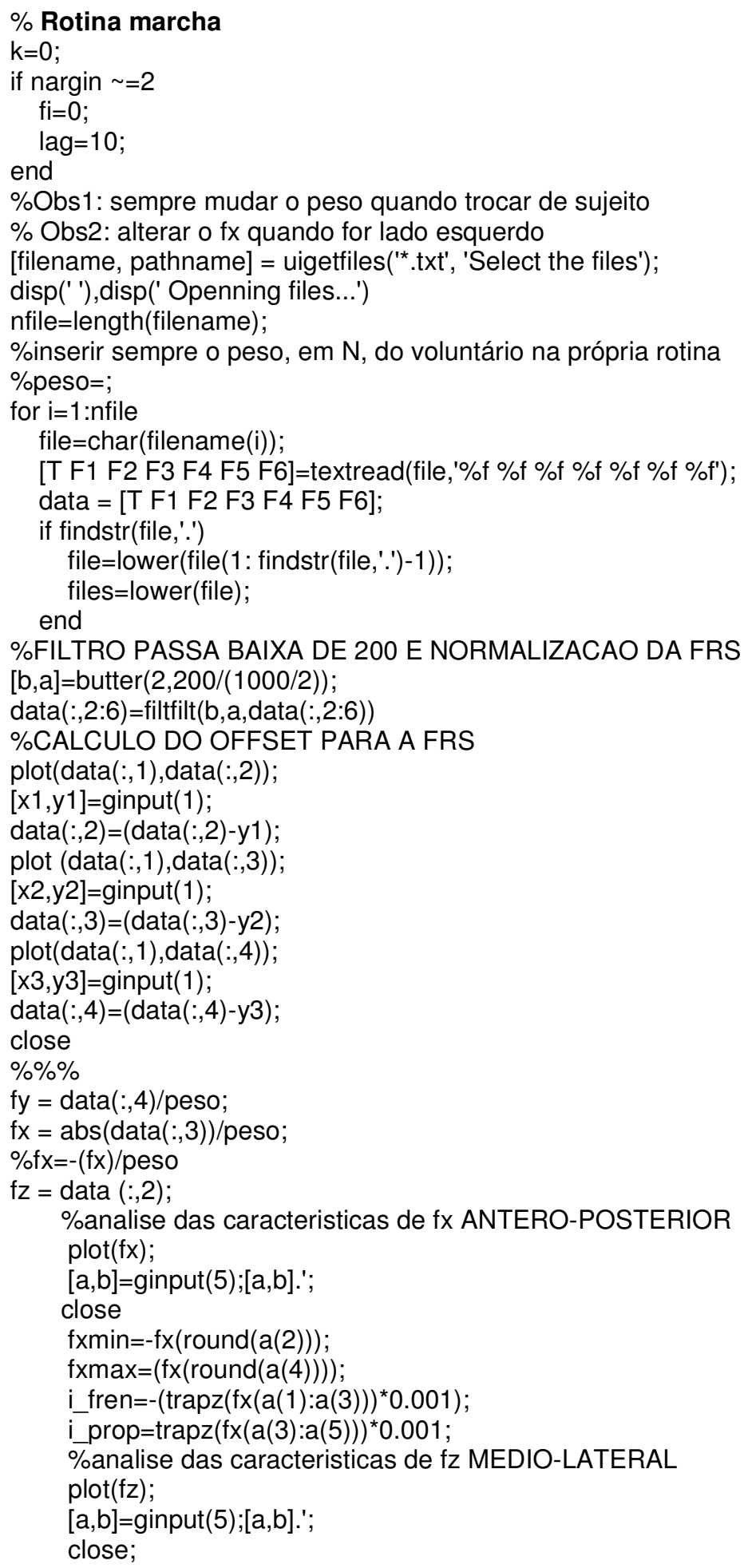




\section{ANEXO III - Rotinas em ambiente matlab (cont.)}

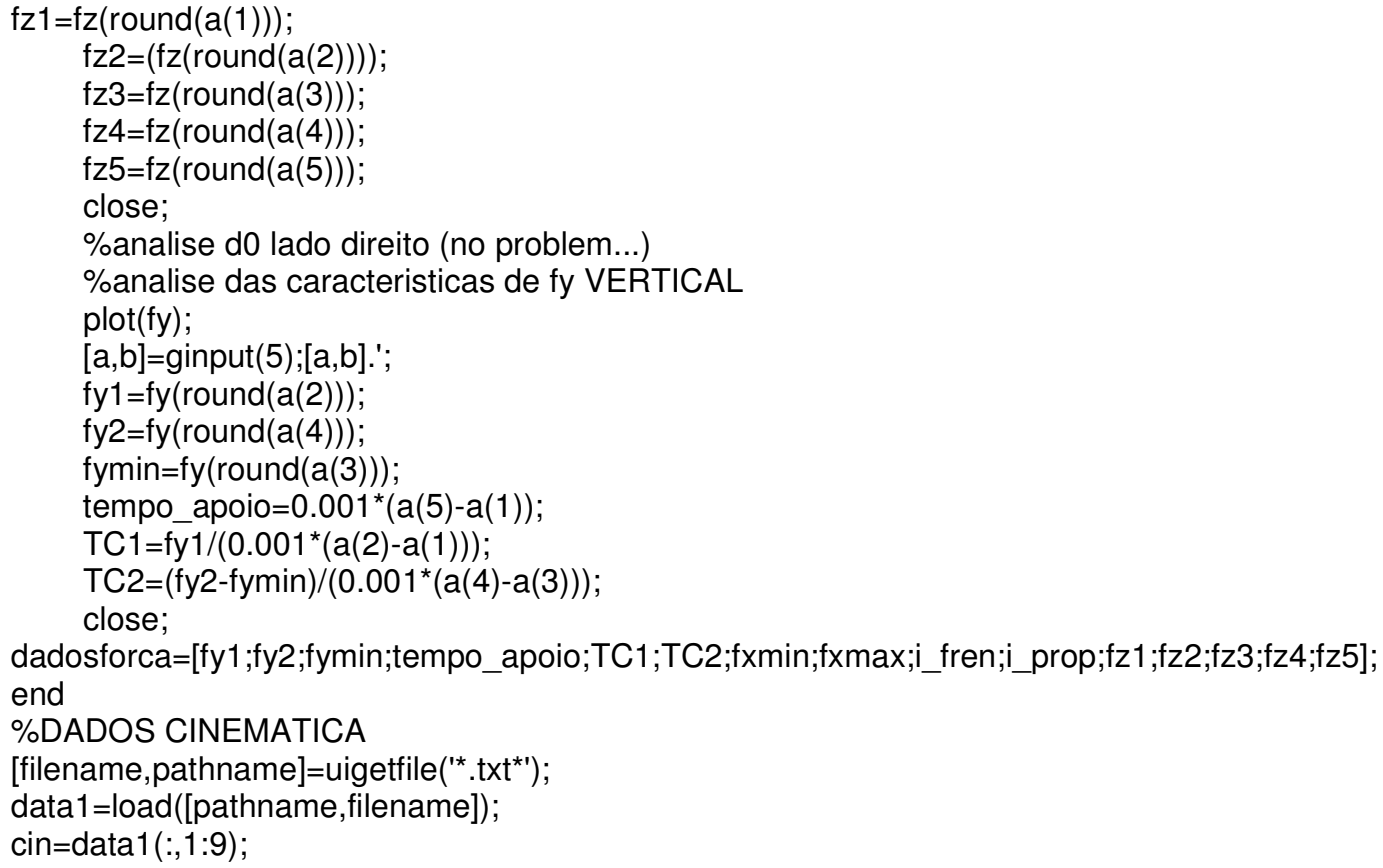




\section{ANEXO III - Rotinas em ambiente matlab (cont.)}

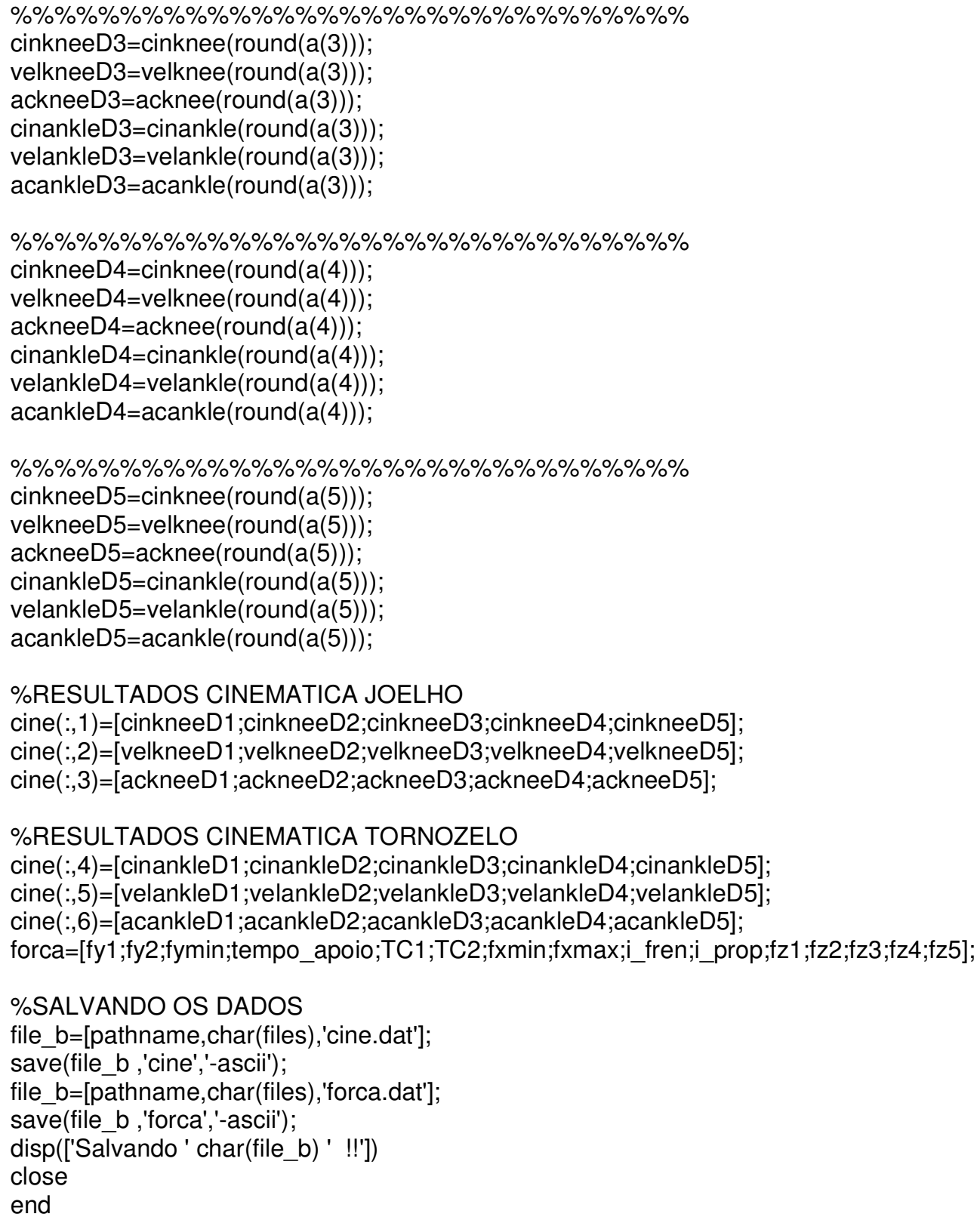




\section{ANEXO III - Rotinas em ambiente matlab (cont.)}

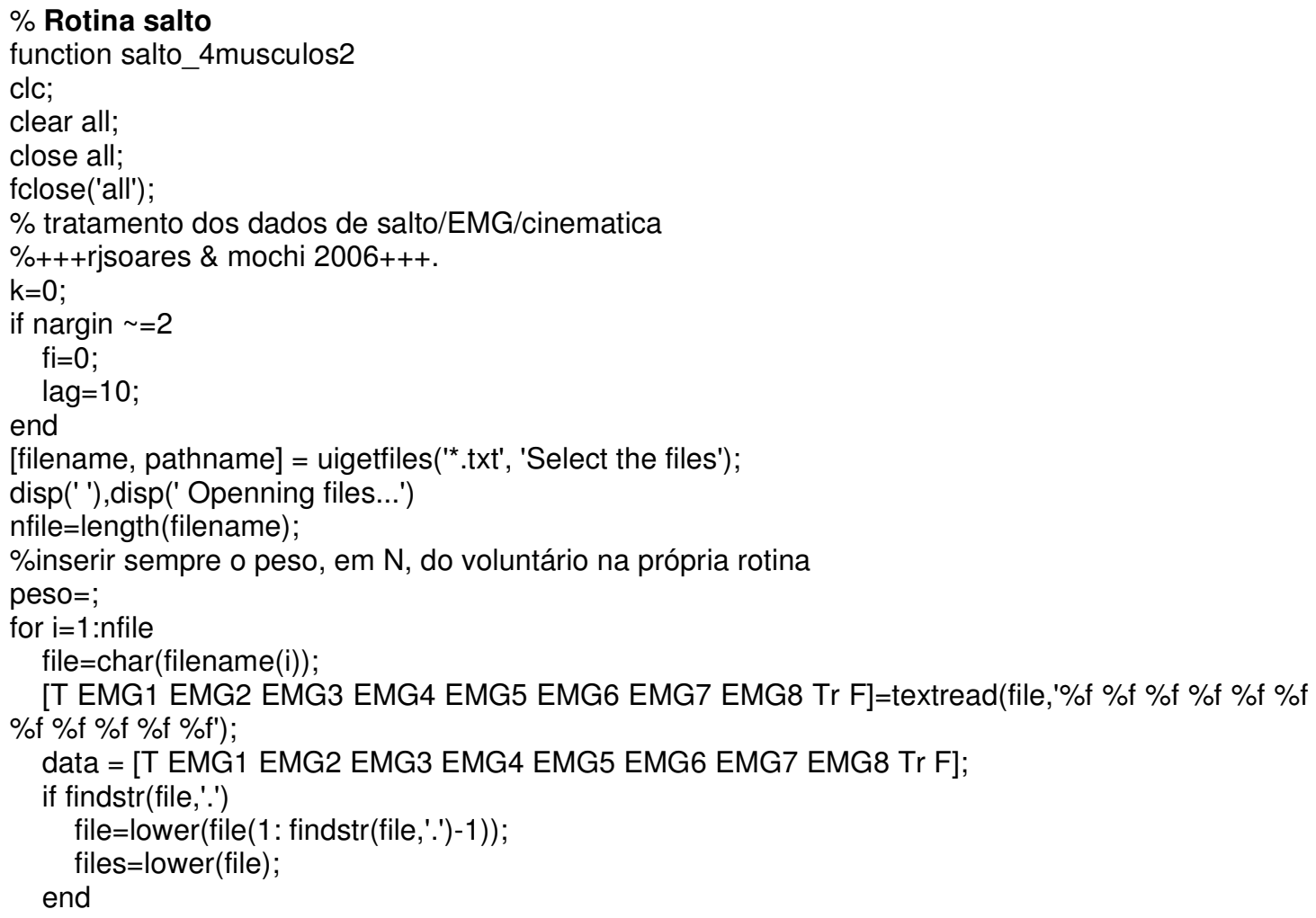




\section{ANEXO III - Rotinas em ambiente matlab (cont.)}

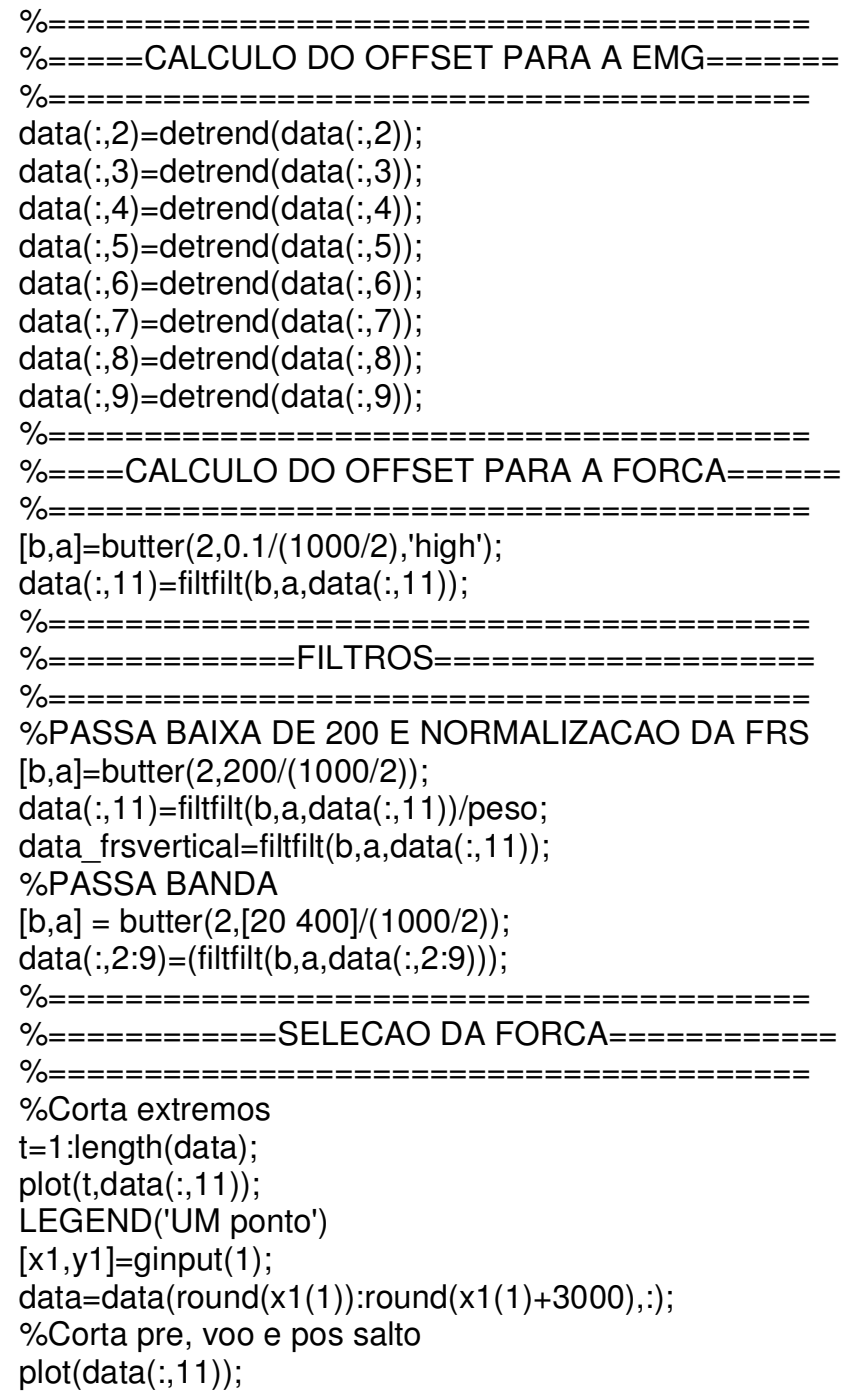




\section{ANEXO III - Rotinas em ambiente matlab (cont.)}

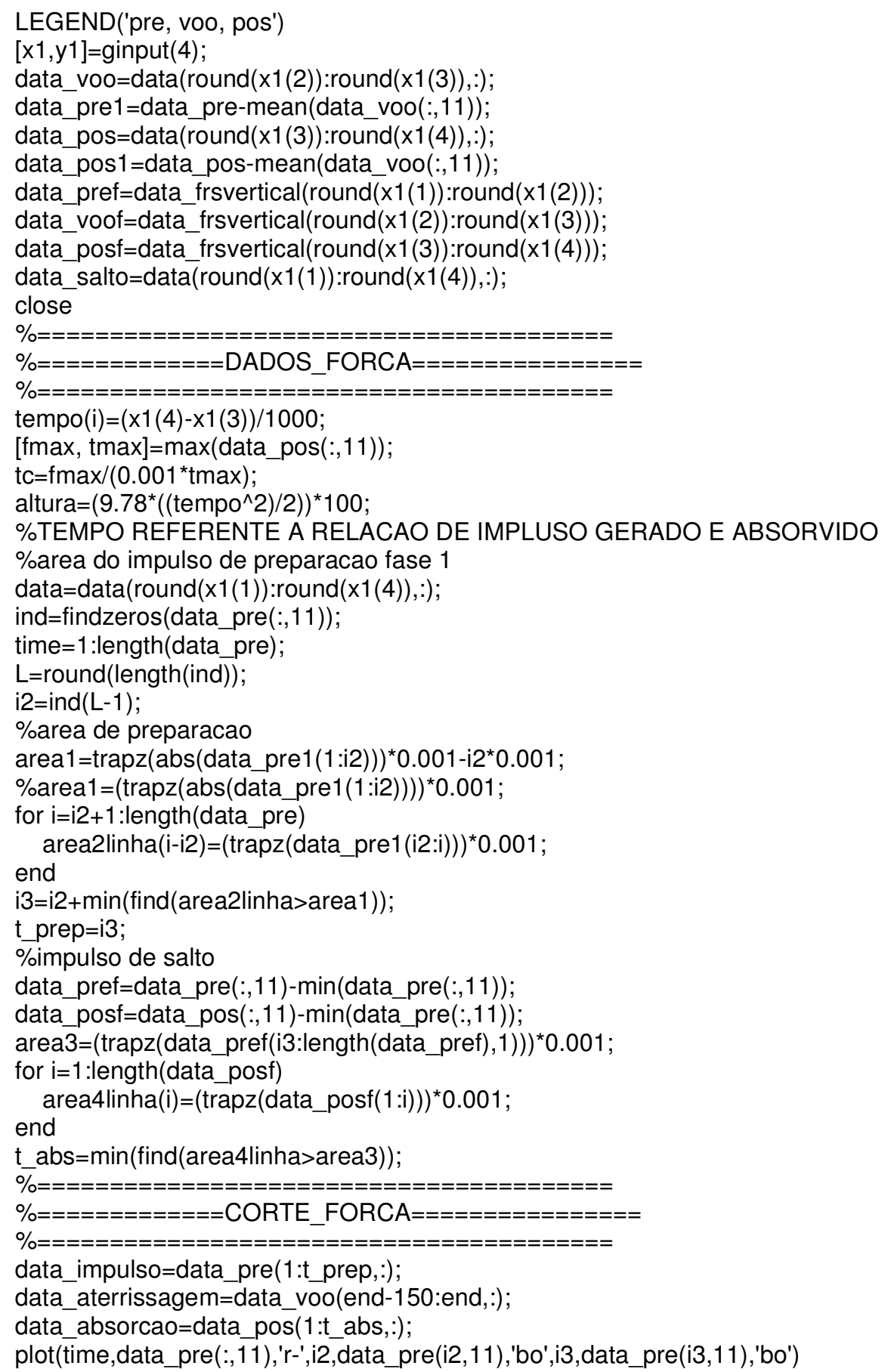




\section{ANEXO III - Rotinas em ambiente matlab (cont.)}

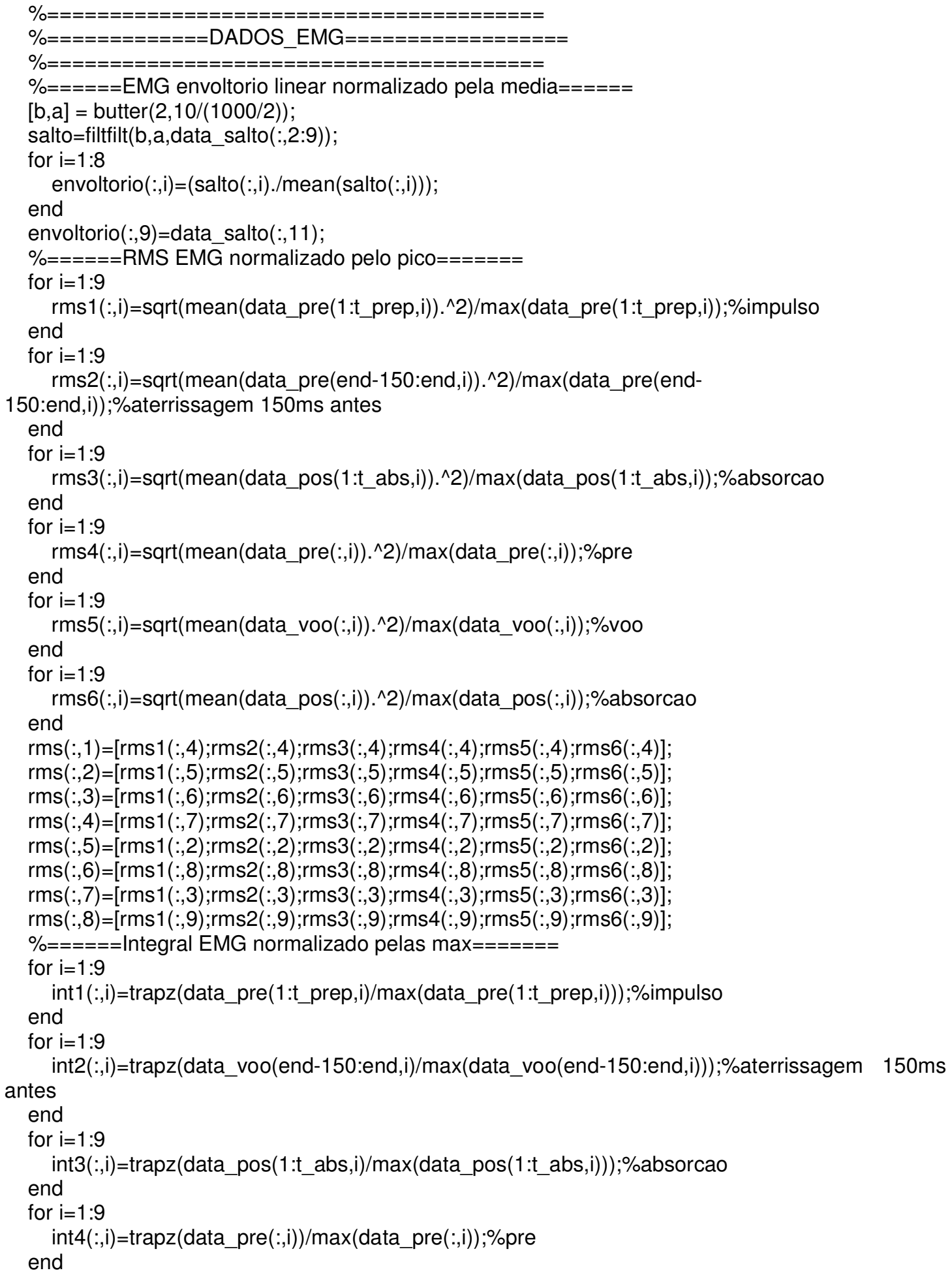




\section{ANEXO III - Rotinas em ambiente matlab (cont.)}

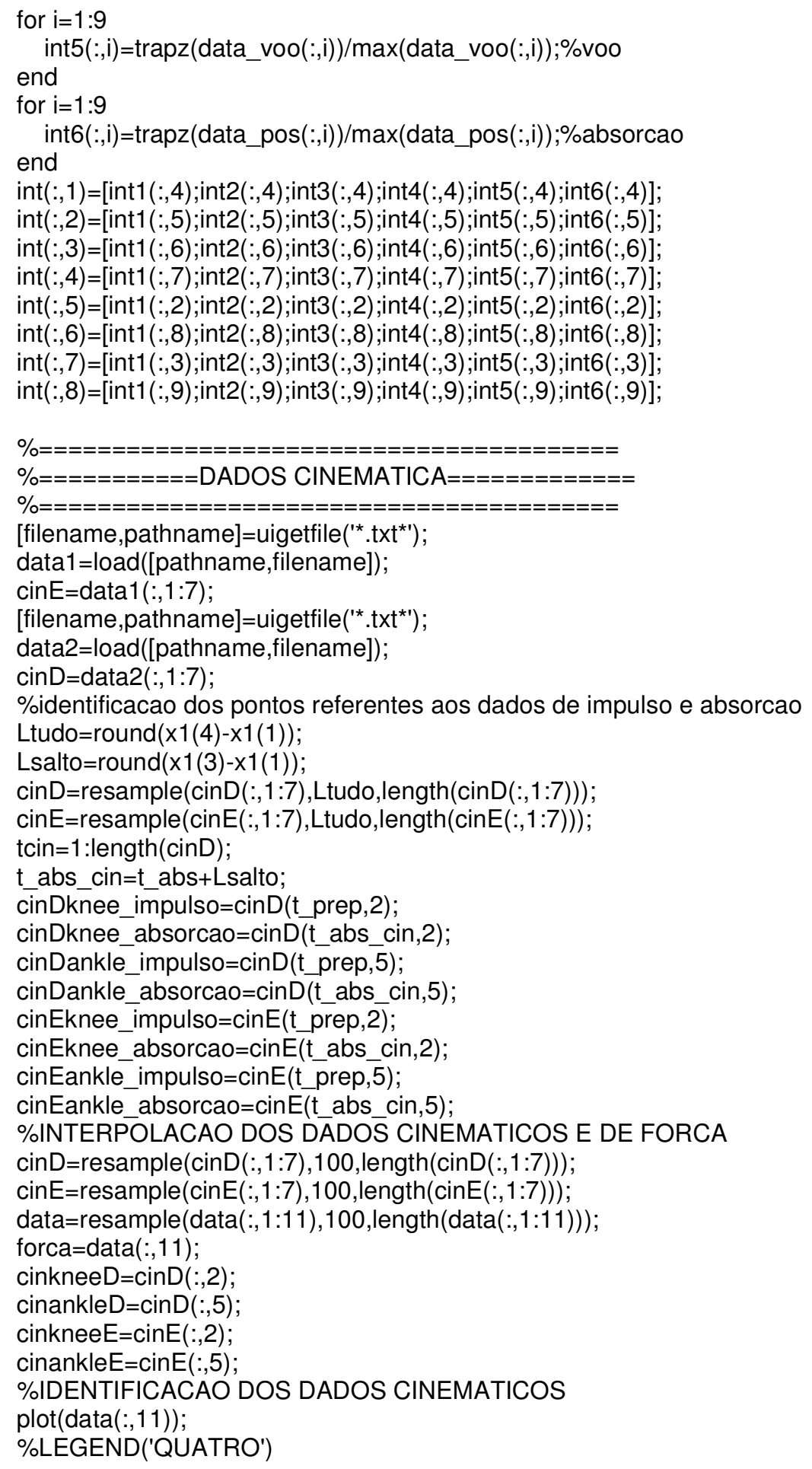




\section{ANEXO III - Rotinas em ambiente matlab (cont.)}

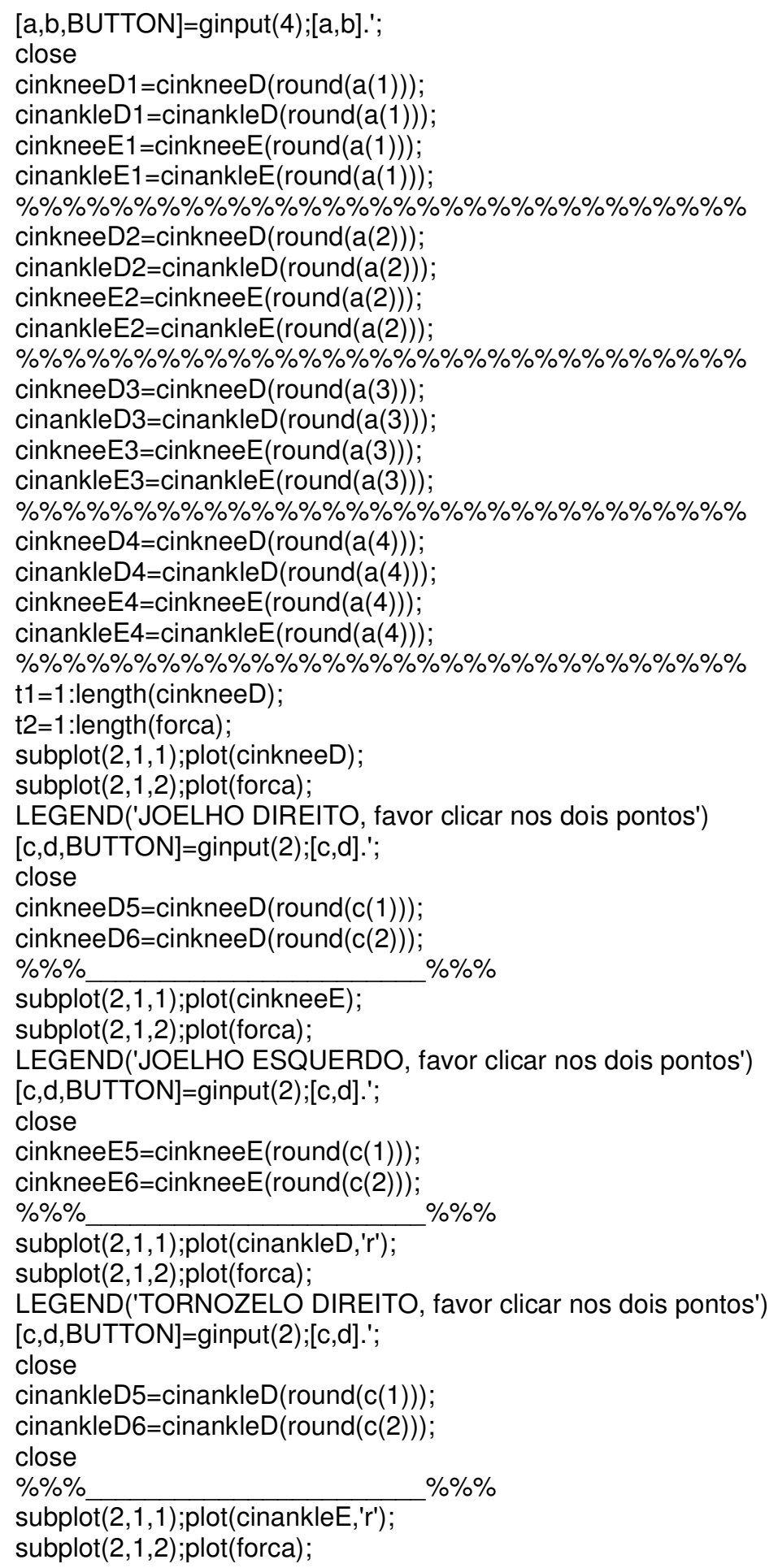




\section{ANEXO III - Rotinas em ambiente matlab (cont.)}

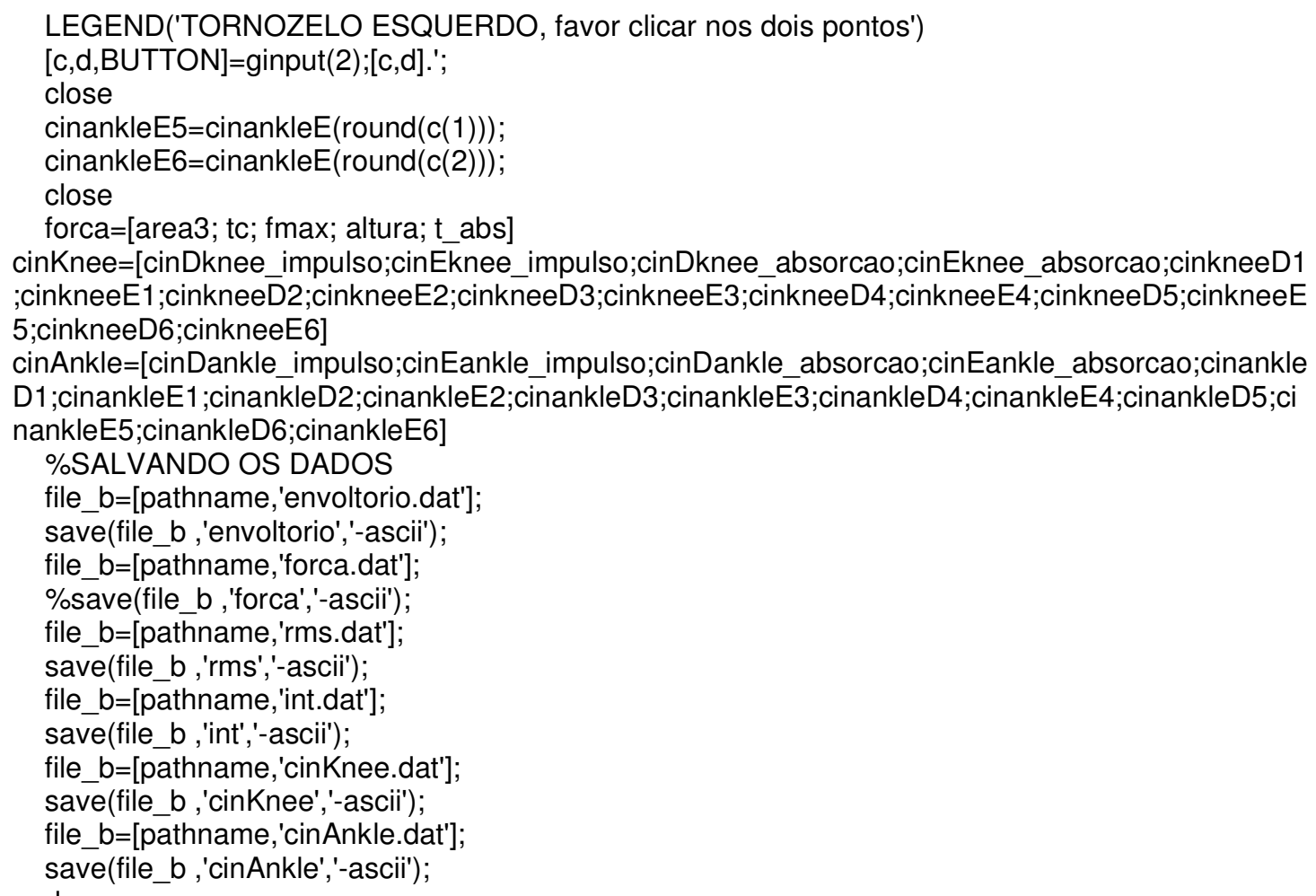




\section{ANEXO IV - Resultados dos experimentos}

TABELA 38 - Dados gerais relacionados com os parâmetros avaliados no experimento 1 do grupo controle.

\begin{tabular}{|c|c|c|c|c|c|c|}
\hline Variáveis & & Média & Mediana & Desvio Padrão & Tamanho & $\overline{p \text {-valor }}$ \\
\hline \multirow{5}{*}{$\begin{array}{l}\text { Fz } 1 \\
(P C)\end{array}$} & Rep 1 & 1,035467 & 1,025664 & 0,060321 & 20 & \multirow{5}{*}{0,236} \\
\hline & Rep 2 & 1,033734 & 1,046692 & 0,057088 & 20 & \\
\hline & Rep 3 & 1,070511 & 1,045613 & 0,084478 & 20 & \\
\hline & Rep 4 & 1,035555 & 1,038828 & 0,047825 & 20 & \\
\hline & $\operatorname{Rep} 5$ & 1,047878 & 1,036016 & 0,073044 & 20 & \\
\hline \multirow{5}{*}{$\begin{array}{l}\text { Fz } 2 \\
\text { (PC) }\end{array}$} & Rep 1 & 1,069895 & 1,075228 & 0,061159 & 20 & \multirow{5}{*}{0,871} \\
\hline & Rep 2 & 1,074714 & 1,062649 & 0,063893 & 20 & \\
\hline & Rep 3 & 1,057754 & 1,036015 & 0,069161 & 20 & \\
\hline & Rep 4 & 1,050033 & 1,041605 & 0,057243 & 20 & \\
\hline & Rep 5 & 1,063738 & 1,048926 & 0,071125 & 20 & \\
\hline \multirow{5}{*}{$\begin{array}{l}\text { Fz min } \\
(P C)\end{array}$} & Rep 1 & 0,854773 & 0,851360 & 0,043574 & 20 & \multirow{5}{*}{0,180} \\
\hline & Rep 2 & 0,831516 & 0,853258 & 0,072499 & 20 & \\
\hline & $\operatorname{Rep} 3$ & 0,843598 & 0,846479 & 0,050345 & 20 & \\
\hline & Rep 4 & 0,860138 & 0,871738 & 0,053262 & 20 & \\
\hline & Rep 5 & 0,855829 & 0,875918 & 0,054890 & 20 & \\
\hline \multirow{5}{*}{$\begin{array}{l}\text { TC } 1 \\
\text { (PC/s) }\end{array}$} & Rep 1 & 0,732558 & 0,715208 & 0,133196 & 20 & \multirow{5}{*}{0,106} \\
\hline & $\operatorname{Rep} 2$ & 0,709389 & 0,673618 & 0,154137 & 20 & \\
\hline & Rep 3 & 0,732972 & 0,720738 & 0,153100 & 20 & \\
\hline & Rep 4 & 0,738836 & 0,710599 & 0,141254 & 20 & \\
\hline & $\operatorname{Rep} 5$ & 0,745127 & 0,710599 & 0,144010 & 20 & \\
\hline \multirow{5}{*}{$\begin{array}{c}\text { T_apoio } \\
(\mathrm{s})\end{array}$} & Rep 1 & 6,575381 & 5,643060 & 4,528030 & 20 & \multirow{5}{*}{0,755} \\
\hline & Rep 2 & 6,046082 & 5,387418 & 2,030911 & 20 & \\
\hline & $\operatorname{Rep} 3$ & 6,361904 & 5,993848 & 2,382825 & 20 & \\
\hline & Rep 4 & 6,891527 & 5,379286 & 6,697358 & 20 & \\
\hline & Rep 5 & 5,861833 & 5,849281 & 1,935230 & 20 & \\
\hline \multirow{5}{*}{$\begin{array}{l}\text { TC } 2 \\
\text { (PC/s) }\end{array}$} & Rep 1 & 1,145618 & 1,022993 & 0,611172 & 20 & \multirow{5}{*}{0,120} \\
\hline & Rep 2 & 1,484416 & 1,063754 & 1,166964 & 20 & \\
\hline & Rep 3 & 1,210097 & 1,164625 & 0,678049 & 20 & \\
\hline & $\operatorname{Rep} 4$ & 1,071572 & 0,766009 & 0,866141 & 20 & \\
\hline & Rep 5 & 1,201421 & 0,795524 & 0,791483 & 20 & \\
\hline \multirow{5}{*}{$\begin{array}{l}\text { Fy min } \\
\text { (PC) }\end{array}$} & $\operatorname{Rep} 1$ & $-0,105407$ & $-0,104585$ & 0,040750 & 20 & \multirow{5}{*}{0,581} \\
\hline & Rep 2 & $-0,111838$ & $-0,098170$ & 0,045636 & 20 & \\
\hline & Rep 3 & $-0,111824$ & $-0,107595$ & 0,042335 & 20 & \\
\hline & $\operatorname{Rep} 4$ & $-0,109967$ & $-0,089781$ & 0,070831 & 20 & \\
\hline & Rep 5 & $-0,118234$ & $-0,103888$ & 0,048102 & 20 & \\
\hline
\end{tabular}




\section{ANEXO IV - Resultados dos experimentos (cont.)}

TABELA 38 - Dados gerais relacionados com os parâmetros avaliados no experimento 1 do grupo controle (cont.).

\begin{tabular}{|c|c|c|c|c|c|c|}
\hline Variáveis & & Média & Mediana & Desvio Padrão & Tamanho & p-valor \\
\hline \multirow{5}{*}{$\begin{array}{l}\text { Fy max } \\
\text { (PC) }\end{array}$} & Rep 1 & 0,131392 & 0,125482 & 0,029068 & 20 & \multirow{5}{*}{0,052} \\
\hline & Rep 2 & 0,152808 & 0,145772 & 0,026881 & 20 & \\
\hline & Rep 3 & 0,139494 & 0,141132 & 0,031517 & 20 & \\
\hline & Rep 4 & 0,141008 & 0,142287 & 0,045821 & 20 & \\
\hline & $\operatorname{Rep} 5$ & 0,139289 & 0,138853 & 0,034152 & 20 & \\
\hline \multirow{5}{*}{$\begin{array}{l}\text { I_fren } \\
\text { (PC.s) }\end{array}$} & Rep 1 & $-0,017712$ & $-0,016148$ & 0,007360 & 20 & \multirow{5}{*}{0,560} \\
\hline & Rep 2 & $-0,019322$ & $-0,018097$ & 0,007640 & 20 & \\
\hline & Rep 3 & $-0,019992$ & $-0,019754$ & 0,007091 & 20 & \\
\hline & Rep 4 & $-0,016911$ & $-0,015858$ & 0,006087 & 20 & \\
\hline & Rep 5 & $-0,019674$ & $-0,018702$ & 0,006042 & 20 & \\
\hline \multirow{5}{*}{$\begin{array}{l}\text { I_prop } \\
\text { (PC.s) }\end{array}$} & Rep 1 & 0,021611 & 0,020868 & 0,006073 & 20 & \multirow{5}{*}{0,377} \\
\hline & Rep 2 & 0,024263 & 0,024467 & 0,006088 & 20 & \\
\hline & Rep 3 & 0,022820 & 0,023160 & 0,005231 & 20 & \\
\hline & Rep 4 & 0,022530 & 0,021094 & 0,007260 & 20 & \\
\hline & Rep 5 & 0,023611 & 0,023141 & 0,006301 & 20 & \\
\hline \multirow{5}{*}{$\begin{array}{l}\text { Fx } 1 \\
(P C)\end{array}$} & $\operatorname{Rep} 1$ & $-0,005775$ & $-0,002896$ & 0,008639 & 20 & \multirow{5}{*}{0,681} \\
\hline & Rep 2 & $-0,011434$ & $-0,005654$ & 0,013725 & 20 & \\
\hline & Rep 3 & $-0,009456$ & $-0,004769$ & 0,010846 & 20 & \\
\hline & Rep 4 & $-0,006363$ & $-0,003514$ & 0,007560 & 20 & \\
\hline & Rep 5 & $-0,009553$ & $-0,003725$ & 0,011625 & 20 & \\
\hline \multirow{5}{*}{$\begin{array}{l}F \times 2 \\
(P C)\end{array}$} & Rep 1 & 0,086096 & 0,082928 & 0,020417 & 20 & \multirow{5}{*}{0,299} \\
\hline & Rep 2 & 0,077352 & 0,075227 & 0,023930 & 20 & \\
\hline & Rep 3 & 0,077889 & 0,071253 & 0,018638 & 20 & \\
\hline & Rep 4 & 0,084781 & 0,081933 & 0,023235 & 20 & \\
\hline & Rep 5 & 0,080631 & 0,075593 & 0,020878 & 20 & \\
\hline \multirow{5}{*}{$\begin{array}{l}\mathrm{F} \times 3 \\
(\mathrm{PC})\end{array}$} & Rep 1 & 0,054218 & 0,052734 & 0,019710 & 20 & \multirow{5}{*}{0,194} \\
\hline & Rep 2 & 0,048910 & 0,044400 & 0,018858 & 20 & \\
\hline & Rep 3 & 0,050407 & 0,049075 & 0,019186 & 20 & \\
\hline & Rep 4 & 0,052859 & 0,050492 & 0,022161 & 20 & \\
\hline & $\operatorname{Rep} 5$ & 0,049842 & 0,049622 & 0,024215 & 20 & \\
\hline \multirow{5}{*}{$\begin{array}{l}F \times 4 \\
(P C)\end{array}$} & Rep 1 & $-0,003726$ & $-0,002530$ & 0,004858 & 20 & \multirow{5}{*}{0,058} \\
\hline & Rep 2 & $-0,006782$ & $-0,006178$ & 0,007744 & 20 & \\
\hline & Rep 3 & $-0,005304$ & $-0,001555$ & 0,008693 & 20 & \\
\hline & Rep 4 & $-0,004159$ & $-0,001233$ & 0,007560 & 20 & \\
\hline & Rep 5 & $-0,007061$ & $-0,003257$ & 0,009220 & 20 & \\
\hline
\end{tabular}




\section{ANEXO IV - Resultados dos experimentos (cont.)}

TABELA 38 - Dados gerais relacionados com os parâmetros avaliados no experimento 1 do grupo controle (cont.).

\begin{tabular}{|c|c|c|c|c|c|c|}
\hline Variáveis & & Média & Mediana & Desvio Padrão & Tamanho & p-valor \\
\hline \multirow{5}{*}{$\begin{array}{c}\text { cine_joelho1 } \\
\text { (Graus) }\end{array}$} & Rep 1 & 8,042508 & 7,659607 & 5,436344 & 20 & \multirow{5}{*}{0,621} \\
\hline & $\operatorname{Rep} 2$ & 7,753627 & 7,121574 & 5,527861 & 20 & \\
\hline & Rep 3 & 8,660906 & 6,952643 & 7,122841 & 20 & \\
\hline & Rep 4 & 10,429675 & 9,810861 & 7,417535 & 20 & \\
\hline & $\operatorname{Rep} 5$ & 7,095048 & 6,484606 & 4,308964 & 20 & \\
\hline \multirow{5}{*}{$\begin{array}{c}\text { cine_joelho2 } \\
\text { (Graus) }\end{array}$} & Rep 1 & 12,606661 & 12,826157 & 6,657127 & 20 & \multirow{5}{*}{0,083} \\
\hline & $\operatorname{Rep} 2$ & 11,680860 & 13,387851 & 6,268962 & 20 & \\
\hline & Rep 3 & 14,824346 & 16,238223 & 5,328089 & 20 & \\
\hline & Rep 4 & 14,497198 & 14,270496 & 5,524018 & 20 & \\
\hline & Rep 5 & 12,386489 & 10,686450 & 5,957951 & 20 & \\
\hline \multirow{5}{*}{$\begin{array}{c}\text { cine_joelho3 } \\
\text { (Graus) }\end{array}$} & Rep 1 & 9,546887 & 9,698921 & 5,707976 & 20 & \multirow{5}{*}{0,826} \\
\hline & Rep 2 & 9,729730 & 10,644754 & 4,267531 & 20 & \\
\hline & $\operatorname{Rep} 3$ & 10,136667 & 8,602506 & 4,273370 & 20 & \\
\hline & Rep 4 & 9,996150 & 10,880136 & 4,186069 & 20 & \\
\hline & Rep 5 & 9,212553 & 8,778097 & 4,713981 & 20 & \\
\hline \multirow{5}{*}{$\begin{array}{c}\text { cine_joelho4 } \\
\text { (Graus) }\end{array}$} & Rep 1 & 10,405987 & 10,039843 & 5,440756 & 20 & \multirow{5}{*}{0,055} \\
\hline & $\operatorname{Rep} 2$ & 8,350040 & 8,709562 & 4,402332 & 20 & \\
\hline & Rep 3 & 8,815737 & 8,173668 & 3,914829 & 20 & \\
\hline & Rep 4 & 7,856724 & 7,549623 & 2,537532 & 20 & \\
\hline & $\operatorname{Rep} 5$ & 8,143915 & 7,892081 & 3,581008 & 20 & \\
\hline \multirow{5}{*}{$\begin{array}{c}\text { cine_joelho5 } \\
\text { (Graus) }\end{array}$} & Rep 1 & 31,082727 & 30,533545 & 11,501931 & 20 & \multirow{5}{*}{0,520} \\
\hline & $\operatorname{Rep} 2$ & 29,137248 & 29,843299 & 10,434090 & 20 & \\
\hline & Rep 3 & 33,920897 & 33,056786 & 11,356773 & 20 & \\
\hline & Rep 4 & 34,983429 & 34,953325 & 10,761308 & 20 & \\
\hline & $\operatorname{Rep} 5$ & 29,930416 & 33,836486 & 11,869064 & 20 & \\
\hline \multirow{5}{*}{$\begin{array}{c}\text { cine_tornozelo1 } \\
\text { (Graus) }\end{array}$} & Rep 1 & 87,278537 & 90,014902 & 10,535476 & 20 & \multirow{5}{*}{0,834} \\
\hline & Rep 2 & 86,838977 & 86,356087 & 10,688180 & 20 & \\
\hline & Rep 3 & 85,755873 & 86,116166 & 11,159860 & 20 & \\
\hline & Rep 4 & 86,559587 & 89,568611 & 11,027999 & 20 & \\
\hline & $\operatorname{Rep} 5$ & 84,934206 & 86,442349 & 12,182777 & 20 & \\
\hline \multirow{5}{*}{$\begin{array}{c}\text { cine_tornozelo2 } \\
\text { (Graus) }\end{array}$} & Rep 1 & 88,115135 & 88,105207 & 4,243958 & 20 & \multirow{5}{*}{0,859} \\
\hline & $\operatorname{Rep} 2$ & 87,955643 & 89,174758 & 4,810004 & 20 & \\
\hline & Rep 3 & 87,409884 & 87,502667 & 3,822618 & 20 & \\
\hline & Rep 4 & 88,130431 & 88,283189 & 3,431163 & 20 & \\
\hline & $\operatorname{Rep} 5$ & 88,239589 & 88,378683 & 3,624316 & 20 & \\
\hline
\end{tabular}




\section{ANEXO IV - Resultados dos experimentos (cont.)}

TABELA 38 - Dados gerais relacionados com os parâmetros avaliados no experimento 1 do grupo controle (cont.).

\begin{tabular}{|c|c|c|c|c|c|c|}
\hline Variáveis & & Média & Mediana & Desvio Padrão & Tamanho & p-valor \\
\hline \multirow{5}{*}{$\begin{array}{c}\text { cine tornozelo3 } \\
\text { (Graus) }\end{array}$} & Rep 1 & 91,698100 & 92,564175 & 3,705138 & 20 & \multirow{5}{*}{0,830} \\
\hline & Rep 2 & 91,204766 & 90,997736 & 4,500802 & 20 & \\
\hline & Rep 3 & 90,494274 & 90,818475 & 5,066444 & 20 & \\
\hline & Rep 4 & 90,284685 & 90,860058 & 4,633310 & 20 & \\
\hline & Rep 5 & 91,474577 & 91,878579 & 2,903118 & 20 & \\
\hline \multirow{5}{*}{$\begin{array}{c}\text { cine_tornozelo4 } \\
\text { (Graus) }\end{array}$} & Rep 1 & 92,173392 & 92,404804 & 6,801303 & 20 & \multirow{5}{*}{0,151} \\
\hline & Rep 2 & 90,539147 & 90,788359 & 5,295024 & 20 & \\
\hline & Rep 3 & 90,935964 & 90,481594 & 7,567820 & 20 & \\
\hline & Rep 4 & 89,802424 & 89,634288 & 4,831781 & 20 & \\
\hline & Rep 5 & 92,782610 & 93,414837 & 4,877134 & 20 & \\
\hline \multirow{5}{*}{$\begin{array}{c}\text { cine_tornozelo5 } \\
\text { (Graus) }\end{array}$} & $\operatorname{Rep} 1$ & 52,434796 & 52,986967 & 17,611820 & 20 & \multirow{5}{*}{0,316} \\
\hline & Rep 2 & 57,169594 & 56,561714 & 22,377012 & 20 & \\
\hline & Rep 3 & 60,732278 & 61,453071 & 23,653593 & 20 & \\
\hline & Rep 4 & 61,983867 & 62,117159 & 20,400444 & 20 & \\
\hline & Rep 5 & 51,708162 & 52,084465 & 22,543087 & 20 & \\
\hline
\end{tabular}




\section{ANEXO IV - Resultados dos experimentos (cont.)}

TABELA 39 - Dados gerais relacionados com os parâmetros avaliados no experimento 1 do grupo de criancas com PTC bilateral.

\begin{tabular}{|c|c|c|c|c|c|c|}
\hline Variáveis & & Média & Mediana & $\begin{array}{l}\text { Desvio } \\
\text { Padrão }\end{array}$ & Tamanho & $p$-valor \\
\hline \multirow{5}{*}{$\begin{array}{l}\text { Fz } 1 \\
(P C)\end{array}$} & Rep 1 & 1,034895 & 0,984431 & 0,118991 & 14 & \multirow{5}{*}{0,649} \\
\hline & Rep 2 & 1,024125 & 0,993155 & 0,087213 & 14 & \\
\hline & Rep 3 & 1,021377 & 1,008268 & 0,080468 & 14 & \\
\hline & Rep 4 & 1,012545 & 0,996231 & 0,082646 & 14 & \\
\hline & Rep 5 & 1,031045 & 1,006872 & 0,085398 & 14 & \\
\hline \multirow{5}{*}{$\begin{array}{l}\text { Fz } 2 \\
\text { (PC) }\end{array}$} & Rep 1 & 1,014096 & 0,991460 & 0,087172 & 14 & \multirow{5}{*}{0,846} \\
\hline & Rep 2 & 0,992880 & 0,988232 & 0,054909 & 14 & \\
\hline & Rep 3 & 1,011188 & 1,000057 & 0,065946 & 14 & \\
\hline & Rep 4 & 1,000471 & 0,996303 & 0,062383 & 14 & \\
\hline & Rep 5 & 0,992262 & 0,986704 & 0,043156 & 14 & \\
\hline \multirow{5}{*}{$\begin{array}{l}\text { Fz min } \\
(P C)\end{array}$} & Rep 1 & 0,893139 & 0,880689 & 0,088958 & 14 & \multirow{5}{*}{0,907} \\
\hline & Rep 2 & 0,876617 & 0,881916 & 0,047867 & 14 & \\
\hline & Rep 3 & 0,888388 & 0,904514 & 0,054921 & 14 & \\
\hline & Rep 4 & 0,883338 & 0,887171 & 0,042678 & 14 & \\
\hline & Rep 5 & 0,877026 & 0,885415 & 0,044159 & 14 & \\
\hline \multirow{5}{*}{$\begin{array}{l}\text { TC } 1 \\
\text { (PC/s) }\end{array}$} & Rep 1 & 0,521347 & 0,496310 & 0,095317 & 14 & \multirow{5}{*}{0,764} \\
\hline & Rep 2 & 0,496215 & 0,495620 & 0,003615 & 14 & \\
\hline & Rep 3 & 0,496709 & 0,496310 & 0,003964 & 14 & \\
\hline & Rep 4 & 0,495030 & 0,494930 & 0,002992 & 14 & \\
\hline & Rep 5 & 0,495327 & 0,497005 & 0,004801 & 14 & \\
\hline \multirow{5}{*}{$\begin{array}{c}\text { T_apoio } \\
\text { (s) }\end{array}$} & Rep 1 & 7,984502 & 8,420027 & 2,169156 & 14 & \multirow{5}{*}{0,290} \\
\hline & Rep 2 & 8,326230 & 7,472147 & 2,956880 & 14 & \\
\hline & Rep 3 & 8,038042 & 8,000271 & 2,050783 & 14 & \\
\hline & Rep 4 & 8,484990 & 8,635294 & 2,514093 & 14 & \\
\hline & Rep 5 & 7,742807 & 7,714342 & 2,188867 & 14 & \\
\hline \multirow{5}{*}{$\begin{array}{l}\text { TC } 2 \\
\text { (PC/s) }\end{array}$} & Rep 1 & 1,277352 & 1,306814 & 0,643096 & 14 & \multirow{5}{*}{0,784} \\
\hline & Rep 2 & 1,019752 & 1,187256 & 0,528081 & 14 & \\
\hline & Rep 3 & 1,151537 & 0,959219 & 0,764196 & 14 & \\
\hline & Rep 4 & 1,093967 & 0,982647 & 0,494245 & 14 & \\
\hline & Rep 5 & 1,295246 & 1,012418 & 1,044414 & 14 & \\
\hline \multirow{5}{*}{$\begin{array}{c}\text { Fy min } \\
\text { (PC) }\end{array}$} & Rep 1 & $-0,112103$ & $-0,103550$ & 0,053085 & 14 & \multirow{5}{*}{0,790} \\
\hline & Rep 2 & $-0,106812$ & $-0,102992$ & 0,042928 & 14 & \\
\hline & Rep 3 & $-0,107371$ & $-0,091712$ & 0,048994 & 14 & \\
\hline & Rep 4 & $-0,118334$ & $-0,129184$ & 0,046011 & 14 & \\
\hline & Rep 5 & $-0,106876$ & $-0,108652$ & 0,041490 & 14 & \\
\hline
\end{tabular}




\section{ANEXO IV - Resultados dos experimentos (cont.)}

TABELA 39 - Dados gerais relacionados com os parâmetros avaliados no experimento 1 do grupo de criancas com PTC bilateral (cont.).

\begin{tabular}{|c|c|c|c|c|c|c|}
\hline Variáveis & & Média & Mediana & $\begin{array}{l}\text { Desvio } \\
\text { Padrão }\end{array}$ & Tamanho & p-valor \\
\hline \multirow{5}{*}{$\begin{array}{c}\text { Fy max } \\
\text { (PC) }\end{array}$} & Rep 1 & 0,122681 & 0,110568 & 0,047105 & 14 & \multirow{5}{*}{$0,093 \#$} \\
\hline & Rep 2 & 0,125910 & 0,120092 & 0,037435 & 14 & \\
\hline & Rep 3 & 0,117394 & 0,120104 & 0,035027 & 14 & \\
\hline & Rep 4 & 0,118749 & 0,113183 & 0,030692 & 14 & \\
\hline & Rep 5 & 0,125852 & 0,125207 & 0,026729 & 14 & \\
\hline \multirow{5}{*}{$\begin{array}{l}\text { Iffren } \\
\text { (PC.s) }\end{array}$} & Rep 1 & $-0,012031$ & $-0,010785$ & 0,004869 & 14 & \multirow{5}{*}{0,758} \\
\hline & Rep 2 & $-0,010999$ & $-0,009945$ & 0,005268 & 14 & \\
\hline & Rep 3 & $-0,011377$ & $-0,010485$ & 0,007046 & 14 & \\
\hline & Rep 4 & $-0,013524$ & $-0,015760$ & 0,005918 & 14 & \\
\hline & Rep 5 & $-0,011275$ & $-0,012415$ & 0,005271 & 14 & \\
\hline \multirow{5}{*}{$\begin{array}{l}\text { I_prop } \\
\text { (PC.s) }\end{array}$} & Rep 1 & 0,017541 & 0,018405 & 0,006536 & 14 & \multirow{5}{*}{0,598} \\
\hline & Rep 2 & 0,016416 & 0,016995 & 0,007068 & 14 & \\
\hline & Rep 3 & 0,015895 & 0,017650 & 0,005635 & 14 & \\
\hline & $\operatorname{Rep} 4$ & 0,014706 & 0,014550 & 0,006144 & 14 & \\
\hline & Rep 5 & 0,015526 & 0,018025 & 0,005631 & 14 & \\
\hline \multirow{5}{*}{$\begin{array}{c}\times 1 \\
\text { (PC) }\end{array}$} & Rep 1 & $-0,004457$ & $-0,003967$ & 0,005841 & 14 & \multirow{5}{*}{0,205} \\
\hline & Rep 2 & $-0,005010$ & $-0,004651$ & 0,005326 & 14 & \\
\hline & Rep 3 & $-0,005634$ & $-0,005634$ & 0,005216 & 14 & \\
\hline & Rep 4 & $-0,002560$ & $-0,000532$ & 0,003841 & 14 & \\
\hline & Rep 5 & $-0,004142$ & $-0,000505$ & 0,008015 & 14 & \\
\hline \multirow{5}{*}{$\begin{array}{l}F \times 2 \\
(P C)\end{array}$} & Rep 1 & 0,090425 & 0,083022 & 0,025417 & 14 & \multirow{5}{*}{0,774} \\
\hline & Rep 2 & 0,083408 & 0,088017 & 0,023463 & 14 & \\
\hline & Rep 3 & 0,086543 & 0,086397 & 0,024787 & 14 & \\
\hline & Rep 4 & 0,086501 & 0,075866 & 0,030248 & 14 & \\
\hline & Rep 5 & 0,080710 & 0,086899 & 0,032276 & 14 & \\
\hline \multirow{5}{*}{$\begin{array}{l}\text { Fx 3 } \\
\text { (PC) }\end{array}$} & Rep 1 & 0,062169 & 0,057565 & 0,020028 & 14 & \multirow{5}{*}{0,628} \\
\hline & Rep 2 & 0,057179 & 0,056846 & 0,023847 & 14 & \\
\hline & Rep 3 & 0,061617 & 0,058250 & 0,020898 & 14 & \\
\hline & Rep 4 & 0,055954 & 0,054941 & 0,019930 & 14 & \\
\hline & Rep 5 & 0,054943 & 0,063669 & 0,024978 & 14 & \\
\hline \multirow{5}{*}{$\begin{array}{l}\text { Fx } 4 \\
\text { (PC) }\end{array}$} & Rep 1 & $-0,009504$ & $-0,007733$ & 0,009139 & 14 & \multirow{5}{*}{0,498} \\
\hline & $\operatorname{Rep} 2$ & $-0,010843$ & $-0,008860$ & 0,009970 & 14 & \\
\hline & Rep 3 & $-0,008041$ & $-0,009259$ & 0,009352 & 14 & \\
\hline & Rep 4 & $-0,008956$ & $-0,009988$ & 0,009695 & 14 & \\
\hline & Rep 5 & $-0,005637$ & $-0,004914$ & 0,007946 & 14 & \\
\hline
\end{tabular}




\section{ANEXO IV - Resultados dos experimentos (cont.)}

TABELA 39 - Dados gerais relacionados com os parâmetros avaliados no experimento 1 do grupo de crianças com PTC bilateral (cont.).

\begin{tabular}{|c|c|c|c|c|c|c|}
\hline Variáveis & & Média & Mediana & $\begin{array}{l}\text { Desvio } \\
\text { Padrão }\end{array}$ & Tamanho & $p$-valor \\
\hline \multirow{5}{*}{$\begin{array}{l}\text { cine_joelho1 } \\
\text { (Graus) }\end{array}$} & Rep 1 & 7,338522 & 3,142152 & 7,478697 & 14 & \multirow{5}{*}{0,846} \\
\hline & Rep 2 & 7,784169 & 6,124161 & 5,519635 & 14 & \\
\hline & Rep 3 & 6,567061 & 5,956000 & 4,747142 & 14 & \\
\hline & Rep 4 & 7,603322 & 7,090000 & 5,964763 & 14 & \\
\hline & Rep 5 & 8,088345 & 6,222736 & 7,651545 & 14 & \\
\hline \multirow{5}{*}{$\begin{array}{c}\text { cine_joelho2 } \\
\text { (Graus) }\end{array}$} & Rep 1 & 16,240010 & 14,790498 & 8,478481 & 14 & \multirow{5}{*}{0,320} \\
\hline & Rep 2 & 15,759914 & 15,916498 & 8,533659 & 14 & \\
\hline & Rep 3 & 12,876023 & 12,060934 & 5,529576 & 14 & \\
\hline & Rep 4 & 13,619264 & 14,498728 & 9,971573 & 14 & \\
\hline & Rep 5 & 14,183666 & 12,221640 & 8,308496 & 14 & \\
\hline \multirow{5}{*}{$\begin{array}{c}\text { cine_joelho3 } \\
\text { (Graus) }\end{array}$} & Rep 1 & 10,426382 & 11,056933 & 5,961414 & 14 & \multirow{5}{*}{0,646} \\
\hline & Rep 2 & 10,665206 & 10,253043 & 7,962226 & 14 & \\
\hline & Rep 3 & 8,071559 & 7,698258 & 5,078658 & 14 & \\
\hline & Rep 4 & 8,466061 & 8,912366 & 5,678968 & 14 & \\
\hline & Rep 5 & 8,055139 & 7,095807 & 5,144484 & 14 & \\
\hline \multirow{5}{*}{$\begin{array}{c}\text { cine_joelho4 } \\
\text { (Graus) }\end{array}$} & Rep 1 & 10,490769 & 11,238245 & 5,786729 & 14 & \multirow{5}{*}{0,064} \\
\hline & Rep 2 & 9,933814 & 10,679635 & 8,793686 & 14 & \\
\hline & Rep 3 & 7,666682 & 6,654160 & 6,499325 & 14 & \\
\hline & Rep 4 & 7,343845 & 5,647989 & 7,348926 & 14 & \\
\hline & Rep 5 & 6,539501 & 5,416329 & 6,865758 & 14 & \\
\hline \multirow{5}{*}{$\begin{array}{l}\text { cine_joelho5 } \\
\text { (Graus) }\end{array}$} & Rep 1 & 37,798140 & 38,336232 & 12,910890 & 14 & \multirow{5}{*}{0,565} \\
\hline & Rep 2 & 39,152454 & 42,094839 & 10,276513 & 14 & \\
\hline & Rep 3 & 35,843233 & 35,827890 & 8,217832 & 14 & \\
\hline & Rep 4 & 38,479594 & 38,371827 & 8,992398 & 14 & \\
\hline & Rep 5 & 32,362384 & 34,751197 & 15,067006 & 14 & \\
\hline \multirow{5}{*}{$\begin{array}{c}\text { cine_tornozelo1 } \\
\text { (Graus) }\end{array}$} & Rep 1 & 89,390320 & 88,842500 & 4,683953 & 14 & \multirow{5}{*}{0,994} \\
\hline & Rep 2 & 91,115026 & 91,139000 & 7,139884 & 14 & \\
\hline & Rep 3 & 91,677746 & 90,034500 & 7,903408 & 14 & \\
\hline & Rep 4 & 90,398087 & 88,822000 & 6,076836 & 14 & \\
\hline & Rep 5 & 91,055850 & 90,040500 & 6,915107 & 14 & \\
\hline \multirow{5}{*}{$\begin{array}{c}\text { cine_tornozelo2 } \\
\text { (Graus) }\end{array}$} & Rep 1 & 90,975281 & 90,958186 & 2,860323 & 14 & \multirow{5}{*}{0,422} \\
\hline & Rep 2 & 89,308052 & 89,531733 & 3,576712 & 14 & \\
\hline & Rep 3 & 89,615353 & 88,246684 & 4,195728 & 14 & \\
\hline & Rep 4 & 88,797134 & 87,713061 & 4,338274 & 14 & \\
\hline & Rep 5 & 89,184971 & 88,256470 & 5,377128 & 14 & \\
\hline \multirow{5}{*}{$\begin{array}{c}\text { cine_tornozelo3 } \\
\text { (Graus) }\end{array}$} & Rep 1 & 93,280204 & 93,173366 & 4,938872 & 14 & \multirow{5}{*}{0,283} \\
\hline & Rep 2 & 93,521385 & 92,273626 & 6,127978 & 14 & \\
\hline & Rep 3 & 92,011192 & 90,491694 & 5,254392 & 14 & \\
\hline & Rep 4 & 90,936530 & 90,805384 & 3,893780 & 14 & \\
\hline & Rep 5 & 90,781371 & 90,300596 & 5,042332 & 14 & \\
\hline
\end{tabular}




\section{ANEXO IV - Resultados dos experimentos (cont.)}

TABELA 39 - Dados gerais relacionados com os parâmetros avaliados no experimento 1 do grupo de criancas com PTC bilateral (cont.).

\begin{tabular}{|c|c|c|c|c|c|c|}
\hline Variáveis & & Média & Mediana & $\begin{array}{l}\text { Desvio } \\
\text { Padrão }\end{array}$ & Tamanho & $p$-valor \\
\hline \multirow{5}{*}{$\begin{array}{c}\text { cine_tornozelo4 } \\
\text { (Graus) }\end{array}$} & Rep 1 & 95,359221 & 93,913450 & 5,059958 & 14 & \multirow{5}{*}{0,333} \\
\hline & Rep 2 & 97,122783 & 94,915919 & 6,997611 & 14 & \\
\hline & Rep 3 & 96,517090 & 96,049040 & 4,834028 & 14 & \\
\hline & Rep 4 & 94,449608 & 94,942081 & 4,516439 & 14 & \\
\hline & Rep 5 & 93,869323 & 94,725218 & 6,047369 & 14 & \\
\hline \multirow{5}{*}{$\begin{array}{c}\text { cine_tornozelo5 } \\
\text { (Graus) }\end{array}$} & Rep 1 & 61,987007 & 60,964274 & 22,298177 & 14 & \multirow{5}{*}{0,912} \\
\hline & Rep 2 & 64,798306 & 65,768841 & 17,706200 & 14 & \\
\hline & Rep 3 & 60,768369 & 64,591119 & 15,826190 & 14 & \\
\hline & Rep 4 & 66,486181 & 65,914516 & 10,371514 & 14 & \\
\hline & Rep 5 & 62,874893 & 67,629081 & 20,491639 & 14 & \\
\hline
\end{tabular}




\section{ANEXO IV - Resultados dos experimentos (cont.)}

TABELA 40 - Dados gerais relacionados com os parâmetros avaliados no experimento 1 do grupo de crianças com PTC unilateral.

\begin{tabular}{|c|c|c|c|c|c|c|}
\hline Variáveis & & Média & Mediana & $\begin{array}{l}\text { Desvio } \\
\text { Padrão }\end{array}$ & Tamanho & p-valor \\
\hline \multirow{5}{*}{$\begin{array}{l}\text { Fz } 1 \\
(P C)\end{array}$} & Rep 1 & 1,042883 & 1,011224 & 0,126630 & 14 & \multirow{5}{*}{0,915} \\
\hline & Rep 2 & 1,037042 & 1,035313 & 0,075834 & 14 & \\
\hline & Rep 3 & 1,024280 & 1,035310 & 0,065545 & 14 & \\
\hline & Rep 4 & 1,027398 & 1,030233 & 0,077025 & 14 & \\
\hline & Rep 5 & 1,023334 & 1,020473 & 0,072930 & 14 & \\
\hline \multirow{5}{*}{$\begin{array}{l}F z 2 \\
(P C)\end{array}$} & Rep 1 & 0,961539 & 0,945774 & 0,058602 & 14 & \multirow{5}{*}{0,830} \\
\hline & $\operatorname{Rep} 2$ & 0,968202 & 0,972846 & 0,064681 & 14 & \\
\hline & Rep 3 & 0,972488 & 0,976546 & 0,065503 & 14 & \\
\hline & Rep 4 & 0,969757 & 0,975571 & 0,060390 & 14 & \\
\hline & Rep 5 & 0,978730 & 0,986370 & 0,065780 & 14 & \\
\hline \multirow{5}{*}{$\begin{array}{l}\text { Fz min } \\
(P C)\end{array}$} & Rep 1 & 0,825724 & 0,849364 & 0,062698 & 14 & \multirow{5}{*}{0,746} \\
\hline & Rep 2 & 0,835341 & 0,830958 & 0,044514 & 14 & \\
\hline & Rep 3 & 0,833757 & 0,842227 & 0,052383 & 14 & \\
\hline & Rep 4 & 0,834718 & 0,848272 & 0,057479 & 14 & \\
\hline & Rep 5 & 0,845468 & 0,847219 & 0,041336 & 14 & \\
\hline \multirow{5}{*}{$\begin{array}{l}\text { TC } 1 \\
\text { (PC/s) }\end{array}$} & Rep 1 & 0,498288 & 0,497700 & 0,003195 & 14 & \multirow{5}{*}{0,236} \\
\hline & Rep 2 & 0,497103 & 0,496310 & 0,004046 & 14 & \\
\hline & Rep 3 & 0,496808 & 0,497005 & 0,001592 & 14 & \\
\hline & Rep 4 & 0,497993 & 0,498390 & 0,002721 & 14 & \\
\hline & Rep 5 & 0,497302 & 0,497700 & 0,002839 & 14 & \\
\hline \multirow{5}{*}{$\begin{array}{c}\text { T_apoio } \\
\text { (s) }\end{array}$} & Rep 1 & 9,232760 & 8,872226 & 2,563474 & 14 & \multirow{5}{*}{0,611} \\
\hline & Rep 2 & 8,716242 & 8,561665 & 2,613265 & 14 & \\
\hline & Rep 3 & 9,523511 & 9,337878 & 2,393280 & 14 & \\
\hline & Rep 4 & 9,592155 & 8,907952 & 1,845809 & 14 & \\
\hline & Rep 5 & 9,310451 & 8,766972 & 1,978526 & 14 & \\
\hline \multirow{5}{*}{$\begin{array}{l}\text { TC } 2 \\
\text { (PC/s) }\end{array}$} & Rep 1 & 1,238133 & 1,389323 & 0,572506 & 14 & \multirow{5}{*}{0,915} \\
\hline & Rep 2 & 1,084833 & 1,023407 & 0,521526 & 14 & \\
\hline & Rep 3 & 1,203433 & 1,038827 & 0,723189 & 14 & \\
\hline & Rep 4 & 1,138412 & 1,030684 & 0,722981 & 14 & \\
\hline & Rep 5 & 1,081141 & 1,110372 & 0,396636 & 14 & \\
\hline \multirow{5}{*}{$\begin{array}{l}\text { Fy min } \\
\text { (PC) }\end{array}$} & Rep 1 & $-0,119823$ & $-0,097664$ & 0,057681 & 14 & \multirow{5}{*}{0,285} \\
\hline & Rep 2 & $-0,115049$ & $-0,111439$ & 0,040487 & 14 & \\
\hline & Rep 3 & $-0,122936$ & $-0,119371$ & 0,037250 & 14 & \\
\hline & Rep 4 & $-0,120662$ & $-0,118249$ & 0,034542 & 14 & \\
\hline & Rep 5 & $-0,133989$ & $-0,130179$ & 0,037840 & 14 & \\
\hline
\end{tabular}




\section{ANEXO IV - Resultados dos experimentos (cont.)}

TABELA 40- Dados gerais relacionados com os parâmetros avaliados no experimento 1 do grupo de crianças com PTC unilateral (cont.).

\begin{tabular}{|c|c|c|c|c|c|c|}
\hline Variáveis & & Média & Mediana & $\begin{array}{l}\text { Desvio } \\
\text { Padrão }\end{array}$ & Tamanho & $p$-valor \\
\hline \multirow{5}{*}{$\begin{array}{l}\text { Fy max } \\
\text { (PC) }\end{array}$} & Rep 1 & 0,109265 & 0,113192 & 0,033003 & 14 & \multirow{5}{*}{0,066} \\
\hline & Rep 2 & 0,102446 & 0,105016 & 0,024045 & 14 & \\
\hline & Rep 3 & 0,118282 & 0,116018 & 0,031008 & 14 & \\
\hline & $\operatorname{Rep} 4$ & 0,123574 & 0,126119 & 0,028095 & 14 & \\
\hline & $\operatorname{Rep} 5$ & 0,115365 & 0,106138 & 0,029966 & 14 & \\
\hline \multirow{5}{*}{$\begin{array}{l}\text { Iffren } \\
\text { (PC.s) }\end{array}$} & $\operatorname{Rep} 1$ & $-0,012683$ & $-0,010960$ & 0,006291 & 14 & \multirow{5}{*}{0,076} \\
\hline & Rep 2 & $-0,011837$ & $-0,011315$ & 0,004218 & 14 & \\
\hline & Rep 3 & $-0,013416$ & $-0,014420$ & 0,004067 & 14 & \\
\hline & Rep 4 & $-0,013017$ & $-0,012710$ & 0,003726 & 14 & \\
\hline & $\operatorname{Rep} 5$ & $-0,014930$ & $-0,014350$ & 0,004003 & 14 & \\
\hline \multirow{5}{*}{$\begin{array}{l}\text { I_prop } \\
\text { (PC.s) }\end{array}$} & Rep 1 & 0,014422 & 0,014895 & 0,004935 & 14 & \multirow{5}{*}{0,065} \\
\hline & Rep 2 & 0,013771 & 0,013120 & 0,004140 & 14 & \\
\hline & Rep 3 & 0,015221 & 0,016550 & 0,003733 & 14 & \\
\hline & Rep 4 & 0,017804 & 0,017930 & 0,004895 & 14 & \\
\hline & $\operatorname{Rep} 5$ & 0,014669 & 0,014215 & 0,003288 & 14 & \\
\hline \multirow{5}{*}{$\begin{array}{l}\text { Fx } 1 \\
\text { (PC) }\end{array}$} & Rep 1 & $-0,005395$ & $-0,000186$ & 0,011201 & 14 & \multirow{5}{*}{0,538} \\
\hline & Rep 2 & $-0,004669$ & $-0,000371$ & 0,010030 & 14 & \\
\hline & Rep 3 & $-0,004698$ & 0,000216 & 0,010420 & 14 & \\
\hline & $\operatorname{Rep} 4$ & $-0,004645$ & 0,000006 & 0,009715 & 14 & \\
\hline & Rep 5 & $-0,006458$ & $-0,000712$ & 0,014254 & 14 & \\
\hline \multirow{5}{*}{$\begin{array}{l}F \times 2 \\
\text { (PC) }\end{array}$} & $\operatorname{Rep} 1$ & 0,087063 & 0,086529 & 0,031884 & 14 & \multirow{5}{*}{0,378} \\
\hline & $\operatorname{Rep} 2$ & 0,093239 & 0,090088 & 0,022904 & 14 & \\
\hline & Rep 3 & 0,091978 & 0,089237 & 0,021528 & 14 & \\
\hline & Rep 4 & 0,096054 & 0,098238 & 0,026640 & 14 & \\
\hline & $\operatorname{Rep} 5$ & 0,096492 & 0,095594 & 0,020854 & 14 & \\
\hline \multirow{5}{*}{$\begin{array}{l}\text { Fx } 3 \\
\text { (PC) }\end{array}$} & Rep 1 & 0,059902 & 0,060184 & 0,024489 & 14 & \multirow{5}{*}{0,210} \\
\hline & Rep 2 & 0,065560 & 0,068075 & 0,022198 & 14 & \\
\hline & Rep 3 & 0,058019 & 0,053218 & 0,014743 & 14 & \\
\hline & $\operatorname{Rep} 4$ & 0,063745 & 0,067532 & 0,020249 & 14 & \\
\hline & Rep 5 & 0,064049 & 0,065120 & 0,022100 & 14 & \\
\hline \multirow{5}{*}{$\begin{array}{l}\text { Fx } 4 \\
\text { (PC) }\end{array}$} & $\operatorname{Rep} 1$ & $-0,003288$ & $-0,003513$ & 0,007459 & 14 & \multirow{5}{*}{0,127} \\
\hline & Rep 2 & $-0,000928$ & 0,000566 & 0,006019 & 14 & \\
\hline & Rep 3 & $-0,004721$ & $-0,003217$ & 0,008694 & 14 & \\
\hline & Rep 4 & $-0,007159$ & $-0,001438$ & 0,012646 & 14 & \\
\hline & Rep 5 & $-0,002941$ & $-0,000355$ & 0,008162 & 14 & \\
\hline
\end{tabular}




\section{ANEXO IV - Resultados dos experimentos (cont.)}

TABELA 40 - Dados gerais relacionados com os parâmetros avaliados no experimento 1 do grupo de criancas com PTC unilateral (cont.).

\begin{tabular}{|c|c|c|c|c|c|c|}
\hline Variáveis & & Média & Mediana & $\begin{array}{l}\text { Desvio } \\
\text { Padrão }\end{array}$ & Tamanho & $p$-valor \\
\hline \multirow{5}{*}{$\begin{array}{c}\text { cine_joelho1 } \\
\text { (Graus) }\end{array}$} & Rep 1 & 9,710327 & 9,080500 & 5,440848 & 14 & \multirow{5}{*}{0,723} \\
\hline & Rep 2 & 10,740331 & 10,668000 & 4,671889 & 14 & \\
\hline & Rep 3 & 8,950863 & 10,073000 & 4,948596 & 14 & \\
\hline & Rep 4 & 9,579278 & 10,424000 & 5,161872 & 14 & \\
\hline & Rep 5 & 11,223357 & 10,550000 & 5,725754 & 14 & \\
\hline \multirow{5}{*}{$\begin{array}{c}\text { cine joelho2 } \\
\text { (Graus) }\end{array}$} & Rep 1 & 24,196211 & 24,606463 & 8,145567 & 14 & \multirow{5}{*}{0,372} \\
\hline & Rep 2 & 23,467866 & 23,175124 & 8,085443 & 14 & \\
\hline & Rep 3 & 22,670940 & 20,606892 & 10,196997 & 14 & \\
\hline & Rep 4 & 21,865200 & 21,396000 & 8,617563 & 14 & \\
\hline & Rep 5 & 23,978183 & 22,696970 & 7,793510 & 14 & \\
\hline \multirow{5}{*}{$\begin{array}{c}\text { cine_joelho3 } \\
\text { (Graus) }\end{array}$} & Rep 1 & 15,669425 & 15,519546 & 6,353985 & 14 & \multirow{5}{*}{0,559} \\
\hline & Rep 2 & 15,044057 & 14,955578 & 5,744727 & 14 & \\
\hline & Rep 3 & 13,220147 & 11,941276 & 8,100431 & 14 & \\
\hline & Rep 4 & 15,142177 & 15,114622 & 7,490663 & 14 & \\
\hline & Rep 5 & 17,215278 & 14,048481 & 7,866352 & 14 & \\
\hline \multirow{5}{*}{$\begin{array}{c}\text { cine_joelho4 } \\
\text { (Graus) }\end{array}$} & Rep 1 & 13,233511 & 15,041308 & 6,658609 & 14 & \multirow{5}{*}{0,598} \\
\hline & Rep 2 & 11,644098 & 9,938840 & 5,481400 & 14 & \\
\hline & Rep 3 & 10,660112 & 10,300368 & 7,448933 & 14 & \\
\hline & Rep 4 & 12,653488 & 11,391652 & 7,590093 & 14 & \\
\hline & Rep 5 & 13,438172 & 13,929743 & 8,377530 & 14 & \\
\hline \multirow{5}{*}{$\begin{array}{l}\text { cine_joelho5 } \\
\text { (Graus) }\end{array}$} & Rep 1 & 34,296856 & 35,214312 & 12,476996 & 14 & \multirow{5}{*}{0,670} \\
\hline & Rep 2 & 34,203090 & 35,948336 & 11,817857 & 14 & \\
\hline & Rep 3 & 34,802770 & 36,699990 & 11,363704 & 14 & \\
\hline & Rep 4 & 37,416809 & 36,332655 & 17,038009 & 14 & \\
\hline & Rep 5 & 34,560853 & 33,784814 & 14,512567 & 14 & \\
\hline \multirow{5}{*}{$\begin{array}{c}\text { cine_tornozelo1 } \\
\text { (Graus) }\end{array}$} & Rep 1 & 87,238573 & 83,385500 & 9,360584 & 14 & \multirow{5}{*}{0,945} \\
\hline & Rep 2 & 86,411637 & 85,607500 & 9,033485 & 14 & \\
\hline & Rep 3 & 85,831694 & 83,681000 & 10,308629 & 14 & \\
\hline & Rep 4 & 87,044032 & 88,776667 & 6,638672 & 14 & \\
\hline & Rep 5 & 85,928357 & 86,917000 & 7,084509 & 14 & \\
\hline \multirow{5}{*}{$\begin{array}{c}\text { cine_tornozelo2 } \\
\text { (Graus) }\end{array}$} & Rep 1 & 90,792816 & 90,112198 & 4,571533 & 14 & \multirow{5}{*}{0,209} \\
\hline & Rep 2 & 91,013648 & 89,835383 & 4,375573 & 14 & \\
\hline & Rep 3 & 90,646528 & 90,847349 & 4,453221 & 14 & \\
\hline & Rep 4 & 91,382969 & 89,894500 & 5,133453 & 14 & \\
\hline & Rep 5 & 92,051237 & 91,244577 & 3,474770 & 14 & \\
\hline
\end{tabular}




\section{ANEXO IV - Resultados dos experimentos (cont.)}

TABELA 40 - Dados gerais relacionados com os parâmetros avaliados no experimento 1 do grupo de criancas com PTC unilateral (cont.).

\begin{tabular}{|c|c|c|c|c|c|c|}
\hline Variáveis & & Média & Mediana & $\begin{array}{l}\text { Desvio } \\
\text { Padrão }\end{array}$ & Tamanho & $\mathrm{p}$-valor \\
\hline \multirow{5}{*}{$\begin{array}{c}\text { cine_tornozelo3 } \\
\text { (Graus) }\end{array}$} & Rep 1 & 96,134032 & 95,981536 & 5,114153 & 14 & \multirow{5}{*}{0,701} \\
\hline & Rep 2 & 94,957671 & 94,569326 & 4,531010 & 14 & \\
\hline & Rep 3 & 94,522712 & 94,210381 & 5,444041 & 14 & \\
\hline & Rep 4 & 94,684598 & 93,447560 & 5,218989 & 14 & \\
\hline & Rep 5 & 96,042994 & 95,470429 & 5,601295 & 14 & \\
\hline \multirow{5}{*}{$\begin{array}{c}\text { cine_tornozelo4 } \\
\text { (Graus) }\end{array}$} & Rep 1 & 99,192092 & 100,715295 & 7,222098 & 14 & \multirow{5}{*}{0,512} \\
\hline & Rep 2 & 99,310915 & 98,702552 & 7,652136 & 14 & \\
\hline & Rep 3 & 97,254601 & 96,395976 & 7,862458 & 14 & \\
\hline & Rep 4 & 98,944195 & 98,345154 & 6,908509 & 14 & \\
\hline & Rep 5 & 98,785492 & 98,660887 & 7,725977 & 14 & \\
\hline \multirow{5}{*}{$\begin{array}{c}\text { cine_tornozelo5 } \\
\text { (Graus) }\end{array}$} & Rep 1 & 60,367400 & 58,345877 & 25,802242 & 14 & \multirow{5}{*}{0,857} \\
\hline & Rep 2 & 58,188990 & 59,301725 & 15,957752 & 14 & \\
\hline & Rep 3 & 63,394102 & 56,594551 & 24,800858 & 14 & \\
\hline & Rep 4 & 63,641036 & 59,826110 & 24,084277 & 14 & \\
\hline & Rep 5 & 60,849298 & 59,377970 & 21,507501 & 14 & \\
\hline
\end{tabular}




\section{ANEXO IV - Resultados dos experimentos (cont.)}

TABELA 41 - Dados referentes aos parâmetros da marcha, nas comparações entre os grupos: Controle (Cont.), PTC bilateral lado direito (Bil. D.), PTC bilateral lado esquerdo (Bil. E.), PTC unilateral lado acometido (Acom.) e PTC unilateral lado não acometido (Ñ Acom.). $\mathrm{p} \leq 0,05$.

\begin{tabular}{|c|c|c|c|c|c|}
\hline Variáveis & & Média & Desvio Padrão & Tamanho & p-valor \\
\hline \multirow{5}{*}{$\begin{array}{l}\text { Fz } 1 \\
\text { (PC) }\end{array}$} & Acom. & 1,02360 & 0,08254 & 35 & \multirow{5}{*}{$0,041^{*}$} \\
\hline & Bil. D. & 1,03249 & 0,08688 & 35 & \\
\hline & Bil. E. & 1,01711 & 0,09302 & 35 & \\
\hline & Cont. & 1,04463 & 0,06597 & 100 & \\
\hline & $\tilde{N}$ Acom. & 1,03837 & 0,08643 & 35 & \\
\hline \multirow{5}{*}{$\begin{array}{l}F z 2 \\
(P C)\end{array}$} & Acom. & 0,96053 & 0,05568 & 35 & \multirow{5}{*}{$<0,001^{*}$} \\
\hline & Bil. D. & 1,00826 & 0,07705 & 35 & \\
\hline & Bil. E. & 0,99610 & 0,04558 & 35 & \\
\hline & Cont. & 1,06323 & 0,06400 & 100 & \\
\hline & $\tilde{\mathrm{N}}$ Acom. & 0,97976 & 0,06615 & 35 & \\
\hline \multirow{5}{*}{$\begin{array}{l}\text { Fz min } \\
(P C)\end{array}$} & Acom. & 0,84742 & 0,04434 & 35 & \multirow{5}{*}{$<0,001^{*}$} \\
\hline & Bil. D. & 0,88545 & 0,06459 & 35 & \\
\hline & Bil. E. & 0,88196 & 0,04903 & 35 & \\
\hline & Cont. & 0,84917 & 0,05560 & 100 & \\
\hline & $\tilde{N}$ Acom. & 0,82258 & 0,05499 & 35 & \\
\hline \multirow{5}{*}{$\begin{array}{c}\text { T_apoio } \\
\text { (s) }\end{array}$} & Acom. & 0,49817 & 0,00284 & 35 & \multirow{5}{*}{$<0,001^{*}$} \\
\hline & Bil. D. & 0,50554 & 0,06043 & 35 & \\
\hline & Bil. E. & 0,49631 & 0,00405 & 35 & \\
\hline & Cont. & 0,73178 & 0,14290 & 100 & \\
\hline & $\hat{N}$ Acom. & 0,49683 & 0,00294 & 35 & \\
\hline \multirow{5}{*}{$\begin{array}{l}\mathrm{TC} 1 \\
(\mathrm{PC} / \mathrm{s})\end{array}$} & Acom. & 9,06322 & 2,39649 & 35 & \multirow{5}{*}{$<0,001^{*}$} \\
\hline & Bil. D. & 7,67652 & 2,44345 & 35 & \\
\hline & Bil. E. & 8,55411 & 2,18474 & 35 & \\
\hline & Cont. & 6,14735 & 3,42905 & 100 & \\
\hline & $\tilde{N}$ Acom. & 9,48683 & 2,11527 & 35 & \\
\hline \multirow{5}{*}{$\begin{array}{l}\text { TC } 2 \\
(\mathrm{PC} / \mathrm{s})\end{array}$} & Acom. & 0,96645 & 0,46345 & 35 & \multirow{5}{*}{0,144} \\
\hline & Bil. D. & 1,31316 & 0,81808 & 35 & \\
\hline & Bil. E. & 1,02198 & 0,55556 & 35 & \\
\hline & Cont. & 1,22262 & 0,83980 & 100 & \\
\hline & $\tilde{\mathrm{N}}$ Acom. & 1,33193 & 0,64334 & 35 & \\
\hline
\end{tabular}

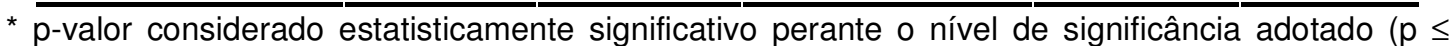
$0,05)$; \# p-valor que por estar próximo do limite de aceitação é considerado que tenda a ser significativo. 


\section{ANEXO IV - Resultados dos experimentos (cont.)}

TABELA 41 - Dados referentes aos parâmetros da marcha, nas comparacões entre os grupos: Controle (Cont.), PTC bilateral lado direito (Bil. D.), PTC bilateral lado esquerdo (Bil. E.), PTC unilateral lado acometido (Acom.) e PTC unilateral lado não acometido (Ñ Acom.). $\mathrm{p} \leq 0,05$ (cont.).

\begin{tabular}{|c|c|c|c|c|c|}
\hline Variáveis & & Média & Desvio Padrão & Tamanho & p-valor \\
\hline \multirow{5}{*}{$\begin{array}{l}\text { Fy_min } \\
\text { (PC) }\end{array}$} & Acom. & $-0,11170$ & 0,04483 & 35 & \multirow{5}{*}{$0,001^{*}$} \\
\hline & Bil. D. & $-0,09597$ & 0,03977 & 35 & \\
\hline & Bil. E. & $-0,12462$ & 0,04695 & 35 & \\
\hline & Cont. & $-0,11145$ & 0,04986 & 100 & \\
\hline & $\tilde{N}$ Acom. & $-0,13328$ & 0,03557 & 35 & \\
\hline \multirow{5}{*}{$\begin{array}{c}\text { Fy_max } \\
\text { (PC) }\end{array}$} & Acom. & 0,11719 & 0,02957 & 35 & \multirow{5}{*}{$<0,001^{*}$} \\
\hline & Bil. D. & 0,12357 & 0,02994 & 35 & \\
\hline & Bil. E. & 0,12066 & 0,04014 & 35 & \\
\hline & Cont. & 0,14080 & 0,03415 & 100 & \\
\hline & $\tilde{N}$ Acom. & 0,11038 & 0,02937 & 35 & \\
\hline \multirow{5}{*}{$\begin{array}{l}\text { Iffren } \\
\text { (PC.s) }\end{array}$} & Acom. & $-0,01157$ & 0,00439 & 35 & \multirow{5}{*}{$<0,001^{*}$} \\
\hline & Bil. D. & $-0,00983$ & 0,00576 & 35 & \\
\hline & Bil. E. & $-0,01385$ & 0,00478 & 35 & \\
\hline & Cont. & $-0,01872$ & 0,00684 & 100 & \\
\hline & $\tilde{N}$ Acom. & $-0,01478$ & 0,00416 & 35 & \\
\hline \multirow{5}{*}{$\begin{array}{l}\text { I_prop } \\
\text { (PC.s) }\end{array}$} & Acom. & 0,01634 & 0,00378 & 35 & \multirow{5}{*}{$<0,001^{*}$} \\
\hline & Bil. D. & 0,01625 & 0,00682 & 35 & \\
\hline & Bil. E. & 0,01578 & 0,00542 & 35 & \\
\hline & Cont. & 0,02297 & 0,00617 & 100 & \\
\hline & $\tilde{\mathrm{N}}$ Acom. & 0,01401 & 0,00462 & 35 & \\
\hline \multirow{5}{*}{$\begin{array}{l}\text { Fx } 1 \\
\text { (PC) }\end{array}$} & Acom. & $-0,00586$ & 0,01195 & 35 & \multirow{5}{*}{$0,002^{*}$} \\
\hline & Bil. D. & $-0,00532$ & 0,00676 & 35 & \\
\hline & Bil. E. & $-0,00340$ & 0,00437 & 35 & \\
\hline & Cont. & $-0,00852$ & 0,01070 & 100 & \\
\hline & $\tilde{N}$ Acom. & $-0,00449$ & 0,00995 & 35 & \\
\hline \multirow{5}{*}{$\begin{array}{l}F \times 2 \\
(P C)\end{array}$} & Acom. & 0,09900 & 0,02119 & 35 & \multirow{5}{*}{$0,003^{*}$} \\
\hline & Bil. D. & 0,08363 & 0,02958 & 35 & \\
\hline & Bil. E. & 0,08741 & 0,02410 & 35 & \\
\hline & Cont. & 0,08135 & 0,02137 & 100 & \\
\hline & $\tilde{N}$ Acom. & 0,08693 & 0,02653 & 35 & \\
\hline \multirow{5}{*}{$\begin{array}{l}F \times 3 \\
(P C)\end{array}$} & Acom. & 0,06587 & 0,01864 & 35 & \multirow{5}{*}{$0,003^{*}$} \\
\hline & Bil. D. & 0,05659 & 0,02328 & 35 & \\
\hline & Bil. E. & 0,06015 & 0,01994 & 35 & \\
\hline & Cont. & 0,05125 & 0,02060 & 100 & \\
\hline & $\tilde{\mathrm{N}}$ Acom. & 0,05864 & 0,02206 & 35 & \\
\hline
\end{tabular}

* $p$-valor considerado estatisticamente significativo perante o nível de significância adotado ( $p \leq$ $0,05)$; \# p-valor que por estar próximo do limite de aceitação é considerado que tenda a ser significativo. 


\section{ANEXO IV - Resultados dos experimentos (cont.)}

TABELA 41 - Dados referentes aos parâmetros da marcha, nas comparacões entre os grupos: Controle (Cont.), PTC bilateral lado direito (Bil. D.), PTC bilateral lado esquerdo (Bil. E.), PTC unilateral lado acometido (Acom.) e PTC unilateral lado não acometido (Ñ Acom.). $\mathrm{p} \leq 0,05$ (cont.).

\begin{tabular}{|c|c|c|c|c|c|}
\hline Variáveis & & Média & Desvio Padrão & Tamanho & $p$-valor \\
\hline \multirow{5}{*}{$\begin{array}{l}\text { Fx } 4 \\
(P C)\end{array}$} & Acom. & $-0,00570$ & 0,00863 & 35 & \multirow{5}{*}{$<0,001^{*}$} \\
\hline & Bil. D. & $-0,00749$ & 0,00957 & 35 & \\
\hline & Bil. E. & $-0,00970$ & 0,00869 & 35 & \\
\hline & Cont. & $-0,00541$ & 0,00772 & 100 & \\
\hline & $\tilde{N}$ Acom. & $-0,00192$ & 0,00881 & 35 & \\
\hline \multirow{5}{*}{$\begin{array}{l}\text { cine_joelho1 } \\
\text { (Graus) }\end{array}$} & Acom. & 10,41954 & 5,85501 & 35 & \multirow{5}{*}{$0,001^{*}$} \\
\hline & Bil. D. & 8,99632 & 6,12150 & 35 & \\
\hline & Bil. E. & 5,95625 & 5,99649 & 35 & \\
\hline & Cont. & 8,39635 & 6,05776 & 100 & \\
\hline & $\tilde{N}$ Acom. & 9,66212 & 4,30965 & 35 & \\
\hline \multirow{5}{*}{$\begin{array}{l}\text { cine_joelho2 } \\
\text { (Graus) }\end{array}$} & Acom. & 20,94117 & 6,78245 & 35 & \multirow{5}{*}{$<0,001^{*}$} \\
\hline & Bil. D. & 15,80201 & 8,94977 & 35 & \\
\hline & Bil. E. & 13,26954 & 7,16783 & 35 & \\
\hline & Cont. & 13,19911 & 5,97570 & 100 & \\
\hline & Ñ Acom. & 25,53019 & 9,29693 & 35 & \\
\hline \multirow{5}{*}{$\begin{array}{l}\text { cine_joelho3 } \\
\text { (Graus) }\end{array}$} & Acom. & 12,93527 & 5,02260 & 35 & \multirow{5}{*}{$<0,001^{*}$} \\
\hline & Bil. D. & 9,42527 & 5,53449 & 35 & \\
\hline & Bil. E. & 8,84847 & 6,48997 & 35 & \\
\hline & Cont. & 9,72440 & 4,58140 & 100 & \\
\hline & $\tilde{\mathrm{N}}$ Acom. & 17,58117 & 8,08103 & 35 & \\
\hline \multirow{5}{*}{$\begin{array}{l}\text { cine_joelho4 } \\
\text { (Graus) }\end{array}$} & Acom. & 10,39287 & 6,17007 & 35 & \multirow{5}{*}{$<0,001^{*}$} \\
\hline & Bil. D. & 9,20346 & 7,47456 & 35 & \\
\hline & Bil. E. & 7,58638 & 6,69735 & 35 & \\
\hline & Cont. & 8,71448 & 4,10612 & 100 & \\
\hline & $\tilde{N}$ Acom. & 14,25888 & 7,41499 & 35 & \\
\hline \multirow{5}{*}{$\begin{array}{l}\text { cine_joelho5 } \\
\text { (Graus) }\end{array}$} & Acom. & 33,27670 & 12,63957 & 35 & \multirow{5}{*}{$0,023^{*}$} \\
\hline & Bil. D. & 36,02267 & 10,68079 & 35 & \\
\hline & Bil. E. & 37,43165 & 12,03650 & 35 & \\
\hline & Cont. & 31,81094 & 11,20256 & 100 & \\
\hline & $\tilde{N}$ Acom. & 36,83545 & 13,80229 & 35 & \\
\hline \multirow{5}{*}{$\begin{array}{c}\text { cine_tornozelo1 } \\
\text { (Graus) }\end{array}$} & Acom. & 87,60360 & 8,59565 & 35 & \multirow{5}{*}{$0,019^{*}$} \\
\hline & Bil. D. & 91,58378 & 7,02831 & 35 & \\
\hline & Bil. E. & 89,87103 & 5,87524 & 35 & \\
\hline & Cont. & 86,27344 & 10,93872 & 100 & \\
\hline & $\tilde{\mathrm{N}}$ Acom. & 85,37812 & 8,10002 & 35 & \\
\hline
\end{tabular}

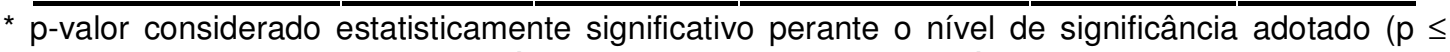
$0,05)$; \# p-valor que por estar próximo do limite de aceitação é considerado que tenda a ser significativo. 


\section{ANEXO IV - Resultados dos experimentos (cont.)}

TABELA 41- Dados referentes aos parâmetros da marcha, nas comparacões entre os grupos: Controle (Cont.), PTC bilateral lado direito (Bil. D.), PTC bilateral lado esquerdo (Bil. E.), PTC unilateral lado acometido (Acom.) e PTC unilateral lado não acometido (Ñ Acom.). $\mathrm{p} \leq 0,05$ (cont.).

\begin{tabular}{|c|c|c|c|c|c|}
\hline Variáveis & & Média & Desvio Padrão & Tamanho & p-valor \\
\hline \multirow{5}{*}{$\begin{array}{c}\text { cine_tornozelo2 } \\
\text { (Graus) }\end{array}$} & Acom. & 90,66420 & 3,58287 & 35 & \multirow{5}{*}{$<0,001^{*}$} \\
\hline & Bil. D. & 91,09890 & 4,22333 & 35 & \\
\hline & Bil. E. & 88,05342 & 3,39715 & 35 & \\
\hline & Cont. & 87,97014 & 3,94580 & 100 & \\
\hline & $\tilde{N}$ Acom. & 91,69068 & 4,97258 & 35 & \\
\hline \multirow{5}{*}{$\begin{array}{c}\text { cine_tornozelo3 } \\
\text { (Graus) }\end{array}$} & Acom. & 94,26365 & 4,03045 & 35 & \multirow{5}{*}{$<0,001^{*}$} \\
\hline & Bil. D. & 93,18497 & 5,44380 & 35 & \\
\hline & Bil. E. & 91,02730 & 4,51775 & 35 & \\
\hline & Cont. & 91,03128 & 4,18244 & 100 & \\
\hline & $\tilde{N}$ Acom. & 96,27315 & 5,85101 & 35 & \\
\hline \multirow{5}{*}{$\begin{array}{c}\text { cine_tornozelo4 } \\
\text { (Graus) }\end{array}$} & Acom. & 97,66624 & 7,47531 & 35 & \multirow{5}{*}{$<0,001^{*}$} \\
\hline & Bil. D. & 95,75224 & 5,91269 & 35 & \\
\hline & Bil. E. & 95,17497 & 5,21176 & 35 & \\
\hline & Cont. & 91,24671 & 5,95718 & 100 & \\
\hline & $\tilde{N}$ Acom. & 99,72868 & 7,07894 & 35 & \\
\hline \multirow{5}{*}{$\begin{array}{c}\text { cine_tornozelo5 } \\
\text { (Graus) }\end{array}$} & Acom. & 58,51028 & 22,24883 & 35 & \multirow{5}{*}{0,100} \\
\hline & Bil. D. & 59,63786 & 16,23825 & 35 & \\
\hline & Bil. E. & 67,12804 & 17,98294 & 35 & \\
\hline & Cont. & 56,80574 & 21,40274 & 100 & \\
\hline & $\tilde{\mathrm{N}}$ Acom. & 64,06605 & 21,98501 & 35 & \\
\hline
\end{tabular}

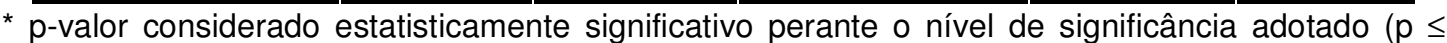
$0,05)$; \# p-valor que por estar próximo do limite de aceitação é considerado que tenda a ser significativo. 


\section{ANEXO IV - Resultados dos experimentos (cont.)}

TABELA 42 - Dados referentes aos parâmetros analisados da marcha auto-selecionada, nas comparações entre apoio esquerdo (Esq.) e direito (Dir.), para o grupo PTC bilateral.

\begin{tabular}{|c|c|c|c|c|c|}
\hline Variáveis & & Média & Desvio Padrão & Tamanho & p-valor \\
\hline \multirow{2}{*}{$\begin{array}{l}\text { Fz } 1 \\
(\mathrm{PC})\end{array}$} & Dir. & 1,03249 & 0,08688 & 35 & \multirow{2}{*}{0,145} \\
\hline & Esq. & 1,01711 & 0,09302 & 35 & \\
\hline \multirow{2}{*}{$\begin{array}{l}\text { Fz } 2 \\
\text { (PC) }\end{array}$} & Dir. & 1,00826 & 0,07705 & 35 & \multirow{2}{*}{0,342} \\
\hline & Esq. & 0,99610 & 0,04558 & 35 & \\
\hline \multirow{2}{*}{$\begin{array}{l}\text { Fz min } \\
(P C)\end{array}$} & Dir. & 0,88545 & 0,06459 & 35 & \multirow{2}{*}{0,896} \\
\hline & Esq. & 0,88196 & 0,04903 & 35 & \\
\hline \multirow{2}{*}{$\begin{array}{c}\text { T_apoio } \\
\text { (s) }\end{array}$} & Dir. & 0,50554 & 0,06043 & 35 & \multirow{2}{*}{0,530} \\
\hline & Esq. & 0,49631 & 0,00405 & 35 & \\
\hline \multirow{2}{*}{$\begin{array}{c}\text { TC 1 } \\
\text { (PC/s) }\end{array}$} & Dir. & 7,67652 & 2,44345 & 35 & \multirow{2}{*}{0,174} \\
\hline & Esq. & 8,55411 & 2,18474 & 35 & \\
\hline \multirow{2}{*}{$\begin{array}{l}\text { TC } 2 \\
(\mathrm{PC} / \mathrm{s})\end{array}$} & Dir. & 1,31316 & 0,81808 & 35 & \multirow{2}{*}{$0,064 \#$} \\
\hline & Esq. & 1,02198 & 0,55556 & 35 & \\
\hline \multirow{2}{*}{$\begin{array}{l}\text { Fy min } \\
\text { (PC) }\end{array}$} & Dir. & $-0,09597$ & 0,03977 & 35 & \multirow{2}{*}{$0,002^{*}$} \\
\hline & Esq. & $-0,12462$ & 0,04695 & 35 & \\
\hline \multirow{2}{*}{$\begin{array}{l}\text { Fy max } \\
\text { (PC) }\end{array}$} & Dir. & 0,12357 & 0,02994 & 35 & \multirow[b]{2}{*}{0,461} \\
\hline & Esq. & 0,12066 & 0,04014 & 35 & \\
\hline \multirow{2}{*}{$\begin{array}{l}\text { I fren } \\
\text { (PC.s) }\end{array}$} & Dir. & $-0,00983$ & 0,00576 & 35 & \multirow{2}{*}{$0,002^{*}$} \\
\hline & Esq. & $-0,01385$ & 0,00478 & 35 & \\
\hline \multirow{2}{*}{$\begin{array}{l}\text { I_prop } \\
\text { (PC.s) }\end{array}$} & Dir. & 0,01625 & 0,00682 & 35 & \multirow{2}{*}{ 0,052\# } \\
\hline & Esq. & 0,01578 & 0,00542 & 35 & \\
\hline \multirow{2}{*}{$\begin{array}{l}\text { Fx 1 } \\
\text { (PC) }\end{array}$} & Dir. & $-0,00532$ & 0,00676 & 35 & \multirow{2}{*}{0,310} \\
\hline & Esq. & $-0,00340$ & 0,00437 & 35 & \\
\hline \multirow{2}{*}{$\begin{array}{l}\text { Fx } 2 \\
(P C)\end{array}$} & Dir. & 0,08363 & 0,02958 & 35 & \multirow{2}{*}{0,523} \\
\hline & Esq. & 0,08741 & 0,02410 & 35 & \\
\hline \multirow{2}{*}{$\begin{array}{l}\text { Fx 3 } \\
\text { (PC) }\end{array}$} & Dir. & 0,05659 & 0,02328 & 35 & \multirow{2}{*}{0,413} \\
\hline & Esq. & 0,06015 & 0,01994 & 35 & \\
\hline \multirow{2}{*}{$\begin{array}{l}\text { Fx } 4 \\
(P C) \\
\end{array}$} & Dir. & $-0,00749$ & 0,00957 & 35 & \multirow{2}{*}{0,101} \\
\hline & Esq. & $-0,00970$ & 0,00869 & 35 & \\
\hline cine_joelho1 & Dir. & 8,99632 & 6,12150 & 35 & $0047^{*}$ \\
\hline (Graus) & Esq. & 5,95625 & 5,99649 & 35 & $0,04 /$ \\
\hline cine_joelho2 & Dir. & 15,80201 & 8,94977 & 35 & ○ $074 \#$ \\
\hline (Graus) & Esq. & 13,26954 & 7,16783 & 35 & $0,014 \pi$ \\
\hline cine joelho3 & Dir. & 9,42527 & 5,53449 & 35 & 0394 \\
\hline (Graus) & Esq. & 8,84847 & 6,48997 & 35 & 0,394 \\
\hline cine_joelho4 & Dir. & 9,20346 & 7,47456 & 35 & ○ $074 \#$ \\
\hline (Graus) & Esq. & 7,58638 & 6,69735 & 35 & $0,014+$ \\
\hline
\end{tabular}

* $p$-valor considerado estatisticamente significativo perante o nível de significância adotado $(p \leq$ $0,05)$; \# p-valor que por estar próximo do limite de aceitação é considerado que tenda a ser significativo 


\section{ANEXO IV - Resultados dos experimentos (cont.)}

TABELA 42 - Dados referentes aos parâmetros analisados da marcha auto-selecionada, nas comparações entre apoio esquerdo (Esq.) e direito (Dir.), para o grupo PTC bilateral (cont.).

\begin{tabular}{|c|c|c|c|c|c|}
\hline Variáveis & & Média & Desvio Padrão & Tamanho & p-valor \\
\hline \multirow{2}{*}{$\begin{array}{c}\text { cine_joelho5 } \\
\text { (Graus) }\end{array}$} & Dir. & 36,02267 & 10,68079 & 35 & \multirow{2}{*}{0,471} \\
\hline & Esq. & 37,43165 & 12,03650 & 35 & \\
\hline \multirow{2}{*}{$\begin{array}{c}\text { cine_tornozelo1 } \\
\text { (Graus) }\end{array}$} & Dir. & 91,58378 & 7,02831 & 35 & \multirow{2}{*}{0,351} \\
\hline & Esq. & 89,87103 & 5,87524 & 35 & \\
\hline \multirow{2}{*}{$\begin{array}{c}\text { cine_tornozelo2 } \\
\text { (Graus) }\end{array}$} & Dir. & 91,09890 & 4,22333 & 35 & \multirow{2}{*}{$0,007^{*}$} \\
\hline & Esq. & 88,05342 & 3,39715 & 35 & \\
\hline \multirow{2}{*}{$\begin{array}{c}\text { cine_tornozelo3 } \\
\text { (Graus) }\end{array}$} & Dir. & 93,18497 & 5,44380 & 35 & \multirow{2}{*}{$0,033^{*}$} \\
\hline & Esq. & 91,02730 & 4,51775 & 35 & \\
\hline \multirow{2}{*}{$\begin{array}{c}\text { cine_tornozelo4 } \\
\text { (Graus) }\end{array}$} & Dir. & 95,75224 & 5,91269 & 35 & \multirow{2}{*}{0,544} \\
\hline & Esq. & 95,17497 & 5,21176 & 35 & \\
\hline \multirow{2}{*}{$\begin{array}{c}\text { cine_tornozelo5 } \\
\text { (Graus) }\end{array}$} & Dir. & 59,63786 & 16,23825 & 35 & \multirow{2}{*}{0,108} \\
\hline & Esq. & 67,12804 & 17,98294 & 35 & \\
\hline
\end{tabular}

* $p$-valor considerado estatisticamente significativo perante o nível de significância adotado $(p \leq$ 0,05 ); \# p-valor que por estar próximo do limite de aceitação é considerado que tenda a ser significativo. 


\section{ANEXO IV - Resultados dos experimentos (cont.)}

TABELA 43 - Dados referentes aos parâmetros analisados da marcha auto-selecionada, nas comparações entre lado acometido e não acometido, para o grupo PTC unilateral.

\begin{tabular}{|c|c|c|c|c|c|}
\hline Variáveis & & Média & Desvio Padrão & $\begin{array}{c}\text { Taman } \\
\text { ho }\end{array}$ & p-valor \\
\hline \multirow{2}{*}{$\begin{array}{l}\mathrm{Fz} 1 \\
(\mathrm{PC})\end{array}$} & Acometido & 1,02360 & 0,08254 & 35 & \multirow{2}{*}{0,404} \\
\hline & Não acometido & 1,03837 & 0,08643 & 35 & \\
\hline \multirow{2}{*}{$\begin{array}{l}\text { Fz } 2 \\
(P C)\end{array}$} & Acometido & 0,96053 & 0,05568 & 35 & \multirow{2}{*}{$0,085 \#$} \\
\hline & Não acometido & 0,97976 & 0,06615 & 35 & \\
\hline \multirow{2}{*}{$\begin{array}{l}\text { Fz min } \\
(P C)\end{array}$} & Acometido & 0,84742 & 0,04434 & 35 & \multirow{2}{*}{$0,016^{\star}$} \\
\hline & Não acometido & 0,82258 & 0,05499 & 35 & \\
\hline \multirow{2}{*}{$\begin{array}{l}\text { T_apoio } \\
(\mathrm{s})\end{array}$} & Acometido & 0,49817 & 0,00284 & 35 & \multirow{2}{*}{0,103} \\
\hline & Não acometido & 0,49683 & 0,00294 & 35 & \\
\hline \multirow{2}{*}{$\begin{array}{l}\text { TC } 1 \\
\text { (PC/s) }\end{array}$} & Acometido & 9,06322 & 2,39649 & 35 & \multirow{2}{*}{0,334} \\
\hline & Não acometido & 9,48683 & 2,11527 & 35 & \\
\hline \multirow{2}{*}{$\begin{array}{l}\text { TC } 2 \\
(\mathrm{PC} / \mathrm{s})\end{array}$} & Acometido & 0,96645 & 0,46345 & 35 & \multirow{2}{*}{$0,005^{\star}$} \\
\hline & Não acometido & 1,33193 & 0,64334 & 35 & \\
\hline \multirow{2}{*}{$\begin{array}{l}\text { Fy min } \\
(P C)\end{array}$} & Acometido & $-0,11170$ & 0,04483 & 35 & \multirow{2}{*}{$0,010^{*}$} \\
\hline & Não acometido & $-0,13328$ & 0,03557 & 35 & \\
\hline \multirow{2}{*}{$\begin{array}{l}\text { Fy max } \\
\text { (PC) }\end{array}$} & Acometido & 0,11719 & 0,02957 & 35 & \multirow{2}{*}{0,105} \\
\hline & Não acometido & 0,11038 & 0,02937 & 35 & \\
\hline \multirow{2}{*}{$\begin{array}{l}\text { fren } \\
\text { (PC.s) }\end{array}$} & Acometido & $-0,01157$ & 0,00439 & 35 & \multirow{2}{*}{$0,006^{*}$} \\
\hline & Não acometido & $-0,01478$ & 0,00416 & 35 & \\
\hline \multirow{2}{*}{$\begin{array}{l}\text { I_prop } \\
\text { (PC.s) }\end{array}$} & Acometido & 0,01634 & 0,00378 & 35 & \multirow{2}{*}{$0,010^{*}$} \\
\hline & Não acometido & 0,01401 & 0,00462 & 35 & \\
\hline \multirow{2}{*}{$\begin{array}{l}\text { Fx } 1 \\
\text { (PC) }\end{array}$} & Acometido & $-0,00586$ & 0,01195 & 35 & \multirow{2}{*}{0,831} \\
\hline & Não acometido & $-0,00449$ & 0,00995 & 35 & \\
\hline \multirow{2}{*}{$\begin{array}{l}\text { Fx } 2 \\
(P C)\end{array}$} & Acometido & 0,09900 & 0,02119 & 35 & \multirow{2}{*}{$0,022^{*}$} \\
\hline & Não acometido & 0,08693 & 0,02653 & 35 & \\
\hline \multirow{2}{*}{$\begin{array}{l}\text { Fx 3 } \\
(P C)\end{array}$} & Acometido & 0,06587 & 0,01864 & 35 & \multirow{2}{*}{0,112} \\
\hline & Não acometido & 0,05864 & 0,02206 & 35 & \\
\hline \multirow{2}{*}{$\begin{array}{l}\text { Fx } 4 \\
(\mathrm{PC})\end{array}$} & Acometido & $-0,00570$ & 0,00863 & 35 & \multirow{2}{*}{$0,010^{*}$} \\
\hline & Não acometido & $-0,00192$ & 0,00881 & 35 & \\
\hline \multirow{2}{*}{$\begin{array}{c}\text { cine_joelho1 } \\
\text { (Graus) }\end{array}$} & Acometido & 10,41954 & 5,85501 & 35 & \multirow{2}{*}{0,342} \\
\hline & Não acometido & 9,66212 & 4,30965 & 35 & \\
\hline cine_joelho2 & Acometido & 20,94117 & 6,78245 & 35 & \\
\hline (Graus) & Não acometido & 25,53019 & 9,29693 & 35 & $0,009^{\wedge}$ \\
\hline
\end{tabular}

continua 


\section{ANEXO IV - Resultados dos experimentos (cont.)}

TABELA 43 - Dados referentes aos parâmetros analisados da marcha auto-selecionada, nas comparações entre lado acometido e não acometido, para o grupo PTC unilateral (cont.).

\begin{tabular}{|c|c|c|c|c|c|}
\hline Variáveis & & Média & Desvio Padrão & $\begin{array}{c}\text { Taman } \\
\text { ho }\end{array}$ & p-valor \\
\hline \multirow{2}{*}{$\begin{array}{c}\text { cine_joelho3 } \\
\text { (Graus) }\end{array}$} & Acometido & 12,93527 & 5,02260 & 35 & \multirow{2}{*}{$0,009^{*}$} \\
\hline & Não acometido & 17,58117 & 8,08103 & 35 & \\
\hline \multirow{2}{*}{$\begin{array}{c}\text { cine_joelho4 } \\
\text { (Graus) }\end{array}$} & Acometido & 10,39287 & 6,17007 & 35 & \multirow{2}{*}{$0,046^{*}$} \\
\hline & Não acometido & 14,25888 & 7,41499 & 35 & \\
\hline \multirow{2}{*}{$\begin{array}{c}\text { cine_joelho5 } \\
\text { (Graus) }\end{array}$} & Acometido & 33,27670 & 12,63957 & 35 & \multirow{2}{*}{0,120} \\
\hline & Não acometido & 36,83545 & 13,80229 & 35 & \\
\hline \multirow{2}{*}{$\begin{array}{c}\text { cine_tornozelo1 } \\
\text { (Graus) }\end{array}$} & Acon & 87,60360 & 8,59565 & 35 & \multirow{2}{*}{0,120} \\
\hline & Não acometido & 85,37812 & 8,10002 & 35 & \\
\hline \multirow{2}{*}{$\begin{array}{c}\text { cine_tornozelo2 } \\
\text { (Graus) }\end{array}$} & Acometido & 90,66420 & 3,58287 & 35 & \multirow{2}{*}{0,523} \\
\hline & Não acometido & 91,69068 & 4,97258 & 35 & \\
\hline \multirow{2}{*}{$\begin{array}{c}\text { cine_tornozelo3 } \\
\text { (Graus) }\end{array}$} & Acometido & 94,26365 & 4,03045 & 35 & \multirow{2}{*}{0,108} \\
\hline & Não acometido & 96,27315 & 5,85101 & 35 & \\
\hline \multirow{2}{*}{$\begin{array}{c}\text { cine_tornozelo4 } \\
\text { (Graus) }\end{array}$} & Acometido & 97,66624 & 7,47531 & 35 & \multirow{2}{*}{ 0,083\# } \\
\hline & Não acometido & 99,72868 & 7,07894 & 35 & \\
\hline \multirow{2}{*}{$\begin{array}{c}\text { cine_tornozelo5 } \\
\text { (Graus) }\end{array}$} & Acometido & 58,51028 & 22,24883 & & \multirow{2}{*}{0,201} \\
\hline & Não acometido & 64,06605 & 21,98501 & & \\
\hline
\end{tabular}

* $p$-valor considerado estatisticamente significativo perante o nível de significância adotado ( $p \leq$ $0,05)$; \# p-valor que por estar próximo do limite de aceitação é considerado que tenda a ser significativo. 


\section{ANEXO IV - Resultados dos experimentos (cont.)}

TABELA 44 - Dados referentes aos parâmetros analisados da marcha auto-selecionada, nas comparações entre os grupos: Controle (Cont.), PTC com acometimento bilateral lado direito (Bil. D.), PTC com acometimento bilateral lado esquerdo (Bil. E.), PTC com acometimento unilateral lado acometido (Acom.) e PTC com acometimento unilateral lado não acometido ( $\tilde{\mathrm{N}}$ Acom.). $\mathrm{p} \leq 0,05$.

\begin{tabular}{|c|c|c|c|c|c|}
\hline Variáveis & Grupos & Acom. & Bil.D & Bil.E & Cont. \\
\hline \multirow{4}{*}{$\begin{array}{l}\text { Fz } 1 \\
(P C)\end{array}$} & Bil. D & 0,856 & & & \\
\hline & Bil. E & 0,394 & 0,213 & & \\
\hline & Cont. & 0,082 & 0,106 & 0,004 & \\
\hline & $\tilde{\mathrm{N}}$ Acom. & 0,414 & 0,485 & 0,094 & 0,595 \\
\hline \multirow{4}{*}{$\begin{array}{l}F z 2 \\
(P C)\end{array}$} & Bil. D & 0,022 & & & \\
\hline & Bil. E & 0,016 & 0,958 & & \\
\hline & Cont. & $<0,001$ & $<0,001$ & $<0,001$ & \\
\hline & $\tilde{\mathrm{N}}$ Acom. & 0,321 & 0,252 & 0,267 & $<0,001$ \\
\hline \multirow{4}{*}{$\begin{array}{l}\text { Fz min } \\
(P C)\end{array}$} & Bil. D & 0,010 & & & \\
\hline & Bil. E & 0,003 & 0,694 & & \\
\hline & Cont. & 0,641 & 0,014 & 0,002 & \\
\hline & $\tilde{N}$ Acom. & 0,083 & $<0,001$ & $<0,001$ & 0,012 \\
\hline \multirow{4}{*}{$\begin{array}{c}\text { T_apoio } \\
\text { (s) }\end{array}$} & Bil. D & 0,004 & & & \multirow{4}{*}{$<0,001$} \\
\hline & Bil. E & 0,066 & 0,417 & & \\
\hline & Cont. & $<0,001$ & $<0,001$ & $<0,001$ & \\
\hline & $\tilde{\mathrm{N}}$ Acom. & 0,071 & 0,215 & 0,794 & \\
\hline \multirow{4}{*}{$\begin{array}{c}\text { TC } 1 \\
\text { (PC/s) }\end{array}$} & Bil. D & 0,038 & & & \\
\hline & Bil. E & 0,388 & 0,096 & & \\
\hline & Cont. & $<0,001$ & $<0,001$ & $<0,001$ & \\
\hline & $\tilde{\mathrm{N}}$ Acom. & 0,333 & 0,005 & 0,109 & $<0,001$ \\
\hline \multirow{4}{*}{$\begin{array}{c}\text { TC } 2 \\
\text { (PC/s) }\end{array}$} & Bil. D & 0,073 & & & \\
\hline & Bil. E & 0,930 & 0,157 & & \\
\hline & Cont. & 0,325 & 0,366 & 0,501 & \\
\hline & $\tilde{N}$ Acom. & 0,020 & 0,601 & 0,059 & 0,121 \\
\hline \multirow{4}{*}{$\begin{array}{l}\text { Fy_min } \\
\text { (PC) }\end{array}$} & Bil. D & 0,130 & & & \\
\hline & Bil. E & 0,164 & 0,008 & & \\
\hline & Cont. & 0,868 & 0,113 & 0,068 & \\
\hline & $\tilde{\mathrm{N}}$ Acom. & 0,006 & $<0,001$ & 0,304 & 0,001 \\
\hline \multirow{4}{*}{$\begin{array}{c}\text { Fy_max } \\
\text { (PC) }\end{array}$} & Bil. D & 0,350 & & & \\
\hline & Bil. E & 0,865 & 0,651 & & \\
\hline & Cont. & $<0,001$ & 0,010 & 0,010 & \\
\hline & $\tilde{\mathrm{N}}$ Acom. & 0,442 & 0,101 & 0,388 & $<0,001$ \\
\hline
\end{tabular}




\section{ANEXO IV - Resultados dos experimentos (cont.)}

TABELA 44 - Dados referentes aos parâmetros analisados da marcha auto-selecionada, nas comparações entre os grupos: Controle (Cont.), PTC com acometimento bilateral lado direito (Bil. D.), PTC com acometimento bilateral lado esquerdo (Bil. E.), PTC com acometimento unilateral lado acometido (Acom.) e PTC com acometimento unilateral lado não acometido (Ñ Acom.). $\mathrm{p} \leq 0,05$ (cont.).

\begin{tabular}{|c|c|c|c|c|c|}
\hline Variáveis & Grupos & Acom. & Bil. D & Bil.E & Cont. \\
\hline \multirow{4}{*}{$\begin{array}{l}\text { Ifren } \\
\text { (PC.s) }\end{array}$} & Bil. D & 0,105 & & & \\
\hline & Bil. E & 0,043 & 0,004 & & \\
\hline & Cont. & $<0,001$ & $<0,001$ & $<0,001$ & \\
\hline & $\tilde{\mathrm{N}}$ Acom. & 0,003 & $<0,001$ & 0,474 & 0,001 \\
\hline \multirow{4}{*}{$\begin{array}{l}\text { I_prop } \\
\text { (PC.s) }\end{array}$} & Bil. D & 0,522 & & & \\
\hline & Bil. E & 0,589 & 0,344 & & \\
\hline & Cont. & $<0,001$ & $<0,001$ & $<0,001$ & \\
\hline & $\tilde{\mathrm{N}}$ Acom. & 0,008 & 0,019 & 0,255 & $<0,001$ \\
\hline \multirow{4}{*}{$\begin{array}{l}\text { Fx } 1 \\
(P C)\end{array}$} & Bil. D & 0,209 & & & \\
\hline & Bil. E & 0,360 & 0,356 & & \\
\hline & Cont. & 0,004 & 0,211 & 0,019 & \\
\hline & $\tilde{\mathrm{N}}$ Acom. & 0,842 & 0,060 & 0,196 & 0,001 \\
\hline \multirow{4}{*}{$\begin{array}{l}F \times 2 \\
(P C)\end{array}$} & Bil. D & 0,012 & & & \\
\hline & Bil. E & 0,029 & 0,315 & & \\
\hline & Cont. & $<0,001$ & 0,817 & 0,089 & \\
\hline & $\tilde{N}$ Acom. & 0,020 & 0,401 & 0,729 & 0,193 \\
\hline \multirow{4}{*}{$\begin{array}{l}F \times 3 \\
(P C)\end{array}$} & Bil. D & 0,207 & & & \\
\hline & Bil. E & 0,356 & 0,545 & & \\
\hline & Cont. & $<0,001$ & 0,211 & 0,013 & \\
\hline & $\tilde{\mathrm{N}}$ Acom. & 0,272 & 0,747 & 0,968 & 0,040 \\
\hline \multirow{4}{*}{$\begin{array}{l}\text { Fx } 4 \\
(\mathrm{PC})\end{array}$} & Bil. D & 0,288 & & & \\
\hline & Bil. E & 0,028 & 0,344 & & \\
\hline & Cont. & 0,740 & 0,127 & 0,003 & \\
\hline & $\tilde{\mathrm{N}}$ Acom. & 0,071 & 0,005 & $<0,001$ & 0,007 \\
\hline \multirow{4}{*}{$\begin{array}{c}\text { cine_joelho1 } \\
\text { (Graus) }\end{array}$} & Bil. D & 0,267 & & & \\
\hline & Bil. E & 0,001 & 0,013 & & \\
\hline & Cont. & 0,034 & 0,567 & 0,006 & \\
\hline & N Acom. & 0,530 & 0,338 & $<0,001$ & 0,056 \\
\hline
\end{tabular}




\section{ANEXO IV - Resultados dos experimentos (cont.)}

TABELA 44 - Dados referentes aos parâmetros analisados da marcha auto-selecionada, nas comparações entre os grupos: Controle (Cont.), PTC com acometimento bilateral lado direito (Bil. D.), PTC com acometimento bilateral lado esquerdo (Bil. E.), PTC com acometimento unilateral lado acometido (Acom.) e PTC com acometimento unilateral lado não acometido (Ñ Acom.). $\mathrm{p} \leq 0,05$ (cont.).

\begin{tabular}{|c|c|c|c|c|c|}
\hline Variáveis & Grupos & Acom. & Bil. D & Bil.E & Cont. \\
\hline \multirow{4}{*}{$\begin{array}{c}\text { cine_joelho2 } \\
\text { (Graus) }\end{array}$} & Bil. D & 0,004 & & & \\
\hline & Bil. E & $<0,001$ & 0,321 & & \\
\hline & Cont. & $<0,001$ & 0,265 & 0,798 & \\
\hline & $\tilde{\mathrm{N}}$ Acom. & 0,079 & $<0,001$ & $<0,001$ & $<0,001$ \\
\hline \multirow{4}{*}{$\begin{array}{c}\text { cine_joelho3 } \\
\text { (Graus) }\end{array}$} & Bil. D & 0,009 & & & \\
\hline & Bil. E & 0,001 & 0,470 & & \\
\hline & Cont. & 0,004 & 0,609 & 0,139 & \\
\hline & N Acom. & 0,016 & $<0,001$ & $<0,001$ & $<0,001$ \\
\hline \multirow{4}{*}{$\begin{array}{c}\text { cine_joelho4 } \\
\text { (Graus) }\end{array}$} & Bil. D & 0,224 & & & \\
\hline & Bil. E & 0,033 & 0,382 & & \\
\hline & Cont. & 0,208 & 0,323 & 0,035 & \\
\hline & $\tilde{\mathrm{N}}$ Acom. & 0,036 & 0,002 & $<0,001$ & $<0,001$ \\
\hline \multirow{4}{*}{$\begin{array}{c}\text { cine_joelho5 } \\
\text { (Graus) }\end{array}$} & Bil. D & 0,224 & & & \\
\hline & Bil. E & 0,055 & 0,553 & & \\
\hline & Cont. & 0,714 & 0,054 & 0,005 & \\
\hline & $\tilde{\mathrm{N}}$ Acom. & 0,171 & 0,747 & 0,747 & 0,033 \\
\hline \multirow{4}{*}{$\begin{array}{c}\text { cine_tornozelo1 } \\
\text { (Graus) }\end{array}$} & Bil. D & 0,094 & & & \\
\hline & Bil. E & 0,333 & 0,315 & & \\
\hline & Cont. & 0,733 & 0,023 & 0,190 & \\
\hline & Ñ Acom. & 0,215 & 0,001 & 0,006 & 0,276 \\
\hline \multirow{4}{*}{$\begin{array}{c}\text { cine_tornozelo2 } \\
\text { (Graus) }\end{array}$} & Bil. D & 0,660 & & & \\
\hline & Bil. E & 0,002 & 0,004 & & \\
\hline & Cont. & $<0,001$ & 0,001 & 0,964 & \\
\hline & Ñ Acom. & 0,643 & 0,911 & 0,001 & $<0,001$ \\
\hline \multirow{4}{*}{$\begin{array}{c}\text { cine_tornozelo3 } \\
\text { (Graus) }\end{array}$} & Bil. D & 0,175 & & & \\
\hline & Bil. E & $<0,001$ & 0,079 & & \\
\hline & Cont. & $<0,001$ & 0,140 & 0,380 & \\
\hline & N Acom. & 0,186 & 0,019 & $<0,001$ & $<0,001$ \\
\hline \multirow{4}{*}{$\begin{array}{c}\text { cine tornozelo4 } \\
\text { (Graus) }\end{array}$} & Bil. D & 0,304 & & & \\
\hline & Bil. E & 0,075 & 0,492 & & \\
\hline & Cont. & $<0,001$ & 0,001 & 0,001 & \\
\hline & $\tilde{N}$ Acom. & 0,262 & 0,020 & 0,005 & $<0,001$ \\
\hline
\end{tabular}




\section{ANEXO IV - Resultados dos experimentos (cont.)}

TABELA 44 - Dados gerais relacionados com os parâmetros avaliados no experimento 2. salto vertical com contra-movimento, do grupo de crianças do Grupo Controle. (cont.)

\begin{tabular}{|c|c|c|c|c|c|c|}
\hline Variáveis & & Média & Mediana & Desvio Padrão & Tamanho & p-valor \\
\hline \multirow{5}{*}{$\begin{array}{l}\mathrm{F} \max 1 \\
(\mathrm{PC})\end{array}$} & Rep 1 & 1,47528 & 1,37900 & 0,44240 & 11 & \multirow{5}{*}{0,911} \\
\hline & Rep 2 & 1,42333 & 1,29322 & 0,39881 & 11 & \\
\hline & Rep 3 & 1,61477 & 1,22600 & 1,06552 & 11 & \\
\hline & Rep 4 & 1,40849 & 1,23362 & 0,52317 & 9 & \\
\hline & Rep 5 & 1,30768 & 1,17844 & 0,39750 & 6 & \\
\hline \multirow{5}{*}{$\begin{array}{c}\mathrm{TC} \\
(\mathrm{PC} / \mathrm{s})\end{array}$} & Rep 1 & 43,41398 & 30,91764 & 44,96787 & 11 & \multirow{5}{*}{0,243} \\
\hline & Rep 2 & 37,99967 & 35,27786 & 20,22609 & 11 & \\
\hline & $\operatorname{Rep} 3$ & 36,77733 & 25,46803 & 27,25538 & 11 & \\
\hline & Rep 4 & 48,71660 & 40,93736 & 35,49602 & 9 & \\
\hline & Rep 5 & 33,94233 & 34,77835 & 18,41515 & 6 & \\
\hline \multirow{5}{*}{$\begin{array}{l}F \max 2 \\
(P C)\end{array}$} & Rep 1 & 2,98037 & 2,81351 & 2,22061 & 11 & \multirow{5}{*}{0,060} \\
\hline & Rep 2 & 2,89848 & 2,71640 & 1,15589 & 11 & \\
\hline & Rep 3 & 2,71768 & 2,01197 & 1,66075 & 11 & \\
\hline & Rep 4 & 3,17979 & 3,02936 & 1,69265 & 9 & \\
\hline & Rep 5 & 2,56948 & 2,65213 & 1,15896 & 6 & \\
\hline \multirow{5}{*}{$\begin{array}{l}\text { Altura } \\
(\mathrm{cm})\end{array}$} & Rep 1 & 106,78429 & 64,40069 & 82,93596 & 11 & \multirow{5}{*}{0,871} \\
\hline & Rep 2 & 146,30565 & 67,29475 & 151,75734 & 11 & \\
\hline & Rep 3 & 125,24515 & 70,25241 & 118,64087 & 11 & \\
\hline & Rep 4 & 116,35222 & 96,20350 & 93,60962 & 9 & \\
\hline & Rep 5 & 139,32811 & 96,23530 & 111,66202 & 6 & \\
\hline \multirow{5}{*}{$\underset{\text { (ua) }}{\text { RMS_GM_pre }}$} & Rep 1 & 0,09614 & 0,09178 & 0,02289 & 22 & \multirow{5}{*}{0,622} \\
\hline & Rep 2 & 0,10684 & 0,09889 & 0,03054 & 22 & \\
\hline & Rep 3 & 0,09104 & 0,09544 & 0,02027 & 22 & \\
\hline & Rep 4 & 0,10138 & 0,08838 & 0,03735 & 18 & \\
\hline & Rep 5 & 0,11028 & 0,10440 & 0,03404 & 14 & \\
\hline \multirow{5}{*}{$\underset{\text { (ua) }}{R M S \text { GM_pos }}$} & Rep 1 & 0,10274 & 0,09327 & 0,04470 & 22 & \multirow{5}{*}{0,430} \\
\hline & Rep 2 & 0,08646 & 0,07712 & 0,03189 & 22 & \\
\hline & Rep 3 & 0,09143 & 0,08159 & 0,03121 & 22 & \\
\hline & Rep 4 & 0,08959 & 0,08662 & 0,02665 & 18 & \\
\hline & Rep 5 & 0,09064 & 0,08084 & 0,02573 & 14 & \\
\hline \multirow{5}{*}{$\underset{\text { (ua) }}{R M S_{-T A} \text { TA pre }}$} & Rep 1 & 0,12833 & 0,11885 & 0,03808 & 22 & \multirow{5}{*}{0,406} \\
\hline & Rep 2 & 0,13574 & 0,14147 & 0,03636 & 22 & \\
\hline & Rep 3 & 0,12632 & 0,12840 & 0,02685 & 22 & \\
\hline & $\operatorname{Rep} 4$ & 0,12875 & 0,12753 & 0,03287 & 18 & \\
\hline & $\operatorname{Rep} 5$ & 0,12481 & 0,12605 & 0,03434 & 14 & \\
\hline
\end{tabular}

${ }^{*} \mathrm{p}$-valor considerado estatisticamente significativo perante o nível de significância adotado $(\mathrm{p} \leq$ $0,05)$; \# p-valor que por estar próximo do limite de aceitação é considerado que tenda a ser significativo. 


\section{ANEXO IV - Resultados dos experimentos (cont.)}

TABELA 44 - Dados gerais relacionados com os parâmetros avaliados no experimento 2. salto vertical com contra-movimento, do grupo de crianças do Grupo Controle. (cont.).

\begin{tabular}{|c|c|c|c|c|c|c|}
\hline Variáveis & & Média & Mediana & Desvio Padrão & Tamanho & $p$-valor \\
\hline \multirow{9}{*}{$\underset{\text { (ua) }}{\text { RMS_TA_pos }}$} & Rep 1 & 0,13932 & 0,13285 & 0,03869 & 22 & \multirow{9}{*}{0,082} \\
\hline & Rep 2 & 0,13240 & 0,13978 & 0,03177 & 22 & \\
\hline & Rep 3 & 0,12241 & 0,12013 & 0,03096 & 22 & \\
\hline & $\operatorname{Rep} 4$ & 0,14589 & 0,15076 & 0,03862 & 18 & \\
\hline & Rep 5 & 0,14409 & 0,15574 & 0,04449 & 14 & \\
\hline & Rep 2 & 68,73384 & 70,98757 & 25,94166 & 20 & \\
\hline & Rep 3 & 72,58294 & 66,52507 & 32,90419 & 20 & \\
\hline & Rep 4 & 69,87585 & 71,32649 & 23,91201 & 16 & \\
\hline & Rep 5 & 68,57201 & 70,55877 & 18,85608 & 12 & \\
\hline \multirow{5}{*}{$\begin{array}{l}\text { cine_joelho1 } \\
\text { (Graus) }\end{array}$} & Rep 1 & 74,16570 & 70,76911 & 10,33368 & 22 & \multirow{5}{*}{0,055} \\
\hline & Rep 2 & 79,67841 & 83,61286 & 9,82027 & 22 & \\
\hline & Rep 3 & 78,02303 & 78,39632 & 8,47570 & 22 & \\
\hline & Rep 4 & 77,95768 & 76,10478 & 10,41331 & 22 & \\
\hline & $\operatorname{Rep} 5$ & 80,69588 & 78,17780 & 11,22662 & 22 & \\
\hline \multirow{5}{*}{$\begin{array}{c}\text { cine_joelho2 } \\
\text { (Graus) }\end{array}$} & Rep 1 & 2,94477 & 2,00832 & 2,36393 & 22 & \multirow{5}{*}{0,079} \\
\hline & Rep 2 & 2,83136 & 1,69773 & 2,76357 & 22 & \\
\hline & Rep 3 & 3,39921 & 2,44258 & 2,64866 & 22 & \\
\hline & Rep 4 & 2,47334 & 2,27167 & 1,52373 & 22 & \\
\hline & Rep 5 & 4,34922 & 3,03316 & 3,96308 & 22 & \\
\hline \multirow{5}{*}{$\begin{array}{c}\text { cine_joelho3 } \\
\text { (Graus) }\end{array}$} & Rep 1 & 9,69734 & 6,88767 & 11,54899 & 22 & \multirow{5}{*}{0,265} \\
\hline & Rep 2 & 5,60856 & 4,07885 & 5,90559 & 22 & \\
\hline & Rep 3 & 5,74973 & 3,58901 & 5,39709 & 22 & \\
\hline & Rep 4 & 5,49151 & 4,56622 & 5,17137 & 22 & \\
\hline & Rep 5 & 8,27325 & 5,07740 & 8,36348 & 22 & \\
\hline \multirow{5}{*}{$\begin{array}{c}\text { cine_joelho4 } \\
\text { (Graus) }\end{array}$} & Rep 1 & 54,37229 & 49,81193 & 21,04196 & 22 & \multirow{5}{*}{$0,035^{*}$} \\
\hline & Rep 2 & 48,93244 & 43,18122 & 22,37409 & 22 & \\
\hline & Rep 3 & 52,17918 & 49,06394 & 15,73514 & 22 & \\
\hline & Rep 4 & 57,88323 & 56,42391 & 19,93123 & 22 & \\
\hline & Rep 5 & 61,40783 & 60,03894 & 12,30372 & 22 & \\
\hline \multirow{5}{*}{$\begin{array}{c}\text { cine_tornozelo1 } \\
\text { (Graus) }\end{array}$} & Rep 1 & 114,58759 & 115,19888 & 8,91480 & 22 & \multirow{5}{*}{0,641} \\
\hline & Rep 2 & 112,83828 & 114,53625 & 8,96083 & 22 & \\
\hline & $\operatorname{Rep} 3$ & 114,91745 & 114,10041 & 8,65193 & 22 & \\
\hline & Rep 4 & 113,57154 & 116,87932 & 10,29044 & 22 & \\
\hline & Rep 5 & 114,50731 & 113,67646 & 8,59361 & 22 & \\
\hline
\end{tabular}




\section{ANEXO IV - Resultados dos experimentos (cont.)}

TABELA 44 - Dados gerais relacionados com os parâmetros avaliados no experimento 2. salto vertical com contra-movimento, do grupo de crianças do Grupo Controle (cont.).

\begin{tabular}{|c|c|c|c|c|c|c|}
\hline Variáveis & & Média & Mediana & Desvio Padrão & Tamanho & p-valor \\
\hline \multirow{5}{*}{$\begin{array}{c}\text { cine_tornozelo2 } \\
\text { (Graus) }\end{array}$} & Rep 1 & 43,06407 & 42,31417 & 6,50730 & 22 & \multirow{5}{*}{0,099} \\
\hline & Rep 2 & 44,02017 & 43,57049 & 7,12280 & 22 & \\
\hline & Rep 3 & 43,12191 & 44,29681 & 7,30370 & 22 & \\
\hline & Rep 4 & 41,60304 & 41,47948 & 7,99340 & 22 & \\
\hline & Rep 5 & 43,58485 & 45,72482 & 8,33089 & 22 & \\
\hline \multirow{5}{*}{$\begin{array}{c}\text { cine_tornozelo3 } \\
\text { (Graus) }\end{array}$} & Rep 1 & 55,53376 & 53,41703 & 11,78905 & 22 & \multirow{5}{*}{0,681} \\
\hline & $\operatorname{Rep} 2$ & 53,53019 & 51,22323 & 10,21601 & 22 & \\
\hline & Rep 3 & 51,58274 & 51,06398 & 9,73226 & 22 & \\
\hline & Rep 4 & 53,32450 & 52,84129 & 8,47661 & 22 & \\
\hline & Rep 5 & 54,72108 & 57,32110 & 8,67573 & 22 & \\
\hline \multirow{5}{*}{$\begin{array}{c}\text { cine_tornozelo4 } \\
\text { (Graus) }\end{array}$} & Rep 1 & 110,91642 & 109,47519 & 9,23275 & 22 & \multirow{5}{*}{0,214} \\
\hline & $\operatorname{Rep} 2$ & 109,23790 & 109,25247 & 8,55902 & 22 & \\
\hline & Rep 3 & 109,33676 & 108,63865 & 7,34501 & 22 & \\
\hline & Rep 4 & 109,47150 & 109,68162 & 8,37195 & 22 & \\
\hline & $\operatorname{Rep} 5$ & 111,91239 & 111,40713 & 7,37373 & 22 & \\
\hline
\end{tabular}




\section{ANEXO IV - Resultados dos experimentos (cont.)}

TABELA 45 - Dados gerais relacionados com os parâmetros avaliados no experimento 2, salto vertical com contra-movimento, do grupo de crianças com PTC bilateral.

\begin{tabular}{|c|c|c|c|c|c|c|}
\hline Variáveis & & Média & Mediana & Desvio Padrão & Tamanho & $\mathrm{p}$-valor \\
\hline \multirow{5}{*}{$\begin{array}{l}F \max 1 \\
(P C)\end{array}$} & Rep 1 & 1,56666 & 1,32789 & 0,51026 & 6 & \multirow{5}{*}{0,435} \\
\hline & Rep 2 & 1,55576 & 1,37630 & 0,49367 & 6 & \\
\hline & Rep 3 & 1,61539 & 1,44990 & 0,48157 & 6 & \\
\hline & Rep 4 & 1,43435 & 1,40562 & 0,44823 & 5 & \\
\hline & Rep 5 & 1,54043 & 1,57687 & 0,42131 & 4 & \\
\hline \multirow{5}{*}{$\begin{array}{c}\mathrm{TC} \\
(\mathrm{PC} / \mathrm{s})\end{array}$} & Rep 1 & 51,88615 & 52,01611 & 22,90257 & 6 & \multirow{5}{*}{0,238} \\
\hline & Rep 2 & 39,57198 & 35,88714 & 14,31444 & 6 & \\
\hline & Rep 3 & 64,55175 & 59,75573 & 32,27706 & 6 & \\
\hline & Rep 4 & 78,11332 & 44,87870 & 46,26701 & 5 & \\
\hline & Rep 5 & 95,07332 & 84,31249 & 70,00516 & 4 & \\
\hline \multirow{5}{*}{$\begin{array}{l}F \max 2 \\
(P C)\end{array}$} & Rep 1 & 2,87618 & 3,01078 & 0,78295 & 6 & \multirow{5}{*}{0,933} \\
\hline & Rep 2 & 2,62301 & 2,71576 & 0,64656 & 6 & \\
\hline & Rep 3 & 3,33619 & 3,23411 & 1,00282 & 6 & \\
\hline & Rep 4 & 3,78110 & 2,69272 & 2,15611 & 5 & \\
\hline & Rep 5 & 4,26012 & 3,53736 & 2,16070 & 4 & \\
\hline \multirow{5}{*}{$\begin{array}{l}\text { Altura } \\
(\mathrm{cm})\end{array}$} & Rep 1 & 81,54287 & 82,71911 & 24,96827 & 6 & \multirow{5}{*}{0,115} \\
\hline & Rep 2 & 96,93963 & 96,09024 & 27,04272 & 6 & \\
\hline & Rep 3 & 60,81243 & 56,38638 & 21,87724 & 6 & \\
\hline & Rep 4 & 71,84347 & 76,04624 & 18,43724 & 5 & \\
\hline & Rep 5 & 72,53247 & 82,58832 & 22,61193 & 4 & \\
\hline \multirow{5}{*}{$\underset{\text { (ua) }}{\text { RMS_GM_pre }}$} & Rep 1 & 0,09254 & 0,09255 & 0,01188 & 12 & \multirow{5}{*}{0,053} \\
\hline & Rep 2 & 0,16753 & 0,09657 & 0,25973 & 12 & \\
\hline & Rep 3 & 0,09908 & 0,10036 & 0,02175 & 12 & \\
\hline & Rep 4 & 0,09202 & 0,09228 & 0,02349 & 12 & \\
\hline & Rep 5 & 0,09093 & 0,08914 & 0,02604 & 10 & \\
\hline \multirow{5}{*}{$\underset{\text { (ua) }}{\text { RMS_GM_pos }}$} & Rep 1 & 0,10341 & 0,10558 & 0,03597 & 12 & \multirow{5}{*}{0,061} \\
\hline & Rep 2 & 0,10174 & 0,09938 & 0,04361 & 12 & \\
\hline & Rep 3 & 0,13418 & 0,13584 & 0,03683 & 12 & \\
\hline & Rep 4 & 0,10882 & 0,09177 & 0,04096 & 12 & \\
\hline & Rep 5 & 0,11174 & 0,10674 & 0,02582 & 10 & \\
\hline \multirow{5}{*}{$\underset{\text { (ua) }}{R M S \text { TA_pre }}$} & Rep 1 & 0,14833 & 0,14008 & 0,02670 & 12 & \multirow{5}{*}{0,075} \\
\hline & Rep 2 & 0,11611 & 0,12901 & 0,02713 & 12 & \\
\hline & Rep 3 & 0,13119 & 0,12028 & 0,02857 & 12 & \\
\hline & Rep 4 & 0,10528 & 0,09774 & 0,04434 & 12 & \\
\hline & Rep 5 & 0,10398 & 0,08202 & 0,04740 & 10 & \\
\hline
\end{tabular}




\section{ANEXO IV - Resultados dos experimentos (cont.)}

TABELA 45 - Dados gerais relacionados com os parâmetros avaliados no experimento 2 , salto vertical com contra-movimento, do grupo de crianças com PTC bilateral (cont.).

\begin{tabular}{|c|c|c|c|c|c|c|}
\hline Variáveis & & Média & Mediana & Desvio Padrão & Tamanho & p-valor \\
\hline \multirow{9}{*}{$\underset{\text { (ua) }}{R M S \text { TA_pos }}$} & Rep 1 & 0,12462 & 0,12746 & 0,03954 & 12 & \multirow{9}{*}{0,345} \\
\hline & Rep 2 & 0,13976 & 0,14801 & 0,03359 & 12 & \\
\hline & Rep 3 & 0,13364 & 0,12305 & 0,04459 & 12 & \\
\hline & Rep 4 & 0,11870 & 0,09896 & 0,04595 & 12 & \\
\hline & Rep 5 & 0,13050 & 0,11054 & 0,04654 & 10 & \\
\hline & Rep 2 & 63,17684 & 62,66877 & 4,07833 & 8 & \\
\hline & Rep 3 & 53,50632 & 55,14160 & 7,74076 & 8 & \\
\hline & Rep 4 & 82,47420 & 91,94346 & 19,98989 & 8 & \\
\hline & $\operatorname{Rep} 5$ & 84,76463 & 94,18899 & 20,10106 & 8 & \\
\hline \multirow{5}{*}{$\begin{array}{c}\text { cine_joelho1 } \\
\text { (Graus) }\end{array}$} & Rep 1 & 72,84945 & 71,64869 & 14,53726 & 12 & \multirow{5}{*}{0,791} \\
\hline & Rep 2 & 71,42535 & 69,28909 & 18,62690 & 12 & \\
\hline & Rep 3 & 72,57326 & 69,65107 & 14,84204 & 12 & \\
\hline & Rep 4 & 72,34072 & 65,42882 & 19,49096 & 10 & \\
\hline & Rep 5 & 71,45080 & 71,64854 & 20,42939 & 8 & \\
\hline \multirow{5}{*}{$\begin{array}{c}\text { cine_joelho2 } \\
\text { (Graus) }\end{array}$} & Rep 1 & 5,52492 & 2,81379 & 5,62251 & 12 & \multirow{5}{*}{0,509} \\
\hline & Rep 2 & 6,09176 & 5,77019 & 5,88234 & 12 & \\
\hline & Rep 3 & 5,47458 & 4,03988 & 3,84745 & 12 & \\
\hline & Rep 4 & 4,59275 & 3,76619 & 3,69821 & 10 & \\
\hline & Rep 5 & 1,86572 & 1,43430 & 1,89244 & 8 & \\
\hline \multirow{5}{*}{$\begin{array}{l}\text { cine_joelho3 } \\
\text { (Graus) }\end{array}$} & Rep 1 & 10,14765 & 9,69524 & 7,88642 & 12 & \multirow{5}{*}{0,223} \\
\hline & Rep 2 & 8,66353 & 10,63755 & 5,99772 & 12 & \\
\hline & Rep 3 & 8,42468 & 5,56384 & 7,11997 & 12 & \\
\hline & Rep 4 & 5,10641 & 3,96563 & 4,03484 & 10 & \\
\hline & Rep 5 & 4,17420 & 3,25532 & 4,06258 & 8 & \\
\hline \multirow{5}{*}{$\begin{array}{l}\text { cine_joelho4 } \\
\text { (Graus) }\end{array}$} & Rep 1 & 55,38046 & 57,61164 & 14,26289 & 12 & \multirow{5}{*}{0,541} \\
\hline & Rep 2 & 49,54353 & 53,25712 & 18,67209 & 12 & \\
\hline & Rep 3 & 56,82367 & 54,90639 & 15,64959 & 12 & \\
\hline & Rep 4 & 46,36278 & 45,42211 & 7,61138 & 10 & \\
\hline & Rep 5 & 49,06445 & 45,91297 & 18,05201 & 8 & \\
\hline \multirow{5}{*}{$\begin{array}{c}\text { cine_tornozelo1 } \\
\text { (Graus) }\end{array}$} & Rep 1 & 108,41317 & 109,68375 & 13,15485 & 12 & \multirow{5}{*}{0,086} \\
\hline & Rep 2 & 106,66935 & 106,51861 & 13,64563 & 12 & \\
\hline & Rep 3 & 106,81619 & 108,96838 & 13,26650 & 12 & \\
\hline & Rep 4 & 107,77891 & 113,70726 & 14,04772 & 10 & \\
\hline & Rep 5 & 105,37916 & 103,40286 & 14,13575 & 8 & \\
\hline
\end{tabular}




\section{ANEXO IV - Resultados dos experimentos (cont.)}

TABELA 45 - Dados gerais relacionados com os parâmetros avaliados no experimento 2 , salto vertical com contra-movimento, do grupo de criancas com PTC bilateral (cont.).

\begin{tabular}{|c|c|c|c|c|c|c|}
\hline Variáveis & & Média & Mediana & Desvio Padrão & Tamanho & $\mathrm{p}$-valor \\
\hline \multirow{5}{*}{$\begin{array}{c}\text { cine_tornozelo2 } \\
\text { (Graus) }\end{array}$} & Rep 1 & 60,33657 & 63,19052 & 7,83488 & 12 & \multirow{5}{*}{0,681} \\
\hline & Rep 2 & 61,31595 & 60,58448 & 7,00393 & 12 & \\
\hline & Rep 3 & 61,84946 & 63,57855 & 7,63298 & 12 & \\
\hline & Rep 4 & 59,11362 & 61,61970 & 9,51025 & 10 & \\
\hline & Rep 5 & 59,40409 & 64,28107 & 10,55575 & 8 & \\
\hline \multirow{5}{*}{$\begin{array}{c}\text { cine_tornozelo3 } \\
\text { (Graus) }\end{array}$} & Rep 1 & 64,95183 & 67,03277 & 9,31521 & 12 & \multirow{5}{*}{0,592} \\
\hline & Rep 2 & 64,68763 & 67,94346 & 7,47034 & 12 & \\
\hline & Rep 3 & 66,05375 & 67,48652 & 10,40258 & 12 & \\
\hline & Rep 4 & 64,99374 & 68,22827 & 13,22543 & 10 & \\
\hline & Rep 5 & 64,33409 & 66,78632 & 15,55602 & 8 & \\
\hline \multirow{5}{*}{$\begin{array}{c}\text { cine_tornozelo4 } \\
\text { (Graus) }\end{array}$} & Rep 1 & 104,31557 & 104,48644 & 10,61755 & 12 & \multirow{5}{*}{0,074} \\
\hline & Rep 2 & 104,78332 & 101,93471 & 12,07700 & 12 & \\
\hline & Rep 3 & 106,00622 & 102,92889 & 11,91275 & 12 & \\
\hline & Rep 4 & 103,95499 & 105,33176 & 8,03078 & 10 & \\
\hline & $\operatorname{Rep} 5$ & 107,29394 & 106,76652 & 9,22396 & 8 & \\
\hline
\end{tabular}




\section{ANEXO IV - Resultados dos experimentos (cont.)}

TABELA 46 - Dados gerais relacionados com os parâmetros avaliados no experimento 2 , salto vertical com contra-movimento, do grupo de criancas com PTC unilateral.

\begin{tabular}{|c|c|c|c|c|c|c|}
\hline Variáveis & & Média & Mediana & Desvio Padrão & Tamanho & p-valor \\
\hline \multirow{5}{*}{$\begin{array}{l}F \max 1 \\
(P C)\end{array}$} & Rep 1 & 1,22427 & 1,22800 & 0,46168 & 6 & \multirow{5}{*}{0,177} \\
\hline & Rep 2 & 1,23843 & 1,19850 & 0,36410 & 6 & \\
\hline & Rep 3 & 1,26796 & 1,19850 & 0,50181 & 6 & \\
\hline & Rep 4 & 1,16027 & 1,08173 & 0,55721 & 4 & \\
\hline & Rep 5 & 1,08173 & 1,08173 & 0,35493 & 2 & \\
\hline \multirow{5}{*}{$\begin{array}{c}\mathrm{TC} \\
(\mathrm{PC} / \mathrm{s})\end{array}$} & Rep 1 & 46,91927 & 45,87276 & 17,05873 & 6 & \multirow{5}{*}{0,592} \\
\hline & Rep 2 & 57,02119 & 43,92962 & 43,62995 & 6 & \\
\hline & Rep 3 & 62,25340 & 43,00038 & 44,80026 & 6 & \\
\hline & Rep 4 & 84,02509 & 64,48521 & 69,15609 & 4 & \\
\hline & Rep 5 & 37,21369 & 37,21369 & 19,61083 & 2 & \\
\hline \multirow{5}{*}{$\begin{array}{l}\mathrm{F} \max 2 \\
(\mathrm{PC})\end{array}$} & Rep 1 & 3,45314 & 2,91218 & 1,44709 & 6 & \multirow{5}{*}{0,435} \\
\hline & Rep 2 & 3,27002 & 3,14804 & 1,09951 & 6 & \\
\hline & Rep 3 & 3,21983 & 2,84135 & 1,17511 & 6 & \\
\hline & Rep 4 & 3,76363 & 3,76435 & 1,39669 & 4 & \\
\hline & Rep 5 & 2,86616 & 2,86616 & 1,14784 & 2 & \\
\hline \multirow{5}{*}{$\begin{array}{l}\text { Altura } \\
(\mathrm{cm})\end{array}$} & Rep 1 & 91,70806 & 89,19004 & 47,30179 & 6 & \multirow{5}{*}{0,327} \\
\hline & Rep 2 & 99,38443 & 100,71625 & 44,05437 & 6 & \\
\hline & Rep 3 & 73,37782 & 58,62783 & 40,29316 & 6 & \\
\hline & Rep 4 & 73,69073 & 54,67487 & 50,28716 & 4 & \\
\hline & Rep 5 & 92,70659 & 92,70659 & 76,01135 & 2 & \\
\hline \multirow{5}{*}{$\underset{\text { (ua) }}{\text { RMS_GM_pre }}$} & Rep 1 & 0,09311 & 0,08697 & 0,01795 & 10 & \multirow{5}{*}{0,463} \\
\hline & Rep 2 & 0,08211 & 0,08448 & 0,02016 & 10 & \\
\hline & Rep 3 & 0,09809 & 0,08592 & 0,03893 & 10 & \\
\hline & Rep 4 & 0,09154 & 0,09908 & 0,02432 & 10 & \\
\hline & Rep 5 & 0,07984 & 0,07711 & 0,02202 & 8 & \\
\hline \multirow{5}{*}{$\underset{\text { (ua) }}{\text { RMS_GM_pos }}$} & Rep 1 & 0,10133 & 0,07808 & 0,05208 & 10 & \multirow{5}{*}{0,082} \\
\hline & Rep 2 & 0,16097 & 0,16637 & 0,06039 & 10 & \\
\hline & Rep 3 & 0,08162 & 0,07163 & 0,02933 & 10 & \\
\hline & Rep 4 & 0,13909 & 0,15668 & 0,05048 & 10 & \\
\hline & Rep 5 & 0,13616 & 0,12876 & 0,04909 & 8 & \\
\hline \multirow{5}{*}{$\underset{\text { (ua) }}{\mathrm{RMS} \text { TA pre }}$} & Rep 1 & 0,13395 & 0,12738 & 0,02462 & 10 & \multirow{5}{*}{0,121} \\
\hline & Rep 2 & 0,12661 & 0,13280 & 0,02321 & 10 & \\
\hline & Rep 3 & 0,14187 & 0,13656 & 0,03927 & 10 & \\
\hline & Rep 4 & 0,12028 & 0,11098 & 0,05067 & 10 & \\
\hline & Rep 5 & 0,10684 & 0,10576 & 0,01623 & 8 & \\
\hline
\end{tabular}




\section{ANEXO IV - Resultados dos experimentos (cont.)}

TABELA 46 - Dados gerais relacionados com os parâmetros avaliados no experimento 2. salto vertical com contra-movimento, do grupo de crianças com PTC unilateral (cont.).

\begin{tabular}{|c|c|c|c|c|c|c|}
\hline Variáveis & & Média & Mediana & Desvio Padrão & Tamanho & $\mathrm{p}$-valor \\
\hline \multirow{5}{*}{$\underset{\text { (ua) }}{\text { RMS_TA_pos }}$} & Rep 1 & 0,13888 & 0,14158 & 0,01501 & 10 & \multirow{5}{*}{0,082} \\
\hline & Rep 2 & 0,14606 & 0,14873 & 0,03037 & 10 & \\
\hline & Rep 3 & 0,19565 & 0,18536 & 0,05105 & 10 & \\
\hline & Rep 4 & 0,12047 & 0,11506 & 0,03787 & 10 & \\
\hline & Rep 5 & 0,09295 & 0,08575 & 0,02855 & 8 & \\
\hline \multirow{5}{*}{$\begin{array}{l}\text { cine joelho1 } \\
\text { (Graus) }\end{array}$} & Rep 1 & 75,53987 & 74,12090 & 10,31555 & 12 & \multirow{5}{*}{0,760} \\
\hline & Rep 2 & 76,34938 & 76,84304 & 7,05205 & 12 & \\
\hline & $\operatorname{Rep} 3$ & 77,25444 & 77,09622 & 10,32878 & 12 & \\
\hline & Rep 4 & 79,44579 & 81,45177 & 13,07433 & 8 & \\
\hline & Rep 5 & 77,61417 & 73,96659 & 10,88162 & 6 & \\
\hline \multirow{5}{*}{$\begin{array}{c}\text { cine joelho2 } \\
\text { (Graus) }\end{array}$} & Rep 1 & 5,85357 & 5,53551 & 4,57640 & 12 & \multirow{5}{*}{0,687} \\
\hline & Rep 2 & 5,03046 & 4,30897 & 2,97823 & 12 & \\
\hline & Rep 3 & 5,89020 & 5,88873 & 3,42165 & 12 & \\
\hline & Rep 4 & 8,02658 & 8,65929 & 7,52918 & 8 & \\
\hline & Rep 5 & 3,33886 & 1,84736 & 4,29249 & 6 & \\
\hline \multirow{5}{*}{$\begin{array}{c}\text { cine joelho3 } \\
\text { (Graus) }\end{array}$} & Rep 1 & 8,41739 & 8,04998 & 2,52064 & 12 & \multirow{5}{*}{0,076} \\
\hline & Rep 2 & 6,90856 & 7,31603 & 3,13169 & 12 & \\
\hline & Rep 3 & 9,14721 & 8,44424 & 4,79161 & 12 & \\
\hline & Rep 4 & 13,76026 & 13,31320 & 4,37349 & 8 & \\
\hline & Rep 5 & 8,89558 & 8,83806 & 4,02179 & 6 & \\
\hline \multirow{5}{*}{$\begin{array}{l}\text { cine joelho4 } \\
\text { (Graus) }\end{array}$} & Rep 1 & 52,27137 & 50,12887 & 11,66006 & 12 & \multirow{5}{*}{0,900} \\
\hline & Rep 2 & 52,82951 & 52,91788 & 11,34289 & 12 & \\
\hline & Rep 3 & 57,27534 & 59,61029 & 19,22198 & 12 & \\
\hline & Rep 4 & 54,06514 & 56,66762 & 16,04788 & 8 & \\
\hline & Rep 5 & 52,76205 & 44,85370 & 26,83405 & 6 & \\
\hline \multirow{5}{*}{$\begin{array}{c}\text { cine_tornozelo1 } \\
\text { (Graus) }\end{array}$} & Rep 1 & 108,74006 & 112,09566 & 9,58661 & 12 & \multirow{5}{*}{0,388} \\
\hline & Rep 2 & 109,31927 & 113,06547 & 10,82922 & 12 & \\
\hline & Rep 3 & 109,16098 & 112,49342 & 10,08421 & 12 & \\
\hline & Rep 4 & 108,45616 & 111,00725 & 9,92070 & 8 & \\
\hline & Rep 5 & 108,03401 & 110,90719 & 11,95265 & 6 & \\
\hline \multirow{5}{*}{$\begin{array}{c}\text { cine_tornozelo2 } \\
\text { (Graus) }\end{array}$} & Rep 1 & 56,91825 & 50,43761 & 18,97359 & 12 & \multirow{5}{*}{0,833} \\
\hline & Rep 2 & 56,94114 & 51,01641 & 18,76248 & 12 & \\
\hline & Rep 3 & 53,99834 & 47,65876 & 17,95356 & 12 & \\
\hline & Rep 4 & 53,68724 & 49,07902 & 18,58296 & 8 & \\
\hline & Rep 5 & 50,64216 & 48,26798 & 16,88884 & 6 & \\
\hline
\end{tabular}




\section{ANEXO IV - Resultados dos experimentos (cont.)}

TABELA 46- Dados gerais relacionados com os parâmetros avaliados no experimento 2 , salto vertical com contra-movimento, do grupo de crianças com PTC unilateral (cont.).

\begin{tabular}{|c|c|c|c|c|c|c|}
\hline Variáveis & & Média & Mediana & Desvio Padrão & Tamanho & $\mathrm{p}$-valor \\
\hline \multirow{5}{*}{$\begin{array}{c}\text { cine_tornozelo3 } \\
\text { (Graus) }\end{array}$} & Rep 1 & 63,76572 & 55,30605 & 19,15754 & 12 & \multirow{5}{*}{0,463} \\
\hline & Rep 2 & 64,46949 & 55,70263 & 18,96467 & 12 & \\
\hline & Rep 3 & 62,36665 & 56,79272 & 16,60060 & 12 & \\
\hline & Rep 4 & 64,70049 & 58,78346 & 16,25018 & 8 & \\
\hline & Rep 5 & 58,11281 & 55,96417 & 16,25201 & 6 & \\
\hline \multirow{5}{*}{$\begin{array}{c}\text { cine tornozelo4 } \\
\text { (Graus) }\end{array}$} & Rep 1 & 106,62278 & 110,28031 & 9,98799 & 12 & \multirow{5}{*}{0,086} \\
\hline & Rep 2 & 105,01016 & 105,13156 & 8,40687 & 12 & \\
\hline & Rep 3 & 105,14194 & 104,86860 & 9,84969 & 12 & \\
\hline & Rep 4 & 108,82870 & 107,59836 & 12,48865 & 8 & \\
\hline & Rep 5 & 102,49661 & 104,00684 & 10,45771 & 6 & \\
\hline
\end{tabular}




\section{ANEXO IV - Resultados dos experimentos (cont.)}

TABELA 47 - Dados referentes aos parâmetros do salto vertical nas comparações entre apoio esquerdo (Esq.) e direito (Dir.), para o grupo PTC bilateral.

\begin{tabular}{|c|c|c|c|c|c|}
\hline Variáveis & & Média & Desvio Padrão & Tamanho & p-valor \\
\hline \multirow{2}{*}{$\begin{array}{c}\text { RMS_GM_pre } \\
\text { (ua) }\end{array}$} & Dir. & 0,09190 & 0,01654 & 29 & \multirow{2}{*}{0,315} \\
\hline & Esq. & 0,12615 & 0,16782 & 29 & \\
\hline \multirow{2}{*}{$\begin{array}{c}\text { RMS_GM_pos } \\
\text { (ua) }\end{array}$} & Dir. & 0,11727 & 0,02788 & 29 & \multirow{2}{*}{0,144} \\
\hline & Esq. & 0,10669 & 0,04603 & 29 & \\
\hline \multirow{2}{*}{${ }_{\text {(ua) }}^{\text {RMS_TA_pre }}$} & Dir. & 0,12261 & 0,03918 & 29 & \multirow{2}{*}{0,787} \\
\hline & Esq. & 0,12052 & 0,03782 & 29 & \\
\hline \multirow{2}{*}{$\begin{array}{c}\text { RMS_TA_pos } \\
\text { (ua) }\end{array}$} & Dir. & 0,13247 & 0,04844 & 29 & \multirow{2}{*}{0,552} \\
\hline & Esq. & 0,12634 & 0,03333 & 29 & \\
\hline \multirow{2}{*}{$\begin{array}{c}\text { cine1_joelho } \\
\text { (Graus) }\end{array}$} & Dir. & 72,31029 & 15,75723 & 27 & \multirow{2}{*}{0,943} \\
\hline & Esq. & 72,03009 & 18,04581 & 27 & \\
\hline \multirow{2}{*}{$\begin{array}{c}\text { cine2_joelho } \\
\text { (Graus) }\end{array}$} & Dir. & 5,15565 & 4,35604 & 27 & \multirow{2}{*}{0,614} \\
\hline & Esq. & 4,69429 & 4,97449 & 27 & \\
\hline \multirow{2}{*}{$\begin{array}{c}\text { cine3_joelho } \\
\text { (Graus) }\end{array}$} & Dir. & 7,08898 & 4,81094 & 27 & \multirow{2}{*}{0,810} \\
\hline & Esq. & 8,14390 & 7,69218 & 27 & \\
\hline \multirow{2}{*}{$\begin{array}{c}\text { cine4_joelho } \\
\text { (Graus) }\end{array}$} & Dir. & 51,72356 & 13,68658 & 27 & \multirow{2}{*}{0,773} \\
\hline & Esq. & 51,87330 & 17,06545 & 27 & \\
\hline \multirow{2}{*}{$\begin{array}{c}\text { cine1_tornozelo } \\
\text { (Graus) }\end{array}$} & Dir. & 106,23652 & 13,23379 & 27 & \multirow{2}{*}{0,084} \\
\hline & Esq. & 107,97115 & 13,18605 & 27 & \\
\hline \multirow{2}{*}{$\begin{array}{c}\text { cine2 tornozelo } \\
\text { (Graus) }\end{array}$} & Dir. & 61,54300 & 7,67186 & 27 & \multirow{2}{*}{$0,024^{*}$} \\
\hline & Esq. & 59,50858 & 8,59895 & 27 & \\
\hline \multirow{2}{*}{$\begin{array}{c}\text { cine3_tornozelo } \\
\text { (Graus) }\end{array}$} & Dir. & 66,49878 & 9,66290 & 27 & \multirow{2}{*}{$0,044^{*}$} \\
\hline & Esq. & 63,60969 & 11,60971 & 27 & \\
\hline \multirow{2}{*}{$\begin{array}{c}\text { cine4_tornozelo } \\
\text { (Graus) }\end{array}$} & Dir. & 105,05372 & 10,92961 & 27 & \multirow{2}{*}{0,810} \\
\hline & Esq. & 105,28564 & 9,89311 & 27 & \\
\hline
\end{tabular}




\section{ANEXO IV - Resultados dos experimentos (cont.)}

TABELA 48 - Dados referentes aos parâmetros analisados do salto vertical com contramovimento, nas comparacões entre lado acometido e lado não acometido para o grupo PTC unilateral.

\begin{tabular}{|c|c|c|c|c|c|}
\hline Variáveis & & Média & Desvio Padrão & Tamanho & p-valor \\
\hline \multirow{2}{*}{$\begin{array}{c}\text { RMS_GM_pre } \\
\text { (ua) }\end{array}$} & Acometido & 0,08173 & 0,03021 & 24 & \multirow{2}{*}{$0,018^{*}$} \\
\hline & Não acometido & 0,09690 & 0,01789 & 24 & \\
\hline \multirow{2}{*}{$\begin{array}{c}\text { RMS_GM_pos } \\
\text { (ua) }\end{array}$} & Acometido & 0,09128 & 0,04084 & 24 & \multirow{2}{*}{$<0,001^{*}$} \\
\hline & Não acometido & 0,15536 & 0,04995 & 24 & \\
\hline \multirow{2}{*}{$\begin{array}{c}\text { RMS_TA_pre } \\
\text { (ua) }\end{array}$} & Acometido & 0,12941 & 0,03010 & 24 & \multirow{2}{*}{0,424} \\
\hline & Não acometido & 0,12400 & 0,03864 & 24 & \\
\hline \multirow{2}{*}{$\begin{array}{c}\text { RMS_TA_pos } \\
\text { (ua) }\end{array}$} & Acometido & 0,14725 & 0,05420 & 24 & \multirow{2}{*}{0,909} \\
\hline & Não acometido & 0,13417 & 0,03936 & 24 & \\
\hline \multirow{2}{*}{$\begin{array}{c}\text { cine1_joelho } \\
\text { (Graus) }\end{array}$} & Acometido & 76,87518 & 9,35455 & 25 & \multirow{2}{*}{0,861} \\
\hline & Não acometido & 77,16385 & 10,52777 & 25 & \\
\hline \multirow{2}{*}{$\begin{array}{c}\text { cine2_joelho } \\
\text { (Graus) }\end{array}$} & Acometido & 6,21707 & 4,35646 & 25 & \multirow{2}{*}{ 0,074\# } \\
\hline & Não acometido & 5,20440 & 4,83139 & 25 & \\
\hline \multirow{2}{*}{$\begin{array}{c}\text { cine3_joelho } \\
\text { (Graus) }\end{array}$} & Acometido & 8,88764 & 3,54180 & 25 & \multirow{2}{*}{0,476} \\
\hline & Não acometido & 9,39770 & 4,90717 & 25 & \\
\hline \multirow{2}{*}{$\begin{array}{c}\text { cine4_joelho } \\
\text { (Graus) }\end{array}$} & Acometido & 51,98806 & 16,20053 & 25 & \multirow{2}{*}{$0,030^{*}$} \\
\hline & Não acometido & 55,91627 & 15,91185 & 25 & \\
\hline \multirow{2}{*}{$\begin{array}{c}\text { cine1_tornozelo } \\
\text { (Graus) }\end{array}$} & Acometido & 104,54384 & 11,36046 & 25 & \multirow{2}{*}{$0,006^{*}$} \\
\hline & Não acometido & 113,15604 & 5,80022 & 25 & \\
\hline \multirow{2}{*}{$\begin{array}{c}\text { cine2 tornozelo } \\
\text { (Graus) }\end{array}$} & Acometido & 59,35484 & 17,88055 & 25 & \multirow{2}{*}{$0,048^{*}$} \\
\hline & Não acometido & 50,55090 & 16,84292 & 25 & \\
\hline \multirow{2}{*}{$\begin{array}{c}\text { cine3_tornozelo } \\
\text { (Graus) }\end{array}$} & Acometido & 67,38112 & 17,81028 & 25 & \multirow{2}{*}{ 0,054\# } \\
\hline & Não acometido & 58,75900 & 15,61998 & 25 & \\
\hline \multirow{2}{*}{$\begin{array}{c}\text { cine4 tornozelo } \\
\text { (Graus) }\end{array}$} & Acometido & 102,67971 & 11,41798 & 25 & \multirow{2}{*}{$0,009^{*}$} \\
\hline & Não acometido & 108,79660 & 6,90239 & 25 & \\
\hline
\end{tabular}


ANEXO IV - Resultados dos experimentos (cont.)

TABELA 49 - Dados referentes aos parâmetros do salto vertical, nas comparações entre os grupos: Controle (Cont.), PTC bilateral lado direito (Bil. D.), PTC bilateral lado esquerdo (Bil. E.), PTC unilateral lado acometido (Acom.) e PTC unilateral lado não acometido (N Acom.), Dados da força foram classificados como: PTC unilateral (Unil.), PTC bilateral (Bil.). $\mathrm{p} \leq 0,05$.

\begin{tabular}{|c|c|c|c|c|c|}
\hline Variáveis & Grupos & Média & $\begin{array}{l}\text { Desvio } \\
\text { Padrão }\end{array}$ & Tamanho & $p$-valor \\
\hline \multirow{3}{*}{$\begin{array}{c}\mathrm{F} \max 1 \\
(\mathrm{PC})\end{array}$} & Unil. & 1.21619 & 0.42289 & 24 & \multirow{3}{*}{$0,019^{*}$} \\
\hline & Bil. & 1.54668 & 0.44335 & 27 & \\
\hline & Cont. & 1.46187 & 0.62440 & 48 & \\
\hline \multirow{3}{*}{$\begin{array}{c}\mathrm{TC} \\
(\mathrm{PC} / \mathrm{s})\end{array}$} & Unil. & 58.65379 & 41.78337 & 24 & \multirow{3}{*}{$0,002^{*}$} \\
\hline & Bil. & 63.21923 & 39.91590 & 27 & \\
\hline & Cont. & 40.46259 & 30.83798 & 48 & \\
\hline \multirow{3}{*}{$\begin{array}{l}F \max 2 \\
(P C)\end{array}$} & Unil. & 3.35187 & 1.17853 & 24 & \multirow{3}{*}{ 0,095\# } \\
\hline & Bil. & 3.29475 & 1.40691 & 27 & \\
\hline & Cont. & 2.88743 & 1.60900 & 48 & \\
\hline \multirow{3}{*}{$\begin{array}{l}\text { Altura } \\
(\mathrm{cm})\end{array}$} & Unil. & 86.12492 & 44.37732 & 24 & \multirow{3}{*}{0,517} \\
\hline & Bil. & 77.22655 & 25.07933 & 27 & \\
\hline & Cont. & 125.93385 & 111.35473 & 48 & \\
\hline \multirow{5}{*}{$\underset{\text { (ua) }}{\text { RMS_GM_pre }}$} & Acom. & 0.08173 & 0.03021 & 24 & \multirow{5}{*}{$0,013^{*}$} \\
\hline & Bil. D & 0.09190 & 0.01654 & 29 & \\
\hline & Bil. E & 0.12615 & 0.06782 & 29 & \\
\hline & Cont. & 0.10038 & 0.02919 & 98 & \\
\hline & $\tilde{\mathrm{N}}$ Acom. & 0.09690 & 0.01789 & 24 & \\
\hline \multirow{5}{*}{$\underset{\text { (ua) }}{R M S \text { (ua_pos }}$} & Acom. & 0.09128 & 0.04084 & 24 & \multirow{5}{*}{$<0,001^{*}$} \\
\hline & Bil. D & 0.11727 & 0.02788 & 29 & \\
\hline & Bil. E & 0.10669 & 0.04603 & 29 & \\
\hline & Cont. & 0.09240 & 0.03334 & 98 & \\
\hline & $\tilde{\mathrm{N}}$ Acom. & 0.15536 & 0.04995 & 24 & \\
\hline \multirow{5}{*}{$\underset{\text { (ua) }}{R M S \text { TA_pre }}$} & Acom. & 0.12941 & 0.03010 & 24 & \multirow{5}{*}{0,752} \\
\hline & Bil. D & 0.12261 & 0.03918 & 29 & \\
\hline & Bil. E & 0.12052 & 0.03782 & 29 & \\
\hline & Cont. & 0.12911 & 0.03344 & 98 & \\
\hline & $\tilde{\mathrm{N}}$ Acom. & 0.12400 & 0.03864 & 24 & \\
\hline \multirow{5}{*}{$\underset{\text { (ua) }}{R M S \text { TA pos }}$} & Acom. & 0.14725 & 0.05420 & 24 & \multirow{5}{*}{0,739} \\
\hline & Bil. D & 0.13247 & 0.04844 & 29 & \\
\hline & Bil. E & 0.12634 & 0.03333 & 29 & \\
\hline & Cont. & 0.13586 & 0.03676 & 98 & \\
\hline & $\tilde{N}$ Acom. & 0.13417 & 0.03936 & 24 & \\
\hline \multirow{5}{*}{$\begin{array}{l}\text { cine1_joelho } \\
\text { (Graus) }\end{array}$} & Acom. & 76.87518 & 9.35455 & 25 & \multirow{5}{*}{ 0,069\# } \\
\hline & Bil. D & 72.31029 & 15.75723 & 27 & \\
\hline & Bil. E & 72.03009 & 18.04581 & 27 & \\
\hline & Cont. & 78.10414 & 10.15674 & 110 & \\
\hline & $\tilde{\mathrm{N}}$ Acom. & 77.16385 & 10.52777 & 25 & \\
\hline
\end{tabular}

continua 
ANEXO IV - Resultados dos experimentos (cont.)

TABELA 49 - Dados referentes aos parâmetros do salto vertical, nas comparações entre os grupos: Controle (Cont.), PTC bilateral lado direito (Bil. D.), PTC bilateral lado esquerdo (Bil. E.), PTC unilateral lado acometido (Acom.) e PTC unilateral lado não acometido (N Acom.), Dados da força foram classificados como: PTC unilateral (Unil.), PTC bilateral (Bil.). $\mathrm{p} \leq 0,05$ (cont.).

\begin{tabular}{|c|c|c|c|c|c|}
\hline Variáveis & Grupos & Média & $\begin{array}{l}\text { Desvio } \\
\text { Padrão }\end{array}$ & Tamanho & p-valor \\
\hline \multirow{5}{*}{$\begin{array}{l}\text { cine2_joelho } \\
\text { (Graus) }\end{array}$} & Acom. & 6.21707 & 4.35646 & 25 & \multirow{5}{*}{$0,025^{*}$} \\
\hline & Bil. D & 5.15565 & 4.35604 & 27 & \\
\hline & Bil. E & 4.69429 & 4.97449 & 27 & \\
\hline & Cont. & 3.19958 & 2.79188 & 110 & \\
\hline & $\tilde{\mathrm{N}}$ Acom. & 5.20440 & 4.83139 & 25 & \\
\hline \multirow{5}{*}{$\begin{array}{l}\text { cine3_joelho } \\
\text { (Graus) }\end{array}$} & Acom. & 8.88764 & 3.54180 & 25 & \multirow{5}{*}{$0,004^{*}$} \\
\hline & Bil. D & 7.08898 & 4.81094 & 27 & \\
\hline & Bil. E & 8.14390 & 7.69218 & 27 & \\
\hline & Cont. & 6.96408 & 7.72117 & 110 & \\
\hline & $\tilde{\mathrm{N}}$ Acom. & 9.39770 & 4.90717 & 25 & \\
\hline \multirow{5}{*}{$\begin{array}{l}\text { cine4_joelho } \\
\text { (Graus) }\end{array}$} & Acom. & 51.98806 & 16.20053 & 25 & \multirow{5}{*}{0,840} \\
\hline & Bil. D & 51.72356 & 13.68658 & 27 & \\
\hline & Bil. E & 51.87330 & 17.06545 & 27 & \\
\hline & Cont. & 54.95499 & 18.82101 & 110 & \\
\hline & $\tilde{\mathrm{N}}$ Acom. & 55.91627 & 15.91185 & 25 & \\
\hline \multirow{5}{*}{$\begin{array}{l}\text { cine1_tornozelo } \\
\text { (Graus) }\end{array}$} & Acom. & 104.54384 & 11.36046 & 25 & \multirow{5}{*}{$0,001^{*}$} \\
\hline & Bil. D & 106.23652 & 13.23379 & 27 & \\
\hline & Bil. E & 107.97115 & 13.18605 & 27 & \\
\hline & Cont. & 114.08443 & 8.96808 & 110 & \\
\hline & $\tilde{\mathrm{N}}$ Acom. & 113.15604 & 5.80022 & 25 & \\
\hline \multirow{5}{*}{$\begin{array}{c}\text { cine2 tornozelo } \\
\text { (Graus) }\end{array}$} & Acom. & 59.35484 & 17.88055 & 25 & \multirow{5}{*}{$<0,001^{*}$} \\
\hline & Bil. D & 61.54300 & 7.67186 & 27 & \\
\hline & Bil. E & 59.50858 & 8.59895 & 27 & \\
\hline & Cont. & 43.07881 & 7.38660 & 110 & \\
\hline & $\tilde{\mathrm{N}}$ Acom. & 50.55090 & 16.84292 & 25 & \\
\hline \multirow{5}{*}{$\begin{array}{c}\text { cine3 tornozelo } \\
\text { (Graus) }\end{array}$} & Acom. & 67.38112 & 17.81028 & 25 & \multirow{5}{*}{$<0,001^{*}$} \\
\hline & Bil. D & 66.49878 & 9.66290 & 27 & \\
\hline & Bil. E & 63.60969 & 11.60971 & 27 & \\
\hline & Cont. & 53.73845 & 9.76233 & 110 & \\
\hline & $\tilde{\mathrm{N}}$ Acom. & 58.75900 & 15.61998 & 25 & \\
\hline \multirow{5}{*}{$\begin{array}{c}\text { cine4_tornozelo } \\
\text { (Graus) }\end{array}$} & Acom. & 102.67971 & 11.41798 & 25 & \multirow{5}{*}{$0,007^{*}$} \\
\hline & Bil. D & 105.05372 & 10.92961 & 27 & \\
\hline & Bil. E & 105.28564 & 9.89311 & 27 & \\
\hline & Cont. & 110.17499 & 8.12703 & 110 & \\
\hline & $\tilde{\mathrm{N}}$ Acom. & 108.79660 & 6.90239 & 25 & \\
\hline
\end{tabular}

* $p$-valor considerado estatisticamente significativo perante o nível de significância adotado $(p \leq$ $0,05)$; \# p-valor que por estar próximo do limite de aceitação é considerado que tenda a ser significativo. 


\section{ANEXO IV - Resultados dos experimentos (cont.)}

TABELA 50 - Dados referentes aos parâmetros analisados do salto vertical, para os parâmetros Fmax1 e TC, nas comparações entre os grupos: Controle (Cont,), PTC bilateral (Bil.) e PTC unilateral (Unil.).

\begin{tabular}{cccc}
\hline Variáveis & & Unil. & Bil. \\
\hline Fmax1 & Bil & 0,009 & - \\
\cline { 2 - 4 } (PC) & Cont. & $0,052 \#$ & 0,148 \\
\hline TC & Bil & 0,637 & - \\
\cline { 2 - 4 } (PC/s) & Cont. & $0,012^{*}$ & $0,001^{*}$ \\
\hline
\end{tabular}

\# p-valor que por estar próximo do limite de aceitação é considerado que tenda a ser significativo.

TABELA 51 - Dados referentes aos parâmetros do salto vertical, nas comparações entre os grupos: Controle (Cont.), PTC bilateral lado direito (Bil. D.), PTC bilateral lado esquerdo (Bil. E.), PTC unilateral lado acometido (Acom.) e PTC

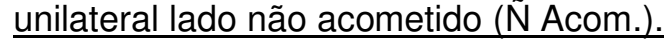

\begin{tabular}{|c|c|c|c|c|c|}
\hline Variáveis & Grupos & Acom. & Bil. D. & Bil. E. & Cont. \\
\hline \multirow{4}{*}{$\underset{\text { (ua) }}{\text { RMS_GM_pre }}$} & Bil. D & 0,025 & & & \\
\hline & Bil. E & 0,010 & 0,785 & & \\
\hline & Cont. & 0,001 & 0,346 & 0,750 & \\
\hline & $\tilde{\mathrm{N}}$ Acom. & 0,004 & 0,411 & 0,761 & 0,926 \\
\hline \multirow{4}{*}{$\underset{\text { (ua) }}{\text { RMS_GM_pos }}$} & Bil. D & 0,004 & & & \\
\hline & Bil. E & 0,204 & 0,133 & & \\
\hline & Cont. & 0,638 & $<0,001$ & 0,186 & \\
\hline & $\tilde{N}$ Acom. & $<0,001$ & 0,003 & 0,001 & $<0,001$ \\
\hline \multirow{4}{*}{$\begin{array}{l}\text { cine2 joelho } \\
\text { (Graus) }\end{array}$} & Bil. D & 0,355 & & & \\
\hline & Bil. E & 0,230 & 0,749 & & \\
\hline & Cont. & 0,003 & 0,106 & 0,433 & \\
\hline & $\tilde{\mathrm{N}}$ Acom. & 0,308 & 0,876 & 0,458 & 0,042 \\
\hline \multirow{4}{*}{$\begin{array}{l}\text { cine3_joelho } \\
\text { (Graus) }\end{array}$} & Bil. D & 0,126 & & & \\
\hline & Bil. E & 0,140 & 0,938 & & \\
\hline & Cont. & 0,002 & 0,242 & 0,417 & \\
\hline & $\tilde{\mathrm{N}}$ Acom. & 0,734 & 0,113 & 0,172 & 0,002 \\
\hline \multirow{4}{*}{$\begin{array}{c}\text { cine1_tornozelo } \\
\text { (Graus) }\end{array}$} & Bil. D & 0,426 & & & \\
\hline & Bil. E & 0,101 & 0,494 & & \\
\hline & Cont. & $<0,001$ & 0,008 & 0,063 & \\
\hline & $\tilde{\mathrm{N}}$ Acom. & 0,017 & 0,094 & 0,426 & 0,377 \\
\hline \multirow{4}{*}{$\begin{array}{c}\text { cine2 tornozelo } \\
\text { (Graus) }\end{array}$} & Bil. D & 0,654 & & & \\
\hline & Bil. E & 0,862 & 0,401 & & \\
\hline & Cont. & $<0,001$ & $<0,001$ & $<0,001$ & \\
\hline & $\tilde{\mathrm{N}}$ Acom. & 0,308 & $<0,001$ & 0,001 & 0,019 \\
\hline
\end{tabular}




\section{ANEXO IV - Resultados dos experimentos (cont.)}

TABELA 51 - Dados referentes aos parâmetros do salto vertical, nas comparações entre os grupos: Controle (Cont.), PTC bilateral lado direito (Bil. D.), PTC bilateral lado esquerdo (Bil. E.), PTC unilateral lado acometido (Acom.) e PTC unilateral lado não acometido (Ñ Acom.) (cont.).

\begin{tabular}{cccccc}
\hline Variáveis & Grupos & Acom. & Bil. D. & Bil. E. & Cont. \\
\hline \multirow{3}{*}{$\begin{array}{c}\text { cine3_tornozelo } \\
\text { (Graus) }\end{array}$} & Bil. D & 0,862 & & & \\
\cline { 2 - 6 } & Bil. E & 0,654 & 0,392 & & \\
\cline { 2 - 6 } & Cont. & 0,002 & $<0,001$ & $<0,001$ & \\
\cline { 2 - 6 } & $\tilde{N}$ Acom. & 0,233 & 0,002 & 0,011 & 0,169 \\
\hline \multirow{3}{*}{$\begin{array}{c}\text { Bine4_tornozelo } \\
\text { (Graus) }\end{array}$} & Bil. E & 0,436 & & & \\
\cline { 2 - 6 } & Cont. & 0,002 & 0,979 & & \\
\cline { 2 - 6 } & $\tilde{N}$ Acom. & 0,037 & 0,223 & 0,036 & \\
\hline
\end{tabular}

TABELA 52 - P-valor para os grupos PTC unilateral lado acometido (Acom.), PTC unilateral lado não acometido ( $\tilde{N}$ Acom.), PTC bilateral lado direito (Bil. Dir.), PTC bilateral lado esquerdo (Bil. Esq.) e grupo controle (Cont.), para as categorias criadas $(1=$ sensibilidade normal; $2=$ predisposição de alteração sensitiva).

\begin{tabular}{|c|c|c|c|c|c|}
\hline Regiões & Grupos & Acom. & Bil. Dir. & Bil. Esq. & Cont. \\
\hline \multirow{4}{*}{$1^{\circ}$ metatarso } & Bil. Dir. & 1,000 & & & \\
\hline & Bil. Esq. & 0,759 & 0,759 & & \\
\hline & Cont. & 0,797 & 0,797 & 0,906 & \\
\hline & $\tilde{\mathrm{N}}$ Acom. & 1,000 & 1,000 & 0,759 & 0,797 \\
\hline \multirow{4}{*}{$3^{\circ}$ metatarso } & Bil. Dir. & 1,000 & & & \\
\hline & Bil. Esq. & 0,743 & 0,743 & & \\
\hline & Cont. & 0,519 & 0,519 & 0,797 & \\
\hline & $\tilde{\mathrm{N}}$ Acom. & 1,000 & 1,000 & 0,743 & 0,519 \\
\hline \multirow{4}{*}{$5^{\circ}$ metatarso } & Bil. Dir. & 1,000 & & & \\
\hline & Bil. Esq. & 0,526 & 0,526 & & \\
\hline & Cont. & 0,519 & 0,519 & 0,906 & \\
\hline & $\tilde{N}$ Acom. & 0,743 & 0,743 & 0,759 & 0,797 \\
\hline \multirow{4}{*}{ calcanhar } & Bil. Dir. & 1,000 & & & \\
\hline & Bil. Esq. & 0,743 & 0,743 & & \\
\hline & Cont. & 0,769 & 0,769 & 0,914 & \\
\hline & $\tilde{\mathrm{N}}$ Acom. & 1,000 & 1,000 & 0,743 & 0,769 \\
\hline \multirow{4}{*}{ mediopé } & Bil. Dir. & 0,495 & & & \\
\hline & Bil. Esq. & 1,000 & 0,495 & & \\
\hline & Cont. & 0,797 & 0,296 & 0,797 & \\
\hline & $\tilde{\mathrm{N}}$ Acom. & 1,000 & 0,495 & 1,000 & 0,797 \\
\hline
\end{tabular}




\section{GLOSSÁRIO}

Capsolotomia - incisão cirúrgica em uma cápsula articular;

Eqüino - pé flexionado em flexão plantar

Estesiômetro - instrumento para mensuração da sensibilidade, percepção;

Idiopática - referente à idiopatia; doença de causa desconhecida;

Necrose avascular - conjunto de alterações morfológicas que se seguem à morte celular devido à falta de suprimento sanguíneo na região;

Osteoartrose - afecção que atinge principalmente a cartilagem hialina e o osso subcondral, ainda que todos os tecidos intra e periarticulares possam estar envolvidos num remanejamento hipertrófico;

Talipes - termo genérico para qualquer deformidade do pé centralizada no talo;

Teste de Telescopagem - teste ortopédico para avaliação da mobilidade do tornozelo;

Tenotomia - Incisão cirúrgica no tecido tendíneo. 